
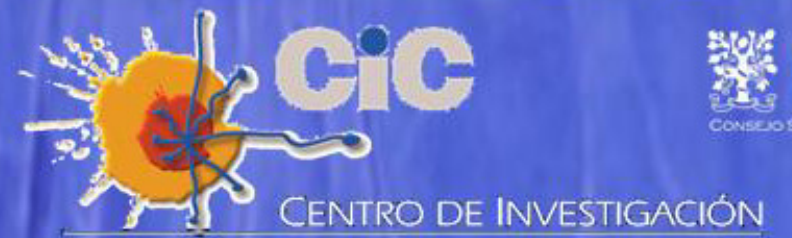

DEL CÁNCER

\title{
Sensibilidad a inhibidores de la familia de quinasas VRK y regulación de NFAT y COX-2 por la quinasa humana VRK2A
}
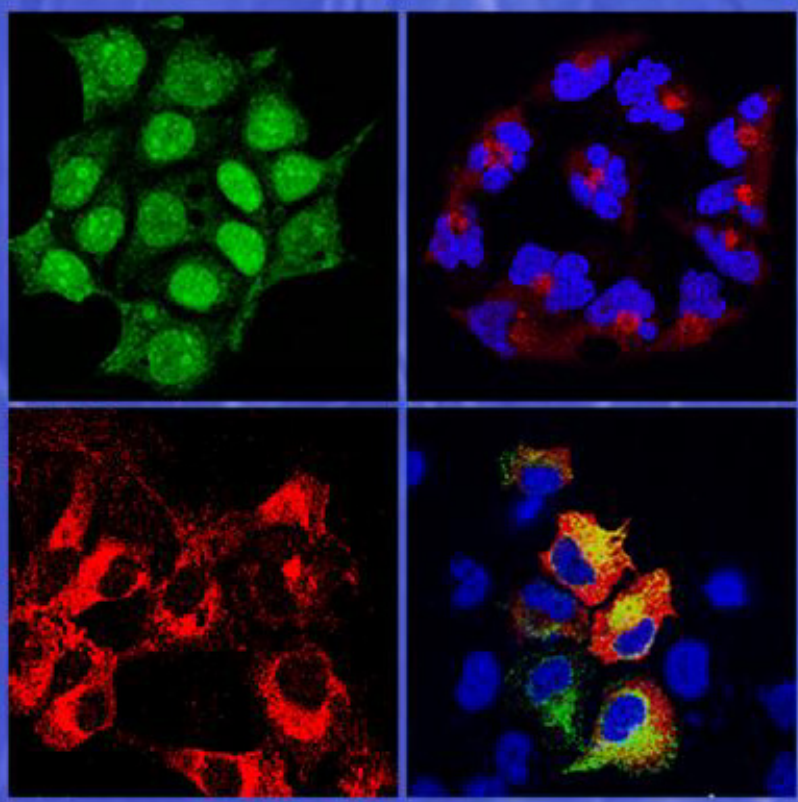

\section{TESIS DOCTORAL}

Marta Vázquez Cedeira

Salamanca 2012 



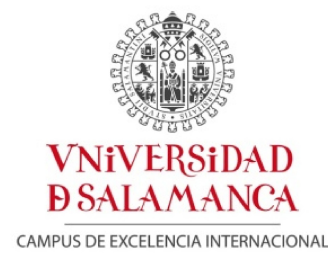

INSTituto de Biología MoleCular y CelULAR del CÁNCER
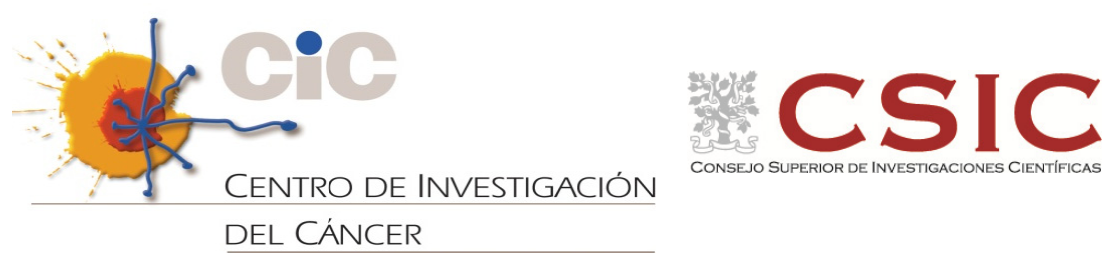

\title{
Sensibilidad a inhibidores de la
} familia de quinasas VRK y

regulación de NFAT y COX-2 por la quinasa humana VRK2A

\author{
TESIS DOCTORAL \\ Marta Vázquez Cedeira
}

Salamanca 2012 



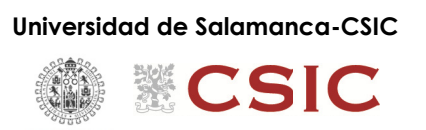

D. PEDRO A. LAZO-ZBIKOWSKI, PROFESOR DE INVESTIGACIÓN DEL CONSEJO SUPERIOR DE INVESTIGACIONES CIENTÍFICAS (CSIC)

\section{CERTIFICA}

Que la memoria titulada "Sensibilidad a inhibidores de la familia de quinasas VRK y regulación de NFAT y COX-2 por la quinasa humana VRK2A" presentada por la licenciada MARTA VÁZQUEZ CEDEIRA ha sido realizada bajo su dirección en el Instituto de Biología Molecular y Celular del Cáncer y reúne, a su juicio, originalidad y contenidos suficientes para que sea presentada ante el tribunal correspondiente y optar al grado de Doctor por la Universidad de Salamanca.

Y para que así conste, a efectos legales, expide el presente certificado en Salamanca a 23 de Marzo de 2012.

Fdo. Pedro A. Lazo-Zbikowski 

Esta memoria ha sido realizada siendo Marta Vázquez Cedeira beneficiaria de una beca de Iniciación a la Investigación y una beca predoctoral JAE del Consejo Superior de Investigaciones Científicas-Fondo Social Europeo para el desarrollo de la tesis doctoral (2006-2010).

La investigación en el laboratorio ha sido financiada por los siguientes proyectos:

- Ministerio de Educación y Ciencia (SAF2004-02900; SAF2007-60242; CDS-2007-0017 y SAF2010-14935)

- Junta de Castilla y León, Consejería de Sanidad (SAN/673/SA05/08; BOCyL N $\left.{ }^{\circ} 170\right)$

- Junta de Castilla y León, Consejería de Educación (CSI14A08; CSI006A11-2 y grupo de excelencia GR-15)

- Kutxa-Fundación INBIOMED 

La ciencia tiene una característica maravillosa, y es que aprende de sus errores; utiliza sus equivocaciones para reexaminar los problemas $y$ volver a intentar resolverlos por nuevos caminos.

(Ruy Pérez Tamayo, científico)

El secreto de la sabiduría y del conocimiento es la humildad.

(Ernest Hemingway) 



\section{ÍNDICE}

\section{INTRODUCCIÓN}

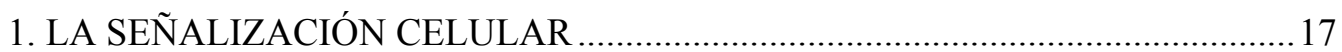

1.1. Importancia de los factores de transcripción en la expresión génica...................17

1.2. Las proteínas quinasa: importancia y conservación ............................................ 17

1.2.1. Las proteínas quinasa como moléculas diana en el tratamiento

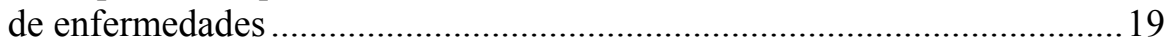

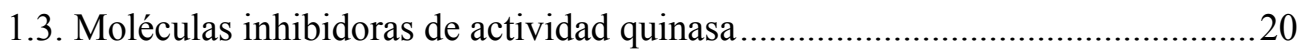

1.3.1. Inhibidores de Cdk: roscovitina e inhibidor de Cdk1 ..............................22

1.3.2. Inhibidores de PKC: estaurosporina y RO 31-8220 ………....................23

1.3.3. Inhibidores de proteínas quinasa implicadas en la respuesta de daño al ADN: KU55933, NU7026, IC86621 y AZD7762 ……………......24

1.3.4. Inhibidores de MAPK y Aurora quinasas: PD98059, PLX-

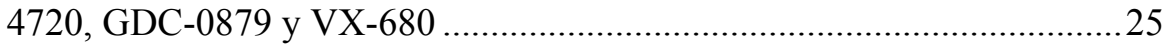

1.3.5. Inhibidores TDZD, no competitivos con el ATP ……………………......26

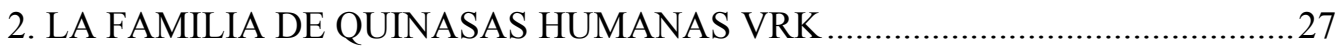

2.1. Dominios y estructura de las quinasas humanas VRK ......................................29

2.1.1. Estructura tridimensional de las proteínas VRK y diferencias

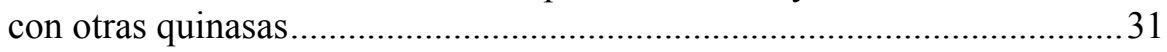

2.2. Características y función de la quinasa humana VRK1 .......................................33

2.2.1. Localización subcelular y expresión de VRK1 ..........................................33

2.2.2. Regulación de factores de transcripción por parte de VRK1 …………......34

2.2.3. Implicación de VRK1 en el ciclo celular ..................................................36

2.2.4. Papel de VRK1 en la dinámica del ensamblaje de la envuelta nuclear y la fragmentación del aparato de Golgi.........................................37

2.2.5. VRK1 y fosforilación de la histona H3 ………………………………........ 39

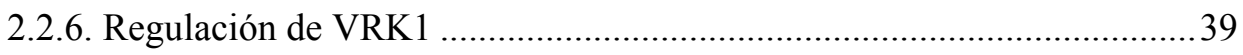

2.3. Características y función de la quinasa humana VRK2 ......................................4 41

2.3.1. Localización subcelular y expresión de VRK2 ……….............................41

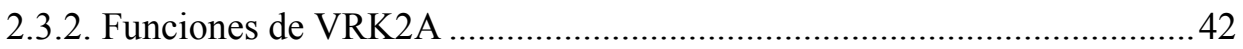

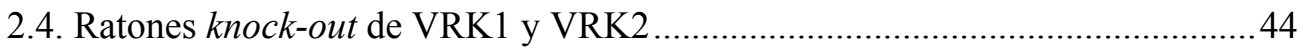

2.5. Las quinasas VRK1 y VRK2 en otras enfermedades humanas..........................44 
3. EL FACTOR DE TRANSCRIPCIÓN NFAT ...................................................46

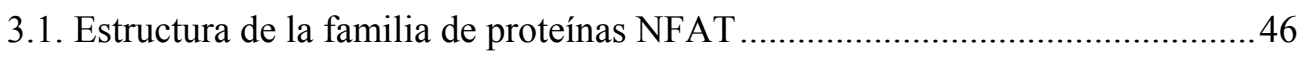

3.1.1. Expresión del factor de transcripción NFAT ........................................48

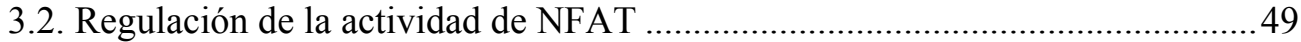

3.2.1. Importancia de la señalización por calcio y desfosforilación/ fosforilación de NFAT .....................................................................50

a) Activación de NFAT por la fosfatasa calcineurina ............................50

b) Proteínas quinasa de NFAT ..........................................................52

c) Potenciación de la actividad transcripcional de NFAT mediante fosforilación

3.2.2. Regulación por proteínas inhibidoras de la actividad de calcineurina

3.2.3. Otros mecanismos de regulación de la señalización de NFAT .................55

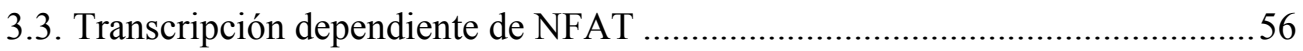

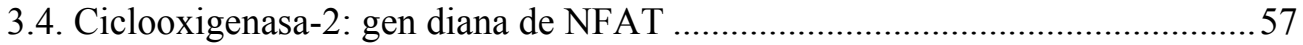

3.4.1. Estructura del promotor de COX-2 y transcripción ...............................57

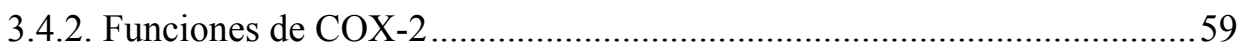

3.5. Implicación de NFAT y COX-2 en invasión tumoral .....................................59

OBJETIVOS

\section{RESULTADOS}

\section{Sensibilidad a inhibidores de la familia de quinasas VRK}

1. Panel de inhibidores y su efecto en la actividad quinasa de VRK1 y VRK2

2. Patrones de respuesta de inhibición de la actividad de VRK1 y VRK2 frente a los inhibidores testados

2.1. Efecto de inhibidores de Cdk sobre la actividad de VRK1 y VRK2.

2.2. Efecto de inhibidores de quinasas implicadas en daño al ADN sobre la actividad de VRK1 y VRK2.....

2.3. Sensibilidad de VRK1 y VRK2 a inhibidores de PKC: RO 31-8220

y estaurosporina

2.4. Efecto de inhibidores no competitivos con ATP, TDZD-8 y TDZD20, sobre la actividad de VRK1 y VRK2

2.5. Diferencias en valores de $\mathrm{IC}_{50}$ de los inhibidores testados para las quinasas VRK1 y VRK2 
3. Comparación del efecto de inhibición de la actividad quinasa entre las proteínas humanas VRK y la quinasa viral B1R

Regulación de NFAT y COX-2 por la quinasa VRK2A e implicación en la invasión y migración celular

1. VRK2A fosforila y regula al factor de transcripción NFAT, identificando una nueva función de VRK2A como quinasa activa......................................................93

1.1. Efecto de la sobreexpresión de VRK2A sobre la actividad de NFAT

1.2. VRK2A no actúa sobre NFAT de forma indirecta a través de la fosforilación de RCAN1

1.3. El factor de transcripción NFAT es fosforilado por VRK2A ...........................100

1.3.1. VRK2 fosforila a NFAT en su dominio de transactivación ...................... 100

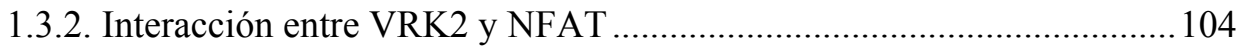

2. Efecto de VRK2A sobre la expresión de ciclooxigenasa-2, un gen diana de NFAT

2.1. La sobreexpresión de VRK2A aumenta la transcripción del promotor de COX-2 en la línea celular MDA-MB-435.

2.2. VRK2A participa en la regulación del promotor de COX-2 en la línea de cáncer de colon SW-620

2.3. El silenciamiento de VRK2 conlleva una disminución de los niveles de expresión de COX-2

2.3.1. Niveles de ARNm de COX-2 tras el silenciamiento de VRK2

2.3.2. Efecto del silenciamiento de VRK2 sobre los niveles de proteína COX-2

2.4. El aumento de la expresión del gen de ciclooxigenasa-2 depende de los sitios de unión para NFAT presentes en el promotor de COX-2

3. Efecto del silenciamiento de VRK2 en la migración e invasión celular

3.1. Efecto del silenciamiento de VRK2 en la invasión celular.....

3.2. Efecto del silenciamiento de VRK2 en la migración celular.

\section{DISCUSIÓN}

1. Sensibilidad de VRK1 y VRK2 a inhibidores de la actividad quinasa.....................125

2. Potenciación de la actividad transcripcional de NFAT por parte de VRK2A.........135

3. VRK2A participa en la regulación de la invasión celular a través de la expresión de COX-2. 


\section{MATERIALES Y MÉTODOS}

1. Técnicas de manipulación de ácidos nucleicos ....................................................... 149

1.1. Aislamiento de ADN plasmídico de E. coli ................................................... 149

1.2. Electroforesis de fragmentos de ADN ........................................................... 149

1.3. Generación de vectores recombinantes de ADN .............................................150

1.4. Transformación de plásmidos en bacterias $E$. coli ........................................... 150

2. Producción de anticuerpos policlonales frente a VRK2 ........................................151

3. Técnicas de manipulación de proteínas ............................................................... 152

3.1. Purificación de proteínas de fusión unidas a GST ............................................152

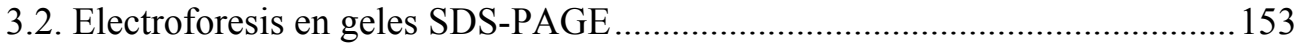

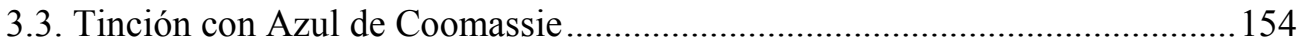

3.4. Transferencia húmeda, western blot y tinción rojo Ponceau ............................. 154

4. Alineamiento de secuencias de proteínas ............................................................... 155

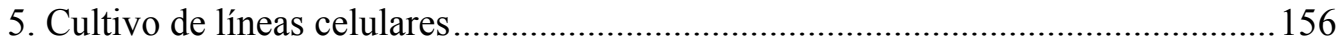

6. Transfección transitoria de ADN en células eucariotas...........................................156

6.1. Electroporación de células en cultivo en suspensión..........................................156

6.2. Transfección de células en cultivo monocapa ……………………...................157

7. Supresión de la expresión génica mediante arn de interferencia ..............................157

8. Obtención de extractos proteicos de células en cultivo y detección de

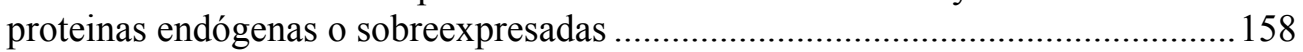

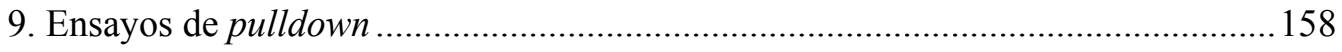

10. Determinación de la actividad transcripcional con genes reporteros de

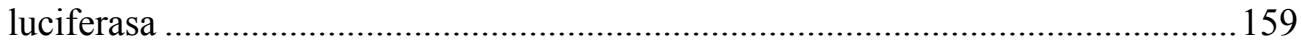

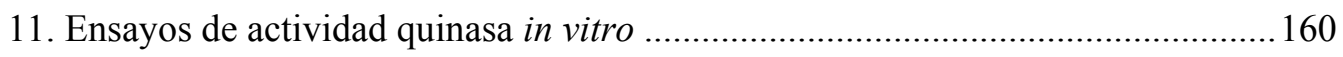

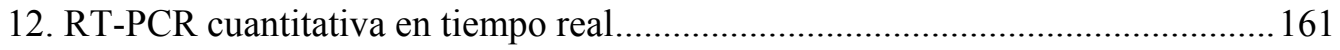

13. Determinación de migración e invasión celular ....................................................162

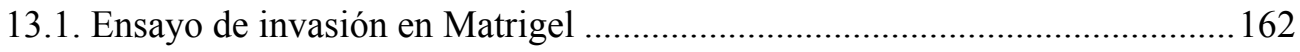

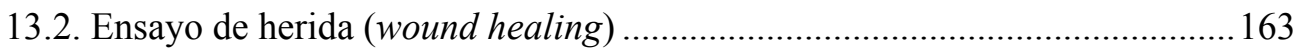

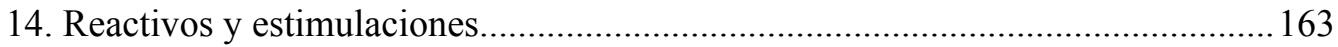

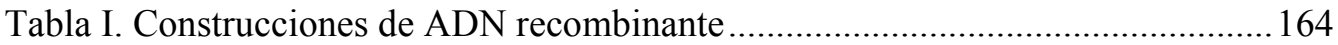




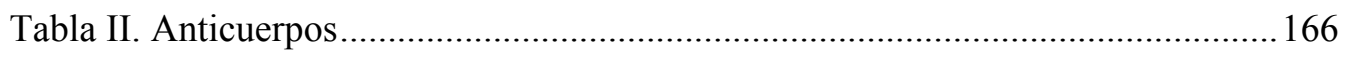

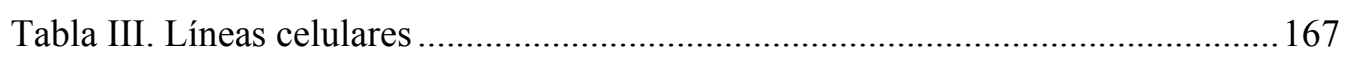

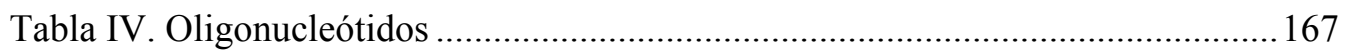

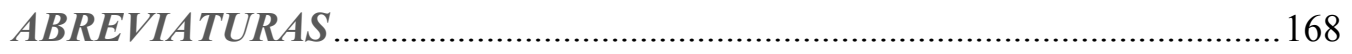

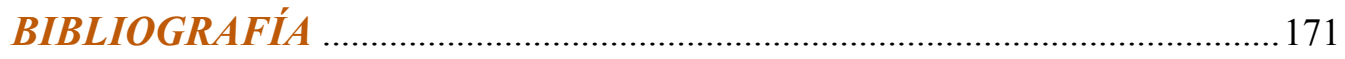

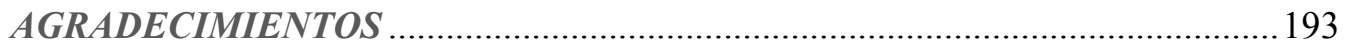



Introducción

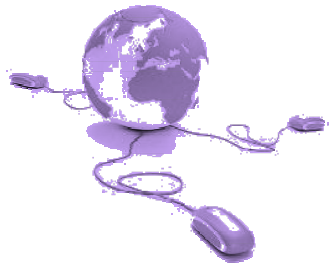





\section{LA SEÑALIZACIÓN CELULAR}

\subsection{Importancia de los factores de transcripción en la expresión génica}

Para el funcionamiento adecuado de cada tipo celular en un organismo es necesario un control estricto de todos los procesos que ocurren en las células. Dicho control se lleva a cabo gracias a las diferentes rutas de señalización existentes en la célula, que son las encargadas de convertir los estímulos extra o intracelulares en cambios en la actividad, localización, conformación o expresión de las proteínas celulares. En este contexto, los factores de transcripción tienen un papel clave puesto que son las dianas finales de las rutas de señalización celular y se encargan de la expresión génica. Por tanto, la regulación de los factores de transcripción es importante para la expresión génica correcta durante el desarrollo y para el mantenimiento y función específica de las células ya diferenciadas.

La regulación de los factores de transcripción tiene lugar principalmente a dos niveles: a nivel de su concentración y a nivel de su actividad (Hill and Treisman, 1995; Calkhoven and $\mathrm{Ab}, 1996)$. La concentración de un factor de transcripción se regula a nivel de ARN mensajero y a nivel de síntesis o degradación de proteína; mientras que la actividad, es decir, su unión al ADN, dimerización, interacción con otras proteínas y su transactivación, se regulan por modificaciones postraduccionales. Dentro de estas últimas, la fosforilación y desfosforilación de un factor de transcripción es uno de los mecanismos principales en la regulación de su actividad transcripcional (Karin and Hunter, 1995; Whitmarsh and Davis, 2000). De este modo, los diferentes patrones de fosforilación/desfosforilación que sufre un factor de transcripción según el tipo de estímulo o de ambiente determinan la interacción con otras proteínas y la especificidad transcripcional, lo que explica la diferente actividad de un mismo factor de transcripción en distintos tipos celulares o bajo diferentes estímulos.

\subsection{Las proteínas quinasa: importancia y conservación}

La fosforilación de proteínas celulares es uno de los mecanismos de regulación de la transducción de señales más importante, ya que permite cambios rápidos y reversibles en la expresión génica, en la conformación, en la localización o en la actividad de las proteínas fosforiladas (Hunter, 1987; Hunter and Karin, 1992; Hanks 
and Hunter, 1995; Hunter, 1995; Karin and Hunter, 1995). Las encargadas de llevar a cabo las fosforilaciones son las proteínas quinasa, enzimas que catalizan la unión covalente de un grupo fosfato a residuos de serina, treonina o tirosina de proteínas celulares.

Las proteínas quinasa constituyen una gran familia y su importancia en la regulación de la señalización celular se refleja en que más de un $2 \%$ del genoma humano codifica para proteínas quinasa (Manning et al., 2002a; Manning et al., 2002b). Además, se estima que un tercio de todas las proteínas celulares se fosforilan (Cohen, 2001). Otro dato que indica la importancia de las proteínas quinasa es la presencia de un dominio catalítico conservado en la evolución. En base a la homología en este dominio catalítico se llevó a cabo una clasificación de las proteínas quinasa en lo que se ha denominado el quinoma humano. Así, se clasificaron un total de 518 genes que codificaban para proteínas quinasa en ocho grupos distintos, a su vez divididos en varias subfamilias (Manning et al., 2002b).

La característica que diferencia a las proteínas quinasa de otras proteínas celulares es la existencia del dominio catalítico, responsable de la actividad de la proteína. Este dominio comprende aproximadamente unos 250-300 aminoácidos (Hanks and Quinn, 1991; Hanks and Hunter, 1995); y la conservación de su secuencia indica la importancia de estas proteínas en los procesos celulares y se debe a la necesidad de preservar su función principal, que es la de transferir un grupo fosfato desde el ATP a la proteína sustrato. La resolución de las estructuras tridimensionales de muchas proteínas quinasa ha ayudado a conocer el papel de los residuos conservados en la función y plegamiento de estas proteínas y así se ha establecido una

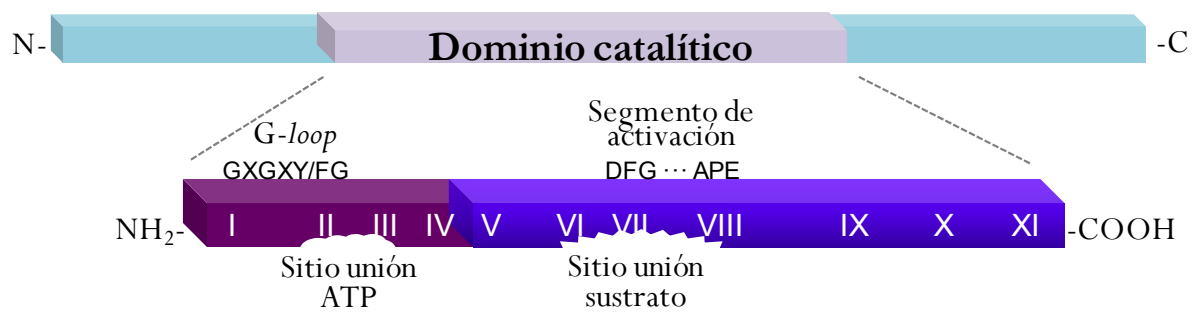

Figura 1. Estructura típica del dominio catalítico de las proteínas quinasa. Se muestran los 11 subdominios del dominio catalítico de las proteínas quinasa. En el lóbulo amino terminal $\left(\mathrm{NH}_{2}\right)$ se localiza el sitio de unión a ATP, en el denominado G-loop, una región rica en glicinas. El segmento de activación, implicado en la regulación de la actividad quinasa se localiza entre los motivos DFG y APE, en el lóbulo carboxilo $(\mathrm{COOH})$. 
secuencia consenso del dominio catalítico que presentan la mayoría de las proteínas quinasa, donde se toma como secuencia tipo a la proteína quinasa A (PKA) (Taylor et al., 1993). Esta región catalítica puede dividirse en 11 subdominios (fig.1) que se pliegan formando un núcleo catalítico central y dos grandes lóbulos (Bossemeyer, 1995; Hanks and Hunter, 1995). La especificidad de sustrato de cada tipo de quinasa viene determinada por diferencias claves en residuos del dominio catalítico y, en base a esta especificidad, pueden dividirse en tres grupos: tirosina quinasas, serina/treonina quinasas o quinasas de especificidad dual.

Sin embargo, existen miembros pertenecientes a familias de proteínas quinasa que no conservan los residuos claves para la actividad catalítica, aunque a pesar de ello mantienen el plegamiento característico. Estas proteínas se denominan pseudoquinasas (Boudeau et al., 2006). También, existen casos de quinasas que no poseen los motivos característicos de la secuencia consenso pero presentan actividad y, por ello, se les ha denominado quinasas atípicas (Kostich et al., 2002; Arena et al., 2005).

\subsubsection{Las proteínas quinasa como moléculas diana en el tratamiento de enfermedades}

Alteraciones en la fosforilación de las proteínas y de la función quinasa se relacionan con situaciones patológicas como cáncer, inflamación o neurodegeneración (Blume-Jensen and Hunter, 2001; Vogelstein and Kinzler, 2004; Capra et al., 2006). Muchos de los oncogenes implicados en el desarrollo de tumores son proteínas quinasa (Futreal et al., 2004; Arena et al., 2005). Debido a esta importancia en las rutas de señalización celular, las proteínas quinasa son buenas candidatas para el desarrollo de fármacos que puedan ser efectivos en el tratamiento del cáncer (Benvenuti et al., 2005; Giamas et al., 2007; Eglen and Reisine, 2009; Piersma et al., 2010). El conocimiento del quinoma humano permitió la posibilidad de caracterizar mejor las quinasas y desarrollar estrategias para manipularlas con intenciones clínicas (Zhang et al., 2009) y para tratar de conocer su función y regulación en condiciones fisiológicas y patológicas (Johnson and Hunter, 2005; Anastassiadis et al., 2011). Se estima que más de un 25\% de los esfuerzos en el desarrollo de fármacos en la industria se centran en la búsqueda de inhibidores de proteínas quinasa (Kaidanovich-Beilin and Eldar-Finkelman, 2006). 
El conocimiento de la estructura tridimensional de una quinasa resulta de ayuda para el diseño de moléculas inhibidoras específicas (Zhang et al., 2009). Sin embargo, la alta conservación del dominio catalítico de las quinasas supone un problema para la especificidad de un inhibidor, puesto que se ve reducida al afectar a varias quinasas diferentes (Anastassiadis et al., 2011; Davis et al., 2011). Esta inhibición cruzada resulta en lo que se denomina promiscuidad de inhibición de un compuesto, la cual puede predecirse en base a la conservación de residuos específicos en el plegamiento de la quinasa. De este modo, las proteínas con menor índice de promiscuidad serán aquellas con una secuencia algo diferente a la de la mayoría de proteínas quinasa y los inhibidores desarrollados contra ellas deberían ser altamente específicos (Fedorov et al., 2007).

Por otro lado, se han definido una serie de criterios que debe cumplir una proteína para ser candidata al desarrollo de fármacos contra ella. Así en la figura 2 se recogen las cuatro características necesarias según el Centro de Investigación del Cáncer de Alemania (DKFZ) para decidir la utilidad de desarrollar fármacos que inhiban la

Figura 2. Criterios que debe cumplir una proteína para resultar útil la investigación y el desarrollo de fármacos que modulen su actividad. Según el Centro de Investigación del Cáncer de Alemania (DKFZ).

Criterios para determinar que una proteína es diana válida de fármacos

1. Accesibilidad de moléculas de pequeño tamaño 0 anticuerpos. No se consideran dianas de fármacos las proteínas sin sitio de unión para moléculas de pequeño tamaño ni las inaccesibles para anticuerpos.

2. Relevancia en enfermedades. La modulación de la actividad de la proteína debe tener efectos beneficiosos en una patología. Esto tiene que determinarse por diferentes métodos alternativos de interferencia de la actividad de la proteína diana; por ejemplo, silenciamiento de la expresión con ARN de interferencia, expresión de alelos dominante negativos u organismos modelo knockout para esa proteína.

3. Novedad. El uso de fármacos contra la proteína debe ampliar los conocimientos más recientes en el campo de estudio de la enfermedad.

4. Ser necesario en medicina. El tratamiento propuesto debe servir para mejorar las terapias ya existentes.

actividad de una proteína concreta.

\subsection{Moléculas inhibidoras de actividad quinasa}

El interés en el desarrollo de inhibidores selectivos de una determinada proteína quinasa no sólo se debe a su utilidad en clínica para el tratamiento de enfermedades (Zhang et al., 2009), sino también a su utilidad para el estudio de las funciones biológicas de una quinasa concreta (Elphick et al., 2007; Anastassiadis et al., 2011). 
Actualmente existen una gran cantidad de compuestos descritos como inhibidores específicos de proteínas quinasa, aunque se está comprobando que muchos de ellos no son tan específicos (Bain et al., 2007; Karaman et al., 2008; Anastassiadis et al., 2011). Generalmente, los inhibidores selectivos de proteínas quinasa son moléculas que presentan anillos heterocíclicos (Knight and Shokat, 2005) y la estrategia más común para conseguir compuestos de mayor especificidad contra una quinasa determinada es la síntesis de derivados de moléculas que presentan efecto inhibidor sobre la quinasa (Martinez et al., 2002; Smyth et al., 2011).

La mayoría de los inhibidores son moléculas dirigidas hacia el sitio de unión del ATP de las proteínas quinasa, impidiendo o disminuyendo la unión del ATP y, en consecuencia, la transferencia del grupo fosfato al sustrato. Por ello, se denominan inhibidores competitivos. Dentro de estos se pueden distinguir inhibidores de tipo I y de tipo II. Los inhibidores de tipo I reconocen la conformación en el estado activo de la proteína quinasa; mientras que los inhibidores de tipo II, interaccionan con la conformación correspondiente al estado inactivo de la quinasa o también llamado DFG-out (Davis et al., 2011). Por otro lado, existen moléculas inhibidoras no competitivas con el ATP, también denominadas inhibidores de tipo III (Dar and Shokat, 2011), que se unen a otras regiones de la proteína quinasa fuera del sitio de unión del ATP. Estos compuestos pueden actuar alostéricamente modulando la actividad quinasa y, de este modo, podrían alterar el balance entre las conformaciones activa e inactiva de las proteínas quinasa (Kirkland and McInnes, 2009). Además, existen otra clase de compuestos que son inhibidores irreversibles. Estos se unen al sitio activo de la quinasa formando una interacción covalente que no puede revertirse (Zhang et al., 2009).

En este trabajo hemos utilizado quince inhibidores conocidos de diferentes proteínas quinasa (tabla 1) implicadas en diversos procesos celulares para estudiar su efecto sobre la actividad de las proteínas de la familia de quinasas VRK, como primer paso para la búsqueda de compuestos que sean específicos para dichas quinasas. Todos los inhibidores utilizados son competitivos con el ATP, excepto PD98059, TDZD-8 y TDZD-20, que son no competitivos. 
Tabla 1. Inhibidores de quinasas. Se indican el nombre de los inhibidores utilizados en el estudio con su estructura química y las quinasas para las que se han descrito como específicos junto con su $\mathrm{IC}_{50}$.

\begin{tabular}{|c|c|c|c|c|c|}
\hline Inhibidor & $\begin{array}{l}\text { Quinasa específica } \\
\text { (IC50) }\end{array}$ & $\begin{array}{l}\text { Estructura } \\
\text { química }\end{array}$ & Inhibidor & Quinasa específica (IC50) & $\begin{array}{l}\text { Estructura } \\
\text { química }\end{array}$ \\
\hline TDZD-8 & GSK-3 $3(2 \mu \mathrm{M})$ & & KU 55933 & $\operatorname{ATM}(2,2 \mathrm{nM})$ & \\
\hline TDZD-20 & GSK-3 $\beta(6,5 \mu \mathrm{M})$ & & NU7026 & DNA-PK $(230 \mathrm{nM})$ & \\
\hline Inhibidor Cdkl & $\mathrm{Cdk} 1(5,8 \mu \mathrm{M})$ & & IC86621 & DNA-PKcs (100 nM) & \\
\hline Roscovitina & $\mathrm{Cdk} 1(650 \mathrm{nM})$ & & AZD 7762 & $\begin{array}{l}\text { CHK1 }(5 \mathrm{nM}) \\
\text { CHK2 }(<10 \mathrm{nM})\end{array}$ & \\
\hline & & & PD98059 & $\operatorname{Mek1}(4 \mu \mathrm{M})$ & \\
\hline Estaurosporina & PKC ( & & PLX-4720 & $\begin{array}{l}\text { B-RafV600E }(13 \mathrm{nM}) \\
\text { B-Raf }(160 \mathrm{nM})\end{array}$ & \\
\hline RO 31-8220 & $\begin{array}{l}\text { PKC is oforms } \\
(5-27 \mathrm{nM})\end{array}$ & & GDC-0879 & B-RafV600E $(0,13 \mathrm{nM})$ & \\
\hline Oxindole I & Flk-1 (390 nM) & & VX-680 & $\begin{array}{c}\text { Aurora A kinase }(0,6 \mathrm{nM}) \\
\text { Aurora } \mathrm{B} \text { kinase }(18,4 \mathrm{nM}) \\
\text { Aurora } \mathrm{C} \text { kinase }(6 \mathrm{nM})\end{array}$ & \\
\hline
\end{tabular}

\subsubsection{Inhibidores de Cdk: roscovitina e inhibidor de Cdk1}

Las proteínas Cdk (Cyclin-dependent kinases) están relacionadas con el ciclo celular y proliferación. Entre los inhibidores existentes frente a ellas seleccionamos la roscovitina, también conocida como Seliciclib o CYC202. La roscovitina es uno de los inhibidores de Cdk más estudiados in vitro e in vivo (Fischer and Gianella-Borradori, 2005; Hassan et al., 2011) y se está aplicando en estudios clínicos (Meijer and Raymond, 2003; Guzi, 2004; Benson et al., 2007; Le Tourneau et al., 2010). Se determinó en complejo con $\mathrm{Cdk} 2$ y se describió como un inhibidor potente y selectivo de Cdk1, Cdk2 y Cdk5 (De Azevedo et al., 1997; Meijer et al., 1997) y también inhibe a Cdk7 y Cdk9 (Hassan et al., 2011). Debido a que es un inhibidor competitivo con el ATP, su modo de actuación es mediante la unión al sitio de unión de ATP del dominio quinasa de la molécula de $\mathrm{Cdk}$. Los valores de $\mathrm{IC}_{50}$ (concentración de inhibidor que disminuye la actividad quinasa a la mitad) de la roscovitina para estas Cdk se encuentran en el rango nanomolar (tabla 1), indicando que este compuesto inhibe eficazmente a estas proteínas quinasa.

Otro inhibidor de Cdk seleccionado fue un inhibidor de Cdk1 que, en un estudio de la determinación de la estructura tridimensional de VRK3 y VRK2, se ha descrito 
que se une a estas quinasas y también a VRK1 (Scheeff et al., 2009). Andreani y colaboradores identificaron este compuesto (Andreani et al., 2000), describiéndose como un inhibidor de $\mathrm{Cdk} 1$ y $\mathrm{Cdk} 5$ con un $\mathrm{IC}_{50}$ de $5,8 \mu \mathrm{M}$ y $25 \mu \mathrm{M}$ respectivamente (tabla 1). Al igual que la roscovitina es un inhibidor competitivo, de modo que se une al sitio de unión del ATP de la proteína quinasa.

Además, otro de los inhibidores descritos que se unen a las proteínas quinasa VRK es oxindole I (Scheeff et al., 2009). Este compuesto se ha descrito como un inhibidor selectivo del receptor tirosina quinasa Flk-1 del factor de crecimiento de endotelio vascular (VEGF). A concentraciones más elevadas también es capaz de inhibir al receptor del factor de crecimiento derivado de plaquetas (PDGFR) y a algunos complejos de ciclinas/Cdk. Sin embargo, no afecta a la actividad quinasa de los receptores tirosina quinasas EGFR o ErbB2 (Sun et al., 1998a; Kent et al., 1999).

\subsubsection{Inhibidores de PKC: estaurosporina y RO 31-8220}

Se han descrito una amplia variedad inhibidores de PKC (Phospholipid/Ca ${ }^{2+}$ dependent protein kinase). Entre ellos se encuentran la estaurosporina y RO 31-8220. La estaurosporina se descubrió y aisló como un alcaloide producido a partir de un cultivo de Streptomyces. Posteriormente se comprobó que tenía propiedades inhibitorias sobre proteínas quinasa, impidiendo la unión de ATP a la molécula de quinasa debido a su fuerte afinidad por el sitio de unión a ATP. A pesar de haberse descrito como un potente inhibidor de PKC (Tamaoki et al., 1986; Tamaoki and Nakano, 1990), la estaurosporina se une a muchas otras quinasas con una alta afinidad, con lo cual este compuesto presenta muy poca selectividad (Karaman et al., 2008) y es uno de los inhibidores conocidos menos específico a nivel general. Además, se ha visto que su utilización induce apoptosis en muchos tipos celulares (Hartel et al., 2003; Hwang et al.) y también puede inhibir la actividad catalítica de otros enzimas, como la topoisomera II (Lassota et al., 1996).

El compuesto RO 31-8220 fue desarrollado como un derivado de la estaurosporina que resultó ser más selectivo para PKC (Davis et al., 1989; Dieter and Fitzke, 1991), aunque estudios recientes muestran que también es inhibidor de otras proteínas quinasa con una eficacia similar a la ejercida sobre PKC (Davies et al., 
2000). Al igual que la estaurosporina, induce apoptosis (Han et al., 2000) entre otros efectos.

1.3.3. Inhibidores de proteínas quinasa implicadas en la respuesta de daño al ADN: KU55933, NU7026, IC86621 y AZD7762

En la respuesta celular frente a daño al ADN participan muchas proteínas quinasa, las cuales resultan buenas candidatas para el tratamiento con inhibidores de su actividad. De este modo, se podrían sensibilizar las células ante los agentes empleados en quimioterapia. Entre los inhibidores seleccionados se incluyeron compuestos que inhiben a quinasas clave en las repuestas de daño al ADN como son ATM (Ataxia Telangiectasia Mutated), DNA-PK (DNA-dependent Protein Kinase) y CHK1/2 (Checkpoint Kinase 1/2).

El inhibidor de ATM que utilizamos fue KU55933. Este compuesto se ha descrito como un potente y específico inhibidor de ATM (Hickson et al., 2004; Hollick et al., 2007). Su utilización in vivo sensibiliza las células frente a los efectos citotóxicos de la radiación ionizante y del daño al $\mathrm{ADN}$ generado por los compuestos quimioterapéuticos (Li and Yang, 2010; Veuger and Durkacz, 2011).

Como inhibidores de las proteínas DNA-PK utilizamos los compuestos NU7026 e IC86621. Ambos compuestos inhiben a DNA-PK de un modo competitivo con el ATP y lo hacen en el rango nanomolar (tabla 1). El inhibidor NU7026 se describió como un potenciador de los efectos citotóxicos de fármacos empleados en el tratamiento de leucemia a través de la inhibición de la reparación del ADN llevada a cabo por las proteínas DNA-PK (Willmore et al., 2004; Amrein et al., 2007). Más recientemente, se ha observado que el tratamiento con este compuesto, en combinación con otros agentes quimioterapéuticos en otros tipos de células tumorales, provoca la parada masiva de las células en fase $\mathrm{G}_{2} / \mathrm{M}$ y la acumulación de lesiones en el ADN, lo cual conduce a la muerte celular (Shang et al., 2010; Davidson et al., 2011). El compuesto IC86621 se ha descrito como un inhibidor específico de la subunidad catalítica de las proteínas DNA-PK, con poco efecto en otros miembros relacionados de la familia PI3K (Phosphatidylinositol kinase) como ATM y ATR (Allen et al., 2003). Además, se observó que la inhibición de la actividad de las proteínas DNA-PK 
con este compuesto producía acumulación de daño en el ADN debido a estrés oxidativo, lo que lo hace adecuado para utilizar en combinación con agentes terapéuticos que induzcan este tipo de daño (Peddi et al., 2010). También se describe a IC86621 como un inhibidor que sólo sensibiliza a las células que presentan daño de rotura de doble cadena del ADN y no otros tipos de daño (Kashishian et al., 2003), debido a su mejor especificidad de inhibición.

Como inhibidor de las quinasas CHK1/2 se utilizó el compuesto AZD7762. Este inhibidor sensibiliza las células ante el tratamiento de radioterapia en combinación con otros fármacos (Mitchell et al., 2010; Morgan et al., 2010) y está siendo utilizado en ensayos clínicos (Ashwell et al., 2008; Cheng et al., 2011).

\subsubsection{Inhibidores de MAPK y Aurora quinasas: PD98059, PLX-4720, GDC-} 0879 y VX-680

Otro grupo de proteínas quinasa que suponen una buena diana para la inhibición de su actividad son las MAPK (Mitogen-Activated Protein Kinase), ya que están implicadas en rutas de supervivencia y proliferación celular. También las proteínas Aurora, que participan en mitosis, resultan interesantes para el desarrollo de inhibidores de su actividad. Para nuestro trabajo seleccionamos inhibidores de Mek1 (PD98059), de B-Raf (PLX-4720 y GDC-0879) y de las quinasas Aurora (VX-680).

Los compuestos PLX-4720 y GDC-0879 han sido descritos como potentes inhibidores competitivos selectivos de B-Raf (Tsai et al., 2008; Wong et al., 2009) y su empleo en modelos preclínicos ha mostrado eficacia antitumoral (Hoeflich et al., 2009a; Hoeflich et al., 2009b; Nucera et al., 2011). El compuesto PD98059 ha sido descrito como un inhibidor no competitivo específico de Mek1 (Alessi et al., 1995; Di Paola et al., 2010) y es ampliamente utilizado en estudios de inhibición de la señalización de Erk (Li et al., 2010; Galuppo et al., 2011).

El inhibidor VX-680 es un compuesto con afinidad por las quinasas Aurora en el rango nanomolar (tabla 1) y se considera un agente antitumoral útil (Shi et al., 2007; Gautschi et al., 2008). 


\subsubsection{Inhibidores TDZD, no competitivos con el ATP}

Los compuestos TDZD (heterocyclic thiadiazolidinones) fueron desarrollados como inhibidores no competitivos con el ATP frente a la quinasa GSK3 en la búsqueda de fármacos útiles para el tratamiento de la enfermedad de Alzheimer (Martinez et al., 2002). Además la utilización de estos compuestos parece reducir el crecimiento tumoral (Zhou et al., 2008; Aguilar-Morante et al., 2010; Zhu et al., 2011). Entre ellos seleccionamos dos: TDZD-8 y TDZD-20, que presentan un $\mathrm{IC}_{50}$ de inhibición de la proteína GSK $3 \beta$ de $2 \mu \mathrm{M}$ y $6,5 \mu \mathrm{M}$ respectivamente.

La búsqueda de inhibidores no competitivos se basa en que la especificidad para una quinasa determinada puede ser mayor al no ir dirigidos al dominio catalítico, región muy conservada en la mayoría de quinasas. Así, el diseño de moléculas que interaccionen con otras regiones de las proteínas quinasa también implicadas en la regulación de su función, pero con mayor divergencia en la secuencia, puede suponer una mayor selectividad de inhibición para una proteína concreta. 


\section{LA FAMILIA DE QUINASAS HUMANAS VRK}

La clasificación de las proteínas quinasa en el quinoma humano hecha por Manning y colaboradores en el 2002 suponía una ampliación a la realizada años antes por Hanks y Hunter (Hanks and Hunter, 1995), con la adición de cuatro nuevos grupos de quinasas y 90 familias, entre las que se estableció el grupo de las caseína quinasas tipo 1 (CK1), dentro del cual se encuentra la familia de serina/treonina quinasas VRK (del inglés Vaccinia-Related Kinases). Las quinasas VRK presentan homología en el dominio catalítico con la familia CK1; sin embargo, divergieron de éstas de forma temprana en la evolución, de modo que sólo están relacionadas con ellas de forma distante (fig. 3).

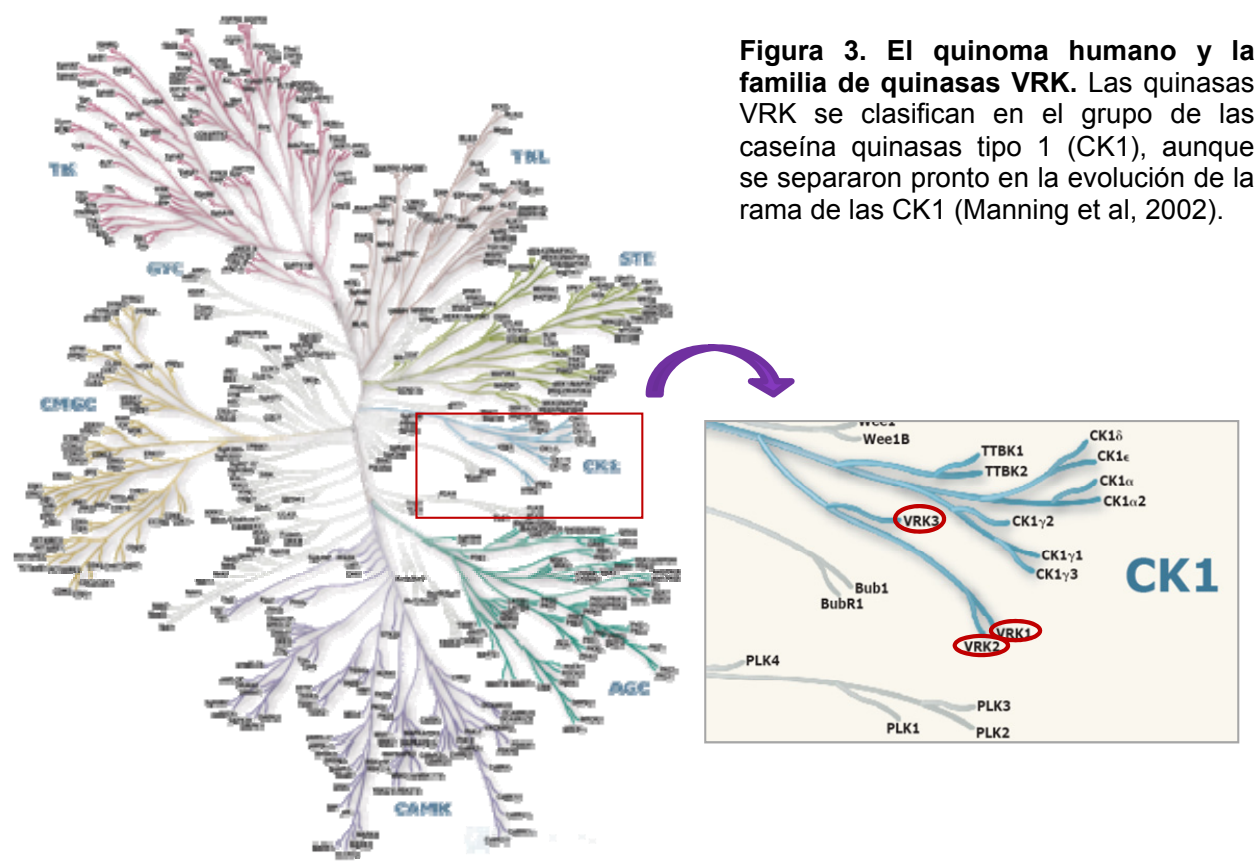

La familia de quinasas humanas VRK está compuesta de tres miembros: VRK1 y VRK2, catalíticamente activos, y VRK3, que es una pseudoquinasa (Lopez-Borges and Lazo, 2000; Nichols and Traktman, 2004; Blanco et al., 2006). VRK2 presenta dos isoformas, generadas por maduración alternativa de su ARN mensajero, y que difieren en su extremo carboxilo (Blanco et al., 2006) (fig. 4, página 30).

VRK1 y VRK2 fueron identificadas como EST (término inglés Expressed Sequence Tag, que hace referencia a secuencias cortas de ADN complementario que 
corresponden a parte de un ARN mensajero que se expresa en una célula) en un estudio sobre la búsqueda de genes implicados en la regulación del ciclo celular (Nezu et al., 1997) y recibieron este nombre por su homología con la quinasa B1R del virus Vaccinia. Esta quinasa viral presenta un 39\% de homología con VRK1 y un 34\% con VRK2 (Nichols and Traktman, 2004). B1R se expresa de forma temprana durante la infección del virus, siendo esencial en la replicación del ADN viral (Lin et al., 1992; Rempel and Traktman, 1992). La expresión de VRK1 puede rescatar parcialmente la deficiencia en la replicación del $\mathrm{ADN}$ viral de un mutante sensible a temperatura del virus Vaccinia deficiente en B1R (Boyle and Traktman, 2004).

En otros organismos existen ortólogos de las proteínas VRK. En invertebrados sólo existe un miembro en esta familia de quinasas, aunque en levaduras no existe ningún ortólogo. En el nematodo Caenorhabditis elegans el homólogo de VRK1 está codificado por el gen F28B12.3 y su silenciamiento con ARN de interferencia da lugar a un fenotipo letal en el embrión debido a defectos en la división celular (Kamath et al., 2003). La quinasa VRK-1 de C. elegans fosforila a BAF (Barrier to Autointegration Factor), proteína implicada en la formación de la envuelta nuclear (Gorjanacz et al., 2007). También se ha descrito que VRK-1 es importante en la formación de los órganos reproductores del nematodo por su participación en la regulación de la señalización del factor de crecimiento de fibroblastos (FGF) (Klerkx et al., 2009a) y por participar en el control de la proliferación de células germinales a través de la modulación de CEP-1 (ortólogo de p53) (Waters et al., 2010). En la mosca Drosophila melanogaster la proteína NHK-1 es la ortóloga de VRK1 y se identificó como quinasa que fosforila a la histona H2A en mitosis (Aihara et al., 2004) y también es capaz de fosforilar a BAF (Lancaster et al., 2007).

En el ratón Mus musculus existen tres miembros en la familia VRK, al igual que en humanos. La proteína ortóloga a VRK1 en ratón se describió inicialmente como 51PK y se trataba de una quinasa nuclear con una elevada autofosforilación en residuos serina (Zelko et al., 1998). Las tres proteínas VRK murinas se expresan durante todo el desarrollo embrionario con niveles más altos en hígado, leucocitos de sangre periférica, bazo y timo, órganos con alta tasa proliferativa. En tejidos adultos el nivel de expresión depende del tipo celular (Vega et al., 2003). Existen además ortólogos de 
las quinasas VRK en otros organismos como el pez cebra Danio rerio, el anfibio Xenopus laevis, la rata Rattus norvegicus o el chimpancé Pan troglodytes.

La existencia de tres miembros en la familia de quinasas VRK en vertebrados y sólo uno en invertebrados refleja la evolución de esta familia, indicando que posiblemente un gen VRK ancestral se duplicó dos veces en la rama de vertebrados, dejando a los invertebrados con un único gen VRK y tres en los vertebrados (Klerkx et al., 2009b).

\subsection{Dominios y estructura de las quinasas humanas VRK}

Los miembros activos de la familia VRK son VRK1 y VRK2 que se demostró que son serina/treonina quinasas con una fuerte actividad de autofosforilación (LopezBorges and Lazo, 2000; Blanco et al., 2006). VRK1 es una proteína de 396 aminoácidos cuyo gen se localiza en la región cromosómica 14q32. El gen de VRK2 se localiza en la región cromosómica 2p16 y codifica para dos isoformas generadas por maduración alternativa de su ARN mensajero: VRK2A, de 508 aminoácidos, y VRK2B, de 397 aminoácidos. Estas dos isoformas poseen una secuencia idéntica hasta el aminoácido 394, siendo reemplazados los aminoácidos del 395 al 508 de VRK2A por tres residuos (VEA) en la secuencia de VRK2B (Blanco et al., 2006).

Tanto VRK1 como VRK2 presentan en su región amino terminal un dominio catalítico, con un sitio de unión a ATP típico y un sitio serina/treonina quinasa activo (fig. 4). Esta región amino presenta homología con la de caseína quinasa de tipo I (CK1), aunque VRK1 difiere de CK1 en los sustratos de fosforilación (Lopez-Borges and Lazo, 2000). Entre VRK1 y VRK2 existe una homología del 44\%, llegando a ser mayor si se consideran sólo los dominios catalíticos (Nichols and Traktman, 2004).

La región carboxilo terminal presenta más divergencia entre VRK1 y VRK2 y se cree que tiene un papel en la regulación de estas quinasas. De hecho, el extremo carboxilo de VRK1 tiene una secuencia única, sin homología con otras proteínas conocidas (Lopez-Borges and Lazo, 2000), por lo que se piensa que esta región podría ser responsable de la regulación de la quinasa y de interacciones específicas. El extremo carboxilo de VRK1 presenta una señal de localización nuclear (NLS) típica (fig. 4). Esta secuencia se localiza dentro de un motivo básico-ácido-básico o BAB (aa 


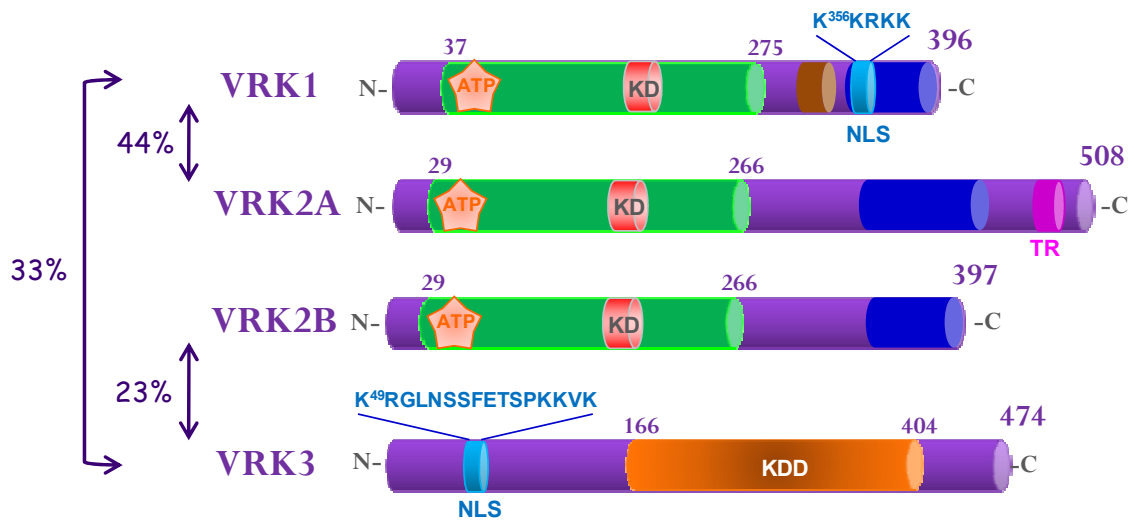

\begin{tabular}{|c|c|}
\hline Dominio catalítico & Motivo básico-ácido-básico (BAB) \\
\hline Sitio de unión a ATP & Secuencia diana lisosoma/endosoma \\
\hline Sitio quinasa activo (KD) & Señal de localización nuclear (NLS) \\
\hline Dominio quinasa degenerado (KDD) & Región transmembrana (TR) \\
\hline
\end{tabular}

Figura 4. Dominios y estructura de las quinasas VRK humanas. Principales motivos y dominios en la secuencia de las proteínas de la familia VRK. VRK1 y VRK2 muestran alta homología en el dominio catalítico pero difieren en la región carboxilo. Los porcentajes indican la homología entre los diferentes miembros de la familia.

356-396), que constituye una región de aminoácidos ácidos flanqueada por dos regiones de aminoácidos básicos. Este motivo es característico y está conservado en varias quinasas VRK de diferentes organismos (Aihara et al., 2004). VRK2A presenta dos motivos BAB solapados, pero la isoforma corta VRK2B presenta el segundo motivo truncado. No se conoce la función de este motivo, pero su conservación indica que es importante en la función de estas proteínas quinasa y quizá esté implicado en la regulación de las mismas. La proteína VRK2A presenta además en su extremo carboxilo una secuencia hidrofóbica (residuos 492-508), que constituye una región transmembrana.

En cuanto a la proteína VRK3, es el miembro más divergente de la familia, con un $33 \%$ de homología con VRK1 y un $23 \%$ con VRK2 (fig. 4). VRK3 consta de 474 aminoácidos y presenta una señal de localización nuclear bipartita en su extremo amino terminal; y en su región carboxilo se localiza un dominio quinasa degenerado, debido a sustituciones en residuos claves en los motivos necesarios para la catálisis. Por tanto, carece de actividad catalítica (Nichols and Traktman, 2004; Kang and Kim, 2006). 
2.1.1. Estructura tridimensional de las proteínas VRK y diferencias con otras quinasas

La resolución de la estructura tridimensional de los dominios catalíticos de VRK2 y VRK3 mostró que presentan un plegamiento típico de proteínas quinasa (Scheeff et al., 2009). Las dos estructuras se encuentran en conformación activa, con los dos lóbulos del dominio quinasa cerrados. Los segmentos de activación son más rígidos que en otras quinasas, como sucede con proteínas del grupo de CK1 (Nolen et al., 2004). Una característica única de la estructura de las proteínas VRK es la presencia de una hélice $\mathrm{C}$ adicional $(\alpha \mathrm{C} 4)$ en el lóbulo amino que ancla la hélice $\alpha \mathrm{C}$ al lóbulo carboxilo (Scheeff et al., 2009). El llamado G-loop, motivo con varios residuos de glicina (GXGXFG) (fig. 5) implicado en la colocación del ATP para una catálisis eficiente, se encuentra degradado en VRK3, siendo reemplazadas las glicinas por residuos de mayor tamaño. Este y otros cambios (fig. 5), como alteraciones en el bolsillo de unión del ATP, la pérdida del residuo ácido aspártico del motivo de unión de metal (DFG) o la sustitución por asparagina del ácido aspártico en el dominio VI esencial para la actividad, hacen que VRK3 sea una pseudoquinasa. Sin embargo, a pesar de estos cambios en la secuencia del dominio catalítico de VRK3, existen algunos residuos que participan en la estabilización de la proteína, dando lugar a que la conformación del sitio activo de VRK2 y VRK3 sea muy similar. La conservación del plegamiento del dominio quinasa en VRK3 a pesar de la falta de unión a ATP y de

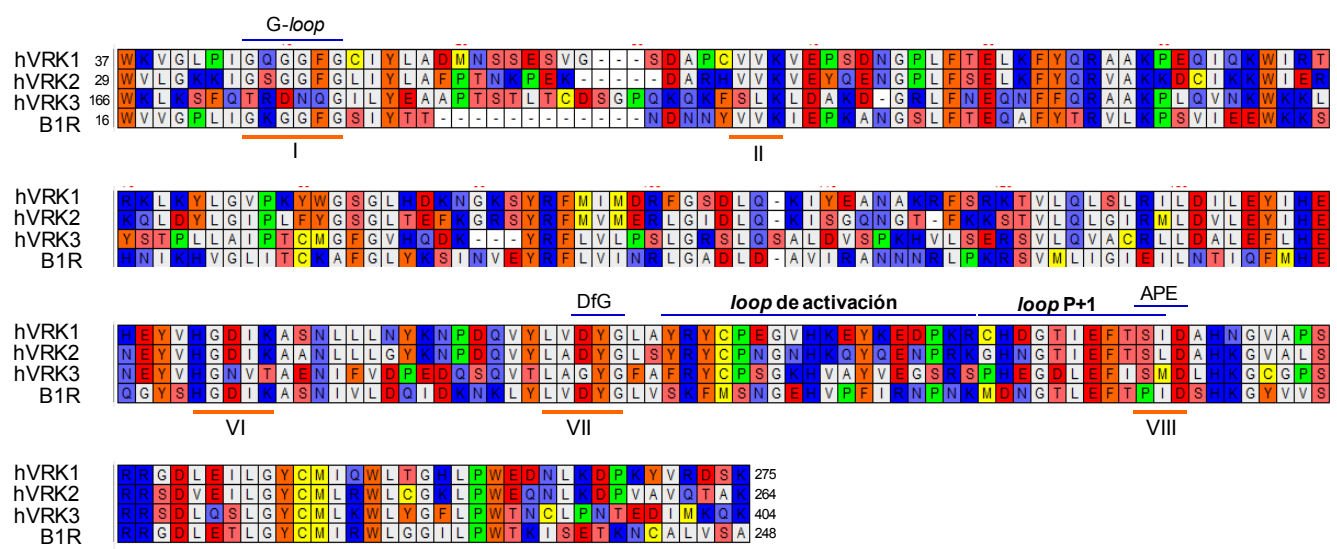

Figura 5. Alineamiento de los dominios catalíticos de las proteínas VRK humanas y la quinasa viral B1R. Se indican los dominios típicos de proteínas quinasa que existen en la familia de proteínas VRK y los motivos implicados en la catálisis como el G-loop y el segmento de activación. Se pueden observar las sustituciones de aminoácidos claves en la secuencia de VRK3. El alineamiento se realizó con el programa DS Gene 1.5. 
actividad quinasa sugiere que la estructura de VRK3 debe ser conservada para que tenga lugar la interacción con otras proteínas y servir así de proteína de anclaje, como se sabe que sucede con otras pseudoquinasas (Boudeau et al., 2006; Rajakulendran and Sicheri, 2010).

El segmento de activación de las proteínas quinasa comprende desde el motivo DFG hasta un motivo APE (fig. 1, página 18). Estos motivos son diferentes en las proteínas VRK, sustituyéndose respectivamente por los motivos DYG y SXD (fig. 5). Entre estos dos motivos existe un loop de activación, cuya fosforilación es responsable de la activación de muchas quinasas, y un loop $\mathrm{P}+1$, importante en la unión del sustrato. En el loop de activación de las proteínas VRK no existe ningún sitio típico de fosforilación, que sí se conserva en muchas otras quinasas. Sin embargo, sí existe una tirosina conservada en las VRK humanas y de ratón; y además, se observan dos residuos treonina conservados en el loop $\mathrm{P}+1$ que participan en la estabilización del segmento de activación (Scheeff et al., 2009). La conservación de estos residuos sugiere que podrían ser importantes para la actividad de estas quinasas. Hacia el final del segmento de activación las secuencias y estructuras de VRK2 y VRK3 divergen.

Más recientemente se ha publicado la estructura de VRK1 mediante resonancia magnética nuclear en su forma catalíticamente activa, revelando un plegamiento típico de proteína quinasa y una conformación del dominio catalítico similar a la de VRK2 y VRK3 (Shin et al., 2011). Por otro lado, Allerston y colaboradores han descrito en la base de datos PDB (ID: 3OP5) la estructura tridimensional de VRK1 obtenida por cristalografía gracias a la mutación de diversos residuos. La hélice $\mathrm{C}$ adicional única de las proteínas de la familia VRK, también se observa en la estructura de VRK1. Pero además, la estructura de VRK1 presenta una característica única y notable: el extremo carboxilo se orienta alrededor del sitio catalítico e interacciona con varios motivos importantes como el G-loop o el segmento de activación. Esto sugiere que para la activación de VRK1 es necesaria la interacción molecular entre el extremo carboxilo y el centro catalítico de la proteína, por lo que sería importante en la activación de VRK1 y en la estabilidad estructural de la proteína (Kang et al., 2011). Este papel regulador del extremo carboxilo ya lo sugería el alto grado de conservación de esta región entre especies (Nichols and Traktman, 2004). 
Todas estas características particulares en el segmento de activación de los miembros de la familia VRK, sumado a que el sitio de unión a ATP también presenta sustituciones características que lo diferencian de otras serina/treonina quinasas, sugieren que las quinasas VRK1 y VRK2 serían candidatas idóneas para el desarrollo de inhibidores específicos. La interacción de estos inhibidores específicos para las quinasas VRK con otras proteínas se vería reducida debido a la menor conservación de la secuencia de las VRKs con la mayoría de quinasas (Fedorov et al., 2007).

\subsection{Características y función de la quinasa humana VRK1}

Dentro de la familia de quinasas VRK, el miembro mejor caracterizado es VRK1. Todos los estudios descritos hasta el momento sobre su expresión y funciones celulares indican que es una quinasa que participa en el control de la proliferación y progresión del ciclo celular (Valbuena et al., 2011b).

\subsubsection{Localización subcelular y expresión de VRK1}

La quinasa humana VRK1 es una proteína de 396 aminoácidos que presenta en su extremo carboxilo una señal de localización nuclear (Lopez-Borges and Lazo, 2000). Sin embargo, aunque la proteína VRK1 endógena es principalmente nuclear y está excluida del nucleolo, su localización varía dependiendo del tipo celular y de las condiciones de crecimiento, pudiéndose detectar en el citoplasma de algunas líneas celulares y tejidos (Valbuena et al., 2007a). Además, se ha detectado una subpoblación de VRK1 en el aparato de Golgi (Valbuena et al., 2007a); y en otros estudios se ha detectado en el nucleolo (Andersen et al., 2005). También se ha descrito que VRK1 se encuentra asociada a la cromatina en interfase y mitosis (Kang et al., 2007), tras la inducción de la expresión de Myc (Shiio et al., 2003), y se ha detectado en complejos de iniciación de la transcripción asociados a la cromatina, junto con factores de ensamblaje y proteínas histonas (Guermah et al., 2006). Esto indica que debe existir algún mecanismo de regulación de su localización, aunque todavía no se conoce.

En cuanto a la expresión de VRK1, se detectan mayores niveles de expresión a nivel transcripcional en los tejidos con alta tasa proliferativa como hígado, timo fetal y testículos. La proteína VRK1 se expresa en todas las líneas celulares estudiadas, 
presentando las líneas celulares tumorales mayores niveles de esta quinasa (Nezu et al., 1997; Valbuena et al., 2007a). En muestras de tumores se detectó que la proteína VRK1 correlacionaba con diversos marcadores tumorales como p53 en tumores escamosos de cabeza y cuello (Santos et al., 2006) y la expresión de VRK1 es mayor en carcinomas escamosos de pulmón que en adenocarcinomas, produciéndose una acumulación de VRK1 en los tumores con mutaciones de p53(Valbuena et al., 2007b). Además, se ha descrito que VRK1 podría ser un marcador en tumores de mama, siendo de buen pronóstico la presencia de bajos niveles de VRK1 (Fournier et al., 2006), y se ha observado relación entre elevada expresión de VRK1 y mal pronóstico en cáncer de mama (Finetti et al., 2008; Martin et al., 2008). También se ha encontrado sobreexpresión de VRK1 a nivel génico en sarcoma de tejidos blandos (Nishijo et al., 2009).

\subsubsection{Regulación de factores de transcripción por parte de VRK1}

La quinasa VRK1 presenta una fuerte actividad de autofosforilación, característica que comparte con el grupo de caseína quinasas (Flotow et al., 1990; Nichols and Traktman, 2004). Sin embargo, en cuanto a actividad de fosforilación de sustratos, VRK1 es capaz de fosforilar tanto proteínas ácidas como básicas, a diferencia de las caseína quinasas, que sólo fosforilan proteínas ácidas (Lopez-Borges and Lazo, 2000). Entre los sustratos de fosforilación de VRK1 se encuentran varios factores de transcripción como p53 (Lopez-Borges and Lazo, 2000; Barcia et al., 2002; Toledo and Wahl, 2006), ATF2 (Sevilla et al., 2004b), CREB (Kang et al., 2008) y cJun (Sevilla et al., 2004a) (fig. 6).

La fosforilación de VRK1 sobre el factor de transcripción p53 ocurre específicamente en la treonina 18 (Lopez-Borges and Lazo, 2000; Barcia et al., 2002; Vega et al., 2004), impidiendo la interacción con Hdm2 (Schon et al., 2002; Ferreon et al., 2009) y promoviendo la acetilación de p53 por parte de p300. De este modo se aumenta la estabilidad de p53 y se evita su degradación (Vega et al., 2004). Además, se ha descrito que existe un circuito de autorregulación entre p53 y VRK1 (Valbuena et al., 2006): la activación de p53 por VRK1 causa la degradación de VRK1 por vía endocitica-lisosomal mediante la inducción del gen de la proteína DRAM (Valbuena et 


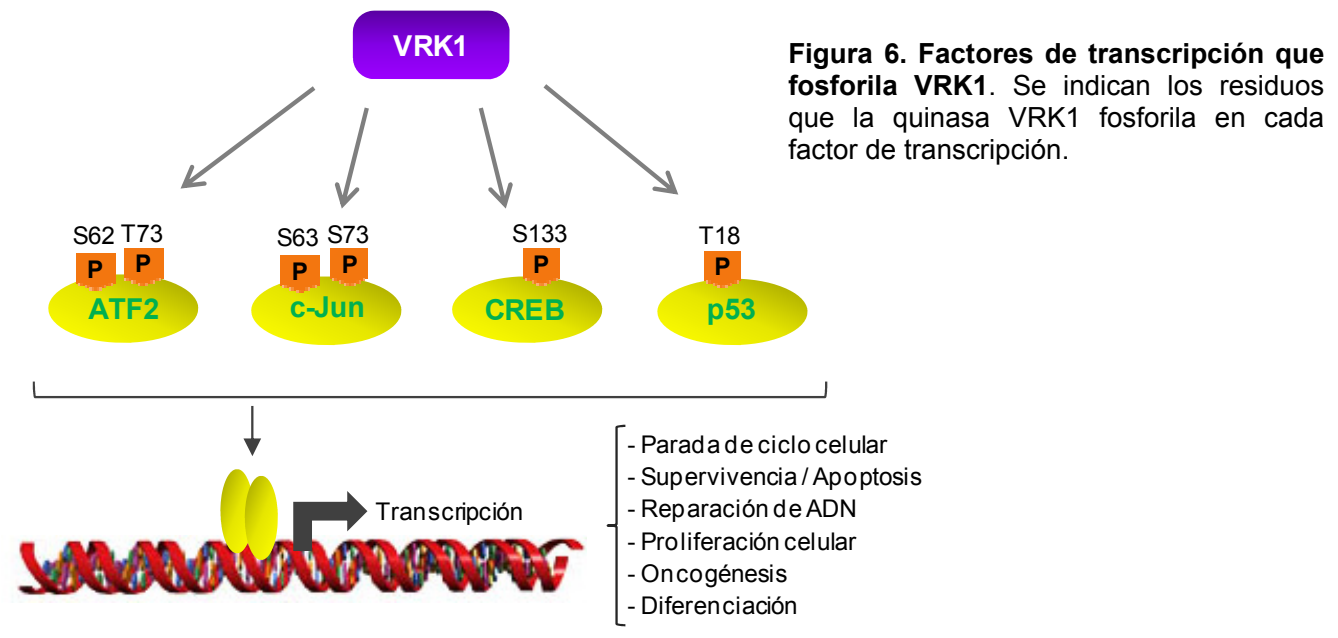

al., 2011a). Por otro lado, el cofactor p300 protege a VRK1 de la degradación inducida por p53 gracias a un cambio en la especificidad de p53 por sus dianas de transcripción (Valbuena et al., 2008a). La existencia de este circuito de autorregulación también se demuestra en que carcinomas de pulmón con mutaciones que inactivan a p53 presentan niveles elevados de VRK1 (Valbuena et al., 2007b). Así, se propone a VRK1 como un regulador de la actividad de p53 en condiciones normales de proliferación manteniendo unos niveles basales de p53 activado; y en caso de llegar algún estímulo de estrés celular, se produciría un cambio en el balance de los niveles de p53 y VRK1 que promovería la estabilización de p53 (Vega et al., 2004; Valbuena et al., 2011a).

Otros factores de transcripción que participan en respuesta a diversos tipos de estrés celular son ATF2 y c-Jun, que son sustratos de fosforilación de VRK1 (fig. 6). ATF2 pertenece a la familia de factores ATF/CREB de respuesta a AMP cíclico y activa genes implicados en crecimiento celular, diferenciación, respuesta inmune y respuesta a estrés y ha sido relacionado con proliferación celular y oncogénesis (van Dam and Castellazzi, 2001; Bhoumik et al., 2007; Vlahopoulos et al., 2008). VRK1 fosforila a ATF2 en los residuos serina 62 y treonina 73, aumentando así la transcripción dependiente de este factor. Además, la fosforilación de ATF2 por VRK1 tiene un efecto aditivo en la estimulación de la actividad de ATF2 provocada por la fosforilación de JNK en otros residuos de ATF2 (treoninas 69 y 71) (Sevilla et al., 2004b). El factor de transcripción c-Jun juega un papel importante en respuesta a diversos estímulos promoviendo proliferación, apoptosis o incluso oncogénesis 
(Shaulian, 2010). VRK1 fosforila a c-Jun en las serinas 63 y 73, provocando la estabilización y acumulación de c-Jun y estimulando así la transcripción dependiente de este factor. Además, el efecto de VRK1 es aditivo al de JNK, quinasa que fosforila a c-Jun en los mismos residuos que VRK1 (Sevilla et al., 2004a).

Otro de los factores de transcripción que fosforila VRK1 es CREB (cAMP response element binding), en la serina 133 (Kang et al., 2008) (fig. 6). Este residuo participa en la activación de CREB (Johannessen et al., 2004), promoviendo la unión de dicho factor al elemento de respuesta a AMP cíclico del gen de la ciclina D1. Esta fosforilación de VRK1 sobre CREB ocurre durante la transición de fase $G_{1}$ a $S$, lo que se relaciona con el papel de VRK1 en la regulación de la progresión del ciclo celular (Valbuena et al., 2008b; Valbuena et al., 2011b).

\subsubsection{Implicación de VRK1 en el ciclo celular}

La mayor expresión de VRK1 en tejidos con alta tasa proliferativa (Nezu et al., 1997) sugería un posible papel de esta quinasa en el control de la progresión del ciclo celular, idea que se ha ido demostrando en diversos estudios posteriores.

La expresión de VRK1 es mayor en la capa basal de epitelios escamosos, zona de mayor proliferación, y su expresión se va perdiendo a medida que las células epiteliales se diferencian (Santos et al., 2006). Además, los niveles de VRK1 correlacionan positivamente con proteínas relacionadas con proliferación celular como Cdk2, Cdk6, Ciclinas B1 y A, Rb fosforilado, survivina, Ki67 y p63; y negativamente con algunos inhibidores del ciclo celular como p27 o p16 (Santos et al., 2006; Valbuena et al., 2007b; Valbuena et al., 2008b). Se ha visto que VRK1 aumenta la actividad de los promotores de los genes de Cdk2 y survivina (Santos et al., 2006), así como también de ciclina D1 mediante la activación de CREB (Kang et al., 2008); y el silenciamiento de la expresión de VRK1 con ARN de interferencia supone una reducción en los niveles de ciclina D1 y A, PCNA y otros marcadores de proliferación, provocando una parada celular en fase $\mathrm{G}_{0}$ (Vega et al., 2004; Valbuena et al., 2008b; Valbuena et al., 2011b).

También se ha descrito que VRK1 es necesaria para la salida de fase $G_{0} y$ entrada en fase $\mathrm{G}_{1}$ del ciclo celular (Valbuena et al., 2008b). Esta activación del gen de 
VRK1 en la transición de $\mathrm{G}_{0}$ a $\mathrm{G}_{1}$ es paralela a la de myc y fos, dos genes de respuesta temprana en la progresión del ciclo celular, y anterior a la de ciclina D1; lo cual sitúa a esta quinasa también como un gen de respuesta temprana.

Este papel de VRK1 en la regulación de la proliferación celular junto con la presencia de elevados niveles de esta proteína en diversos tipos de cáncer, sugieren que el desarrollo de inhibidores específicos de la actividad de VRK1 podría ser útil en terapia oncológica.

2.2.4. Papel de VRK1 en la dinámica del ensamblaje de la envuelta nuclear y la fragmentación del aparato de Golgi

Al final de la mitosis la membrana nuclear debe ensamblarse de nuevo en las células hijas. La proteína BAF (Barrier to Autointegration Factor) desempeña un papel esencial en este proceso de dinámica de la envuelta nuclear. BAF forma homodímeros que se unen al ADN y a los dominios LEM presentes en algunas proteínas de la membrana interna del núcleo (Shumaker et al., 2001) y es necesaria para el mantenimiento de la arquitectura nuclear, participando además en la organización de la cromatina y en expresión génica (Segura-Totten and Wilson, 2004; Margalit et al., 2007; Montes de Oca et al., 2009). La localización de BAF varía durante el ciclo celular. Así, en interfase se localiza en la membrana nuclear interna anclando la cromatina a la envuelta nuclear. Al comienzo de la mitosis BAF se libera de su unión a la cromatina y a proteínas de la membrana nuclear y su localización es más difusa. En anafase participa en el reclutamiento de proteínas de la membrana nuclear interna, resultando esencial para el ensamblaje de la envuelta nuclear al final de la mitosis (Haraguchi et al., 2001). VRK1 fosforila a BAF en su extremo amino terminal, principalmente en serina 4, y en menor medida en las treoninas 2 y 3 (fig. 7). Esta fosforilación impide la unión de BAF al ADN, alterando su localización subcelular, y reduciendo la capacidad de interacción de BAF con proteínas con motivos LEM. Se postula que mediante esta regulación de BAF, VRK1 participa en la dinámica de la envuelta nuclear (Nichols et al., 2006). Además, BAF está implicada en la integración del ADN viral de los virus MMLV (Moloney Murine Leukemia Virus) o VIH (Virus de inmunodeficiencia humana) en el ADN de la célula infectada (Margalit et al., 2007). 


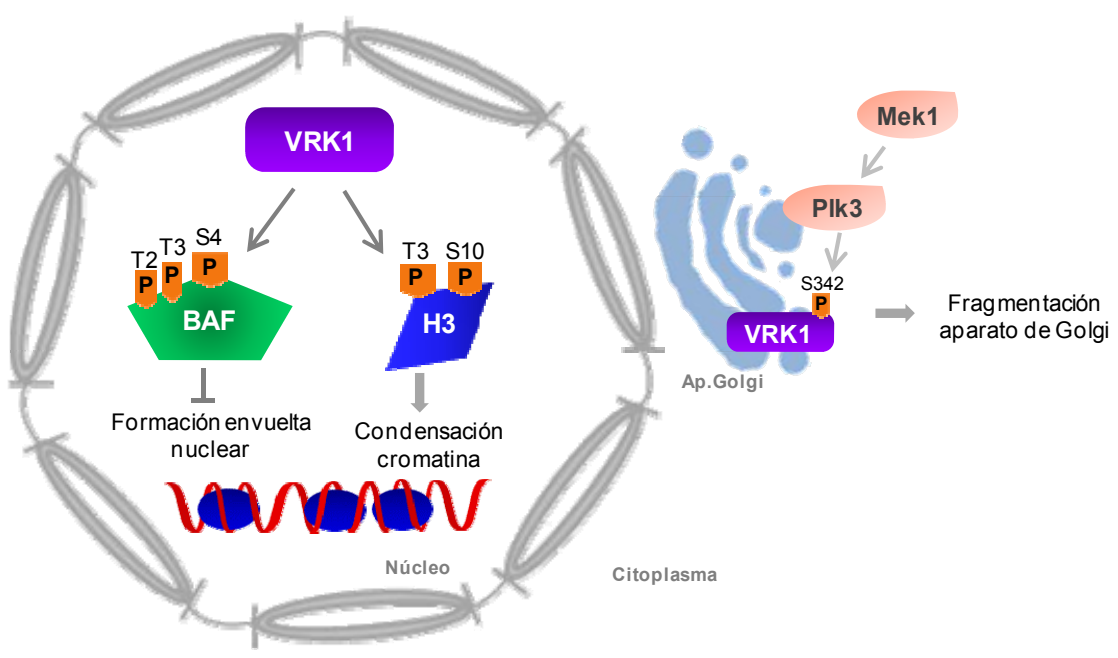

Figura 7. Funciones de VRK1 en la dinámica de la envuelta nuclear, fragmentación del aparato de Golgi y condensación de la cromatina. VRK1 fosforila a la proteína BAF en los residuos señalados inhibiendo la formación de la envuelta nuclear. La fosforilación en treonina 3 y serina 10 de la histona H3 está implicada en la condensación de la cromatina. Además, VRK1 participa en la fragmentación del aparato de Golgi inducida por Mek1 y Plk3.

En un estudio reciente se describe que VRK1 y VRK2 impiden la integración del ADN viral en el ADN nuclear mediante su efecto de fosforilación sobre BAF (Suzuki et al., 2010).

También durante la mitosis otro proceso importante es la redistribución de los orgánulos celulares en las dos células hijas. Durante esta distribución tiene lugar un proceso de fragmentación del aparato de Golgi, aunque los mecanismos implicados no se conocen en profundidad. Se han descrito algunas proteínas que están implicadas en el proceso de fragmentación del aparato de Golgi, como Mek1 (Shaul and Seger, 2006; Shaul et al., 2009) y Plk3 (Xie et al., 2004). Tanto VRK1 como Plk3 colocalizan en el aparato de Golgi y la quinasa Plk3 fosforila a VRK1 en serina 342 (fig.7). Además, el silenciamiento de la expresión de VRK1 con ARN de interferencia bloquea parcialmente la fragmentación del aparato de Golgi inducida por Mek1 y Plk3 durante la mitosis, algo que también tiene lugar al sobreexpresar el mutante de VRK1 sin actividad quinasa y el mutante no fosforilable en la serina 342 (Lopez-Sanchez et al., 2009). Estos resultados sitúan a VRK1 en una ruta de señalización necesaria para la correcta fragmentación del aparato de Golgi en la transición de la fase $\mathrm{G}_{2}$ a mitosis, como una quinasa por debajo de Mek1 y Plk3. 


\subsubsection{VRK1 y fosforilación de la histona $\mathrm{H3}$}

La condensación de la cromatina o la transcripción génica son procesos en los que las modificaciones postraduccionales de las colas de las histonas juegan un papel importante (Baek, 2011). VRK1 fosforila a la histona H3 en treonina 3 y serina 10 (Kang et al., 2007; Perez-Cadahia et al., 2009) (fig. 7), residuos que también son fosforilados por las quinasas Haspin y Aurora B respectivamente. La fosforilación en serina 3 por Haspin se relaciona con el correcto alineamiento de los cromosomas en mitosis (Dai et al., 2005; Wang et al., 2010) y la fosforilación en serina 10 por Aurora B se relaciona con la condensación de la cromatina (Sauve et al., 1999; Crosio et al., 2002; Prigent and Dimitrov, 2003; Perez-Cadahia et al., 2009). Para la total fosforilación de la histona $\mathrm{H} 3$ en serina 10 durante la mitosis es necesaria la participación tanto de VRK1 como de Aurora B (Kang et al., 2007). Además, la sobreexpresión de una forma constitutivamente activa de VRK1 produce la condensación de la cromatina en células en interfase. Estos datos sugieren que VRK1 contribuye a la condensación de los cromosomas en la transición de fase $\mathrm{G}_{2}$ a mitosis mediante la fosforilación de histonas (Kang et al., 2007).

\subsubsection{Regulación de VRK1}

A pesar de la gran cantidad de información existente acerca de las funciones biológicas de la quinasa VRK1, se conoce poco sobre su regulación. Sin embargo, la expresión, localización y actividad de VRK1 deben estar reguladas para que dicha quinasa pueda desempeñar el papel adecuado dependiendo del estímulo y la respuesta celular necesaria en cada momento.

A nivel transcripcional, los factores de crecimiento o mitógenos existentes en el suero pueden regular la expresión de VRK1, ya que en células privadas de suero los niveles de VRK1 disminuyen y tras la adición de suero su expresión aumenta de nuevo (Valbuena et al., 2008b). También se ha descrito que los factores de transcripción E2F1 y Myc son capaces de promover la expresión de VRK1 a nivel de su promotor (Santos et al., 2006; Kang et al., 2008).

Además de la regulación de la expresión, las modificaciones postraduccionales de una proteína son relevantes a la hora de controlar su localización subcelular y 
actividad. Las quinasas VRK1 y VRK2 presentan una fuerte actividad de autofosforilacion (Lopez-Borges and Lazo, 2000; Blanco et al., 2006) y la región carboxilo parece estar implicada en la regulación de la quinasa VRK1. La autofosforilación puede estar jugando un papel en la estabilidad de la proteína ya que la quinasa inactiva es mucho más inestable que la silvestre y su vida media es más corta (Valbuena et al., 2008b). Mediante ensayos in vitro se determinó la treonina 355 como un residuo de autofosforilación en el extremo carboxilo de VRK1 importante para su regulación (Barcia et al., 2002). Recientemente, se ha descrito que la proteína quinasa PKC $\delta$ fosforila a VRK1 en la treonina 355 e inhibe su actividad quinasa (Park et al., 2011), proponiendo un modelo en el que en condiciones de proliferación VRK1 estaría localizada principalmente en el núcleo fosforilando dianas esenciales para la progresión del ciclo celular (como CREB, histona H3 o BAF); pero en condiciones de muerte celular, VRK1 sería fosforilada por $\mathrm{PKC} \delta$ y contribuiría a la parada del ciclo celular y apoptosis dependiente de p53 (Park et al., 2011).

Por otro lado, programas de predicción de potenciales sitios de fosforilación en la secuencia de VRK1 por parte de otras quinasas pronostican sitios fosforilables en la región carboxilo. Así, en un estudio con técnicas proteómicas realizado para identificar residuos fosforilados por ATM o ATR en respuesta a luz ultravioleta, se identificó la treonina 378 de VRK1 como residuo de fosforilación (Stokes et al., 2007). Estudios del laboratorio han mostrado que la actividad de VRK1 aumenta tras la exposición de las células a radiación ionizante, luz ultravioleta o fármacos que causan daño en el ADN como doxorrubicina o etopósido, estabilizándola y provocando un rápido aumento en los niveles de VRK1 (Valbuena et al., 2006; Valbuena et al., 2011a).

Además de la regulación de la actividad de VRK1 mediante fosforilaciones, la interacción estable con otras proteínas podría modificar la actividad de la quinasa. En este contexto, mediante técnicas proteómicas se identificó a la GTPasa Ran (Rasrelated nuclear) como una proteína que interacciona con VRK1, y también con VRK2A y VRK2B. Estas quinasas son activas cuando se unen a RanGTP e inactivas al interaccionar con RanGDP (Sanz-Garcia et al., 2008). En el caso de la fosforilación de la histona $\mathrm{H} 3$, ésta debe ocurrir durante la mitosis, pero no en interfase. En esta regulación se ha descrito que participa una variante de la histona $\mathrm{H} 2$, la macroH2A1, 
que, a través de la interacción con VRK1 en interfase, impide la actividad de fosforilación de VRK1 sobre la H3 y también sobre BAF, sin afectar a la actividad de autofosforilación de VRK1 (Kim et al., 2011).

\subsection{Características y función de la quinasa humana VRK2}

Existen menos estudios sobre las funciones y regulación de la quinasa VRK2A. Inicialmente se postuló, como en el caso de VRK1, un posible papel de VRK2 en proliferación celular puesto que su expresión a nivel de ARN mensajero era mayor en tejidos con alta tasa proliferativa (Nezu et al., 1997; Vega et al., 2003).

\subsubsection{Localización subcelular y expresión de VRK2}

La quinasa humana VRK2 presenta dos isoformas, VRK2A y VRK2B, generadas por un procesamiento alternativo del ARN mensajero (Blanco et al., 2006). La isoforma VRK2A, de 508 aminoácidos, se localiza anclada a membranas del retículo endoplasmático, mitocondrias y envuelta nuclear mediante la región transmembrana que presenta en su extremo carboxilo terminal (fig. 8). La isoforma VRK2B, de 397 aminoácidos, carece de esta región hidrofóbica y se detecta tanto en el citoplasma como en el núcleo (Blanco et al., 2006). VRK2A se expresa en todas las líneas celulares estudiadas hasta el momento. Sin embargo, VRK2B se expresa sólo en determinadas líneas celulares (Blanco et al., 2006; Fernandez et al., 2010).

La función de VRK2B tiene redundancia con la de VRK1, pudiendo reemplazar funcionalmente a VRK1 en el núcleo. Esta idea se apoya en que la isoforma VRK2B, pero no VRK2A, es capaz de fosforilar al factor de transcripción p53 y promover su

\section{r}

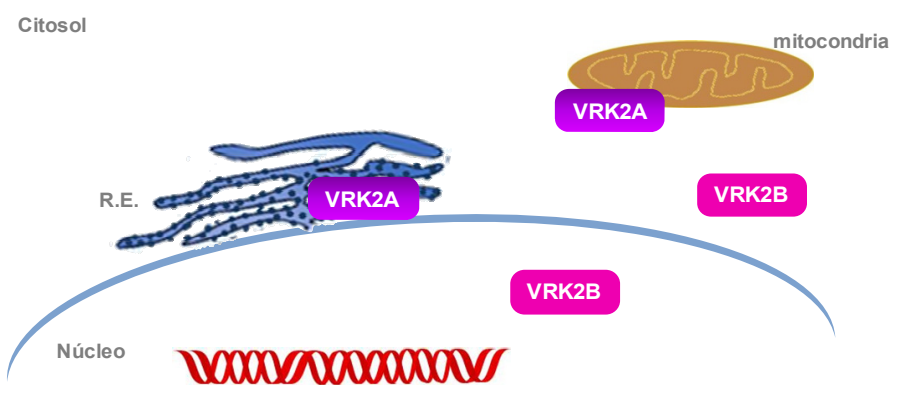

Figura 8. Localización subcelular de las isoformas de VRK2. VRK2A se encuentra en el citoplasma anclada a membranas y VRK2B puede ser citosólica o nuclear. 
estabilización (Blanco et al., 2006). Además, el análisis de la expresión de VRK1 y VRK2B muestra que cuando VRK1 presenta una localización más citoplasmática, existe una mayor expresión de VRK2B nuclear (Blanco et al., 2006).

Estudios de expresión génica mediante arrays indican que el gen de VRK2 está regulado positivamente en células $\mathrm{T}$ de sangre periférica estimuladas con anticuerpos anti-CD3 y anti-CD28 o con fitohemaglutinina (PHA), ionomicina o PMA (forbol 12miristato 13-acetato) (Diehn et al., 2002); y negativamente en células mononucleares de sangre periférica estimuladas con lipopolisacárido o ionomicina y PMA (Boldrick et al., 2002).

Estudios de expresión de la proteína VRK2 en tejidos tumorales de cáncer de mama muestran un patrón con correlación inversa con el receptor ErbB2, observándose mayores niveles de proteína VRK2 en aquellos tejidos clasificados como negativos para ErbB2 y menores niveles en los clasificados como ErbB2 positivos (Fernandez et al., 2010). El receptor de estrógenos (ER) sigue este mismo patrón de expresión: menores niveles proteicos en tejidos tumorales de mama ErbB2 positivos y viceversa (Ariga et al., 2005). En concordancia con esto, en tumores de mama la expresión de VRK2 muestra una correlación positiva con los niveles de proteína de receptores de estrógenos y también con los niveles de receptores de progesterona (Fernandez et al., 2010).

\subsubsection{Funciones de VRK2A}

La mayor parte de los datos que existen sobre funciones biológicas de VRK2A son en relación a regulación de rutas mediadas por MAPK quinasas (Mitogen-activated protein kinases). Una de esas funciones es la modulación de la respuesta celular mediada por interleuquina-1 $\beta$ y la respuesta a condiciones de hipoxia (Blanco et al., 2007; Blanco et al., 2008). La proteína JNK es estimulada en respuesta a hipoxia e induce la transcripción de genes con sitios AP-1 (Activator protein 1) (Zhang et al., 2008). El factor de transcripción AP-1 está compuesto por heterodímeros de las proteínas Jun y Fos (Vesely et al., 2009). En esta vía de señalización la proteína de anclaje JIP1 (JNK-interacting protein) es la encargada de ensamblar los complejos de MAPKs que incluyen a MLK, MKK7 y JNK (Whitmarsh et al., 2001), fosforilando 
esta última al factor de transcripción c-Jun (fig. 9). En esta respuesta también participa TAK1 (TGF- $\beta$ activated kinase), que se activa ante señales de hipoxia y promueve el ensamblaje de JIP1 en un complejo que incluye TAK1, MKK7 y JNK (fig. 9). VRK2A y VRK2B interfieren en la respuesta a hipoxia mediada por TAK1 a través de la interacción con esos complejos de señalización (Blanco et al., 2007). Del mismo modo, VRK2A, y en menor medida VRK2B, regulan negativamente la respuesta a interleuquina-1 $\beta$ que se transmite a través de la vía de TAK1 y JNK (Blanco et al., 2008).

Otro papel de VRK2A en relación a rutas de MAPKs tiene que ver con la señalización de Erk1/2 y la respuesta al factor de crecimiento epidérmico (EGF), actuando como modulador negativo. Esta modulación negativa de la ruta de Erk1/2 tiene lugar de forma independiente de la actividad quinasa de VRK2A, mediante la interacción con Mek1 y la proteína de anclaje KSR1 (fig. 9). Así, VRK2A retiene a KSR1 y Mek1 en complejos multiproteicos, inhibiendo la señalización mediada por Erk1/2 (Fernandez et al., 2010).

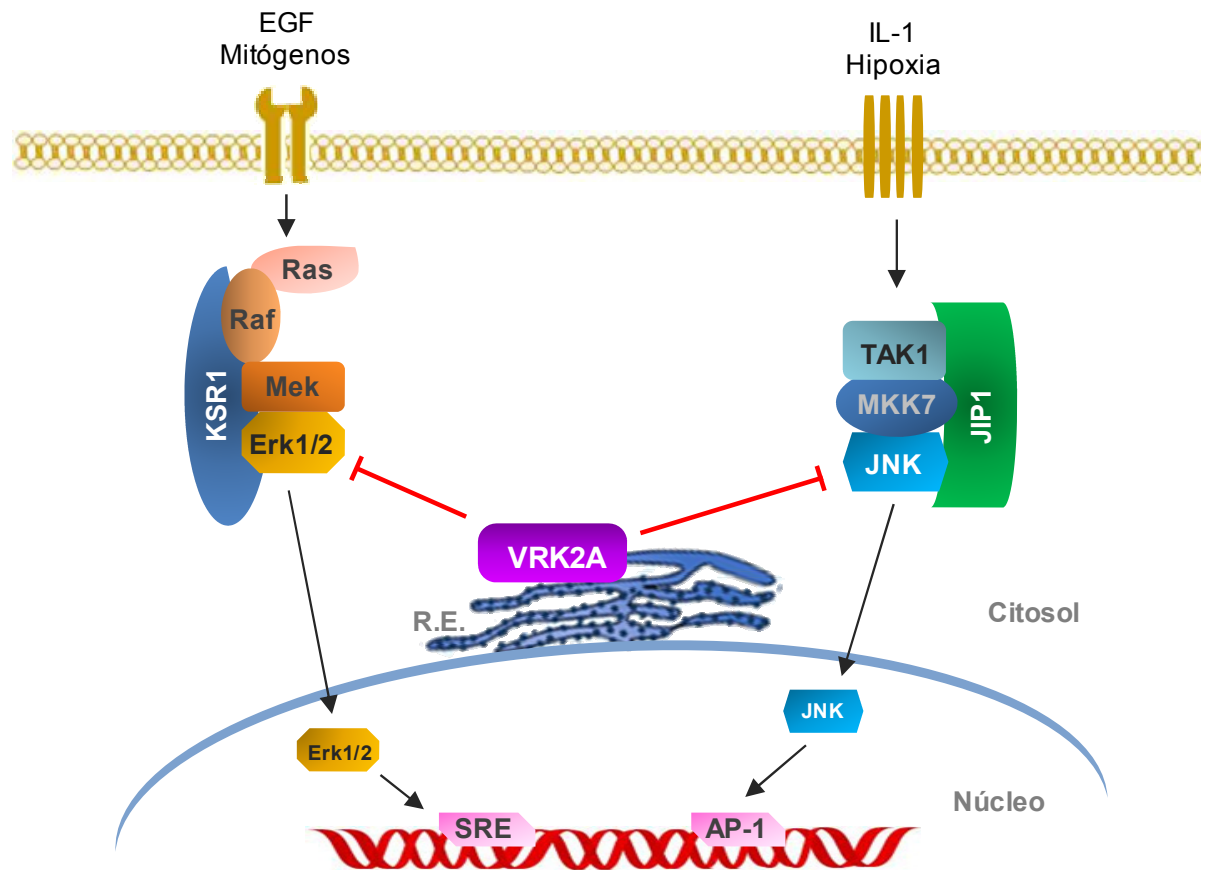

Figura 9. Funciones de VRK2A en rutas de señalización de MAPK. VRK2A inhibe la activación transcripcional de AP-1 mediada por JNK en respuesta a interleuquina-1 (IL-1) e hipoxia (derecha); e inhibe la señalización de Erk1/2 en respuesta a EGF o factores del suero que estimulan la proliferación celular (izquierda). Ambas funciones son independientes de la actividad quinasa de VRK2A. SRE: elemento de respuesta a suero. AP-1: Activator protein 1. 
Otra de las funciones descritas de VRK2A es la interacción con la proteína viral BHRF1 del virus Epstein-Barr, homóloga a la proteína anti-apoptótica Bcl-2. Esta interacción permite aumentar la supervivencia celular del virus tras la infección (Li et al., 2006).

\subsection{Ratones knock-out de VRK1 y VRK2}

El estudio de ratones hipomórficos para VRK1, en los que una inserción en el gen de VRK1 genera una expresión de tan sólo el 15\% respecto a ratones silvestres, mostró que tanto los machos como las hembras son viables pero estériles. La esterilidad ocurre por una falta de mitosis y meiosis en las células reproductoras debida a defectos en la capacidad proliferativa de esas células (Choi et al., 2010; Wiebe et al., 2010). Otro estudio, también con ratones con una inserción que impide la expresión de VRK1, relaciona a esta quinasa con la gametogénesis. La reducción de los niveles de VRK1 en estos ratones produce esterilidad tanto en machos como hembras. Sin embargo, se detectan diferencias entre sexos. Los machos al principio son fértiles pero sufren una pérdida progresiva de espermatogénesis que da lugar a la esterilidad; mientras que las hembras son totalmente estériles y presentan múltiples defectos durante el desarrollo de los oocitos (Schober et al., 2011).

También se ha estudiado el efecto de la alteración del gen de VRK2. El gen de VRK2 en ratón se transcribe en sentido opuesto al gen pog. Se compararon ratones con una mutación recesiva que altera los genes vrk2 y pog y se observó que los ratones doble knock-out (vrk2-/- y pog -/-) presentaban una esterilidad más severa que los ratones knock-out sólo para el gen pog. Por ello, es posible que VRK2 también tenga un papel importante en el desarrollo de las células germinales (Lu and Bishop, 2003).

\subsection{Las quinasas VRK1 y VRK2 en otras enfermedades humanas}

Además de los datos que sitúan a VRK1 como quinasa importante en el control del ciclo y proliferación celular, estudios recientes empiezan a situar a VRK1 como una proteína que participa en el desarrollo del sistema nervioso y el mantenimiento neuronal. Se ha encontrado una mutación en el gen $V R K 1$ que introduce un codón de parada en la secuencia de localización nuclear (R358X), dando lugar a una proteína 
VRK1 truncada. Esta mutación produce un síndrome denominado atrofia muscular espinal con hipoplasia pontocerebelosa (SMA-PCH), una variante rara de atrofia infantil (Renbaum et al., 2009; Wee et al., 2010). Esto sugiere que en neuronas, un tejido con muy baja tasa proliferativa, VRK1 también podría tener un papel importante. Recientemente se ha descrito que VRK1 fosforila a coilina, proteína esencial en la formación de los cuerpos de Cajal de las neuronas (Sanz-Garcia et al., 2011).

Además de VRK1, VRK2 también podría tener implicaciones neurológicas. Se ha descrito un paciente con retraso cognitivo, microcefalia y otros problemas cuyo síndrome está causado por microdeleción en la región cromosómica 2p15-p16, aunque esta deleción no incluye el gen VRK2 (Felix et al., 2010). Sin embargo, diversos estudios han sugerido que el gen de VRK2, situado en la región 2 p16, podría ser responsable de las malformaciones de la corteza cerebral observada en algunos pacientes (Chandler et al., 2006; Chabchoub et al., 2008). También recientemente se ha asociado el gen de VRK2 con riesgo de sufrir esquizofrenia (Steinberg et al., 2011).

Estos resultados indican que la familia de quinasas VRK parece tener implicaciones neurológicas además de en cáncer. 


\section{EL FACTOR DE TRANSCRIPCIÓN NFAT}

La llegada a la célula de diferentes estímulos provoca el inicio de una serie de cascadas de señalización que dan lugar finalmente a la transcripción de genes. Los factores de transcripción son las dianas finales de estas rutas de transducción y su actividad debe estar regulada para que se transcriban los genes necesarios y no otros. Esta regulación tiene lugar mediante diferentes modificaciones postraduccionales sobre cada factor de transcripción, como fosforilaciones, acetilaciones o sumoilación. Además, según las interacciones con otras proteínas, como otros factores de transcripción, coactivadores o represores, la transcripción génica puede ser diferente a pesar de tratarse de un mismo factor de transcripción.

El factor de transcripción NFAT (Factor Nuclear de células T Activadas) es una proteína cuya actividad transcripcional está estrictamente regulada mediante fosforilación y desfosforilación y es activado por señalización de $\mathrm{Ca}^{2+}$-calcineurina (Clipstone and Crabtree, 1992). La proteína NFAT inicialmente se identificó como un factor nuclear inducible capaz de unirse al elemento de respuesta del receptor de antígeno presente en el promotor del gen humano de la interleuquina-2 (IL-2), regulando la transcripción génica durante la activación de linfocitos T (Shaw et al., 1988). Sin embargo, posteriormente se observó que también se expresa en muchos otros tipos celulares fuera del sistema inmune (Graef et al., 2001b; Crabtree and Olson, 2002; Hill-Eubanks et al., 2003; Nguyen and Di Giovanni, 2008), participando en la regulación de genes implicados en desarrollo, crecimiento, proliferación y diferenciación celular. Además, se está observando la importancia de la señalización de NFAT en oncogénesis (Viola et al., 2005; Mancini and Toker, 2009).

\subsection{Estructura de la familia de proteínas NFAT}

Inicialmente se identificaron dos componentes de NFAT: uno nuclear y otro citoplasmático cuya translocación al núcleo necesita la movilización de calcio en la célula (Flanagan et al., 1991). Posteriormente se demostró que el componente nuclear era el conocido factor de transcripción AP-1 (Jain et al., 1992), un heterodímero compuesto por miembros de las familias de proteínas Jun y Fos (Vesely et al., 2009). El componente citoplasmático se purificó (McCaffrey et al., 1993; Tokumitsu et al., 
1993; Northrop et al., 1994) y su caracterización mostró la existencia de cuatro miembros en la familia de proteínas NFAT. Estas cuatro proteínas de la familia están reguladas a través de señalización por $\mathrm{Ca}^{2+}$-calcineurina y pueden presentar variantes resultantes de maduración alternativa del ARN mensajero que difieren en el extremo amino o carboxilo terminal, pero mantienen la región central conservada (Imamura et al., 1998; Masuda et al., 1998; Chuvpilo et al., 1999). Esta región conservada está compuesta por dos dominios principales situados en tándem: una región de homología a NFAT (NHR, del inglés NFAT Homology Region), que regula la localización intracelular de la proteína, y un dominio con similaridad al dominio de unión al ADN

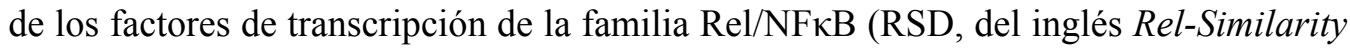
Domain) (Nolan, 1994), responsable de la especificidad de unión al ADN y de la interacción con el complejo AP-1, la cual estabiliza la interacción de NFAT con el ADN (Rao et al., 1997; Macian et al., 2001) (fig. 10).

El dominio RSD presenta una elevada conservación de secuencia entre los diferentes miembros de la familia y se puede dividir en dos subdominios: uno que comprende los 190 aminoácidos de la región amino y que está más conservado; y otro que comprende los 100 aminoácidos del extremo carboxilo, menos conservado. Las proteínas NFAT pueden unirse al ADN como monómeros (al contrario que las proteínas Rel, que se unen como dímeros) (Hoey et al., 1995) y el primer subdominio

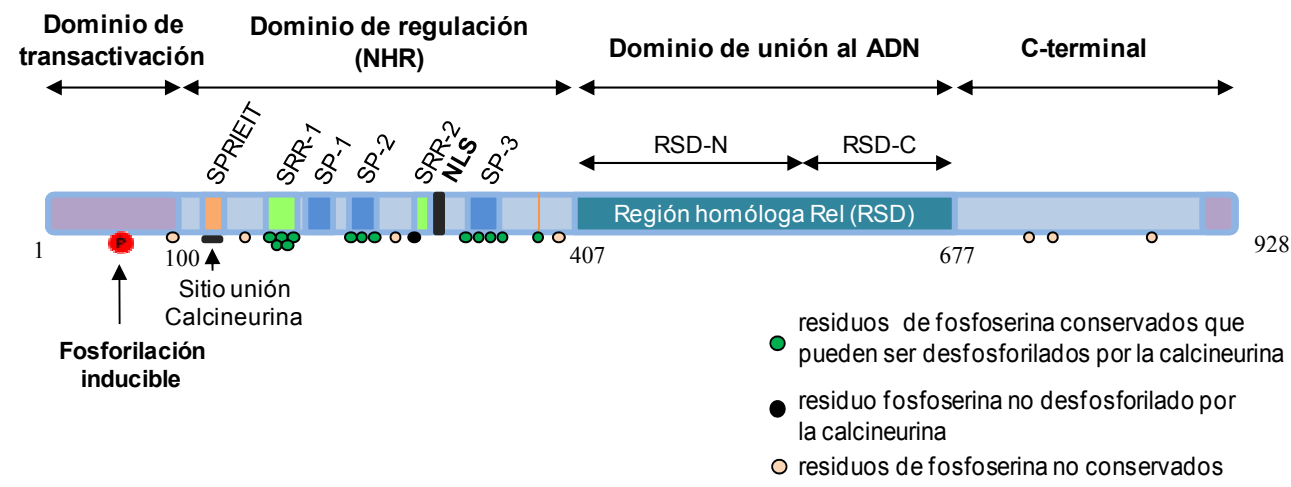

Figura 10. Estructura y dominios del factor de transcripción NFAT. La estructura corresponde al NFAT1 de ratón. Los dominios de regulación y de unión al ADN están conservados entre todas las proteínas NFAT. En el dominio de regulación se indican los distintos motivos implicados en la regulación de la localización subcelular de NFAT y el sitio de unión de calcineurina. En el dominio de transactivación del extremo amino tiene lugar una fosforilación que aumenta la actividad transcripcional de NFAT. 
del RSD parece suficiente para la unión especifica al ADN y para la interacción con AP-1 (Jain et al., 1995; Wolfe et al., 1997).

El dominio RSD va precedido de una secuencia de unos 400 aminoácidos que presenta menor conservación entre los miembros de la familia y que puede dividirse en una región amino terminal de 100 aminoácidos de poca conservación seguida de una región rica en serinas y prolinas con una similaridad mayor, que es el dominio NHR (fig. 10). La función principal del dominio NHR o de regulación es el control de la localización intracelular de las proteínas NFAT, ya que es necesaria la desfosforilación de residuos de esta región por la fosfatasa calcineurina para la importación al núcleo de NFAT (Luo et al., 1996b; Beals et al., 1997a; Masuda et al., 1997; Porter et al., 2000). En este dominio NHR existe una secuencia de localización nuclear (NLS) (fig. 10). Otros motivos conservados en la región NHR incluyen regiones ricas en serina (SSR) y tres motivos SP (motivos de serina y prolina) (fig. 10). La mayoría de serinas de la región SRR1 se encuentran fosforiladas constitutivamente, lo que enmascara la señal de localización nuclear (Okamura et al., 2004). Además de desfosforilar a NFAT en esta región, la fosfatasa calcineurina se asocia establemente con el dominio NHR (Takeuchi et al., 2007). Se cree que esta asociación podría contribuir al mantenimiento de NFAT en el núcleo.

Además de estas dos regiones conservadas entre los miembros de la familia NFAT, existen en la proteína NFAT1 dos dominios de transactivación (TAD) (Luo et al., 1996a), localizados en los extremos amino y carboxilo terminales. El más relevante en lo referente a la actividad transcripcional de NFAT1 es el TAD del extremo amino, que comprende los primeros 100 aminoácidos de la proteína (Luo et al., 1996b). Este dominio de transactivación amino terminal puede sufrir fosforilaciones inducibles que potencian la actividad de transcripción de NFAT1 (fig. 10) (San-Antonio et al., 2002; Gomez-Casero et al., 2007).

\subsubsection{Expresión del factor de transcripción NFAT}

Las proteínas NFAT se expresan en casi todos los tejidos celulares, aunque los niveles y patrones de expresión de cada isoforma difieren (Chuvpilo et al., 1999; Sherman et al., 1999; Hock and Brown, 2003). Todos los miembros de la familia 
NFAT, excepto NFAT3, presentan niveles elevados en el sistema inmune, en el timo, el bazo y linfocitos de sangre periférica (Cockerill et al., 1995; Masuda et al., 1995; Imamura et al., 1998). También se han encontrado en otros tejidos celulares, incluido el cerebro (Vihma et al., 2008).

NFAT1 se identificó a partir de una genoteca de ADN complementario de un clon de células $\mathrm{T}$ de ratón (McCaffrey et al., 1993). En ratón se han descrito tres variantes generadas por maduración alternativa del ARN mensajero (NFAT1-A, NFAT1-B y NFAT1-C) y en humanos existen dos variantes (que se corresponden con las B y C de ratón) (Luo et al., 1996a), que difieren en el extremo carboxilo terminal. Entre NFAT1 de ratón y humano existe un 90\% de identidad en la secuencia aminoacídica. La proteína NFAT1 se expresa en bazo, timo y algunas regiones del sistema nervioso central; pero no se ha encontrado en músculo esquelético o cardiaco, intestino delgado, hígado, riñón o cerebro (Plyte et al., 2001). En el sistema inmune NFAT1 se expresa en células T y B, células NK, mastocitos, monocitos y macrófagos, pero no en neutrófilos (Wang et al., 1995). Cuando se sobreexpresa en la línea de células T Jurkat, NFAT1 aumenta la transcripción de los promotores de diversas citoquinas (Luo et al., 1996a). Además, se expresa en otras líneas celulares tumorales como líneas de cáncer de colon (Duque et al., 2005) y de cáncer de mama (Jauliac et al., 2002; Yiu and Toker, 2006).

En este trabajo hemos estudiado la proteína NFAT1, por lo que a partir de ahora nos centraremos en la regulación y función de este miembro de la familia.

\subsection{Regulación de la actividad de NFAT}

La existencia de múltiples isoformas sugiere que existe una gran complejidad en la regulación de la función de los miembros de la familia NFAT; e incluso también podría existir cierta redundancia entre las funciones de varias isoformas. El control de la ruta de señalización de NFAT es complejo y participan muchas otras proteínas regulando positiva o negativamente a este factor de transcripción mediante diversos mecanismos, tanto directos como indirectos. 
3.2.1. Importancia de la señalización por calcio y desfosforilación/ fosforilación de NFAT

La señalización de NFAT mediante señales de calcio es uno de mecanismos mejor caracterizados de señales iniciadas en receptores de la superficie celular. Los mecanismos de activación de NFAT se identificaron por el estudio en células inmunes (Rao et al., 1997; Feske et al., 2003), aunque esos mismos mecanismos tienen lugar en otros tipos celulares (Nilsson et al., 2008; Konig et al., 2010).

\subsection{1.a. Activación de NFAT por la fosfatasa calcineurina}

La activación de NFAT tiene lugar a partir de receptores de la superficie celular que desencadenan señales de calcio mediante la activación de la fosfolipasa C- $\gamma$ (PLC$\gamma)$, la cual hidroliza el fosfatidil-inositol-bifosfato para producir inositol trifosfato $\left(\mathrm{IP}_{3}\right)$ y diacilglicerol (DAG). El $\mathrm{IP}_{3}$ induce la liberación de calcio de los almacenes intracelulares. Esto desencadena la apertura de canales de calcio activados por liberación de calcio (CRAC) en la membrana plasmática y así se mantienen elevados los niveles de calcio intracelular (fig. 11). El calcio se une a calmodulina y esta activa a la fosfatasa calcineurina, lo cual conduce a la desfosforilación de NFAT y su translocación al núcleo para llevar a cabo la transcripción génica. La activación de calcineurina es un paso limitante en la activación de NFAT en todas las células. Por ello, el inhibidor de la actividad de calcineurina ciclosporina A, utilizado en terapia inmunosupresora, inhibe la señalización de NFAT.

En estado basal NFAT se localiza en el citoplasma en una conformación inactiva y con su región reguladora hiperfosforilada. Se han identificado más de 20 sitios de fosforilación en NFAT1, de los cuales 18 se localizan en el dominio de regulación (Okamura et al., 2000; Villar et al., 2006). Estos residuos se encuentran en los motivos SRR y SP de la molécula de NFAT1. De los 14 residuos fosforilables en NFAT1 que han sido conservados en los miembros de la familia regulados por calcineurina, todos, excepto uno, son desfosforilados por calcineurina y se localizan en los motivos SRR1, SP2 y SP3 (fig. 10, página 47) (Okamura et al., 2000). La desfosforilación de los motivos SP expone la señal de localización nuclear, promoviendo la translocación al núcleo de NFAT y la activación de la transcripción (fig. 11). La calcineurina activada 
mantiene a NFAT en el núcleo en un estado desfosforilado (Zhu and McKeon, 1999). Además de la desfosforilación de NFAT por calcineurina se ha descrito interacción entre ambas proteínas (Wesselborg et al., 1996), la cual tiene lugar en un motivo específico en la región amino terminal de NFAT, que se ha conservado entre los miembros de la familia, con la secuencia consenso PXIXIT, que en NFAT1 es SPRIEIT (fig. 10) (Garcia-Cozar et al., 1998; Li et al., 2004; Rodriguez et al., 2009). Péptidos diseñados con esta secuencia actúan como inhibidores selectivos de la activación de NFAT al competir por la unión a calcineurina (Aramburu et al., 1999). Aunque el mecanismo que desencadena la translocación al núcleo de NFAT es la

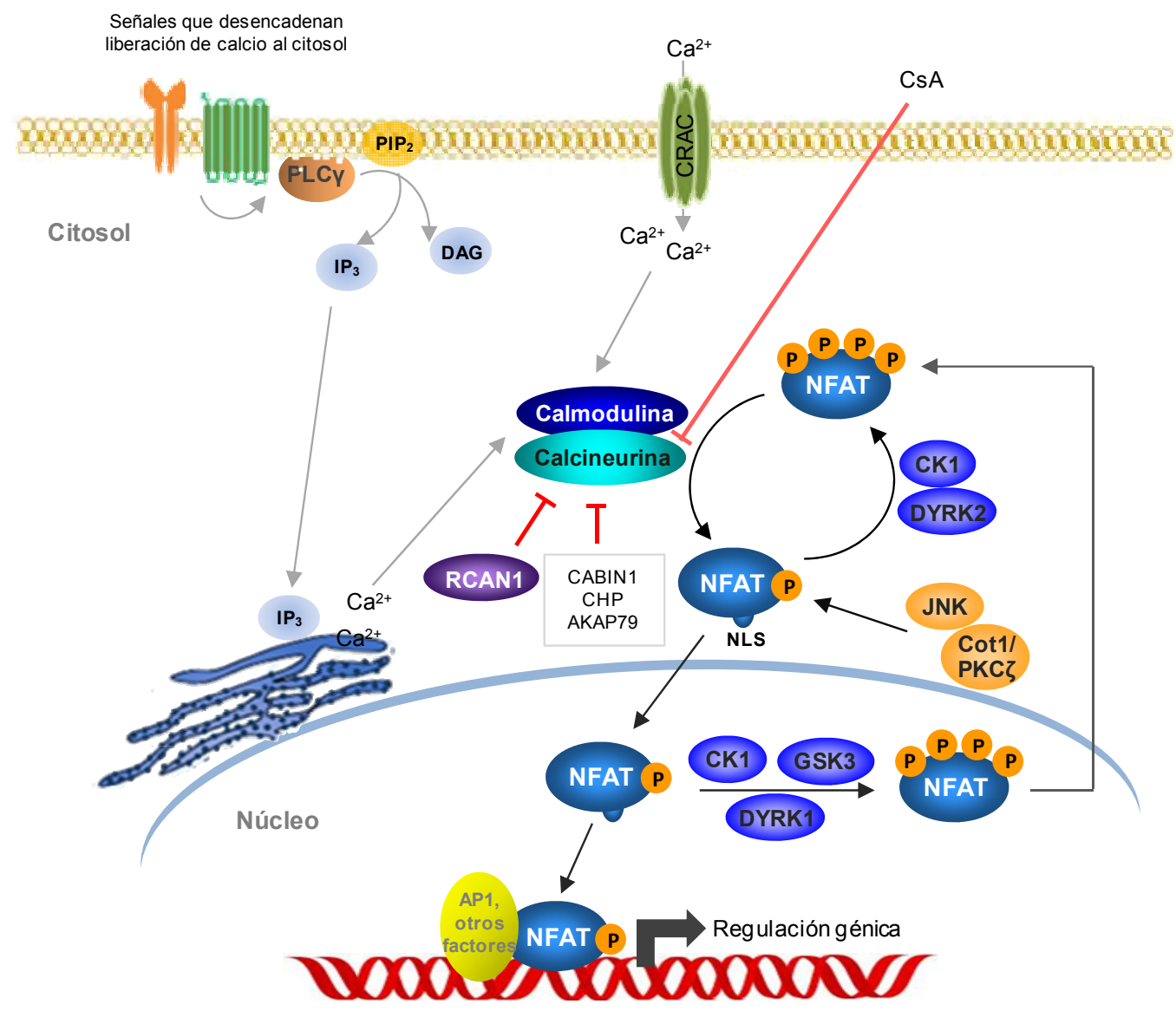

Figura 11. Ruta de señalización del factor de transcripción NFAT. Estímulos que desencadenan la liberación de calcio intracelular activan la fosfatasa calcineurina, que desfosforila a NFAT, desenmascarando la señal de localización nuclear (NLS). NFAT en el núcleo se une a otros factores de transcripción para regular la transcripción de sus genes diana. Algunas proteínas quinasa (en azul) refosforilan el dominio de regulación de NFAT para mantenerlo en el citosol o para que sea exportado fuera del núcleo. Otras quinasas (en naranja) fosforilan a NFAT aumentando su actividad transcripcional. Existen proteínas inhibidoras de la actividad de calcineurina, como RCAN1; y la ciclosporina A (CsA) también actúa inhibiendo a calcineurina. 
desfosforilación en sí misma, la interacción con calcineurina activada ayuda a mantener a NFAT en el núcleo (Al-Daraji et al., 2002).

\subsection{1.b. Proteínas quinasa de NFAT}

La exportación fuera del núcleo de NFAT es esencial para terminar su actividad transcripcional y el cese de la señalización. Se pueden diferenciar dos tipos de quinasas que participan en la acumulación de NFAT en el citoplasma: unas que se denominan quinasas de mantenimiento, encargadas de actuar en el citosol para mantener a NFAT en un estado totalmente fosforilado y evitar su translocación al núcleo, y otras denominadas quinasas de exportación, que refosforilan a NFAT nuclear promoviendo su exportación fuera del núcleo (fig. 11).

La proteína quinasa glucógeno sintasa 3 (GSK3) fosforila a NFAT1 (fig. 11) en el motivo SP2 (Beals et al., 1997b). GSK3 es una quinasa constitutivamente activa que se fosforila e inactiva por la señalización de PI3K y Akt, que suele ser una ruta alterada en tumores humanos (Chin and Toker, 2009; Baselga, 2011). Esto sugiere que la relación entre las rutas de PI3K y NFAT podría tener consecuencias importantes en cáncer (Yoeli-Lerner et al., 2009).

La proteína caseína quinasa 1 (CK1) funciona tanto como quinasa de mantenimiento como de exportación (fig. 11), fosforilando la región SRR1 de NFAT1 (Okamura et al., 2004). Proteínas de la ruta de MAPK como p38 también fosforilan a NFAT1 en la región SRR1, inhibiendo su activación (Gomez del Arco et al., 2000; Molkentin, 2004). Sin embargo, aunque está descrito que p38 promueve la exportación de NFAT1 del núcleo; en otros pasos de la señalización de NFAT1, facilita su activación ( $\mathrm{Wu}$ et al., 2003), lo que indica que una misma quinasa puede tener funciones opuestas dependiendo del momento en que actúe sobre NFAT1.

Más recientemente, en un estudio en Droshophila con ARN de interferencia, se identificaron las proteínas DYRK (Dual-specificity tyrosine-phosphorylation-regulated kinase) como modificadoras de la localización de las proteínas NFAT (Gwack et al., 2006). Estas quinasas fosforilan a NFAT1 en el motivo SP3, permitiendo así la subsecuente fosforilación de los motivos SP2 y SRR1 por GSK3 y CK1 (Arron et al., 2006). DYRK1 actúa como quinasa de exportación de NFAT1 fuera del núcleo y 
DYRK2 como quinasa de mantenimiento de NFAT1 fosforilado en el citoplasma (fig. 11) (Mancini and Toker, 2009). El gen que codifica para las proteínas DYRK se sitúa en el cromosoma 21 próximo al gen de las proteínas RCAN, que son inhibidoras de calcineurina (Park et al., 2009).

Seguramente, debido al elevado número de residuos fosforilables en la molécula de NFAT1, existen más proteínas quinasa que participan en el control de su localización subcelular, pero no se han identificado todavía. El conocimiento de todas ellas podría abrir nuevas vías en terapia puesto que a menudo su regulación se encuentra alterada en cáncer.

\subsection{1.c. Potenciación de la actividad transcripcional de NFAT mediante fosforilación}

Además de fosforilaciones en el dominio de regulación que inhiben la actividad de NFAT1, se han descrito otras que la activan. Es el caso de la proteína JNK, que fosforila residuos específicos en esta región de regulación (Villar et al., 2006), aumentando así la actividad de NFAT1 (Ortega-Perez et al., 2005).

También, al igual que ocurre en otros factores de transcripción, NFAT1 puede ser regulado mediante modificación de sus dominios de transactivación. Se ha descrito una fosforilación inducible del dominio de transactivación amino terminal que potencia la actividad de NFAT1 (fig. 10) y que es necesaria para alcanzar la actividad transcripcional total de NFAT1. La quinasa Cot1/Tp12 coopera con PKC $\zeta$ para llevar a cabo esta potenciación de la actividad transcripcional de NFAT (fig. 11) a través de la fosforilación de las serinas 53, 54 y 56 del dominio de transactivación de NFAT1 de ratón (en NFAT1 humano la serina 54 es reemplazada por una prolina), aumentando así la actividad transcripcional dependiente de este factor (de Gregorio et al., 2001; Gomez-Casero et al., 2007).

\subsubsection{Regulación por proteínas inhibidoras de la actividad de calcineurina}

La actividad de la fosfatasa calcineurina no sólo se controla mediante calcio y calmodulina, sino que también existen proteínas inhibidoras de calcineurina (fig. 11). Entre ellas se encuentran las proteínas CABIN1 (Lai et al., 1998; Sun et al., 1998b), 
CHP (Lin et al., 1999), AKAP79 (Kashishian et al., 1998) y proteínas de la familia RCAN (Rothermel et al., 2000). La proteína CABIN1 (Calcineurin-binding protein) actúa como un inhibidor no competitivo de la actividad de calcineurina; mientras que la proteína CHP (Calcineurin homologous protein) compite con la unión de la subunidad reguladora de calcineurina, $\mathrm{CnB}$, a la subunidad catalítica, $\mathrm{CnA}$. La proteína de anclaje AKAP79 (A-kinase-anchoring protein) se une a calcineurina y a PKA, anclando a calcineurina en lugares específicos e impidiendo así la acción sobre sus sustratos.

Las proteínas reguladoras de calcineurina o RCAN son inhibidores competitivos de la actividad fosfatasa de calcineurina. Previamente se denominaron DSCR (Down syndrome candidate región) por su localización en el cromosoma 21, en la región de la trisomía que conduce al síndrome de Down (Fuentes et al., 1997). Otros nombres son debidos a su función y así se denominaron proteínas MCIP (del inglés, Modulatory calcineurin-interacting protein), por su capacidad de unión a calcineurina (Vega et al., 2002). En humanos existen tres miembros, que presentan identidad de secuencia en la región central y el extremo carboxilo. Todos ellos tienen la capacidad de unirse e inhibir a la fosfatasa calcineurina, pero cada uno presenta diferente patrón de regulación.

La proteína RCAN1 interacciona con la subunidad catalítica de calcineurina (CnA) e inhibe su actividad fosfatasa. En la estructura de RCAN1 se pueden distinguir tres regiones: una central responsable de la inhibición competitiva y los extremos carboxilo y amino terminales, que participan en la unión e inhibición de calcineurina (Kingsbury and Cunningham, 2000; Vega et al., 2002; Rothermel et al., 2003). RCAN1 posee una similitud estructural con las proteínas NFAT en cuanto a la existencia en su secuencia aminoacídica de un dominio SP (fig. 12A). En el motivo SP de RCAN1 pueden tener lugar fosforilaciones que podrían participar en la estabilidad y regulación de la proteína. Fosforilación en la serina 112 de RCAN1 por proteínas MAPK, permite que la quinasa GSK3 pueda fosforilar la serina 108. Esta última serina es sustrato de la fosfatasa calcineurina (Vega et al., 2002). También, el sitio de unión a calcineurina del extremo carboxilo de RCAN1 recuerda al motivo PxIxIT de NFAT (Aubareda et al., 2006; Martinez-Martinez et al., 2009) (fig. 12A). 
A

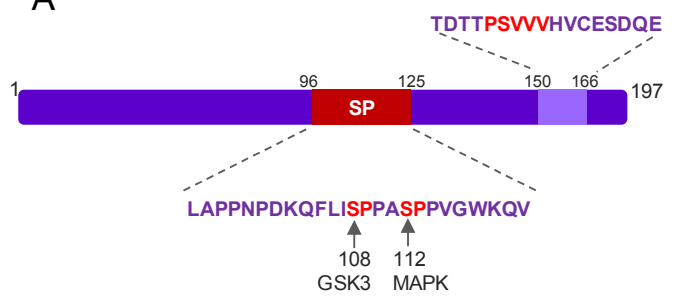

B

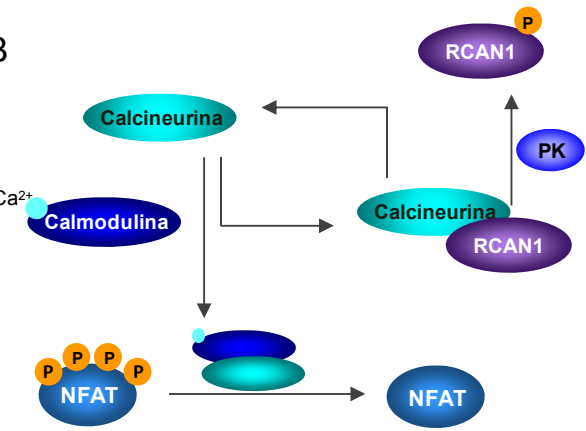

Figura 12. Inhibición de calcineurina por RCAN1. A) Esquema de la proteína RCAN1. En rojo se muestra el motivo SP y en el extremo carboxilo terminal la secuencia que recuerda al sitio de interacción con calcineurina en NFAT, PxIxIT. Las serinas 108 y 112 de RCAN1 pueden ser fosforiladas por GSK3 y MAPK, respectivamente. B) Esquema de la inhibición de RCAN1 sobre calcineurina. RCAN1 interacciona con calcineurina impidiendo que calmodulina se una a ella y se active. Proteínas quinasas (PK) fosforilan a RCAN1, provocando la disociación de calcineurina, la cual queda libre para unirse a calmodulina y desfosforilar a NFAT.

La capacidad de inhibición de RCAN1 sobre la actividad de calcineurina conlleva a la inhibición de las proteínas que son sustrato de esta fosfatasa, como es el caso del factor de transcripción NFAT (Fuentes et al., 2000). La sobreexpresión de RCAN1 inhibe la actividad transcripcional de NFAT y su translocación al núcleo (Abbasi et al., 2005). Se ha descrito que proteínas MAPK participan en la regulación de la capacidad inhibidora de RCAN1 sobre calcineurina mediante fosforilación de RCAN1, provocando su separación de calcineurina y permitiendo la activación de la señalización de NFAT (fig. 12B) (Abbasi et al., 2005; Abbasi et al., 2006). También la quinasa TAK1 fosforila a RCAN1 y activa la señalización de NFAT (Liu et al., 2009).

\subsubsection{Otros mecanismos de regulación de la señalización de NFAT}

Además de fosforilaciones, la proteína NFAT1 puede sufrir otros tipos de modificaciones postraduccionales que regulan su actividad. Una de ellas es la sumoilación, que da lugar a la retención nuclear de NFAT1 (Terui et al., 2004). También se ha descrito ubiquitinación de NFAT1 por Mdm2 a través de la señalización de Akt y GSK3 (Yoeli-Lerner et al., 2005; Yoeli-Lerner et al., 2009). Y la caspasa-3 se ha descrito como regulador negativo de NFAT1 puesto que envía a este factor a degradación proteolítica (Wu et al., 2006). 
Por otro lado, existen mecanismos de retroalimentación para suprimir la actividad de NFAT1 (Yang et al., 2000). En células donde la fosfatasa calcineurina está inactiva, la tasa de transcripción de RCAN1 es baja y la proteína se degrada rápidamente. Tras la activación de calcineurina, NFAT1 desfosforilado entra en el núcleo y entre sus genes diana está el de RCAN1. Así se sintetiza RCAN1, que actúa previniendo la actividad excesiva de calcineurina y por tanto, inhibiendo la actividad de NFAT1.

Además se ha descrito un complejo de anclaje formado por ARN y proteínas que participa en la regulación de la desfosforilación de NFAT (Sharma et al., 2011) mediante la localización eficiente del factor de transcripción con sus reguladores en el citoplasma o con sus genes diana en el núcleo. También las proteínas de anclaje Homer compiten con calcineurina por la unión a NFAT1 y previenen su desfosforilación y activación (Huang et al., 2008).

\subsection{Transcripción dependiente de NFAT}

Una vez en el núcleo, el factor de transcripción NFAT reconoce y se une a la secuencia consenso para NFAT, (A/T)GGAAA(A/N), en los elementos de los promotores de sus genes diana. La unión al ADN de NFAT puede tener lugar como homodímero o interaccionando con otros factores de transcripción (fig. 11) (Graef et al., 2001a; Falvo et al., 2008). Generalmente, las proteínas NFAT participan en la regulación génica cooperando con otros factores de transcripción. Entre ellos, el más conocido es AP-1, que forma un complejo cuaternario con NFAT y el ADN (Chen et al., 1998). Otros factores de transcripción que también interaccionan con NFAT son las proteínas MAF, GATA o STAT (Ho et al., 1996; Monticelli et al., 2004; Manukyan et al., 2010). La unión con diferentes factores de transcripción permite a las proteínas NFAT cooperar con ellos e integrar diferentes rutas de señalización para activar patrones de respuesta concretos según el tipo de estímulo.

Entre los genes diana que regula el factor de transcripción NFAT se encuentra el gen de ciclooxigenasa-2 (COX-2), un gen que se induce mediante la estimulación de las células y en el que nos centraremos en este trabajo. 


\subsection{Ciclooxigenasa-2: gen diana de NFAT}

Existen dos isoformas de proteínas ciclooxigenasa: COX-1 y COX-2. Ambas catalizan el paso limitante en la síntesis de prostaglandinas, que es la conversión del ácido araquidónico a prostaglandina $\mathrm{H}_{2}\left(\mathrm{PGH}_{2}\right)$, precursora de otras moléculas mediadoras de procesos de inflamación (fig. 13). COX-1 es un enzima que se expresa constitutivamente en la mayoría de tejidos y es responsable de la síntesis de prostaglandinas que median las funciones fisiológicas normales. Sin embargo, el enzima COX-2 no se detecta en condiciones normales, pero su expresión es inducida por estímulos relacionados con activación celular e inflamación y se relaciona con procesos patológicos. NFAT es un factor de transcripción importante en la regulación de la expresión de COX-2.

Figura 13. Síntesis de prostaglandinas. Las proteínas ciclooxigenasa catalizan la transformación del ácido araquidónico a prostaglandina $\mathrm{H}_{2}$.

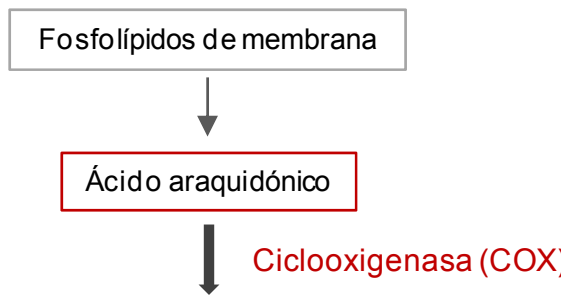

Prostaglandina $\mathrm{H}_{2}\left(\mathrm{PGH}_{2}\right)$

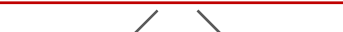

Prostaglandinas y prostaciclinas $\left(\mathrm{PGI}_{2}, \mathrm{PGD}_{2}, \mathrm{PGE}_{2}\right)$
Tromboxano $\mathrm{A}_{2}\left(\mathrm{TXA}_{2}\right)$

\subsubsection{Estructura del promotor de COX-2 y transcripción}

La activación de la señalización por NFAT mediante el tratamiento con éster de forbol (PMA) más ionomicina (que mimetiza la activación por señalización de calcio), induce la expresión del gen de ciclooxigenasa-2. La expresión de COX-2 está regulada por diferentes factores de transcripción que presentan sitios de unión en su promotor.

El promotor de COX-2 (fig.14) consta de una caja TATA, que se considera la principal secuencia de muchos promotores de genes ya que es el sitio de unión de factores de transcripción e histonas y está implicada en el proceso de transcripción por la ARN polimerasa. Muchos de los promotores que presentan este motivo corresponden a genes de respuesta a estrés (Basehoar et al., 2004; Zou et al., 2011). 
También posee una caja $\mathrm{E}$, que es un lugar de unión de factores de transcripción que ayudan a iniciar o aumentar la transcripción. Esta caja E se sitúa al lado de un elemento de respuesta a AMP cíclico (CRE) y ambos participan en la regulación de la transcripción del promotor (Mestre et al., 2001). El promotor del gen Cox-2 además posee sitios de unión para factores de transcripción como $\mathrm{NF \kappa B}$, el factor de transcripción del gen de interleuquina-6 (NF-IL6), C/EBP (CCAAT enhancer-binding protein), AP-2, AP-1 y NFAT. Respecto a este último factor, se localizan dos sitios de unión: uno distal, denominado dNFAT, que es un sitio puro de unión para NFAT, y otro proximal, pNFAT, que contiene adyacente un sitio para AP-1 (Iniguez et al., 1999; Iniguez et al., 2000).

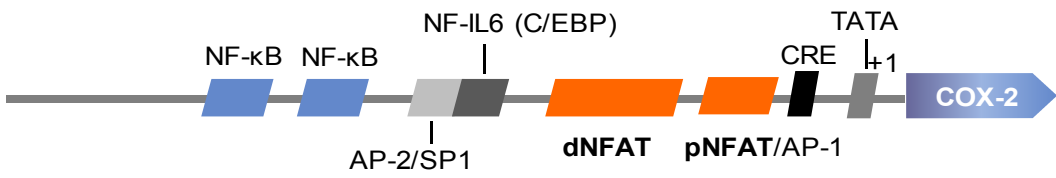

Figura 14. Estructura del promotor del gen de ciclooxigenasa-2. Se indican sitios de unión para diferentes factores de transcripción.

Aunque se ha descrito la expresión constitutiva de COX-2 en algunos tejidos como cerebro, riñón, aparato reproductor femenino o hueso (Lipsky et al., 2000; Rouzer and Marnett, 2009; Li et al., 2011), en la mayoría de tejidos la proteína COX-2 es indetectable en situaciones basales. Sin embargo, diversas moléculas inducen la transcripción del gen de COX-2 (Fosslien, 2000). Entre ellas, las más conocidas son factores que favorecen la inflamación como interleuquinas, el factor de necrosis tumoral (TNF $\alpha$ ), interferon $\gamma$, lipopolisacárido (LPS) y ésteres de forbol. También, la expresión del gen de COX-2 se induce en respuesta a algunas hormonas como la hormona folículoestimulante (FSH), la hormona luteínizante (LH) y estrógenos (Tanabe and Tohnai, 2002; Grishin et al., 2006; Kao et al., 2011). Además se han descrito oncogenes como v-Src y v-Ras (Subbaramaiah et al., 1996) y la señalización mediada por receptores de TGF- $\beta$ o por los factores de crecimiento EGF, PDGF y FGF (Matsumura et al., 2009; Wang et al., 2012) como señales que inducen la expresión de COX-2. También algunas MAPK como Erk1/2, JNK y p38 participan en la inducción de la expresión de COX-2 (Tanabe and Tohnai, 2002); y se ha descrito que la 
expresión de COX-2 está regulada en condiciones de hipoxia (Cook-Johnson et al., 2006; Kaidi et al., 2006).

Además de inductores, existen moléculas que inhiben la expresión de COX-2. Entre ellas se encuentran ligandos de los receptores activados por proliferadores de peroxisomas (PPAR) (Subbaramaiah et al., 2001; Cuzzocrea et al., 2008) y glucocorticoides (Sun et al., 2008; Cho and Kim, 2009).

\subsubsection{Funciones de COX-2}

La función más conocida de ciclooxigenasa-2 es en la respuesta inflamatoria, encargándose de la síntesis de moléculas mediadoras de la inflamación. Además, participa en otros procesos celulares, muchos de ellos relacionados con inflamación.

Por otro lado, parece que COX-2 tiene funciones de regulación de la homeostasis en algunos tejidos. Esto lo sugiere el hecho de que ratones knock-out para COX-2 muestran graves problemas en el desarrollo del riñón (Norwood et al., 2000) y las hembras son estériles debido a fallos en la ovulación e implantación del embrión (Langenbach et al., 1999). También COX-2 parece actuar en la homeostasis del sistema vascular, puesto que el uso prolongado de inhibidores selectivos de COX-2 tiene efectos de toxicidad cardiovascular (Grosser et al., 2006); y se observa que un tercio de los ratones knock-out para COX-2 mueren a los dos días de nacer debido a fallos en el conducto arterioso (Loftin et al., 2001).

Cualquier alteración de las funciones de COX-2 puede implicar situaciones patológicas y una regulación inadecuada de su expresión dar lugar a enfermedades como el cáncer, ya que COX-2 participa en procesos de angiogénesis, invasión y migración celular entre otros.

\subsection{Implicación de NFAT y COX-2 en invasión tumoral}

Para la metástasis de los tumores sólidos, las células tumorales deben adquirir características de migración e invasión. Cada vez se conocen más datos sobre la participación de NFAT en la modulación de la migración e invasión de diversos tumores (Jauliac et al., 2002; Viola et al., 2005; Mancini and Toker, 2009; Muller and Rao, 2010). También para el desarrollo del tumor las células tumorales promueven la 
formación de nuevos vasos sanguíneos o angiogénesis. En la angiogénesis participa el factor de crecimiento de endotelio vascular (VEGF), que activa a la fosfolipasa $\mathrm{C} \gamma$ (Takahashi and Shibuya, 1997). Esto conlleva un aumento del calcio intracelular, la activación de la fosfatasa calcineurina y la translocación al núcleo de NFAT, con la subsecuente transcripción de genes que favorecerán la angiogénesis. Se ha descrito que la expresión aumentada de RCAN1 conlleva una reducción de la angiogénesis tumoral mediante la supresión de la activación de NFAT y la disminución de VEGF en las células endoteliales (Minami et al., 2004; Yao and Duh, 2004). Esto es consistente con el hecho de que los pacientes con síndrome de Down, en los que se detectan elevados niveles de RCAN1 (y también de DYRK1, una quinasa de mantenimiento de NFAT), tienen una incidencia menor de cáncer (Baek et al., 2009). Por otro lado, NFAT induce la transcripción de quimioquinas que atraen a células del sistema inmune. Algunas de estas quimioquinas promueven la migración e invasión de las células epiteliales (Allavena et al., 2011). Esto indica que el microambiente generado por NFAT alrededor del tumor favorece la migración e invasión de las células tumorales e incluso la transformación de las células adyacentes mediante mecanismos de acción paracrinos (Wyckoff et al., 2004).

Es evidente que el mecanismo por el cual NFAT actúa como un factor que favorece la invasión tumoral es debido a los genes que induce en las células tumorales. Entre ellos, el enzima ciclooxigenasa-2 se ha descrito como una proteína importante en el aumento de la capacidad de invasión de las células tumorales (Singh et al., 2005; Yiu and Toker, 2006; Yiu et al., 2011). El papel de COX-2 en el desarrollo y progresión tumoral ha sido ampliamente estudiado en cáncer de colon (Greenhough et al., 2009; Wu et al., 2011). Sin embargo, han aparecido muchos estudios que sugieren a COX-2 como un enzima importante en otros tipos de cáncer, como el cáncer de mama. Se ha descrito que COX-2 es un marcador de mal pronóstico y baja supervivencia en cáncer de mama (Glynn et al., 2010; Miglietta et al., 2010). También la expresión de COX-2 es mayor en tumores metastásicos y se ha identificado como un gen que participa en la metástasis de cáncer de mama al cerebro o hueso (Singh et al., 2007; Bos et al., 2009). Utilizando un modelo transgénico de ratón con sobreexpresión dirigida de COX-2 en la glándula mamaria, se observó que la expresión de COX-2 era 
suficiente para inducir el desarrollo de carcinomas de mama (Liu et al., 2001); y la utilización de inhibidores de COX-2 en modelos animales reduce la incidencia y crecimiento de los carcinomas de mama (Harris et al., 2000; Connolly et al., 2002).

El microambiente que rodea al tumor favorece la expresión de COX-2 y esta proteína desencadena mecanismos que potencian el desarrollo y la malignidad del tumor. Así, la elevada expresión de COX-2 participa en el desarrollo tumoral a través de la regulación de la respuesta inflamatoria, de la angiogénesis, la apoptosis y la invasión celular y por metabolismo de agentes carcinógenos (Dempke et al., 2001).

Se conoce desde hace tiempo que la inflamación crónica es un factor de riesgo para la carcinogénesis (Weitzman and Gordon, 1990). Además, las prostaglandinas pueden suprimir la proliferación de las células inmunes, lo que ayuda a que las células tumorales puedan evadir los mecanismos de inmunidad del organismo. También, los niveles elevados de prostaglandinas conducen a un aumento en el AMP cíclico celular, lo que da lugar a reducción de la apoptosis y aumento de la supervivencia celular debido a la modulación de la proteína Bcl-2 (Shimizu et al., 2006).

Los efectos angiogénicos de COX-2 se deben a la inducción de factores como VEGF, FGF (factor de crecimiento de fibroblastos), TGF-1 (factor de crecimiento transformante), PDGF (factor de crecimiento derivado de plaquetas) y endotelina. Se ha descrito correlación entre los niveles de VEGF y COX-2 en cáncer de mama invasivo (Perrone et al., 2005). El crecimiento tumoral de ratones knock-out para COX2 respecto a los ratones de tipo silvestre está atenuado y esos tumores tienen menor densidad vascular (Howe et al., 2005).

Las metaloproteasas de la matriz celular son enzimas que pueden estar implicadas en patología, ya que podrían causar una degradación aberrante de la matriz extracelular. El aumento de expresión de COX-2 lleva a un aumento de la metaloproteasa MMP-2, lo que da lugar a mayor invasión celular (Deryugina and Quigley, 2006). Se ha propuesto que la capacidad de COX-2 de aumentar la expresión de diferentes metaloproteasas y de CD44 (receptor de hialuronato de la superficie celular) favorece la invasión del tumor. COX-2 aumenta la invasión de cáncer de mama también a través de la producción de interleuquina-8 (IL-8), mediante la activación de PKC (Simeone et al., 2007) 
Por otro lado, el propio metabolismo de COX-2 puede inducir la formación de moléculas mutagénicas. Por ejemplo, el MDA (malondialdehído) es una molécula carcinogénica que puede inducir daño en el ADN (Sharma et al., 2001; Tunstall et al., 2006). Este compuesto se forma por la isomerización de $\mathrm{PGH}_{2}$, al presentar esta niveles elevados debido a la sobreexpresión de COX-2. Además, COX-2 también puede tener actividad peroxidasa y así permitir la formación de moléculas carcinogénicas capaces de dañar el ADN a partir de una amplia variedad de agentes de la dieta y ambientales (Vogel, 2000; Lauber and Gooderham, 2011).

En conclusión, la sobreexpresión de COX-2 prolonga la supervivencia de las células cancerosas al inhibir la apoptosis y participa en su invasión y diseminación, además de favorecer la acumulación de cambios genéticos en las células que pueden contribuir a la carcinogénesis. 


\section{OBJETIVOS}

Estudiar la sensibilidad a inhibidores de los miembros catalíticamente activos de la familia de proteínas quinasa VRK, VRK1 y VRK2, y comparación con la quinasa homóloga B1R del virus Vaccinia

Estudiar el efecto de la quinasa humana VRK2A sobre la regulación de la actividad del factor de transcripción NFAT

Determinar la relación de VRK2A en la transcripción del gen de ciclooxigenasa-2 y en la invasión y migración celular a través de la regulación de NFAT 



\section{Resultados}

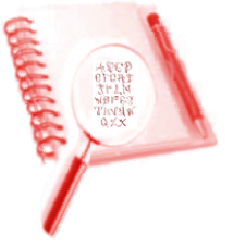



Sensibilidad a inhibidores de la familia de quinasas VRK 



\section{Panel de inhibidores $y$ su efecto en la actividad quinasa de VRK1 y VRK2}

Muchas situaciones patológicas son consecuencia de alteraciones de la actividad quinasa de las proteínas. Por ello, actualmente ha surgido un gran interés en el estudio y desarrollo de inhibidores específicos de la actividad de las proteínas quinasa celulares. Los dominios catalíticos de las proteínas suponen una región diana adecuada y útil para el desarrollo de moléculas inhibidoras de la actividad quinasa. Sin embargo, la alta conservación de la secuencia y estructura de estos dominios supone un problema ya que disminuye la especificidad de los inhibidores, de forma que pueden afectar a más de una proteína quinasa (Davies et al., 2000; Bain et al., 2007; Davis et al., 2011). La promiscuidad de una quinasa se puede predecir en base a la conservación de residuos específicos en el plegamiento de la proteína. Las proteínas con secuencias más divergentes presentarán menor índice de promiscuidad y serán las mejores candidatas para el desarrollo de inhibidores altamente específicos (Fedorov et al., 2007). Este es el caso de la familia de quinasas VRK, que como se ha descrito en el apartado de introducción, presentan algunas modificaciones respecto a la secuencia consenso de la mayoría de proteínas quinasa; lo cual sugiere que los inhibidores de estas quinasas presentarán una promiscuidad reducida. Sin embargo, estudios a gran escala de inhibidores de proteínas quinasa no han identificado todavía ningún compuesto inhibidor de la actividad de las proteínas VRK (Karaman et al., 2008; Anastassiadis et al., 2011). Debido a esto, comenzamos este trabajo con el fin de determinar si los miembros catalíticamente activos de la familia de quinasas VRK, VRK1 y ambas isoformas de VRK2, presentan una sensibilidad parecida o diferente a una serie de inhibidores de quinasas conocidos, como punto de partida para el desarrollo en el futuro de inhibidores específicos con poca o ninguna inhibición cruzada. Además, nos interesaba conocer la especificidad de estas quinasas y determinar si se podría discriminar entre ellas mediante la utilización de compuestos inhibidores de su actividad, de forma que se inhibiese sólo uno de los miembros de la familia sin afectar al otro y así poder estudiar más en detalle las funciones celulares de cada una de las proteínas VRK. 
Otros motivos que nos incitaban a comenzar este estudio fueron las características de VRK1 ya descritas, como su elevada expresión en tejidos tumorales (Valbuena et al., 2007b) y en la zona de mayor proliferación de los epitelios (Santos et al., 2006), así como que parece ser un marcador de peor pronóstico en cáncer de mama (Martin et al., 2008). Esto nos sugería que el desarrollo de inhibidores específicos podría resultar de utilidad en terapia oncológica para el control de la proliferación celular. Además, las quinasas de la familia VRK cumplen los cuatro criterios que se han definido en cuanto a la utilidad del desarrollo de inhibidores para una determinada proteína (fig. 2, página 20).

VRK1 y VRK2 son capaces de fosforilar a los mismos sustratos in vitro. Sin embargo, existen diferencias en las secuencias de ambas proteínas, existiendo entre ellas a nivel de secuencia del dominio catalítico un porcentaje de similitud del 79\% y un $64 \%$ de identidad (fig. 15). Esto sugería que VRK1 y VRK2 podrían diferir en cuanto a sensibilidad a inhibidores, permitiendo encontrar una diferencia funcional entre ambas.

\footnotetext{
VRK1 (37-275) WKVGLPIGQGGFGCIYLADMNSSESVGSDAPCVVKVEPSDNGPLFTELKFYQRAAKPEQI 60

VRK2 (29-264) WVLGKKIGSGGFGLIYLAFPTNKPEK--DARHVVKVEYQENGPLFSELKFYQRVAKKDCI 58 $*: * * *, * * * * * * *$... . $* * * * * *, . * * * * * ; * * * * * *, * *$ : *

VRK1 (37-275) QKWIRTRKLKYLGVPKYWGSGLHDKNGKSYRFMIMDRFGSDLQKIYEANAKRFSRKTVLQ 120

VRK2 (29-264) KKWIERKQLDYLGIPLFYGSGLTEFKGRSYRFMVMERLGIDLQKISGQNGI-FKKSTVLQ 117

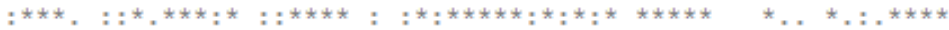

VRK1 (37-275) LSLRILDILEYIHEHEYVHGDIKASNLLLNYKNPDQVYLVDYGLAYRYCPEGVHKEYKED 180

VRK2 (29-264) LGIRMLDVLEYIHENEYVHGDIKA_ANLLIGYKNPDQVYLADYGLSYRYCPNGNHKQYQEN 177

$*_{*}: *: * *: * * * * * *: * * * * * * * * *: * * * *, * * * * * * * * *, * * * *: * * * * *: * * *: *: *$ :

VRK1 (37-275) PKRCHDGIIEFTSIDAHNGVAPSRRGDLEILGYCMIQWLTGHLPWEDNLKDPKYVRDSK 239

VRK2 (29-264) PRKGHNGT IEFTSLDAHKGVALSRRSDVEILGYCMLRWLCGKLPWEQNLKDPVAVQTAK 236

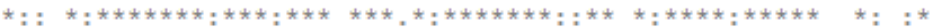

Figura 15. Alineamiento de las secuencias del dominio catalítico de VRK1 y VRK2 humanas. El alineamiento se realizó con el programa ClustalW2. El cálculo de la identidad y similitud se detalla en el apartado de materiales y métodos.

* residuo idéntico

: sustituciones conservadas (aminoácidos del mismo grupo)

- sustituciones semi-conservadas (aminoácidos de tamaños similares).
}

Como estudio inicial, probamos el efecto de un panel de quince inhibidores sobre la actividad quinasa de VRK1 y VRK2, con el objetivo de identificar alguno que afectara a la actividad de estas proteínas. Estos inhibidores se han descrito en el 
apartado de introducción (tabla 1, página 22) y comprenden diferentes grupos de proteínas relacionadas con diversas funciones celulares.

Realizamos ensayos quinasa in vitro con las proteínas recombinantes humanas VRK1, VRK2A y VRK2B fusionadas al epítopo GST expresadas y purificadas a partir de cultivo de bacterias $E$. coli, en presencia de $5 \mu \mathrm{Ci}\left[\gamma^{32} \mathrm{P}\right] \mathrm{ATP}$ y $5 \mu \mathrm{M}$ de ATP no radiactivo. Esta concentración de ATP es mil veces menor a la concentración intracelular de ATP (Knight and Shokat, 2005) y permite unas condiciones de mayor especificidad en la determinación de la sensibilidad a los inhibidores. Así, aquellos inhibidores que tienen algún efecto en el rango micromolar in vitro no se podrán utilizar in vivo, puesto que la concentración de ATP en la célula es mil veces mayor. Entre los inhibidores seleccionados se encuentran oxindole I y un inhibidor de Cdk1, que en un estudio de la determinación de la estructura tridimensional de VRK3 y VRK2 se han descrito que se unen a estas quinasas y también a VRK1 (Scheeff et al., 2009). Determinamos el efecto de los inhibidores en base a la actividad de autofosforilación y de fosforilación de la histona $\mathrm{H} 3$ recombinante comercial como sustrato. Previamente al ensayo incubamos la quinasa con el sustrato y el inhibidor durante 10 minutos para favorecer la unión de la molécula inhibidora a la quinasa, debido a que la mayoría de los inhibidores empleados, excepto PD98059, TDZD-8 y TDZD-20, son moléculas competitivas con el ATP.

Como se puede observar en la figura 16, muchos de los inhibidores no tuvieron ningún efecto o el efecto fue muy débil a la concentración utilizada (100 $\mu \mathrm{M})$. Sin embargo, sí se detectaron diferencias de sensibilidad a estos inhibidores entre VRK1 y VRK2. Así, VRK1 presentó mayor sensibilidad al inhibidor TDZD-8, mientras que VRK2A lo fue a la roscovitina y al inhibidor de Cdk1. Además, ambas quinasas mostraron inhibición frente a estaurosporina, RO 31-8220 y AZD7762, aunque en estos casos también se pudo observar que la respuesta de inhibición era diferente entre VRK1 y VRK2A. Observamos también que la respuesta de inhibición fue similar para la actividad de autofosforilación y para la fosforilación del sustrato histona H3. En el caso de la quinasa VRK2B (fig. 16C), el patrón de inhibición en estos ensayos fue el mismo que el de VRK2A (fig. 16B), lo cual resulta lógico puesto que ambas isoformas presentan una secuencia idéntica en el dominio catalítico. 
A
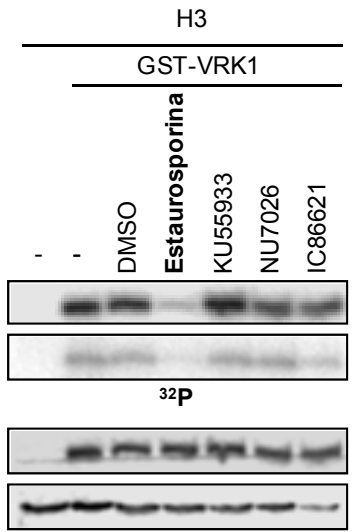

Coomassie
$\mathrm{H} 3$
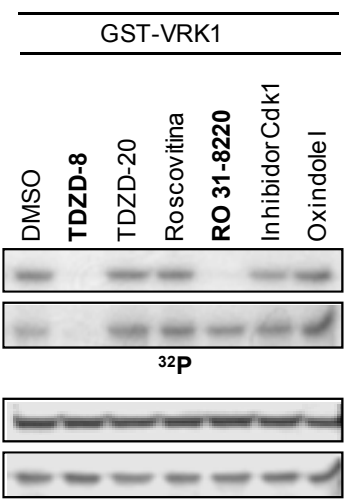

Coomassie
$\mathrm{H} 3$

$\overline{\text { GST-VRK1 }}$

B

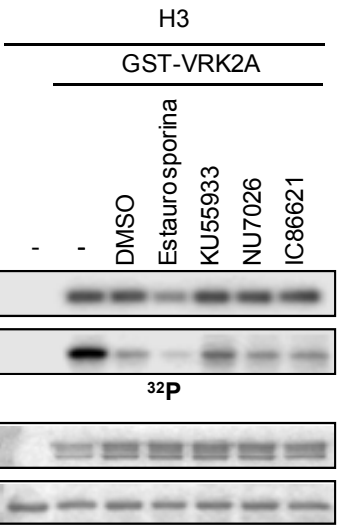

Coomassie

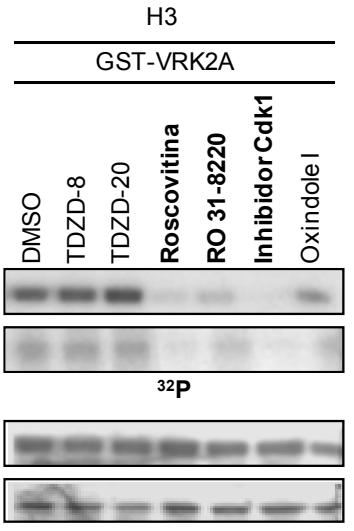

Coomassie

$\frac{\mathrm{H} 3}{\text { GST-VRK2A }}$
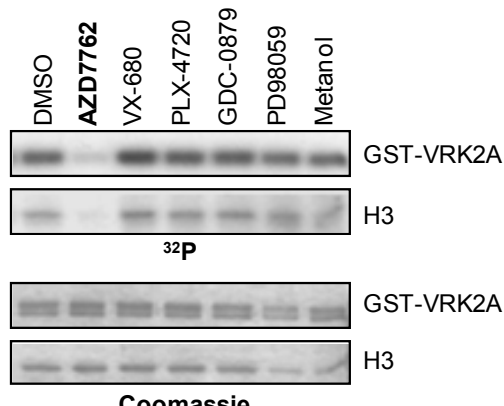

Coomassie

$\mathrm{H} 3$

$\overline{\text { GST-VRK2B }}$
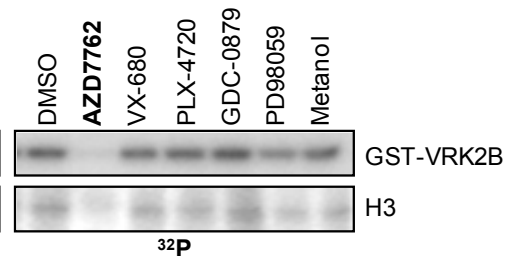

${ }^{32} \mathrm{P}$

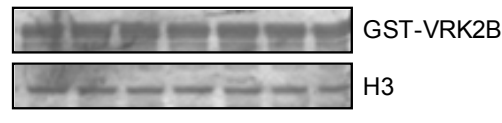

Coomassie

Figura 16. Efecto de inhibidores en la actividad quinasa de las proteínas VRK humanas. Ensayos quinasa in vitro con $2 \mu \mathrm{g}$ de las proteínas recombinantes GST-VRK1 (A), GST-VRK2A (B) y GST-VRK2B (C) frente a quince inhibidores a una concentración de $100 \mu \mathrm{M}$ y utilizando $1 \mu \mathrm{g}$ de la histona $\mathrm{H} 3$ recombinante como sustrato de fosforilación. VRK2A y VRK2B presentan el mismo patrón de respuesta a los inhibidores, pero diferente de VRK1. En negrita se destacan los inhibidores a los que cada quinasa fue más sensible. 
Además, quisimos comprobar si los inhibidores que mostraron efecto en la proteína VRK1 recombinante también afectaban a la actividad quinasa de la proteína VRK1 endógena. Para esto, inmunoprecipitamos la proteína VRK1 endógena de células HEK-293T creciendo activamente y ese inmunoprecipitado se utilizó para un ensayo quinasa in vitro con los inhibidores que presentaron mayor efecto frente a la proteína GST-VRK1 en los ensayos anteriores. Utilizamos además el inhibidor de Cdk1 como control de un inhibidor que no afectaba a la quinasa recombinante. Observamos que la actividad de la quinasa VRK1 endógena era inhibida frente a los mismos compuestos que la quinasa recombinante (fig. 17).

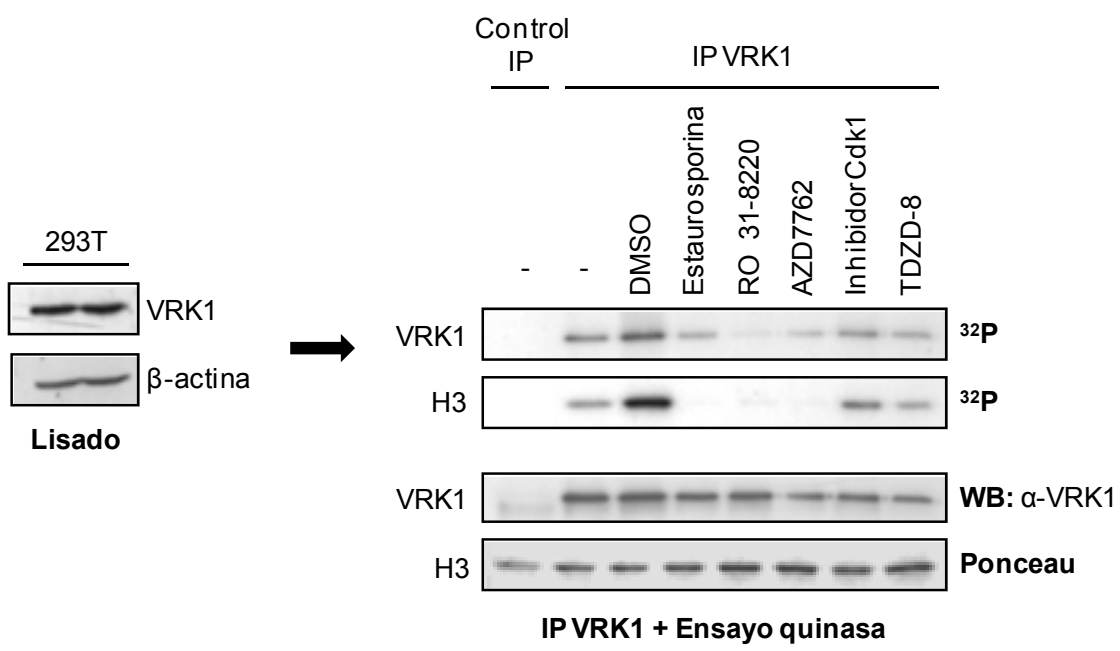

Figura 17. Actividad quinasa de VRK1 endógena en respuesta a inhibidores. Se llevó a cabo un ensayo quinasa in vitro con la proteína VRK1 inmunoprecipitada de células HEK-293T y los inhibidores que presentaron mayor efecto con la quinasa recombinante a una concentración de 75 $\mu \mathrm{M}$. Como sustrato de fosforilación se utilizó $1 \mu \mathrm{g}$ de histona H3. La proteína VRK1 endógena fue sensible a los mismos inhibidores que la proteína VRK1 purificada de bacterias.

\section{Patrones de respuesta de inhibición de la actividad de VRK1 y VRK2 frente a los inhibidores testados}

Una vez determinada la sensibilidad a una concentración fija y elevada de los quince compuestos inhibidores, pasamos a estudiar más detalladamente la diferente respuesta que observábamos entre VRK1 y VRK2.

Para ello, realizamos curvas de dosis de la concentración de cada uno de los compuestos frente a los que observamos inhibición, siempre en un rango de 
concentraciones para las que la respuesta de inhibición de alguna de las dos quinasa era lineal, y con ello determinar los valores de $\mathrm{IC}_{50}$ (concentración de inhibidor a la cual la actividad quinasa disminuye a la mitad). También analizamos si estos valores diferían entre ambas quinasas, para finalmente estudiar si alguno de los compuestos podría ser utilizado en estudios posteriores in vivo para inhibir a las proteínas VRK endógenas.

\subsection{Efecto de inhibidores de Cdk sobre la actividad de VRK1 y VRK2}

Diversos estudios han situado a VRK1 como un gen de respuesta temprana en la progresión del ciclo celular y como una quinasa necesaria para la salida de fase $\mathrm{G}_{0} \mathrm{y}$ entrada en $\mathrm{G}_{1}$ (Vega et al., 2004; Valbuena et al., 2008b). Por este motivo se emplearon en este estudio inhibidores de Cdk como roscovitina y un inhibidor de Cdk1.

Roscovitina se describió como un inhibidor potente y selectivo de Cdk1, Cdk2 y Cdk5 (De Azevedo et al., 1997; Meijer et al., 1997) y también inhibe a Cdk7 y Cdk9 (Hassan et al., 2011). La descripción de roscovitina se determinó en complejo con Cdk2 (De Azevedo et al., 1997) y es un inhibidor competitivo con el ATP, que se une al sitio activo de unión de ATP del dominio quinasa de la molécula de Cdk2 (Noble et al., 2004). Llevamos a cabo ensayos quinasa in vitro con las proteínas purificadas VRK1 y VRK2A fusionadas a GST frente a diferentes concentraciones de roscovitina comprendidas entre 10 y $500 \mu \mathrm{M}$ para determinar el efecto de inhibición de este compuesto sobre la familia de quinasas VRK. Incubamos previamente durante 10 minutos la quinasa con el sustrato histona $\mathrm{H} 3$ y el inhibidor antes de la adición de ATP, como se describe en el apartado de materiales y métodos (página 160). Al igual que se había observado en la primera aproximación con una concentración de $100 \mu \mathrm{M}$ (fig. 16, página 72), VRK2A fue más sensible a roscovitina (fig. 18A); mientras que VRK1 sólo mostró inhibición a $500 \mu \mathrm{M}$ (fig. 18C). En el caso de VRK2A, cuantificamos la cantidad de fosfato incorporado y la representamos gráficamente, pudiendo observar que, tanto para la autofosforilación como para la fosforilación del sustrato histona $\mathrm{H} 3$, la inhibición siguió un patrón de respuesta similar (fig. 18A).

El inhibidor de Cdk1 utilizado en este trabajo también es un inhibidor competitivo, de modo que se une al sitio activo de unión del ATP de la proteína quinasa (Andreani et al., 2000). Realizamos ensayos quinasa in vitro con las proteínas 
A

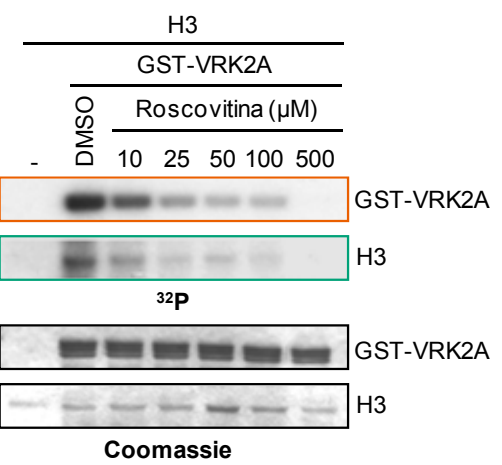

GST-VRK2A

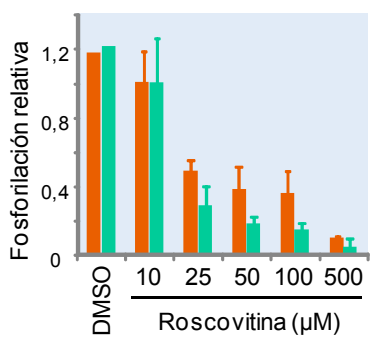

C

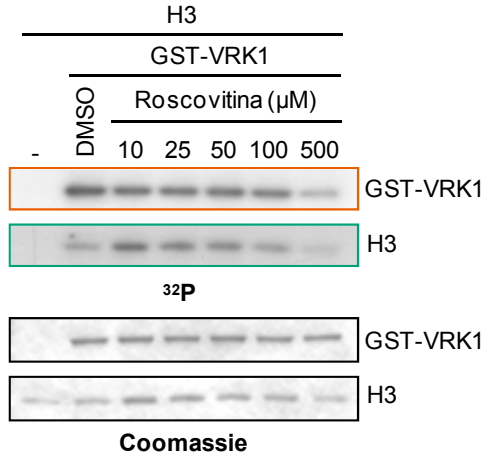

B
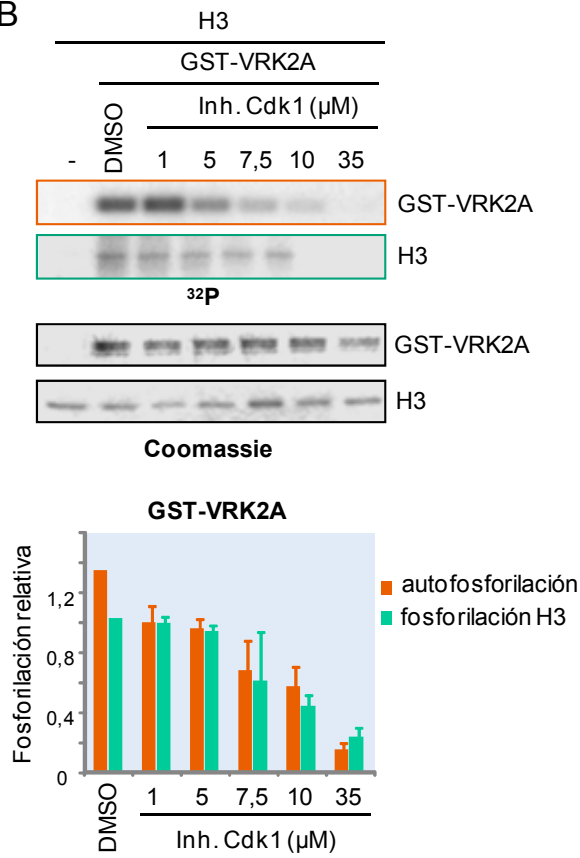

D

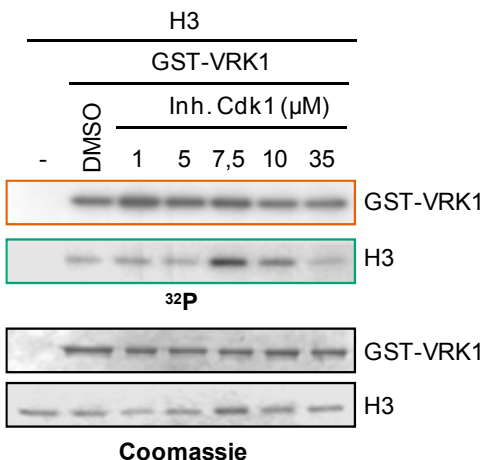

Figura 18. Diferente sensibilidad entre VRK2A y VRK1 a inhibidores de Cdk. Se llevaron a cabo ensayos quinasa in vitro con $2 \mu \mathrm{g}$ de las proteínas recombinantes GST-VRK2A (A y B) y GST-VRK1 (C y D) frente a diferentes concentraciones de los inhibidores roscovitina ( $A$ y $C$ ) y el inhibidor de Cdk1 (B y D) en presencia de $5 \mu \mathrm{M}$ de ATP y $5 \mu \mathrm{Ci}$ de [Y- $\left.{ }^{32} \mathrm{P}\right] \mathrm{ATP}$. Como sustrato de fosforilación se utilizó $1 \mu \mathrm{g}$ de histona $\mathrm{H} 3$ recombinante. Arriba se muestra la incorporación de la radiactividad $\left({ }^{32} \mathrm{P}\right)$ y abajo la tinción con azul de Coomassie. En el caso de VRK2A se cuantificó la cantidad de fosfato incorporado y la media de tres experimentos con su desviación típica se representó gráficamente.

purificadas GST-VRK2A y GST-VRK1 con este inhibidor en un rango de concentraciones entre 1 y $35 \mu \mathrm{M}$ (rango en el que la respuesta de inhibición de la actividad quinasa de VRK2A era lineal) y utilizando la histona H3 como sustrato. La quinasa, el inhibidor y el sustrato se incubaron previamente a la adición de ATP durante 10 minutos. Como en el caso anterior de roscovitina, VRK2A fue la quinasa 
con la que observamos efecto de inhibición frente el inhibidor de Cdk1. Cuantificamos la cantidad de fosfato incorporado y la representamos gráficamente, observando un patrón de inhibición similar para la actividad de autofosforilación y de fosforilación del sustrato histona H3 (fig. 18B). En el caso de VRK1 no observamos inhibición frente al inhibidor de Cdk1 en el rango utilizado (fig. 18D) y tampoco a $100 \mu \mathrm{M}$ (fig. 16A, página 72).

2.2. Efecto de inhibidores de quinasas implicadas en daño al ADN sobre la actividad de VRK1 y VRK2

Estudios en nuestro laboratorio sitúan a VRK1 como una quinasa importante en las rutas de reparación de daño génico, por lo que entre los inhibidores seleccionados se incluyeron algunos que inhiben a quinasas clave en las repuestas de daño al ADN como son ATM (Ataxia Telangiectasia Mutated), DNA-PK (DNAdependent Protein Kinase) y CHK1/2 (Checkpoint Kinase 1/2).

El inhibidor de ATM que utilizamos fue KU55933. Este compuesto se ha descrito como un potente y específico inhibidor de ATM (Hickson et al., 2004; Hollick et al., 2007) y su utilización en células las sensibiliza a los efectos citotóxicos de la radiación ionizante y del daño al $\mathrm{ADN}$ generado por los compuestos quimioterapéuticos (Li and Yang, 2010; Veuger and Durkacz, 2011). Es también un compuesto inhibidor competitivo con el ATP. En el panel con los quince inhibidores (fig. 16) no observamos ningún efecto de inhibición de KU55933 sobre la actividad quinasa de ninguno de los miembros de la familia VRK. De todos modos, puesto que hemos visto en nuestro laboratorio que VRK1 parece participar en la señalización de la respuesta de daño al $\mathrm{ADN}$, llevamos a cabo ensayos quinasa in vitro con la proteína purificada GST-VRK1 frente a este inhibidor en un rango de concentraciones entre 1 y $500 \mu \mathrm{M}$ (fig. 19A), para descartar completamente que estuviese afectando a la actividad de esta quinasa. Como sustrato de fosforilación se utilizó la histona H3 y esta se incubó con la quinasa y el inhibidor durante 10 minutos previamente a la adición de ATP. Observamos que no hubo ninguna respuesta de inhibición ni siquiera a la concentración más elevada (fig. 19A). 
A

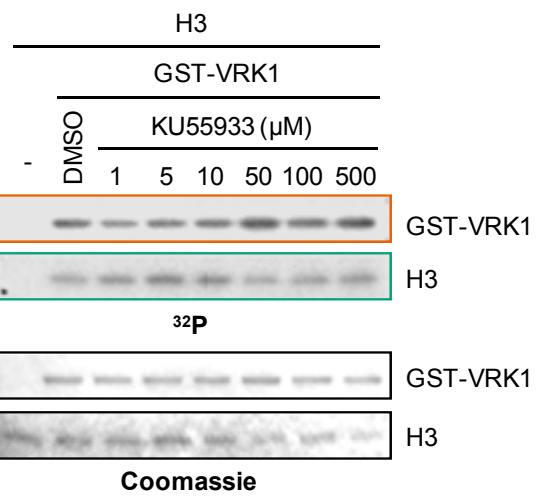

B

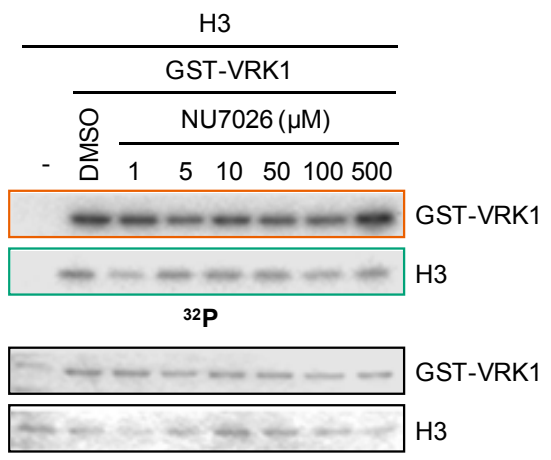

Coomassie
Figura 19. La actividad de VRK1 no se afecta por inhibidores de ATM y DNA-PK. Ensayos quinasa in vitro con la proteína recombinante GST-VRK1 frente a los compuestos KU55933 (A), inhibidor de ATM, NU7026 (B) e IC86621 (C), inhibidores de DNA-PKs, en presencia de $\left[\mathrm{\gamma}^{32} \mathrm{P}\right] \mathrm{ATP}$. Como sustrato de fosforilación se utilizó la histona H3. Arriba se muestra la incorporación de la radiactividad $\left({ }^{32} \mathrm{P}\right)$ y abajo la tinción con azul de Coomassie.

C

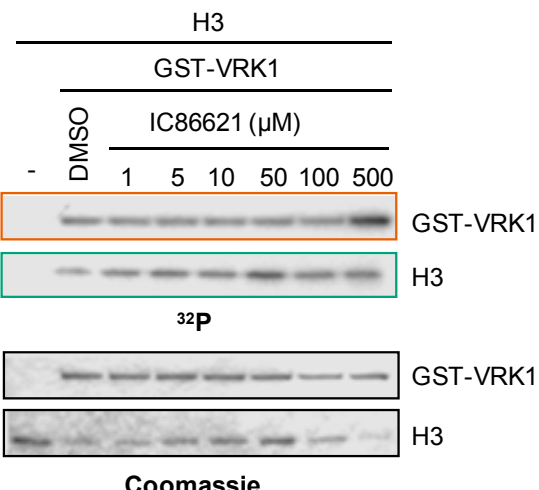

Como inhibidores de las proteínas DNA-PK utilizamos los compuestos NU7026 e IC86621. Ambos compuestos inhiben a DNA-PK de un modo competitivo con el ATP y sensibilizan a las células a daño en el ADN al ser utilizados en combinación con otros fármacos quimioterapéuticos (Willmore et al., 2004; Amrein et al., 2007; Peddi et al., 2010; Shang et al., 2010; Davidson et al., 2011). Con los dos inhibidores llevamos a cabo ensayos quinasa in vitro con la proteína purificada VRK1 fusionada a GST a una concentración comprendida entre 1 y $500 \mu \mathrm{M}$ en presencia de 5 $\mu \mathrm{M}$ de ATP y $5 \mu \mathrm{Ci}$ de $\left[\gamma_{-}{ }^{32} \mathrm{P}\right] \mathrm{ATP}$, utilizando como sustrato de fosforilación la histona H3 recombinante. La quinasa, el inhibidor y el sustrato se incubaron durante 10 minutos previamente a la adición de ATP. Ninguno de estos dos inhibidores mostró efecto sobre la actividad quinasa de VRK1 (fig. 19B y C).

De los inhibidores de quinasas implicadas en daño al ADN utilizados hasta ahora, ninguno afectó a la actividad de las proteínas de la familia VRK. Sin embargo, 
encontramos en el panel con los quince inhibidores (fig. 16, página 72) que el inhibidor de las quinasas CHK1/2, el compuesto AZD7762, sí mostró efecto sobre la actividad de las proteínas VRK y además, de forma diferencial entre VRK1 y VRK2A. Este compuesto AZD7762 actúa también compitiendo con el ATP por la unión al sitio catalítico de la quinasa. Al igual que en los ensayos anteriores, llevamos a cabo ensayos quinasa in vitro tanto para VRK1 como para VRK2A purificadas y fusionadas al epítopo GST, con diferentes concentraciones de AZD7762 y observamos el efecto a nivel de actividad de autofosforilación y de fosforilación de la histona H3 como sustrato. Para el ensayo, previamente a la adición de ATP, incubamos durante 10 minutos las quinasas sólo con el inhibidor y el sustrato. Posteriormente cuantificamos la cantidad de fosfato incorporado para representarla gráficamente. En ambos casos, la respuesta de inhibición para la actividad de autofosforilación y de fosforilación de la histona H3 siguió un patrón similar. En cuanto a la respuesta de VRK1 (fig. 20A), se

A

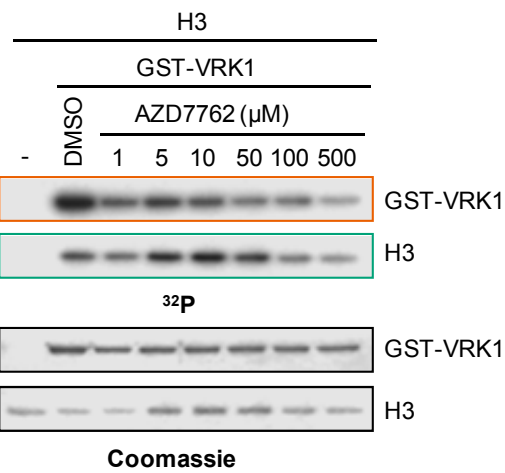

GST-VRK1

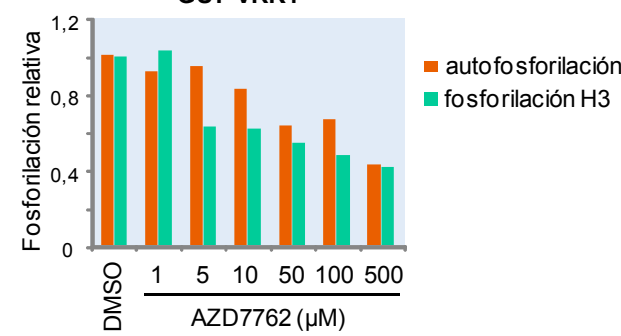

B

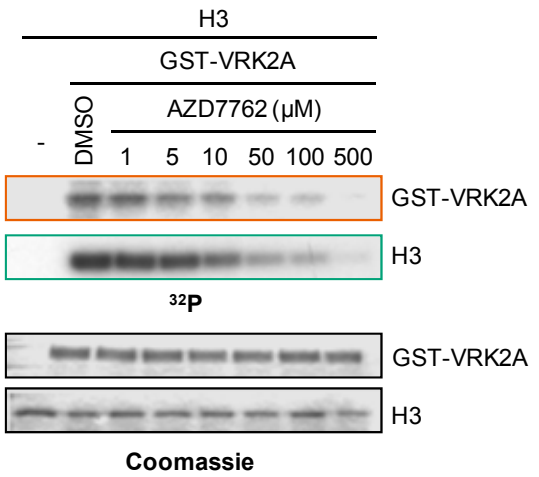

GST-VRK2A

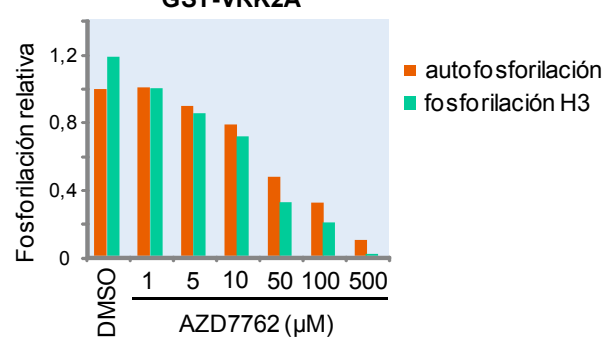

Figura 20. El inhibidor AZD7762 afecta a la actividad de VRK2A pero sólo ligeramente la de VRK1. Se llevaron a cabo ensayos quinasa in vitro con las proteínas recombinantes GST-VRK1 (A) y GSTVRK2A (B) frente a diferentes concentraciones del inhibidor AZD7762 en presencia de $5 \mu \mathrm{M}$ de ATP y 5 $\mu \mathrm{Ci}$ de [Y- $\left.{ }^{32} \mathrm{P}\right] \mathrm{ATP}$. Como sustrato de fosforilación se utilizó $1 \mu \mathrm{g}$ de histona H3 recombinante. Arriba se muestra la incorporación de la radiactividad $\left({ }^{32} \mathrm{P}\right)$ y abajo la tinción con azul de Coomassie. Se cuantificó la incorporación de fosfato y se representó gráficamente. 
produjo una ligera inhibición de su actividad, pero a concentraciones elevadas (mayores de $50 \mu \mathrm{M}$ ). Por el contrario, la quinasa VRK2A mostró una sensibilidad mayor a AZD7762 (fig. 20B). De nuevo, encontramos una diferente respuesta de inhibición entre VRK1 y VRK2 y, por tanto, se trata de otro compuesto que permite discriminar entre ambas quinasas. Esto indica que a pesar de su similitud estructural, las diferencias entre VRK1 y VRK2 en la secuencia del dominio catalítico las hacen ligeramente diferentes a la respuesta ante compuestos inhibidores de su actividad, lo que sugiere que es posible desarrollar inhibidores específicos de sólo uno de los miembros de familia sin afectar al otro.

\subsection{Sensibilidad de VRK1 y VRK2 a inhibidores de PKC: RO 31-8220 y estaurosporina}

Los inhibidores de PKC utilizados en este trabajo fueron la estaurosporina y RO 31-8220. La estaurosporina presenta una fuerte afinidad por el sitio de unión a ATP de las proteínas quinasa y, a pesar de haberse descrito como un potente inhibidor de PKC (Tamaoki et al., 1986; Tamaoki and Nakano, 1990), se une también a muchas otras quinasas con una alta afinidad, de modo que es un compuesto muy poco selectivo (Karaman et al., 2008). RO 31-8220 es un derivado de la estaurosporina que resultó ser más selectivo para PKC (Davis et al., 1989; Dieter and Fitzke, 1991), aunque estudios posteriores a su descripción mostraron que también es inhibidor de otras proteínas quinasa con una eficacia similar a la ejercida sobre PKC (Davies et al., 2000).

En un amplio estudio sobre la selectividad de inhibidores analizando la interacción de estos con las proteínas del quinoma humano (Karaman et al., 2008), la estaurosporina se describió como un posible inhibidor, aunque poco eficiente, de las proteínas VRK. Por ello, además de por su baja selectividad, quisimos determinar si la estaurosporina y RO 31-8220 también afectaban a la actividad de las quinasas VRK. Realizamos ensayos quinasa in vitro con una curva de dosis de ambos inhibidores con las proteínas purificadas GST-VRK1 y GST-VRK2A utilizando la histona H3 como sustrato de fosforilación, en presencia de $5 \mu \mathrm{M}$ de ATP y $5 \mu \mathrm{Ci}$ de $\left[\gamma_{-}{ }^{32} \mathrm{P}\right] \mathrm{ATP}$. Previamente a la adición de ATP incubamos las quinasas con el inhibidor y el sustrato durante 10 minutos. Al igual que sucedía con otros inhibidores ya testados, las 
quinasas VRK1 y VRK2A mostraron una respuesta diferente ante la inhibición por estos compuestos.

En el caso de la estaurosporina, como se observa en la figura 21, VRK1 fue más sensible, mostrando una respuesta de inhibición similar para la actividad de autofosforilación y de fosforilación de la histona H3 (fig. 21A), aunque la concentración a la que son inhibidas se encuentra lejos del rango nanomolar descrito para PKC (tabla 1, página 22), con lo cual se verifica que no es un inhibidor eficiente de VRK1. En cuanto a la actividad de VRK2A, se observó una ligera inhibición a 100 $\mu \mathrm{M}$ (fig. 21B).

A

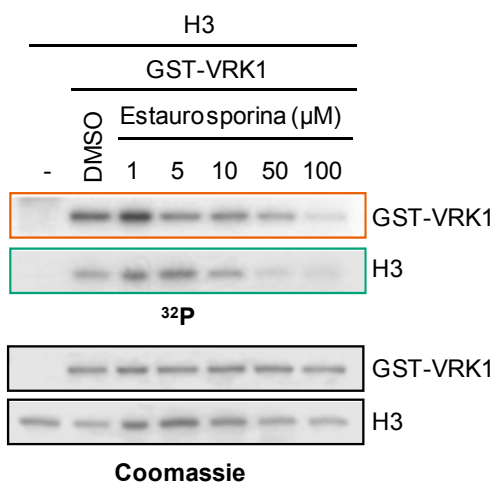

GST-VRK1

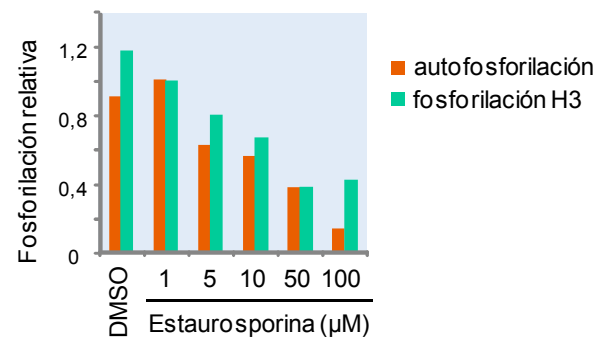

B

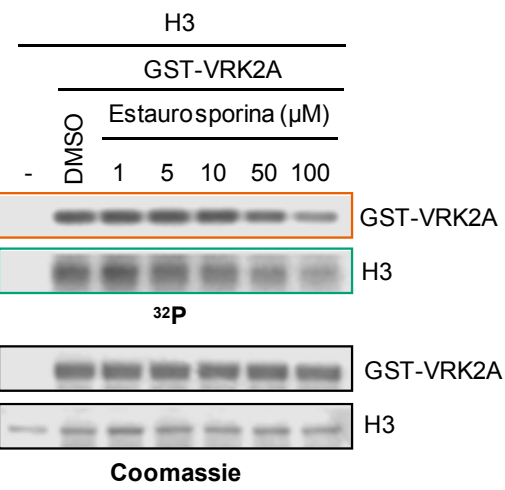

Figura 21. Diferente sensibilidad de VRK1 y VRK2A frente a estaurosporina. Ensayo quinasa in vitro con $2 \mu \mathrm{g}$ de las proteínas recombinantes GST-VRK1 (A) y GST-VRK2A (B) frente a diferentes concentraciones del inhibidor estaurosporina. Arriba se muestra la incorporación de la radiactividad $\left({ }^{32} \mathrm{P}\right)$ y abajo la tinción con azul de Coomassie. En el caso de VRK1 la cantidad de fosforilación fue cuantificada y representada gráficamente.

En cuanto al inhibidor RO 31-8220, tanto VRK1 como VRK2 mostraron sensibilidad a este compuesto (fig. 22). Observando las gráficas donde se representa la cantidad de fosfato incorporado (fig. 22, parte inferior), a nivel de actividad de autofosforilación, VRK1 fue más sensible que VRK2. Sin embargo, aunque observamos esta diferencia a nivel de actividad de autofosforilación, en el caso de la actividad de fosforilación de un sustrato como es la histona H3, esas diferencias 
A

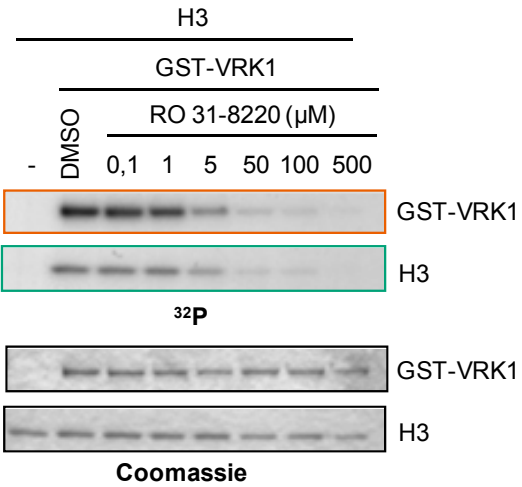

GST-VRK1

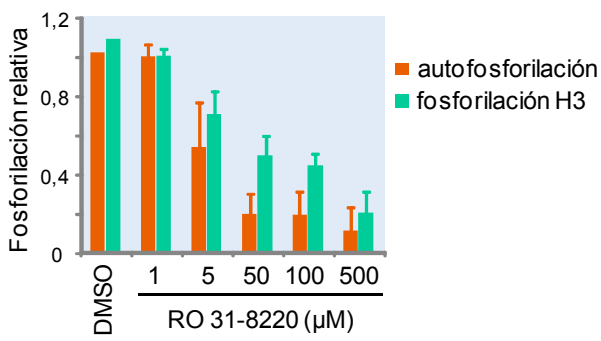

B

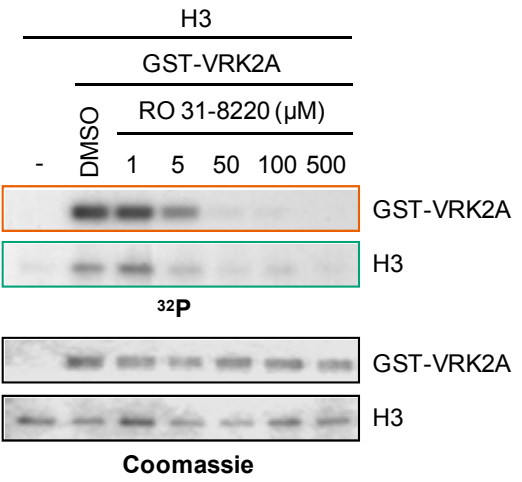

GST-VRK2A

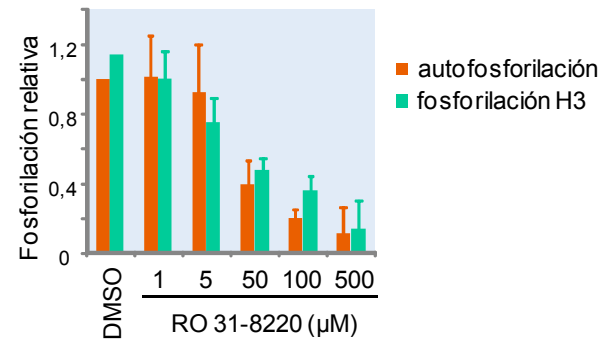

Figura 22. VRK1 y VRK2A muestran una sensibilidad similar frente al inhibidor RO 31-8220. Se llevaron a cabo ensayos quinasa in vitro con $2 \mu \mathrm{g}$ de las proteínas recombinantes GST-VRK1 (A) y GST-VRK2A (B) frente a diferentes concentraciones del inhibidor RO 31-8220 y empleando como sustrato de fosforilación $1 \mu \mathrm{g}$ de histona H3 recombinante. Arriba se muestra la incorporación de la radiactividad $\left({ }^{32} \mathrm{P}\right)$ y abajo la tinción con azul de Coomassie. La cantidad de fosfato incorporado fue cuantificada en tres experimentos independientes y se representaron gráficamente las medias y sus desviaciones típicas.

desaparecieron y la inhibición siguió un patrón de respuesta similar para ambas quinasas.

2.4. Efecto de inhibidores no competitivos con ATP, TDZD-8 y TDZD-20, sobre la actividad de VRK1 y VRK2

Los compuestos TDZD (heterocyclic thiadiazolidinones) se desarrollaron como inhibidores no competitivos con el ATP frente a la quinasa GSK3 (Martinez et al., 2002). Los inhibidores no competitivos están dirigidos hacia regiones más divergentes de las proteínas, relacionadas con la regulación de su función, pero generalmente fuera del dominio catalítico de la quinasa (Kirkland and McInnes, 2009; Dar and Shokat, 2011). Esto podría suponer una mayor selectividad de inhibición de la actividad de una proteína concreta. 
Quisimos probar dos de estos compuestos sobre la actividad quinasa de la familia de proteínas VRK. En la figura 16 (página 72) con el panel de los quince inhibidores a una concentración de $100 \mu \mathrm{M}$ observamos que sólo TDZD-8 inhibía la actividad de VRK1. Decidimos analizar cómo variaba la respuesta de inhibición de la actividad de VRK1 con diferentes concentraciones de TDZD-8 y así llevamos a cabo ensayos quinasa in vitro con la proteína purificada GST-VRK1 y concentraciones de TDZD-8 comprendidas entre $500 \mathrm{nM}$ y $10 \mu \mathrm{M}$ (fig. 23A). Como sustrato de fosforilación utilizamos la histona H3. Debido a que TDZD-8 es un inhibidor no competitivo con el ATP, no sería necesario favorecer su unión con la quinasa realizando una incubación previa a la adición de ATP, como habíamos hecho en el caso de los inhibidores competitivos. Sin embargo, para mantener exactamente las mismas condiciones del ensayo que en casos anteriores, realizamos la incubación con la quinasa, el inhibidor y el sustrato durante 10 minutos antes de añadir el ATP. Los resultados mostraron que tanto para la actividad de autofosforilación como para la de fosforilación de la histona H3 parecía existir una respuesta de todo o nada frente al inhibidor TDZD-8. La actividad quinasa no se veía afectada a una concentración de 5 $\mu \mathrm{M}$ de TDZD-8, pero a 7,5 $\mu \mathrm{M}$ se inhibió casi completamente la actividad de VRK1 (fig. 23A). Probablemente este efecto se debe a que al no ser un inhibidor que compita con el ATP, la respuesta de inhibición no es dependiente de la dosis y tampoco se

A

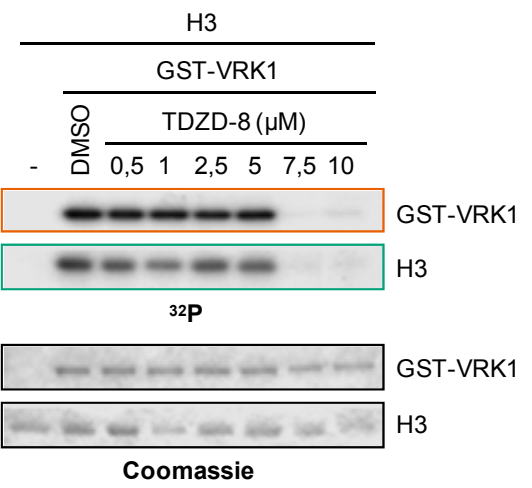

B

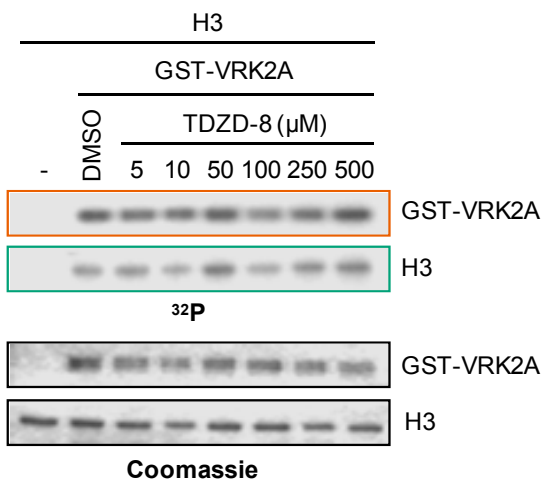

Figura 23. VRK1 presenta una respuesta de inhibición de todo o nada frente al compuesto TDZD-8. Ensayos quinasa in vitro con $2 \mu \mathrm{g}$ de las proteínas recombinantes GST-VRK1 (A) y GST-VRK2A (B) frente a diferentes concentraciones del inhibidor TDZD-8, empleando como sustrato de fosforilación $1 \mu \mathrm{g}$ de histona $\mathrm{H} 3$ recombinante. Arriba se muestra la incorporación de la radiactividad $\left({ }^{32} \mathrm{P}\right)$ y abajo la tinción con azul de Coomassie. Tan sólo VRK1 mostró sensibilidad a TDZD-8 a partir de una determinada concentración umbral. 
produce gradualmente, sino que existe una determinada concentración de inhibidor a la que VRK1 sí es sensible, pero por debajo de ese umbral, la quinasa no se ve afectada. Respecto a la actividad de VRK2A, a pesar de no observar inhibición a $100 \mu \mathrm{M}$ (fig. 16), quisimos llevar a cabo un ensayo quinasa in vitro con diferentes concentraciones del compuesto TDZD-8. En este caso, la actividad quinasa de VRK2A no se vio alterada, ni siquiera a una concentración tan alta como $500 \mu \mathrm{M}$ (fig. 23B). Con lo cual, TDZD-8 supone un inhibidor no competitivo que es capaz de diferenciar entre VRK1 y VRK2.

Además de TDZD-8, empleamos en el estudio otro compuesto similar, TDZD20. En el panel con los quince inhibidores (fig. 16) pudimos observar que TDZD-20 no presentó ningún efecto sobre la actividad de VRK1 ni sobre la de VRK2. Sin embargo, llevamos a cabo un ensayo quinasa in vitro con la proteína purificada GST-VRK1 en el mismo rango de concentraciones en las que se producía el efecto de todo o nada de TDZD-8 y observamos que VRK1 no fue sensible a TDZD-20 (fig. 24).

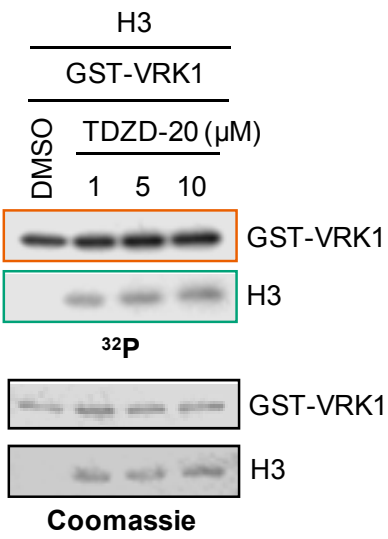

Figura 24. La actividad quinasa de VRK1 no se ve inhibida por TDZD-20. Ensayo quinasa in vitro con $2 \mu \mathrm{g}$ de la proteína recombinante GST-VRK1 frente al inhibidor TDZD-20. Arriba se muestra la incorporación de la radiactividad $\left({ }^{32} \mathrm{P}\right)$ y abajo la tinción con azul de Coomassie.

2.5. Diferencias en valores de $\mathrm{IC}_{50}$ de los inhibidores testados para las quinasas VRK1 y VRK2

Una vez realizados los ensayos quinasa con las diferentes concentraciones de inhibidores y cuantificada la cantidad de fosfato incorporado, calculamos los valores de $\mathrm{IC}_{50}$ (concentración de inhibidor con la que se reduce a la mitad la actividad de una proteína quinasa) para los inhibidores competitivos testados en el trabajo frente a los que VRK1 y VRK2A presentaron sensibilidad. Decidimos clasificar como "no 
inhibición" los casos en que la respuesta de inhibición fue débil, tomando como referencia que la inhibición se comenzase a observar a concentraciones de $50 \mu \mathrm{M}$ o superiores, concentraciones de inhibidor que serían demasiado elevadas para considerar que la inhibición esté siendo específica.

Con los datos relativizados de la cuantificación de varios experimentos independientes y, empleando el programa estadístico SPSS v.19, llevamos a cabo el cálculo de la recta de regresión lineal correspondiente a cada inhibidor que presentó efecto en alguna de las dos quinasas, VRK1 o VRK2A. La decisión de calcular una regresión lineal se debió a que el rango de concentración escogida para los ensayos quinasa con cada inhibidor se encontraba dentro del rango lineal de la respuesta de inhibición para alguna de las dos proteínas. Así, una vez determinada la ecuación de la recta de regresión, calculamos el valor de la concentración de inhibidor a la que la actividad de la quinasa VRK correspondiente era del 50\%, es decir, el valor del $\mathrm{IC}_{50}$ en el rango micromolar para cada inhibidor y la proteína quinasa respectiva. En el caso del inhibidor no competitivo con el ATP, TDZD-8, no se hizo ningún cálculo porque la respuesta de inhibición no fue gradual, sino que se produjo a partir de una determinada concentración del inhibidor.

En la figura 25 se muestran las gráficas de las rectas de regresión lineal para los inhibidores que fueron capaces de inhibir la actividad de VRK1: RO 31-8220 y estaurosporina. En las gráficas se indica además la ecuación de la recta de regresión y

A

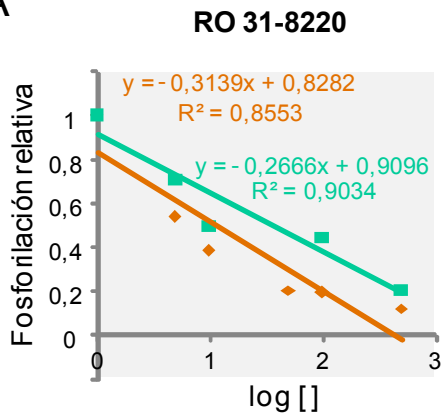

B

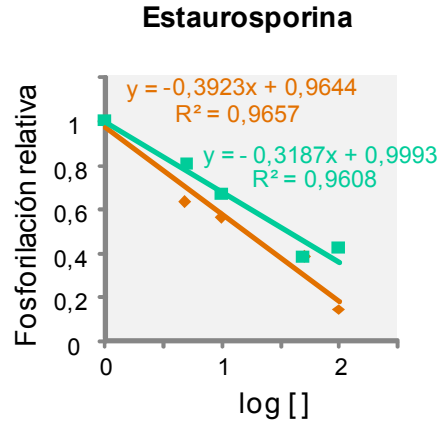

Figura 25. Gráficas de regresión lineal de la respuesta de inhibición de la actividad de VRK1. El cálculo de las ecuaciones de regresión lineal en el caso de los inhibidores RO 31-8220 (A) y estaurosporina (B), tanto para la actividad de autofosforilación (en naranja) como para la fosforilación del sustrato histona H3 (en verde), se realizó con el programa estadístico SPSS v.19, indicándose el coeficiente de determinación para cada una de ellas $\left(R^{2}\right)$, 
el valor del coeficiente de determinación $\left(\mathrm{R}^{2}\right)$, valor que indica cuánto se ajustan los datos a la recta de regresión. Cuanto más cercano a 1 sea este valor, más fiable es la ecuación de regresión.

En la figura 26 están representadas las gráficas de la regresión lineal en el caso de los inhibidores que afectaron a la actividad de VRK2A: el inhibidor de Cdk1, roscovitina, RO 31-8220 y AZD7762.

A

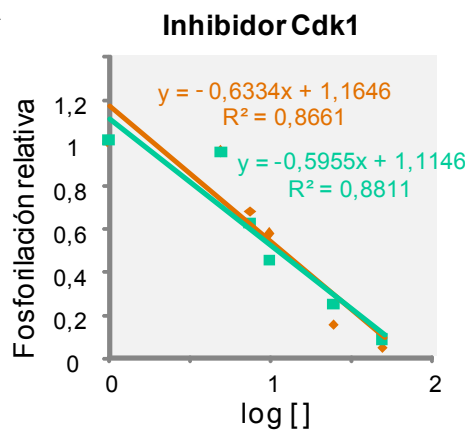

B

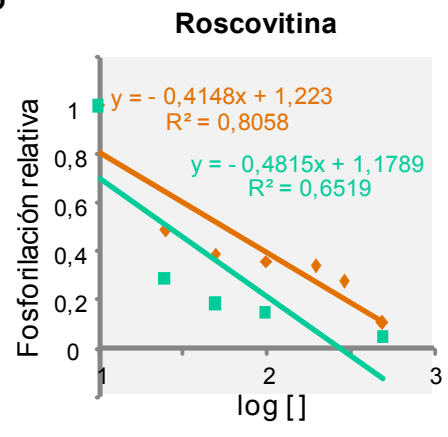

autofosforilación

$\mathrm{D}$

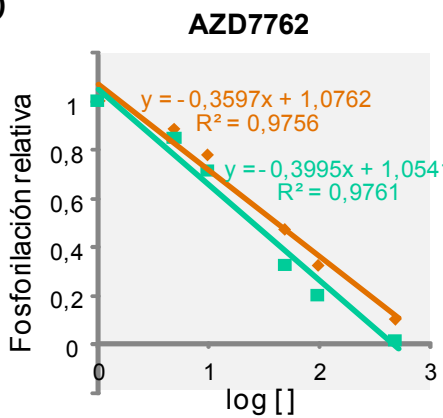

Figura 26. Gráficas de regresión lineal de la respuesta de inhibición de la actividad de VRK2A. Para el inhibidor de Cdk1 (A), roscovitina (B), RO 31-8220 (C) y AZD7762 (D) se realizó el cálculo de las ecuaciones de regresión lineal, tanto para la actividad de autofosforilación de VRK2A (en naranja) como para la fosforilación del sustrato histona $\mathrm{H} 3$ (en verde), con el programa estadístico SPSS V.19, indicándose el coeficiente de determinación para cada una de ellas $\left(R^{2}\right)$.

En la tabla 2 se muestran los resultados de este estudio sobre la sensibilidad a inhibidores de las proteínas quinasa humanas VRK1 y VRK2A, indicando como "sin inhibición", como ya hemos explicado, el caso en que la actividad de la quinasa no se vio afectada o el efecto de inhibición fue muy débil (la inhibición se detecta a concentraciones mayores de $50 \mu \mathrm{M}$ ). En el caso de los inhibidores frente a los que 
alguna de las dos quinasas presentó sensibilidad se indican los valores de $\mathrm{IC}_{50}$, en unidades en el rango micromolar, con su desviación estándar correspondiente (SD).

Estos resultados muestran que para todos los compuestos en los que se detecta inhibición, excepto RO 31-8220, sólo una de ambas quinasas se vio afectada. Esto indica que la sensibilidad a inhibidores es una característica que podría permitir diferenciar entre VRK1 y VRK2. En el caso del inhibidor RO 31-8220, los valores de $\mathrm{IC}_{50}$ difieren entre VRK1 y VRK2A en cuanto a actividad de autofosforilación. Sin embargo, a nivel de actividad de fosforilación del sustrato histona H3, esas diferencias no existen, resultando unos valores de $\mathrm{IC}_{50}$ similares para ambas quinasas.

Tabla 2. Sensibilidad de las proteínas humanas VRK1 y VRK2A a inhibidores de quinasas. Se indican los valores de $\mathrm{IC}_{50}$ junto con su desviación estándar ( $\pm \mathrm{SD}$ ) para los inhibidores frente a los que se detecta sensibilidad. "Sin inhibición" hace referencia a que la actividad quinasa no se afecta o la inhibición es muy débil. En el caso de TDZD-8 se indica la concentración a partir de la cual se inhibe la actividad de VRK1.

\begin{tabular}{|c|c|c|c|c|}
\hline & \multicolumn{4}{|c|}{$I_{50}(\boldsymbol{M} M)$} \\
\hline & \multicolumn{2}{|c|}{ GST-VRK1 } & \multicolumn{2}{|c|}{ GST-VRK2A } \\
\hline & Autofosforilación & Fosforilación H3 & Autofosforilación & Fosforilación H3 \\
\hline Inhibidor Cdk1 & \multicolumn{2}{|c|}{ Sin inhibición } & $11,2 \pm 1,33$ & $10,77 \pm 1,29$ \\
\hline Roscovitina & \multicolumn{2}{|c|}{ Sin inhibición } & $25,7 \pm 1,23$ & $55,34 \pm 1,60$ \\
\hline RO 318220 & $11,11 \pm 1,16$ & $34,39 \pm 1,05$ & $31,77 \pm 1,15$ & $33,63 \pm 1,04$ \\
\hline Estaurosporina & $15,27 \pm 1,10$ & $36,87 \pm 1,09$ & \multicolumn{2}{|c|}{ Sin inhibición } \\
\hline AZD7762 & \multicolumn{2}{|c|}{ Sin inhibición } & $39,98 \pm 1,07$ & $24,38 \pm 1,07$ \\
\hline KU55933 & \multicolumn{2}{|c|}{ Sin inhibición } & \multicolumn{2}{|c|}{ Sin inhibición } \\
\hline NU7026 & \multicolumn{2}{|c|}{ Sin inhibición } & \multicolumn{2}{|c|}{ Sin inhibición } \\
\hline IC86621 & \multicolumn{2}{|c|}{ Sin inhibición } & \multicolumn{2}{|c|}{ Sin inhibición } \\
\hline PLX-4720 & \multicolumn{2}{|c|}{ Sin inhibición } & \multicolumn{2}{|c|}{ Sin inhibición } \\
\hline GDC-0879 & \multicolumn{2}{|c|}{ Sin inhibición } & \multicolumn{2}{|c|}{ Sin inhibición } \\
\hline VX-680 & \multicolumn{2}{|c|}{ Sin inhibición } & \multicolumn{2}{|c|}{ Sin inhibición } \\
\hline Oxindole I & \multicolumn{2}{|c|}{ Sin inhibición } & \multicolumn{2}{|c|}{ Sin inhibición } \\
\hline & \multicolumn{4}{|c|}{ Inhibidores no competitivos } \\
\hline PD98059 & \multicolumn{2}{|c|}{ Sin inhibición } & \multicolumn{2}{|c|}{ Sin inhibición } \\
\hline TDZD-8 & \multicolumn{2}{|c|}{ Inhibición a $7,5 \mu \mathrm{M}$ * } & \multicolumn{2}{|c|}{ Sin inhibición } \\
\hline TDZD-20 & \multicolumn{2}{|c|}{ Sin inhibición } & \multicolumn{2}{|c|}{ Sin inhibición } \\
\hline
\end{tabular}

* la actividad de VRK1 es inhibida prácticamente al 100\% a la concentración indicada. 
Los valores de $\mathrm{IC}_{50}$ obtenidos indican que ninguno de estos inhibidores testados es eficiente a la hora de inhibir la actividad quinasa de las proteínas de la familia VRK y no serían adecuados para utilizar en ensayos in vivo. Sin embargo, no se puede descartar que la síntesis de moléculas derivadas de aquellos inhibidores que permiten distinguir entre VRK1 y VRK2, mediante modificaciones de cadenas laterales o anillos heterocíclicos, pueda resultar en compuestos inhibidores específicos.

\section{Comparación del efecto de inhibición de la actividad quinasa entre las proteínas humanas VRK y la quinasa viral B1R}

El genoma del virus Vaccinia codifica para una única quinasa, la proteína B1R, implicada en la replicación viral y la cual dio el nombre a la familia de proteínas VRK (Vaccinia-Related Kinases). El alineamiento de las secuencias de los dominios catalíticos de B1R con VRK1 (fig. 27A) muestra que entre estas dos proteínas existe una identidad del 39\% y una similitud de secuencias del 60\%. En el caso de VRK2 (fig. 27B), la identidad de secuencia con B1R es igual que la de VRK1, un 39\%, y la similitud es de $62 \%$.

En cuanto a actividad, también existen diferencias entre B1R y las proteínas quinasa VRK. B1R presenta poca actividad de autofosforilación y fosforila a la molécula p53 en múltiples residuos (Santos et al., 2004); mientras que VRK1 y VRK2 fosforilan a p53 en un único residuo (treonina 18) y poseen una fuerte actividad de autofosforilación (Lopez-Borges and Lazo, 2000; Blanco et al., 2006). Debido a la existencia de estas diferencias entre las quinasas VRK y B1R quisimos determinar si B1R presentaba diferencias en la respuesta de inhibición frente al panel de quince inhibidores utilizados para el estudio con VRK1 y VRK2.

Llevamos a cabo ensayos quinasa in vitro con la proteína GST-B1R expresada y purificada de cultivo de bacterias E. coli con los quince inhibidores a una concentración de $100 \mu \mathrm{M}$ en presencia de $5 \mu \mathrm{M}$ de ATP y $5 \mu \mathrm{Ci}$ de $\left[\gamma_{-}{ }^{32} \mathrm{P}\right] \mathrm{ATP}$. Como sustrato de fosforilación se empleó la histona $\mathrm{H} 3$ recombinante comercial y también la proteína GST-p53 expresada y purificada de cultivo de E. coli, que corresponde al fragmento que comprende del aminoácido 1 al 85 de la proteína p53 murina. Debido a la baja actividad de autofosforilación de la quinasa viral B1R, determinamos la 
A

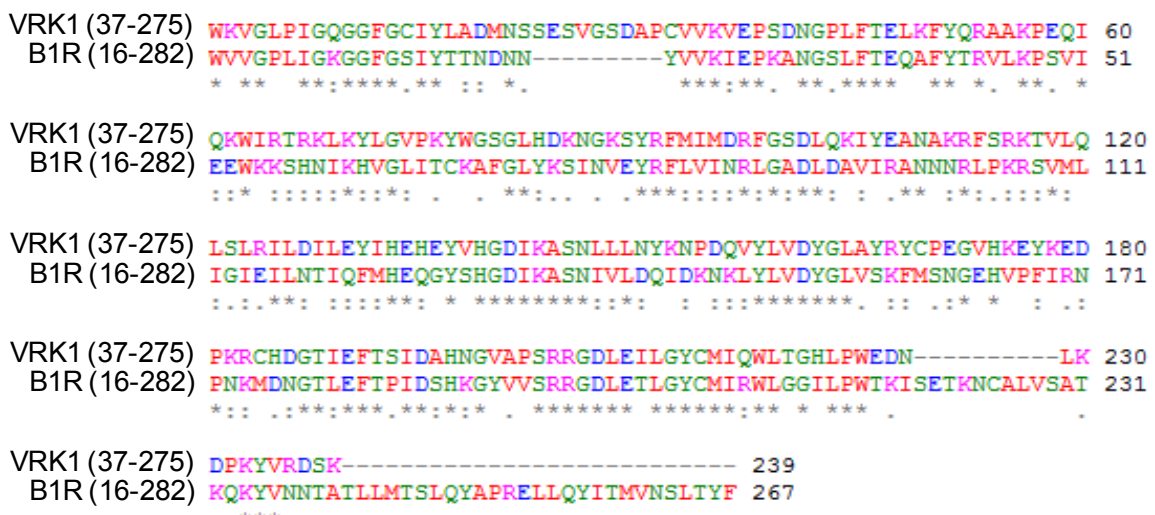
$* * * .:$ :

B
VRK2 (29-264) WVLGKKIGSGGFGLIYLAFPTNKPEKDARHVVKVEYQENGPLFSELKFYQRVAKKDCIKK 60 B1R (16-282) WVVGPLIGKGGFGSIYTTNDNN-------YVVKIEPKANGSLFTEQAFYTRVLKPSVIEE 53 $* *: * * *, * * * * *: \quad * \quad \quad: * * * ; *: * *, * * ; * * * * * *, * *:$
VRK2 (29-264) WIERKQLDYLGIPLFYGSGLTEFKGRSYRFMVMERLGIDLQKIS-GQNGTFKKSTVLQIG 119 B1R (16-282) WKKSHNIKHVGLITCKAFGLYKSINVEYRFLVINRLGADLDAVIRANNNRLPKRSVMLIG 113

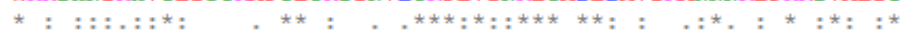
VRK2 (29-264) IRMLDVLEYIHENEYVHGDIKAANLLIGYKNPDQVYLADYGLSYRYCPNGNHKQYQENPR 179 B1R (16-282) IEILNTIQFMHEQGYSHGDIKASNIVLDQIDKNKLYLVDYGLVSKFMSNGEHVPFIRNPN 173

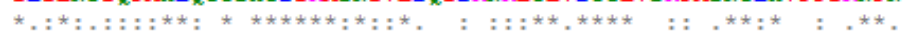

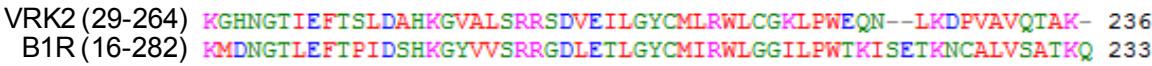
VRK2 (29-264)
B1R (16-282) KYVNNTATLLMTSLQYAPRELIQYITMVNSLTYF 267

Figura 27. Alineamiento de las secuencias del dominio catalítico de B1R con las proteínas VRK1 (A) y VRK2 (B) humanas. El alineamiento se realizó con el programa ClustalW2. El cálculo de la identidad y similitud de secuencias se detalla en el apartado de materiales y métodos.

* residuo idéntico

: sustituciones conservadas (aminoácidos del mismo grupo)

- sustituciones semi-conservadas (aminoácidos de tamaños similares).

respuesta de inhibición sólo en base a la fosforilación de estos dos sustratos. En la figura 28 observamos que B1R presentó sensibilidad a estaurosporina, al inhibidor de ATM (KU55933), a RO 31-8220, al inhibidor de Cdk1 y al inhibidor de Mek1 (PD98059). La respuesta de inhibición para estos compuestos fue similar en el caso de los dos sustratos utilizados, H3 y p53. Además, hubo una ligera inhibición también en respuesta a otros compuestos, aunque fue más débil. Estos resultados tienen cierta similitud con los observados para el caso de VRK1 y VRK2 (fig. 16, página 72), compartiendo con ambas la sensibilidad a RO 31-8220 y con VRK1 la sensibilidad a 
estaurosporina. Con VRK2 coincide en sensibilidad frente al inhibidor de Cdk1. Pero además, la respuesta de B1R presenta alguna particularidad, puesto que su actividad quinasa se vio afectada por inhibidores que no mostraron efecto para las proteínas VRK humanas como fueron KU77933 y PD98059.

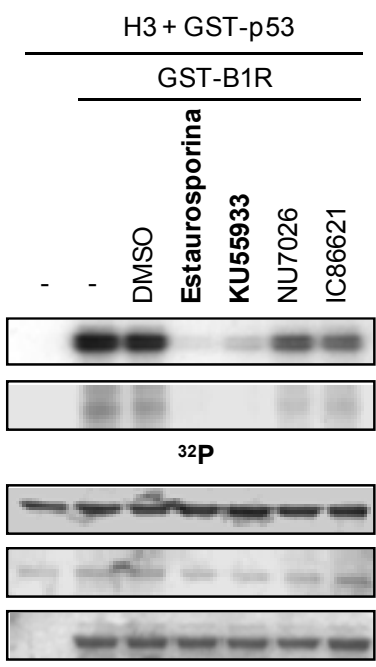

Coomassie

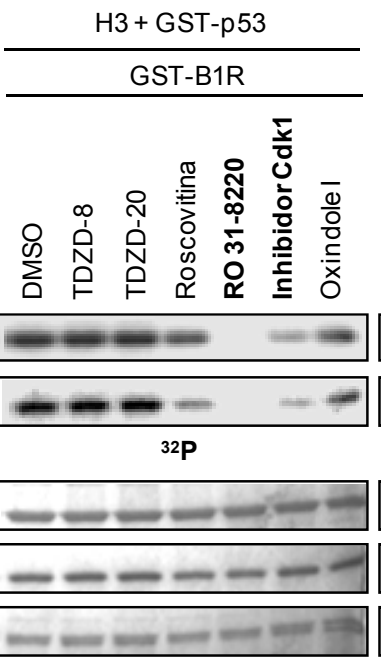

Coomassie
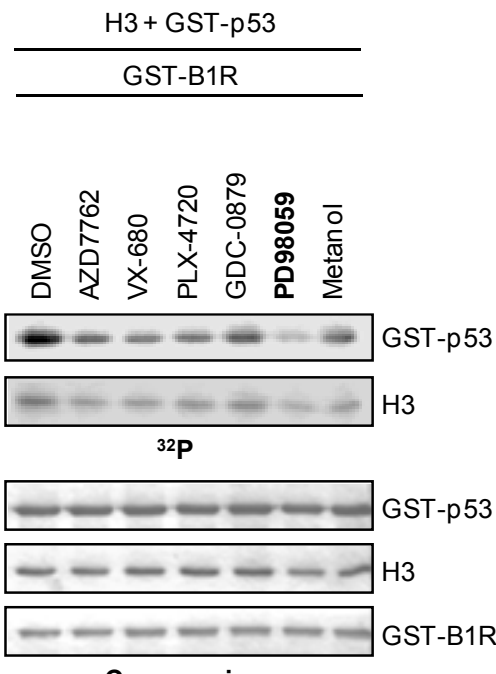

Coomassie

Figura 28. Efecto de inhibidores en la actividad quinasa de la proteína viral B1R. Ensayo quinasa in vitro con $2 \mu \mathrm{g}$ de la proteína recombinante GST-B1R frente a quince inhibidores a una concentración de $100 \mu \mathrm{M}$ y utilizando $1 \mu \mathrm{g}$ de la histona H3 y $2 \mu \mathrm{g}$ de GST-p53 como sustratos de fosforilación. Arriba se muestra la incorporación de la radiactividad $\left({ }^{32} \mathrm{P}\right)$ y abajo la tinción con azul de Coomassie. En negrita se destacan los inhibidores a los que la quinasa B1R fue más sensible. 

Regulación de NFATy COX-2 por la quinasa VRK2A e implicación en la invasión y migración celular 



\section{VRK2A fosforila y regula al factor de transcripción NFAT, identificando una nueva función de VRK2A como quinasa activa}

Dentro de la familia de quinasas humanas VRK el miembro mejor caracterizado es VRK1. En cuanto a VRK2A hay pocos datos acerca de sus funciones celulares, si bien in vitro es capaz de fosforilar los mismos sustratos que VRK1, como por ejemplo p53 (Blanco et al., 2006) o la histona H3 (Sanz-Garcia et al., 2008).

Hasta el momento, las funciones descritas para VRK2A son independientes de su actividad quinasa debidos a interacciones proteína-proteína en rutas de señalización que implican a las quinasas MAPK. VRK2A interacciona con las proteínas de anclaje JIP1 y KSR1 inhibiendo la señalización mediada a través de JNK y Erk1/2 respectivamente (Blanco et al., 2008; Fernandez et al., 2010). También se ha descrito interacción de VRK2 con la proteína BHRF1 del virus Epstein-Bar, aumentando la supervivencia celular ( $\mathrm{Li}$ et al., 2006). En cuanto a sustratos de fosforilación, como ya se ha comentado, VRK2A es capaz de fosforilar in vitro a los mismos sustratos que VRK1, pero seguramente, debido a la diferente localización subcelular de ambas quinasas, VRK2A no es capaz de llevar a cabo los efectos in vivo descritos para VRK1, como puede ser la estabilización de p53 en el núcleo, que sí es capaz de realizar la isoforma nuclear VRK2B (Blanco et al., 2006). VRK2A fosforila a JIP1, aunque se desconoce el significado de dicha fosforilación puesto que el efecto que se observa sobre la ruta de señalización sólo requiere de interacción y es independiente de la actividad quinasa de VRK2A (Blanco et al., 2008).

Por estos motivos, nos resultaba interesante estudiar en mayor profundidad la proteína humana VRK2A, puesto que la conservación de su actividad quinasa sugiere que debe tener funciones en la célula que impliquen fosforilación de algún sustrato y no sólo interacción con otras proteínas celulares.

Se ha descrito en estudios de expresión génica que el gen de VRK2 está regulado positivamente en células $\mathrm{T}$ de sangre periférica estimuladas con ionomicina (Io) o forbol-12-miristato 13-acetato (PMA) (Diehn et al., 2002); y en un estudio de búsqueda de nuevos genes que pudieran ser indicadores de una respuesta efectiva en peces frente a infecciones bacterianas, $V r k 2$ aparece como uno de los genes indicadores de células inmunes activadas (Rhodes et al., 2009). De este modo, pensamos en el 
factor de transcripción NFAT (del inglés Nuclear Factor of Activated T Cells) como un posible candidato para ser sustrato de VRK2A, puesto que se trata de un factor de transcripción que presenta elevados niveles en células del sistema inmunitario y participa en la activación de los linfocitos T. Además, la actividad de este factor de transcripción está estrictamente regulada mediante fosforilaciones y desfosforilaciones. Se han descrito diversas quinasas, como JNK, Cot1/Tp12, PKCל, CK1 y GSK3, como reguladoras de la actividad transcripcional de NFAT, ya sea activando o inhibiendo su señalización (Okamura et al., 2004; Ortega-Perez et al., 2005; Gwack et al., 2006; Gomez-Casero et al., 2007). Por ello, decidimos analizar si la quinasa VRK2A podría estar afectando a la actividad de NFAT.

\subsection{Efecto de la sobreexpresión de VRK2A sobre la actividad de NFAT}

El factor de transcripción NFAT fue descrito por primera vez en el sistema inmune como un factor necesario para la expresión inducible de moléculas de la respuesta inmune (Shaw et al., 1988). Para que lleve a cabo su función transcripcional es necesaria la activación de la fosfatasa calcineurina (Clipstone and Crabtree, 1992) tras el aumento del calcio intracelular en respuesta a estímulos en la célula. Esta fosfatasa desfosforila a NFAT en su dominio de regulación, permitiendo su translocación al núcleo. La utilización del éster de forbol PMA (forbol 12-miristato 13acetato) más ionomicina (Io) mimetiza estas condiciones de activación de calcineurina y, por tanto, de NFAT. Posteriormente a su descubrimiento en el sistema inmune, se observó que NFAT se expresa en muchos otros tipos celulares y regula respuestas importantes para la supervivencia y el crecimiento celular o para la angiogénesis (Crabtree and Olson, 2002; Horsley and Pavlath, 2002). También, en líneas celulares tumorales, como líneas de cáncer de colon y de mama, la activación de este factor promueve la invasión tumoral (Duque et al., 2005; Yoeli-Lerner et al., 2005; Yiu et al., 2011). Por estos motivos, decidimos estudiar si VRK2A aumentaba la actividad de NFAT y si su efecto era independiente del tipo celular.

Comenzamos el estudio en la línea celular tumoral MDA-MB-435, línea en la que con un reportero de luciferasa sintético para NFAT (NFATLuc), que presenta tres sitios de unión para NFAT, observamos mejor respuesta de activación de NFAT tras 
estimular las células con PMA más Io. En esta línea realizamos ensayos de luciferasa transfectando el reportero de luciferasa NFATLuc y cantidades crecientes de la quinasa HA-VRK2A. Tras 24 horas estimulamos las células con $100 \mathrm{ng} / \mathrm{mL}$ de PMA y $0,5 \mu \mathrm{M}$ de ionomicina (Io) durante 16 horas o las dejamos sin estimular (fig. 29A). Los resultados mostraron que la quinasa VRK2A aumentaba la actividad transcripcional de NFAT de forma dependiente de la dosis y esto ocurría únicamente cuando las células eran estimuladas con PMA más Io.

Además, quisimos comprobar si el efecto que tenía lugar sobre la actividad de NFAT era específico sólo de VRK2A o también la otra isoforma, VRK2B, que presenta una secuencia idéntica hasta el aminoácido 394, y VRK1 podrían estar actuando sobre NFAT. Así, transfectamos células MDA-MB-435 con el reportero de luciferasa NFATLuc y las quinasas silvestres HA-VRK2A, HA-VRK2B y HA-VRK1 y tras 24 horas, las estimulamos con PMA más Io durante 16 horas para posteriormente

A

MDA-MB-435/NFATLuc
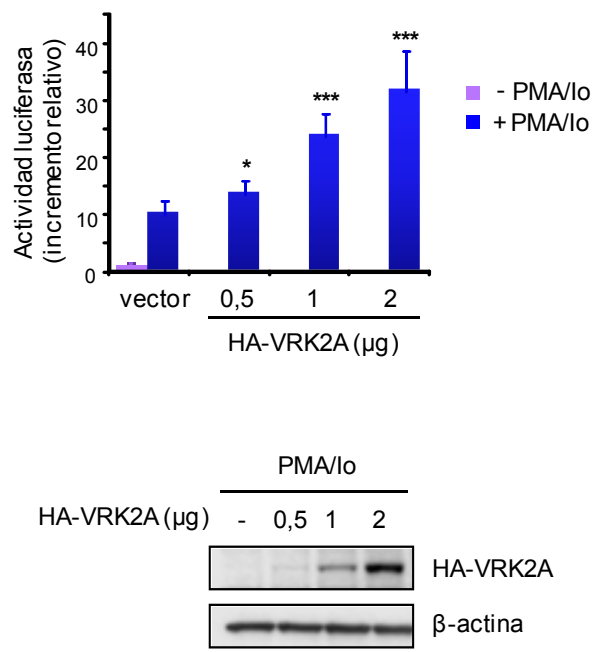

B
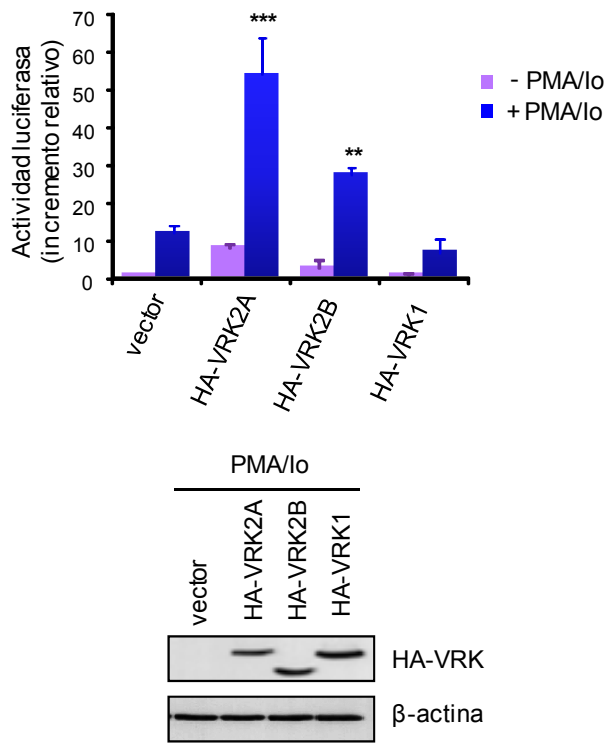

Figura 29. VRK2A aumenta la actividad transcripcional de NFAT en células MDA-MB-435. Se transfectaron las células con $1 \mu \mathrm{g}$ del reportero de luciferasa NFATLuc y cantidades crecientes de pCEFL-HA-VRK2A (A) o con $1 \mu \mathrm{g}$ de los plásmidos que codifican para las tres quinasas activas de la familia VRK (B). Tras 24 horas se estimularon con PMA más ionomicina (lo) durante 16 horas o se dejaron sin estimular. Posteriormente, se recogieron los extractos y se midió la actividad luciferasa. Los resultados son una media de cuatro experimentos independientes realizados por triplicado y se analizaron con el test estadístico T de Student. ${ }^{*} p<0,05 ;{ }^{* *} p<0,005 ;{ }^{* * *} p<0,0005$. En la parte inferior de cada gráfica se muestra el western blot de los extractos celulares revelados con un anticuerpo anti-HA y $\beta$-actina como control de carga. 
llevar a cabo el ensayo de luciferasa (fig. 29B). Observamos que ambas isoformas de VRK2 fueron capaces de aumentar de forma significativa la actividad de NFAT tras la estimulación; sin embargo, VRK1 no presentó efecto.

Debido a la identificación inicial de NFAT en el sistema inmune, quisimos comprobar si también la quinasa VRK2A era capaz de aumentar la actividad transcripcional de NFAT en la línea celular de linfocitos T Jurkat y así, además, determinar si dicho efecto era independiente del tipo celular. Realizamos ensayos de luciferasa para medir la actividad transcripcional de NFAT electroporando células Jurkat con el reportero de luciferasa NFATLuc y cantidades crecientes de la quinasa HA-VRK2A silvestre y la forma mutante sin actividad quinasa, HA-VRK2A ${ }^{\mathrm{K} 169 \mathrm{E}}$, manteniendo las células sin estimular o estimulándolas durante 6 horas con PMA más ionomicina a las 24 horas postransfección (fig. 30). Observamos que VRK2A era capaz de aumentar la actividad de NFAT de forma dependiente de la dosis y que este efecto dependía de su actividad quinasa, puesto que el mutante inactivo HA-VRK2A ${ }^{\mathrm{K} 169 \mathrm{E}}$ no era capaz de llevar a cabo el aumento de la actividad transcripcional de NFAT. Por tanto, estos resultados sugieren que VRK2A aumenta la actividad del factor de transcripción NFAT independientemente del tipo celular. Además, observamos de nuevo que este efecto se produce sólo cuando las células son estimuladas con PMA más Io, lo que indica que la actuación de VRK2A sobre NFAT necesita que la fosfatasa calcineurina actúe sobre dicho factor de transcripción en el citoplasma de las células estimuladas y así NFAT pueda translocarse al núcleo, donde lleva a cabo su

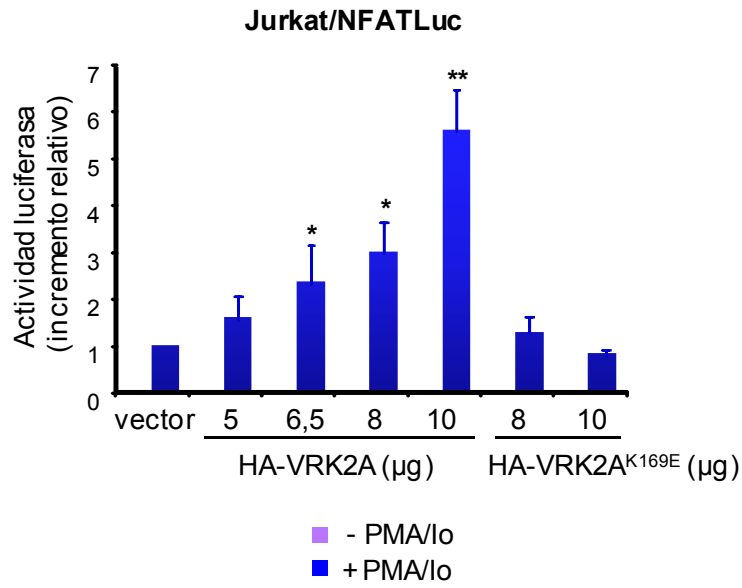

Figura 30. VRK2A aumenta la actividad transcripcional de NFAT en células Jurkat. Se electroporaron células Jurkat con $10 \mu \mathrm{g}$ del reportero de luciferasa NFATLuc y cantidades crecientes de pCEFL-HA-VRK2A $y$ el mutante pCEFL-HA-VRK2A ${ }^{\mathrm{K} 169 \mathrm{E}}$. Tras 24 horas, se estimularon con $20 \mathrm{ng} / \mathrm{mL}$ de PMA y $1 \mu \mathrm{M}$ de ionomicina (lo) durante $6 \mathrm{~h}$ o se dejaron sin estimular. Posteriormente, se recogieron los extractos y se midió la actividad luciferasa. Los resultados se expresan en unidades relativas y son una media de 5 experimentos independientes realizados por duplicado y se analizaron con el test estadístico $\mathrm{T}$ de Student. ${ }^{*} \mathrm{p}<0,05$; ${ }^{* *} p<0,005$. 
función de regulación de la transcripción génica.

1.2. VRK2A no actúa sobre NFAT de forma indirecta a través de la fosforilación de RCAN1

Puesto que la potenciación de la actividad de NFAT que producía VRK2A ocurría solamente cuando estimulábamos las células con PMA más Io, decidimos analizar si este efecto podría estar ocurriendo indirectamente a través de alguna regulación de la actividad de calcineurina. El tratamiento con PMA más Io aumenta la concentración de calcio en el citosol y activa a la fosfatasa calcineurina. La proteína RCAN1 es moduladora de la actividad de calcineurina, ya que interacciona con dicha fosfatasa e inhibe su actividad (Fuentes et al., 2000). Se han descrito proteínas quinasa que fosforilan a RCAN1, de forma que se separa de calcineurina y ésta queda libre para poder llevar a cabo la desfosforilación de proteínas como NFAT, permitiendo que dicho factor pueda translocarse al núcleo y llevar a cabo su función de regulador transcripcional (Abbasi et al., 2005; Abbasi et al., 2006).

Para comprobar si VRK2A actuaba de esta manera, llevamos a cabo ensayos de luciferasa con el reportero NFATLuc. En el caso de que VRK2A estuviese aumentando la actividad de NFAT de forma indirecta a través de la fosforilación de RCAN1, esta quinasa debería revertir el efecto inhibidor de RCAN1 sobre NFAT, como se ha descrito en el caso de una forma constitutivamente activa de Mek5 (Abbasi et al., 2005). Transfectamos células MDA-MB-435 con el reportero de luciferasa NFATLuc y las proteínas Myc-RCAN1 y HA-VRK2A por separado y en combinación; y estimulamos las células con PMA más Io durante 16 horas a las 24 horas de la transfección. Como control positivo se utilizó la construcción Flag-Mek5 CA (mutante constitutivamente activo) (fig. 31A). Como esperábamos, la quinasa VRK2A por sí sola aumentó la actividad transcripcional de NFAT y la proteína RCAN1 inhibió la actividad de NFAT. Cuando cotransfectamos RCAN1 y VRK2A, esta quinasa no fue capaz de revertir el efecto inhibidor de RCAN1 sobre la actividad de NFAT, acción que sí tuvo lugar en el caso del control positivo con la quinasa Mek5 constitutivamente activa. Además, en el western blot se puede detectar la diferente movilidad en el gel de las formas fosforilada y sin fosforilar de RCAN1 y observamos que el nivel de RCAN1 
A

MDA-MB-435/NFATLuc

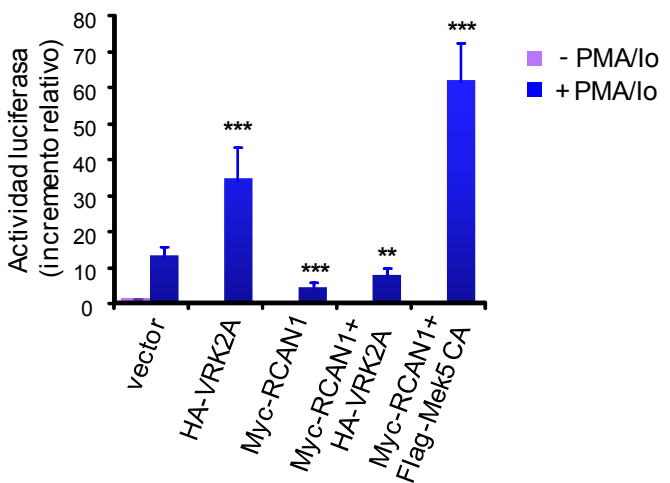

B

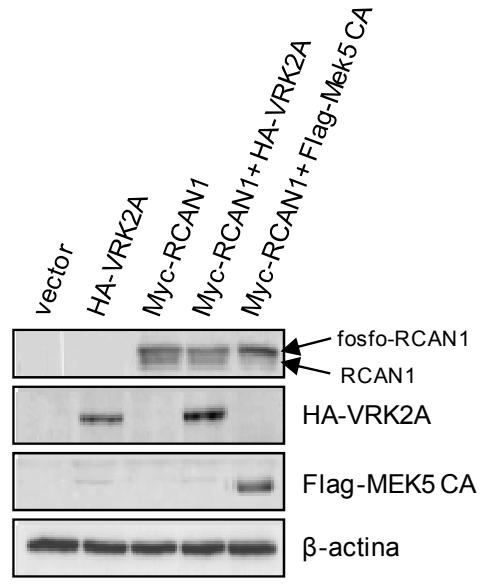

Figura 31. El efecto inhibidor de RCAN1 sobre NFAT no es revertido por VRK2A. A) Se transfectaron células MDA-MB-435 con $1 \mu \mathrm{g}$ del reportero de luciferasa NFATLuc, $1 \mu \mathrm{g}$ de los plásmidos pCEFL-HA-VRK2A, Myc-RCAN1 y como control positivo pCEFL-Flag-Mek5 CA (constitutivamente activo). Tras 24 horas se estimularon con $100 \mathrm{ng} / \mathrm{mL}$ de PMA y $0,5 \mu \mathrm{M}$ de ionomicina (lo) durante 16 horas o se dejaron sin estimular. Posteriormente, se recogieron los extractos y se midió la actividad luciferasa. Los resultados son una media de al menos tres experimentos independientes realizados por triplicado y se analizaron con $\mathrm{T}$ de Student. ${ }^{* *} \mathrm{p}<0,005$; ${ }^{* * *} p<0,0005$. B) Western blot de los extractos celulares revelados con anticuerpos dirigidos contra los epítopos de las proteínas expresadas y $\beta$-actina como control de carga. En el caso de RCAN1 se puede distinguir la forma fosforilada (fosfo-RCAN1) de la no fosforilada (RCAN1) por su diferente movilidad en el gel.

fosforilado no varía en presencia de VRK2A, pero sí en presencia de Mek5 constitutivamente activa (fig. 31B). Con este resultado descartamos que VRK2A aumente la actividad transcripcional de NFAT de forma indirecta a través de la proteína moduladora de calcineurina RCAN1 en la línea celular MDA-MB-435. También nos indica que el efecto de VRK2A sobre la actividad de NFAT depende de que calcineurina esté libre y activa para desfosforilar a NFAT.

Además, quisimos descartar este efecto indirecto en la línea celular Jurkat y llevamos a cabo experimentos de luciferasa similares a los anteriores electroporando el reportero NFATLuc y los plásmidos que codifican para HA-VRK2A y Myc-RCAN1 solos o en combinación (fig. 32A). Observamos que, al igual que en el caso de la línea celular MDA-MB-435, VRK2A no es capaz de revertir el efecto inhibidor de RCAN1 sobre la actividad de NFAT en las células Jurkat. A nivel de western blot (fig. 32B) tampoco observamos cambio en los niveles de RCAN1 fosforilado. 
A

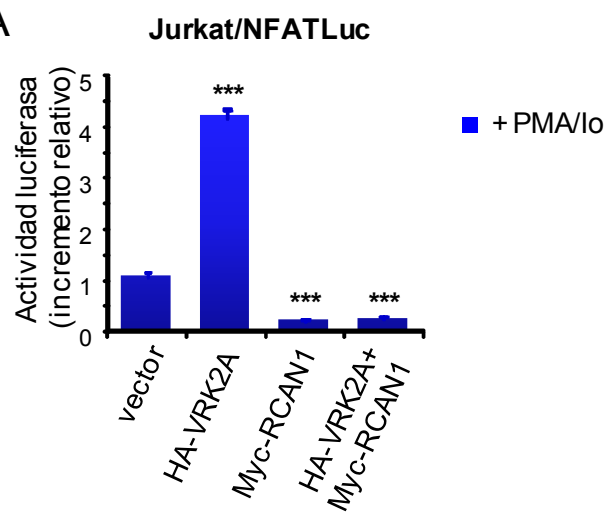

B PMA/lo

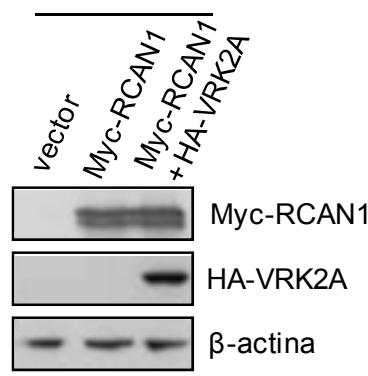

Figura 32. VRK2A no revierte el efecto de RCAN1 sobre NFAT. A) Se electroporaron células Jurkat con $10 \mu \mathrm{g}$ del reportero de luciferasa NFATLuc y los plásmidos pCEFL-HA-VRK2A y Myc-RCAN1. Tras 24 horas se estimularon con $20 \mathrm{ng} / \mathrm{mL}$ de PMA y $1 \mu \mathrm{M}$ de ionomicina (lo) durante 6 horas. Posteriormente, se recogieron los extractos celulares y se midió la actividad luciferasa. Los resultados se expresan en unidades relativas y son una media de tres experimentos independientes realizados por duplicado y se analizaron con T de Student. ${ }^{* * *} \mathrm{p}<0,0005$. B) Western blot de los extractos celulares del ensayo de luciferasa.

Para terminar de confirmar que VRK2A no fosforila a la proteína RCAN1, decidimos llevar a cabo un ensayo quinasa in vitro con la quinasa recombinante GSTVRK2A purificada de bacterias E. coli, utilizando como sustrato la proteína MycRCAN1 inmunoprecipitada. Para ello, transfectamos células HEK-293T con la construcción Myc-RCAN1 y vector vacío como control y la inmunoprecipitamos con un anticuerpo anti-Myc policlonal. También inmunoprecipitamos con un anticuerpo anti-HA monoclonal la proteína HA-NFAT1 transfectada en células HEK-293T para determinar al mismo tiempo la posibilidad de la fosforilación directa sobre NFAT1. Incubamos estos inmunoprecipitados con la quinasa recombinante GST-VRK2A en presencia de $\left[\gamma-{ }^{32} \mathrm{P}\right] \mathrm{ATP}$. En la figura 33 se muestra el resultado de este ensayo quinasa, y observamos que VRK2A no fosforiló a RCAN1. Sin embargo, sí se detectó fosforilación de HA-NFAT1. Esto nos indicaba de nuevo que VRK2A no regula la actividad de NFAT mediante fosforilación de la proteína RCAN1, sino que el efecto podría ser a través de la fosforilación directa sobre el factor de transcripción NFAT1. 


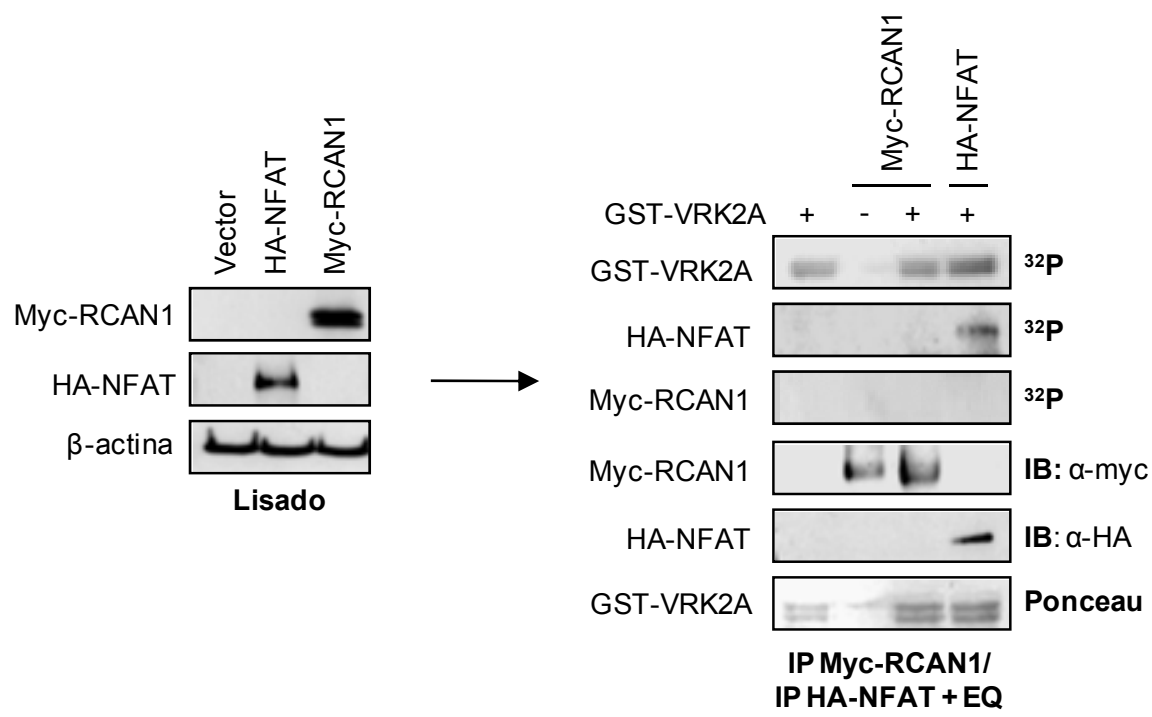

Figura 33. VRK2A no fosforila a la proteína RCAN1. Ensayo quinasa in vitro de la proteína recombinante GST-VRK2A utilizando como sustratos de fosforilación las proteínas Myc-RCAN1 y HA-NFAT1 transfectadas e inmunoprecipitadas de células HEK-293T. A la izquierda se muestra la expresión de los plásmidos Myc-RCAN1 y HA-NFAT1 en los extractos celulares. A la derecha, la incorporación de la radiactividad $\left({ }^{32} \mathrm{P}\right)$, los controles de las inmunoprecipitaciones (IB) y la tinción con rojo Ponceau para detectar las proteínas recombinantes.

\subsection{El factor de transcripción NFAT es fosforilado por VRK2A}

\subsubsection{VRK2 fosforila a NFAT en su dominio de transactivación}

La fosforilación en el dominio de regulación de NFAT1 conlleva una inactivación del mismo puesto que provoca su exportación al citoplasma (Park et al., 2000). Sin embargo, varios estudios han mostrado la existencia de fosforilaciones en el dominio de regulación o en el dominio de transactivación del extremo amino de NFAT1 que aumentan la actividad transcripcional de dicho factor (Okamura et al., 2000). Entre las quinasas descritas que llevan a cabo esta potenciación de la capacidad transcripcional de NFAT1 están JNK, o PKCל y Cot1/Tpl2 (San-Antonio et al., 2002; Ortega-Perez et al., 2005; Gomez-Casero et al., 2007). Puesto que VRK2A estaba aumentando la actividad transcripcional de NFAT y no inhibiéndola, pensamos que podría fosforilar a NFAT de un modo similar y así potenciar su función transcripcional. Para comprobar esta hipótesis, y dado que en el apartado anterior habíamos visto que 
VRK2A fosforilaba a NFAT1, llevamos a cabo distintos ensayos quinasa in vitro en presencia de $\left[\gamma-{ }^{32} \mathrm{P}\right] \mathrm{ATP}$ con la quinasa VRK2A recombinante fusionada al epítopo GST expresada en bacterias E. coli.

La primera aproximación fue determinar si la región de NFAT1 que fosforilaba VRK2 correspondía al dominio de transactivación, puesto que en esa región se han descrito fosforilaciones inducibles que potencian la actividad de NFAT1 (GomezCasero et al., 2007). Llevamos a cabo un ensayo quinasa in vitro con la proteína GSTVRK2A purificada de cultivo de E. coli sobre diferentes proteínas de fusión de fragmentos de NFAT1 murino (fig. 34A). Dos de los fragmentos incluyen sólo parte de la región de transactivación del extremo amino de NFAT1 y comprenden los aminoácidos del 4 al 57 y del 4 al 68. La otra construcción incluye además el dominio de regulación de NFAT1, comprendiendo desde el aminoácido 4 al 384. Como se aprecia en la figura 34B del alineamiento del dominio de transactivación de la proteína NFAT1 murina y humana, las secuencias entre ambas son muy similares y, al contrario que en el dominio de regulación, existen pocos residuos de serina. Entre estos residuos

A<smiles>[AsH2][AsH][SeH]</smiles><smiles>[As][As][SeH]</smiles>

Dominio de transactivación

Dominio de regulación

B

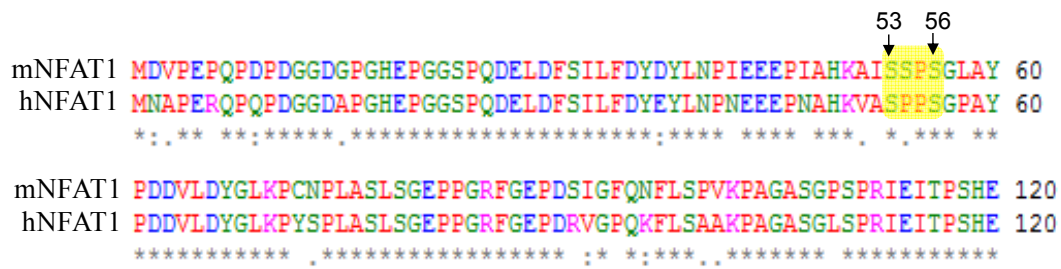

Figura 34. A) Esquema de las proteínas NFAT1 fusionadas a GST-HA utilizadas en los ensayos quinasa. Los fragmentos del aminoácido 4 al 57 y 68 incluyen sólo parte de la región de transactivación (en violeta), mientras que el fragmento del aminoácido 4 al 384 incluye también el dominio de regulación (en azul). B) Comparación de las secuencias del dominio de transactivación de las proteínas NFAT1 murina (mNFAT1) y humana (hNFAT1). Con flechas se indican los residuos descritos cuya fosforilación potencia la actividad de NFAT1. El alineamiento se realizó con el programa ClustalW2.

* residuo idéntico

: sustituciones conservadas (aminoácidos del mismo grupo)

- sustituciones semi-conservadas (aminoácidos de tamaños similares) 
los que se han descrito como sitios de fosforilación que potencian la actividad de NFAT1 son las serinas 53, 54 y 56 en NFAT de ratón (en humanos la posición 54 corresponde a un residuo prolina) (Gomez-Casero et al., 2007).

Los resultados de este ensayo quinasa se reflejan en la figura $35 \mathrm{~A}$, donde observamos fosforilación de todos los fragmentos de NFAT1, lo cual nos sugiere que dicha quinasa fosforila directamente a NFAT1 y lo hace en su dominio de transactivación, antes del aminoácido 57. Como control se empleó la proteína mutante
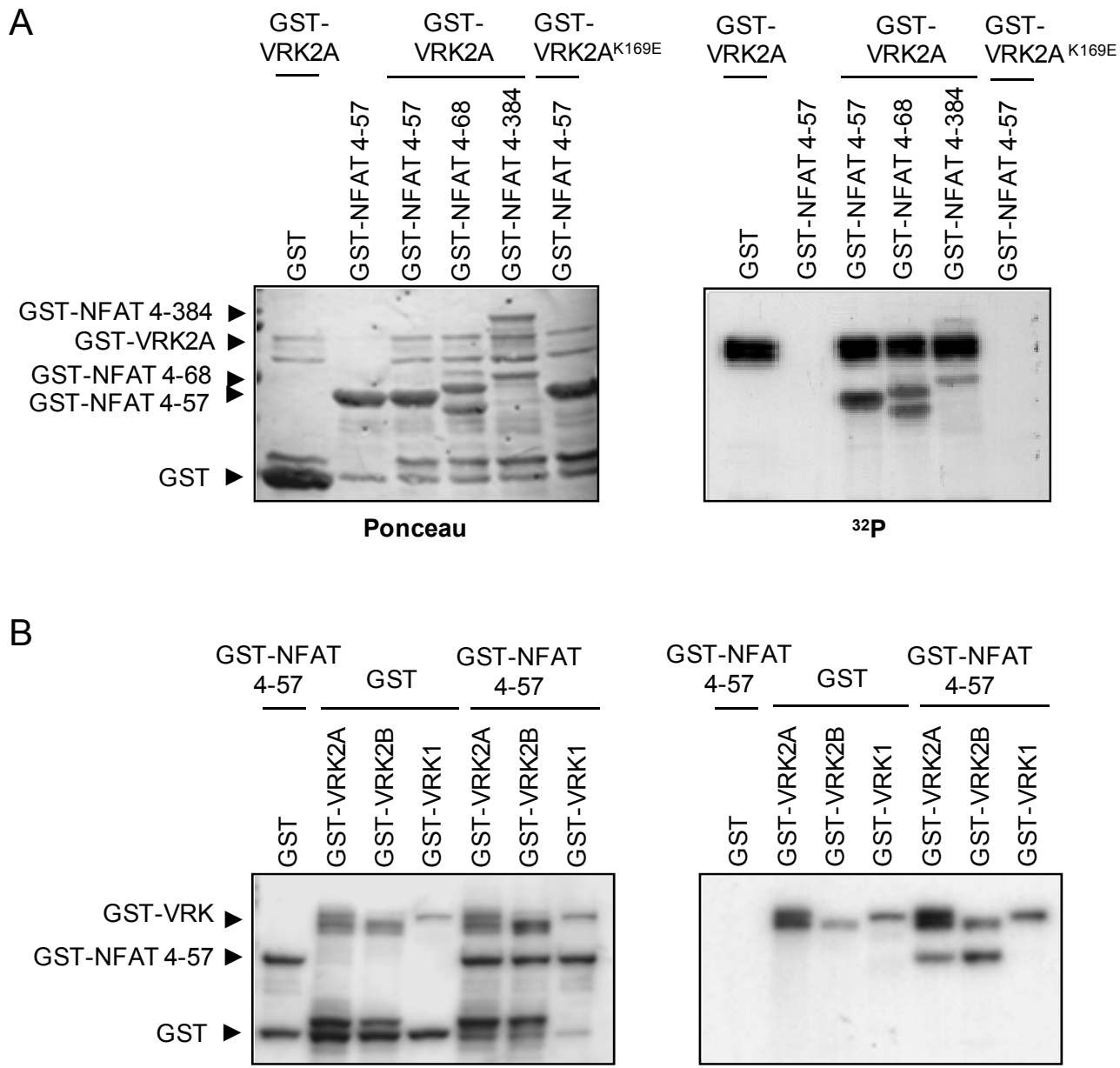

Coomassie

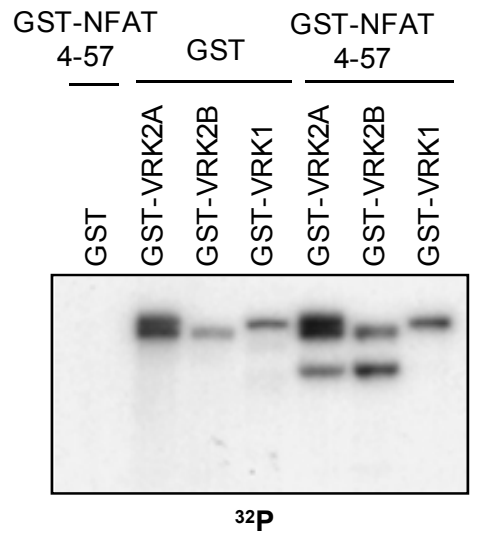

Figura 35. Fosforilación del dominio de transactivación de NFAT1 por VRK2. A) Ensayo quinasa in vitro con $2 \mu \mathrm{g}$ de la proteína recombinante GST-VRK2A utilizando como sustrato $5 \mu \mathrm{g}$ de los distintos fragmentos purificados de NFAT1 murino. Como control se empleó el plásmido GST vacío. A la izquierda se muestra la tinción con rojo Ponceau y a la derecha la incorporación de la radiactividad. B) Ensayo quinasa in vitro con $2 \mu \mathrm{g}$ de las proteínas recombinantes GST-VRK2A, GST-VRK2B y GST-VRK1 utilizando como sustrato la proteína purificada GST-NFAT 4-57. A la izquierda, la tinción con azul de Coomassie y a la derecha la incorporación de la radiactividad $\left({ }^{32} \mathrm{P}\right)$. 
sin actividad quinasa GST-VRK2 $\mathrm{A}^{\mathrm{K} 169 \mathrm{E}}$ y observamos que no hubo fosforilación. También como control se utilizó el plásmido GST vacío para comprobar que la fosforilación era sobre NFAT1 y no sobre el epítopo GST.

Puesto que en los experimentos de luciferasa observamos un aumento significativo de la actividad de NFAT sólo en presencia de ambas isoformas de VRK2 y no de VRK1, quisimos comprobar si también sólo VRK2 fosforilaba a NFAT1 en el dominio de transactivación. Así, realizamos ensayos quinasa in vitro con las tres proteínas VRK recombinantes fusionadas a GST y la proteína expresada y purificada de $E$. coli que corresponde al fragmento de NFAT1 que comprende los aminoácidos del 4 al 57. Como se puede apreciar en la figura 35B, VRK2A y VRK2B fueron capaces de fosforilar dicha construcción de NFAT1, mientras que VRK1 no la fosforiló. Como control se utilizó la proteína GST expresada del vector vacío para comprobar que la fosforilación era específica sobre el fragmento de NFAT1 y no sobre el epítopo que lleva la proteína recombinante. Esto concuerda con los experimentos de luciferasa del apartado 1.1 (página 94). Por ello, todo apunta a que el efecto de potenciación de la transcripción de NFAT es específico de VRK2 y tiene lugar mediante un mecanismo de fosforilación directa del dominio de transactivación del factor de transcripción.

A continuación, decidimos comprobar de nuevo que la fosforilación ocurría también en la proteína NFAT1 expresada en las células. Para ello, determinamos la fosforilación sobre la proteína NFAT1 completa, transfectando células HEK-293T con el plásmido HA-NFAT1 que codifica para la proteína murina completa. Al cabo de 40 horas de la transfección llevamos a cabo la inmunoprecipitación de NFAT1 sobreexpresado y del control con el vector vacío con un anticuerpo anti-HA monoclonal. Estos inmunoprecipitados se utilizaron para un ensayo quinasa in vitro con las proteínas de fusión GST-VRK2A y GST-VRK2B (isoformas de VRK2 que comparten una secuencia en el dominio catalítico idéntica y que observamos en los ensayos anteriores que eran las quinasas capaces de fosforilar a NFAT1 en su dominio de transactivación). En la figura 36 observamos que ambas isoformas de VRK2 fosforilaron a la proteína NFAT1. Estos resultados apoyan los observados en los 


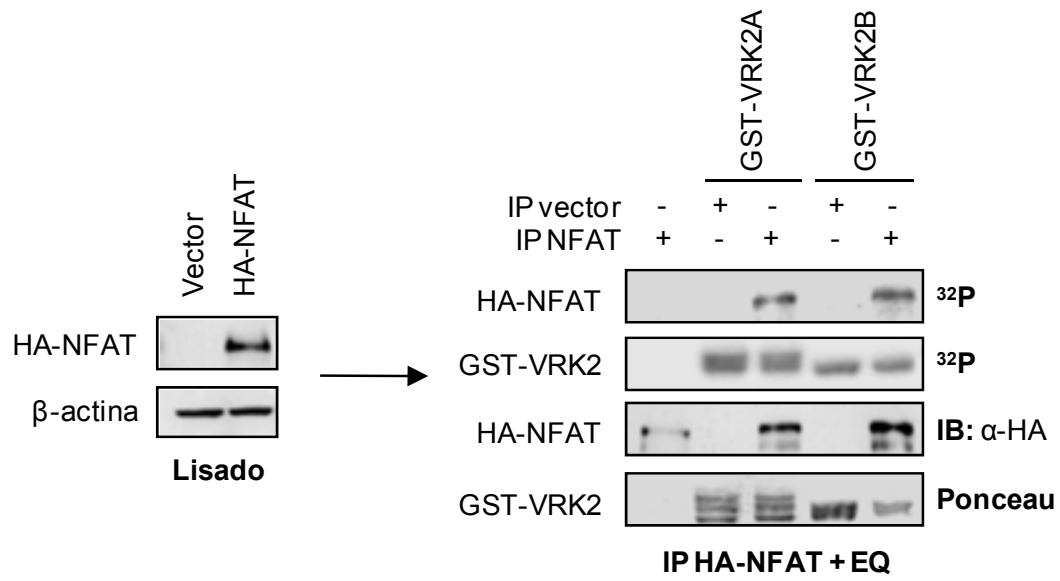

Figura 36. Ambas isoformas de VRK2 fosforilan a NFAT1. Ensayo quinasa (EQ) in vitro con las proteínas recombinantes GST-VRK2A y GST-VRK2B sobre la proteína HA-NFAT1 completa inmunoprecipitada de células HEK-293T en presencia de $\left[\mathrm{r}^{-32} \mathrm{P}\right] \mathrm{ATP}$. A la izquierda se muestra la expresión del plásmido HA-NFAT1 en el extracto celular. A la derecha, la incorporación de la radiactividad $\left({ }^{32} \mathrm{P}\right)$, los controles de la inmunoprecipitación (IB) y la tinción con rojo Ponceau para detectar las proteínas recombinantes.

ensayos de luciferasa, donde tanto VRK2A como VRK2B aumentaban la actividad transcripcional de NFAT tras el estímulo con PMA más Io (fig. 29B, página 95).

\subsubsection{Interacción entre VRK2 y NFAT}

Lo siguiente que quisimos comprobar es si existía interacción entre VRK2 y NFAT1, ya que habíamos visto que VRK2 fosforila directamente a NFAT1; y también si esta interacción se producía sólo con VRK2 y no con VRK1. Para ello transfectamos células HEK-293T con los plásmidos pCEFL-GST-VRK2A, GST-VRK2B y GSTVRK1 separadamente o en presencia del plásmido que codifica para la proteína murina completa HA-NFAT1. Comprobamos la correcta expresión de las proteínas sobreexpresadas en los extractos celulares y estos extractos se incubaron con la resina Glutatión Sefarosa para llevar a cabo los ensayos de pulldown, en los que se precipitan las proteínas que llevan unido GST como epítopo. Transfectamos también como control negativo el plásmido pCEFL-GST, que expresa la proteína GST sola. Posteriormente a la precipitación de las proteínas unidas a GST, realizamos un western blot con un anticuerpo anti-HA para detectar la presencia de HA-NFAT1 en los precipitados de Glutatión Sefarosa (fig. 37). En la membrana correspondiente a estos 


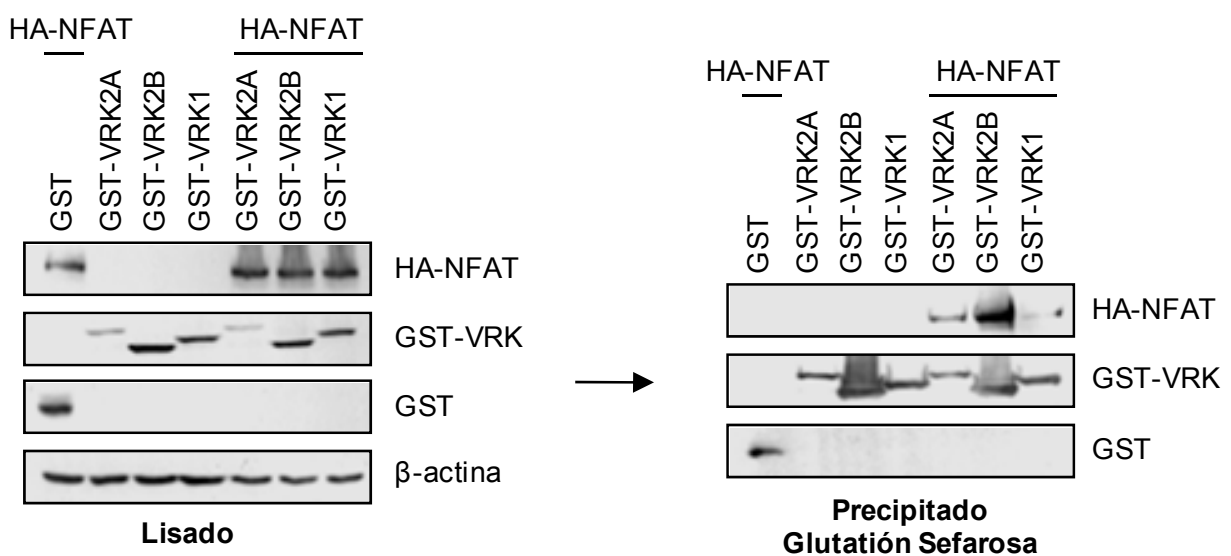

Figura 37. Interacción entre VRK2 y NFAT. Se transfectaron células HEK-293T con los plásmidos pCEFL-GST-VRK2A, pCEFL-GST-VRK2B o pCEFL-GST-VRK1 solos o con $1 \mu \mathrm{g}$ del plásmido pEFBOS-HA-NFAT1. Como control se usó el plásmido pCEFL-GST vacío. Se utilizó $1 \mathrm{mg}$ de extracto para cada incubación con la resina Glutation Sefarosa. Las proteínas precipitadas se analizaron por western blot con anticuerpos anti-HA y anti-GST. La expresión de los plásmidos se detectó en los extractos celulares totales por western blot con los anticuerpos anti-HA, anti-GST y anti- $\beta$-actina como control de carga.

precipitados sólo detectamos la proteína HA-NFAT1 en caso de cotransfección con GST-VRK2A y GST-VRK2B, y no observamos interacción en el caso de GST-VRK1 o del control con GST. Este resultado indicaba, como esperábamos, que la interacción con NFAT1 es específica de VRK2, corroborando los resultados anteriores de ensayos quinasa y luciferasa.

Además, quisimos determinar qué región de VRK2A estaba implicada en la interacción con NFAT1. Transfectamos células HEK-293T con los plásmidos que codifican para diferentes fragmentos de VRK2 con el epítopo GST: uno para la región amino terminal comprendida entre los aminoácidos 1 y 320; y dos construcciones del extremo carboxilo, una entre los aminoácidos 256 y 508 y otra entre 364 y 508 (fig. 38A). El primero de los fragmentos de la región carboxilo presenta parte de secuencia que también se encuentra en la isoforma VRK2B, pero el otro fragmento del extremo carboxilo corresponde sólo a la proteína VRK2A. Llevamos a cabo ensayos de pulldown para precipitar estos fragmentos y ver con cuál de ellos interaccionaba la proteína HA-NFAT1 cotransfectada con los plásmidos para VRK2A (fig. 38B). Observamos que la región amino terminal de VRK2A, entre los aminoácidos 1 y 320, es la implicada en la interacción con NFAT1 y puesto que es una zona que comparte 
A

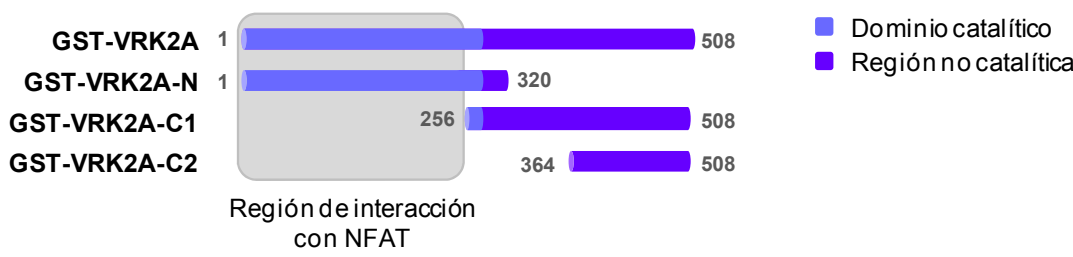

B
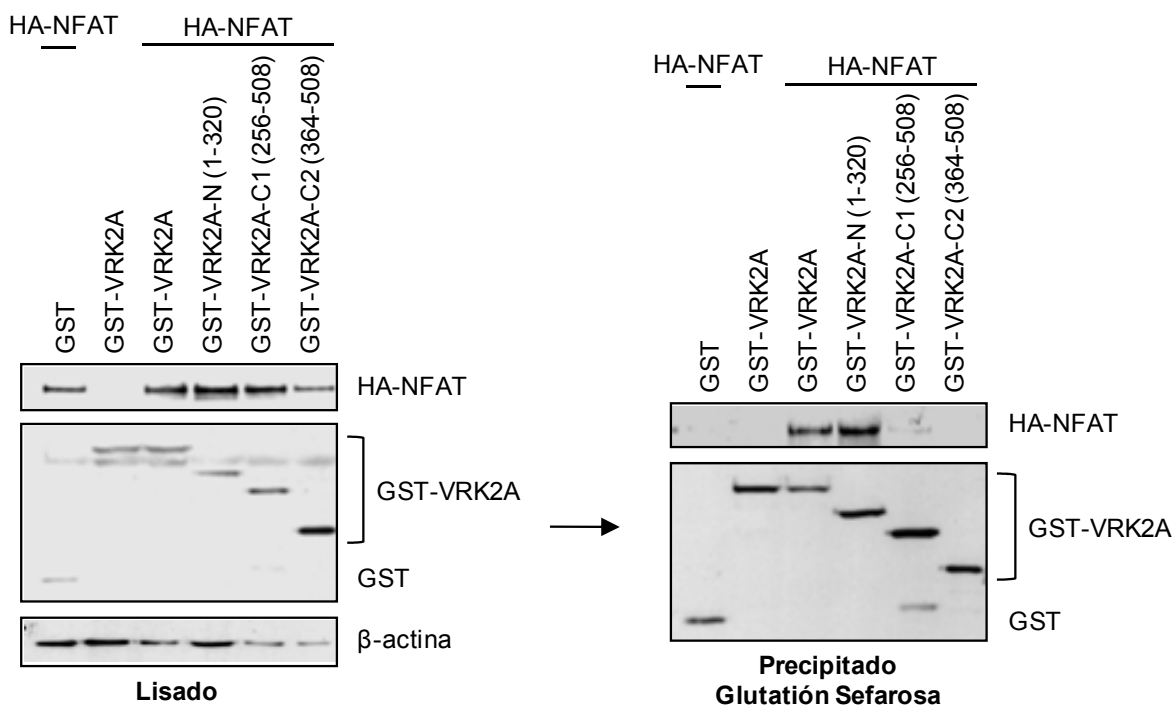

Figura 38. La región catalítica de VRK2 interacciona con NFAT. Se transfectaron células HEK293T con plásmidos pCEFL-GST VRK2A completa y diferentes fragmentos de VRK2A solos o con 1

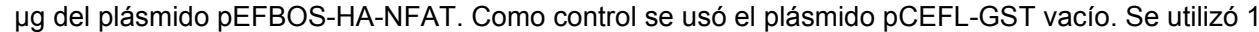
$\mathrm{mg}$ de extracto para cada incubación con la resina Glutation Sefarosa. Las proteínas precipitadas se analizaron por western blot con anticuerpos anti-HA y anti-GST. La expresión de los plásmidos se detectó en los extractos celulares totales por western blot con los anticuerpos anti-HA, anti-GST y anti- $\beta$-actina como control de carga.

identidad de secuencia con VRK2B, NFAT1 interacciona con ambas isoformas. Esta región de interacción se corresponde además con la región catalítica de VRK2.

Por otro lado, llevamos a cabo ensayos de pulldown in vitro para determinar la zona de interacción de NFAT1 con la proteína VRK2 endógena. Incubamos extracto celular de la línea MDA-MB-231 con las proteínas NFAT1 purificadas y fusionadas a GST correspondientes a los fragmentos de NFAT1 utilizados en los ensayos quinasa (fig. 39A). En la figura 39B observamos que la región de interacción con la quinasa VRK2 endógena se localiza entre los residuos 68 y 384 de NFAT1, que incluyen el final del dominio de transactivación y el dominio de regulación de NFAT1. 
A

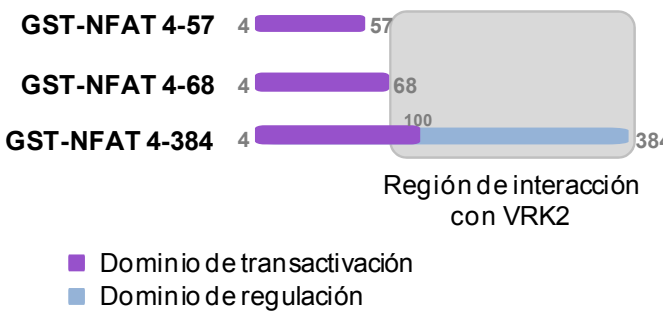

Figura 39. VRK2 interacciona con la región de NFAT comprendida entre los aminoácidos 68 y 384 . A) Fragmentos de NFAT fusionados a GST. Se indica la zona de interacción con VRK2 endógena. B) Ensayo de pulldown in vitro con extracto de células MDA-MB-231 y las proteínas purificadas correspondientes a diferentes fragmentos de NFAT fusionados a GST. Como control se utilizó la proteína purificada GST. La proteína VRK2 endógena se detectó por western blot con un anticuerpo anti-VRK2 policlonal. Para la detección de las bandas de las proteínas NFAT se tiñó la membrana con rojo Ponceau.
B

MDA-MB-231

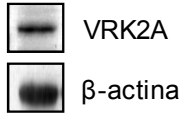

Lisado
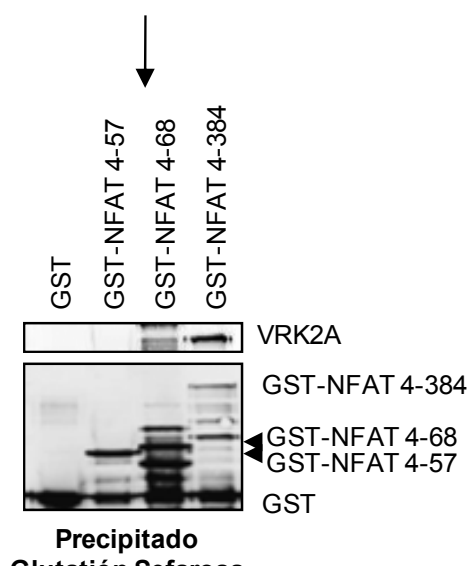

Glutatión Sefarosa

A la vista de los resultados obtenidos, todo indica que VRK2A presenta una función como quinasa activa implicada en la regulación del factor de transcripción NFAT1.

\section{Efecto de VRK2A sobre la expresión de ciclooxigenasa-2, un gen diana de NFAT}

Una vez determinado que VRK2A fosforila directamente a NFAT potenciando su actividad transcripcional, el siguiente paso fue estudiar la posible implicación de este efecto sobre algún gen diana de NFAT. Se ha descrito que altos niveles de la proteína NFAT promueven la migración e invasión de células de cáncer de mama (Yiu and Toker, 2006; Yiu et al., 2011) y que este factor de transcripción es importante para la capacidad promotora de tumores (Werneck et al., 2011). El mecanismo por el que la actividad de NFAT puede modular la invasión es a través de la inducción de genes que favorecen la motilidad celular o la invasión. Entre ellos se conoce que la transcripción del gen de ciclooxigenasa-2 (COX-2) en células cancerosas aumenta la migración e invasión y NFAT desempeña un papel importante en su expresión (Iniguez et al., 2000). COX-2 es responsable de la síntesis de prostaglandinas, como la $\mathrm{PGE}_{2}$, que es 
un potente factor que favorece la invasión celular (Timoshenko et al., 2003; Wu et al., 2011). Puesto que la expresión de este gen resulta ser de importancia en la diseminación de las células tumorales y que se encuentra sobreexpresado en diversos tipos de tumores, decidimos analizar si VRK2A actuaba en la regulación del mismo a través de su efecto sobre NFAT.

2.1. La sobreexpresión de VRK2A aumenta la transcripción del promotor de COX-2 en la línea celular MDA-MB-435

El gen de ciclooxigenasa-2 (COX-2) es un gen inducible cuyo promotor presenta sitios de unión para varios factores de transcripción. Entre ellos existen dos sitios de unión para NFAT, llamados distal (dNFAT) y proximal (pNFAT). Ya que VRK2A aumentaba la actividad transcripcional de NFAT, pensamos que también podría aumentar la transcripción de COX-2 mediante su efecto sobre NFAT. Para comprobar esta hipótesis, llevamos a cabo ensayos de luciferasa utilizando un plásmido reportero que incluye la región del promotor de COX-2 donde se encuentran los sitios de unión para NFAT (fig. 40A). Transfectamos células MDA-MB-435 con este reportero junto con el plásmido pCEFL-HA-VRK2A, que codifica para la quinasa silvestre, o con el plásmido pCEFL-HA vacío como control y tras 24 horas las dejamos sin estimular o las estimulamos con PMA más Io durante 16 horas. Observamos que VRK2A aumentó la transcripción del promotor de ciclooxigenasa-2 de forma significativa cuando estimulamos las células con PMA más Io (fig. 40B).

Además, quisimos comprobar que este aumento de la transcripción era debido a un mecanismo a través de la activación de NFAT. El compuesto ciclosporina A (CsA) es un inhibidor de la actividad de calcineurina por lo que, indirectamente, inhibe la activación de NFAT incluso en presencia de estimulación con PMA más Io, impidiendo su translocación al núcleo y en consecuencia, inhibiendo la transcripción de los genes diana de NFAT. Con esta idea, en el mismo ensayo de luciferasa tratamos las células transfectadas con la quinasa VRK2A o el vector vacío como control durante 1 hora con ciclosporina A, previamente a la estimulación con PMA más Io (fig. 40B). Observamos que la quinasa VRK2A no fue capaz de llevar a cabo el aumento en la transcripción del promotor de ciclooxigenasa-2 en presencia de ciclosporina A. Esto 


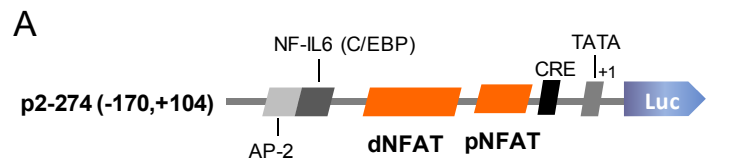

B

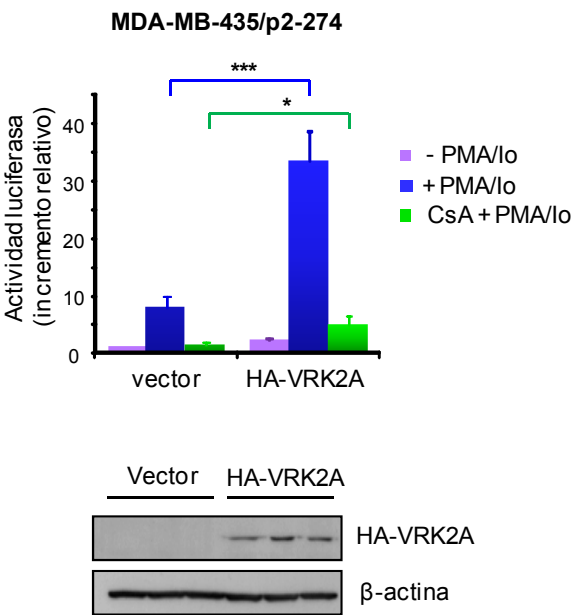

C MDA-MB-435/p2-274

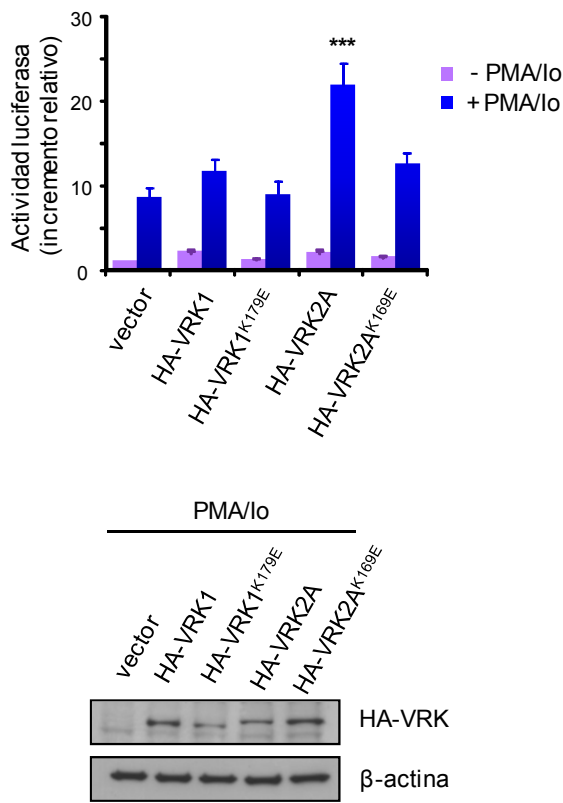

Figura 40. VRK2A aumenta la transcripción del gen de ciclooxigenasa-2. A) Esquema de la estructura de la región del promotor de COX-2 que contiene el reportero de luciferasa p2-274. B) Ensayo de luciferasa de células MDA-MB-435 transfectadas con $1 \mu \mathrm{g}$ del reportero de luciferasa p2274 y $1 \mu \mathrm{g}$ del plásmido pCEFL-HA-VRK2A o con el vector vacío como control. Tras 24 horas se estimularon con $100 \mathrm{ng} / \mathrm{mL}$ de PMA y $0,5 \mu \mathrm{M}$ de ionomicina (lo) durante 16 horas o se dejaron sin estimular. Se añadió $10 \mu \mathrm{M}$ de ciclosporina A (CsA) durante 1 hora previamente a la estimulación con PMA más lo. Posteriormente, se recogieron los extractos y se midió la actividad luciferasa y se llevó a cabo un western blot para comprobar la expresión de los plásmidos. Los resultados son una media de tres experimentos independientes realizados por triplicado y se analizaron con $T$ de Student. ${ }^{*}<<0,05 ;{ }^{* *} p<0,0005$. C) Ensayo de luciferasa con el reportero $p 2-274$ en células MDA-MB435 con $1 \mu \mathrm{g}$ de las quinasas HA-VRK1 y HA-VRK2 silvestres y sus mutantes sin actividad quinasa HA-VRK $1^{K 179 E}$ y HA-VRK2A ${ }^{\mathrm{K} 169 \mathrm{E}}$.

indica que VRK2A aumenta la transcripción de COX-2 a través de la activación de NFAT y, para que tenga lugar este efecto, es necesaria la actividad de calcineurina sobre NFAT para desfosforilarlo y que pueda translocarse al núcleo.

También en este caso, al igual que con el reportero sintético para NFAT, quisimos comprobar que el efecto de aumento de la transcripción de un gen diana de NFAT era específico de VRK2A. Para ello, transfectamos células MDA-MB-435 con el plásmido reportero de luciferasa p2-274 y las quinasas HA-VRK1 y HA-VRK2A, tanto la forma activa como el mutante sin actividad quinasa, y 24 horas después de la transfección las estimulamos con PMA más Io durante 16 horas (fig. 40C). Los resultados mostraron que sólo VRK2A en su forma activa tuvo el efecto de aumento significativo de la transcripción del promotor de ciclooxigenasa-2. Esto sigue 
corroborando la idea sobre la especificidad de VRK2A en esta función y situando a la proteína VRK2A como una quinasa activa que participa en la modulación de un gen diana de NFAT a través de la regulación de la actividad transcripcional de dicho factor.

2.2. VRK2A participa en la regulación del promotor de COX-2 en la línea de cáncer de colon SW-620

En líneas de cáncer colon también se ha descrito la expresión de NFAT regulando la expresión de COX-2 (Duque et al., 2005) y en muchos cánceres de colon se detecta sobreexpresión de la proteína COX-2 (Zhang and Sun, 2002; Soumaoro et

A
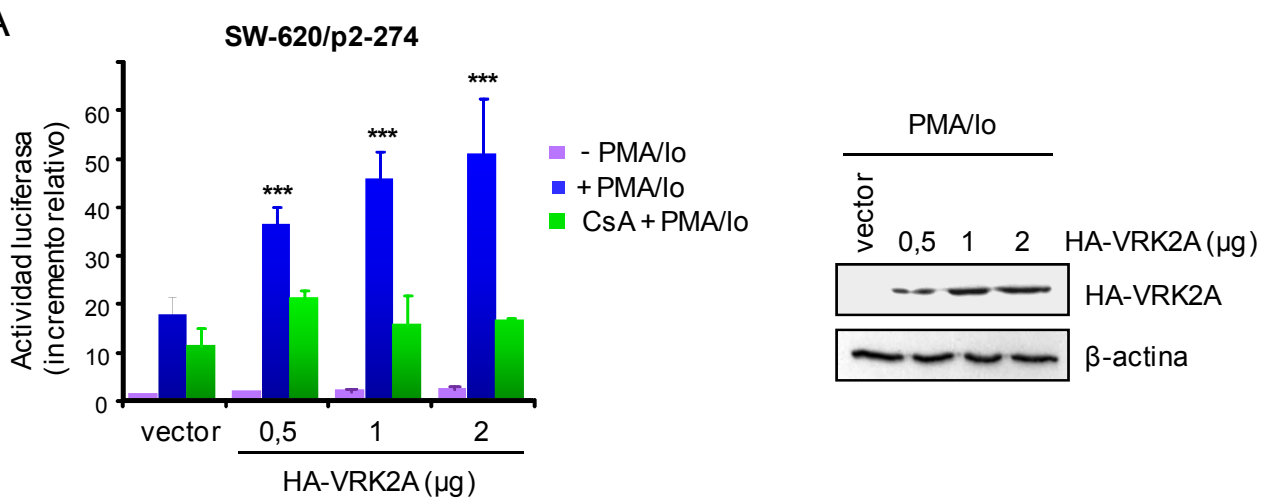

B

SW-620/p2-274
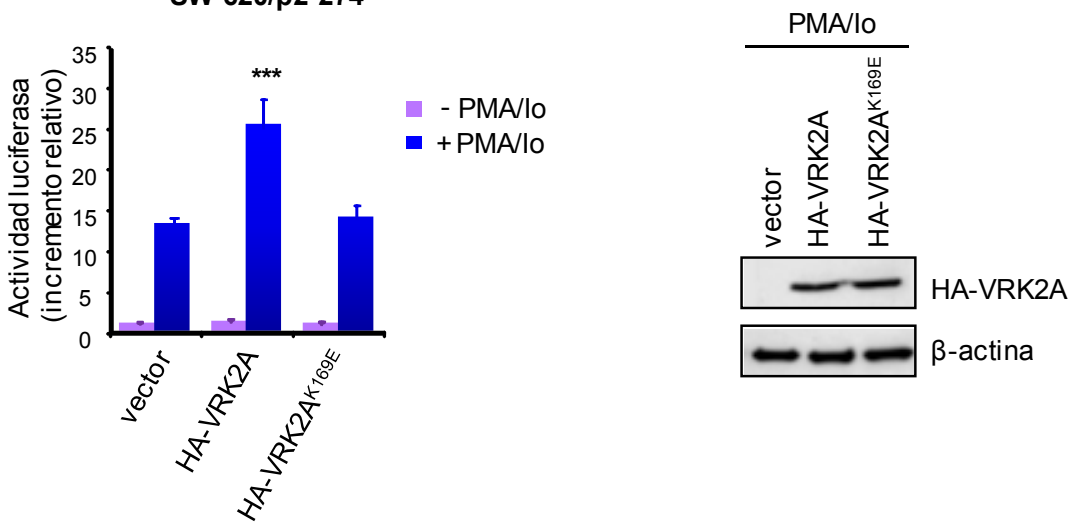

Figura 41. VRK2A aumenta la transcripción del gen de ciclooxigenasa-2 en células de cáncer de colon. A) Ensayo de luciferasa en células SW-620 transfectadas con $1 \mu \mathrm{gg}$ del reportero de luciferasa p2-274 y cantidades crecientes del plásmido pCEFL-HA-VRK2A y estimuladas o no con $100 \mathrm{ng} / \mathrm{mL}$ de PMA y $0,5 \mu \mathrm{M}$ de ionomicina (lo) durante 16 horas. Se añadió $10 \mu \mathrm{M}$ de ciclosporina $\mathrm{A}$ (CsA) durante 1 hora previamente a la estimulación con PMA más lo. B) Ensayo de luciferasa con el reportero p2-274 en células SW-620 con la quinasa HA-VRK2A silvestre y su mutante sin actividad quinasa HA-VRK2A ${ }^{\mathrm{K} 169 \mathrm{E}}$. Los resultados son una media de al menos tres experimentos independientes realizados por triplicado y se analizaron con T de Student. ${ }^{* * *} p<0,0005$. 
al., 2004). Por ello, y ya que el efecto de VRK2A sobre NFAT parecía independiente del tipo celular, nos resultaba interesante estudiar si el efecto de aumento de la transcripción del gen de ciclooxigenasa-2 también tenía lugar en líneas de cáncer de colon. Con esta idea, llevamos a cabo ensayos de luciferasa en la línea celular de cáncer de colon SW-620 similares a los anteriores sobreexpresando cantidades crecientes de la quinasa VRK2A silvestre y también utilizando el mutante sin actividad quinasa como control para verificar que el efecto ocurría de forma dependiente de la actividad quinasa. Como se puede observar en la figura 41A, VRK2A aumenta la transcripción del promotor de ciclooxigenasa-2 significativamente de forma dependiente de la dosis y también observamos que este efecto sólo se produce en presencia de la forma activa de la quinasa (fig. 41B). Además, si previamente a la estimulación con PMA más Io tratábamos las células con ciclosporina A durante 1 hora, VRK2A no era capaz de aumentar la actividad transcripcional del reportero de luciferasa (fig. 41A), lo que nos indicaba, como en el caso de la línea celular MDAMB-435, que VRK2A ejerce su efecto sobre la expresión del gen de ciclooxigenasa-2 a través de la regulación de la actividad transcripcional de NFAT.

Otra aproximación que llevamos a cabo en esta línea celular de cáncer de colon, SW-620, fue el silenciamiento de VRK2 con ARN de interferencia para ver si la bajada de los niveles proteicos de esta quinasa se correlacionaban con una disminución en la transcripción del gen de COX-2. De este modo, primero comprobamos el funcionamiento de un ARN de interferencia específico para VRK2 en esta línea celular. Transfectamos células SW-620 con un ARN de interferencia control (que no tiene ninguna secuencia diana en la célula) y con ARN de interferencia específico para VRK2 e incubamos las células durante 48 y 90 horas. Además, como control adicional utilizamos células sin transfectar. Realizamos un western blot de estos extractos celulares con un anticuerpo policlonal contra VRK2 y cuantificamos las bandas para calcular la bajada de la expresión de proteína al silenciar el gen de VRK2 con ARN de interferencia específico (fig. 42A). A las 48 horas se produjo una bajada del $40 \%$ en la expresión de VRK2 y a las 90 horas, los niveles de VRK2 alcanzaron un 50\% menos respecto al control. No conseguimos una eficiencia mayor en el silenciamiento de VRK2 porque se trata de una proteína muy estable, de larga vida media. 
A

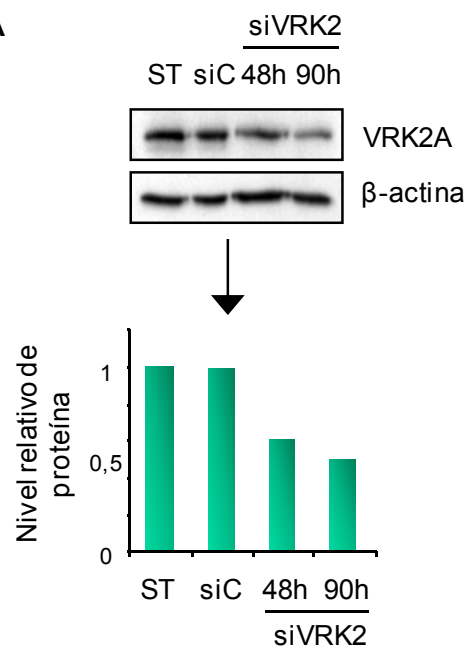

B

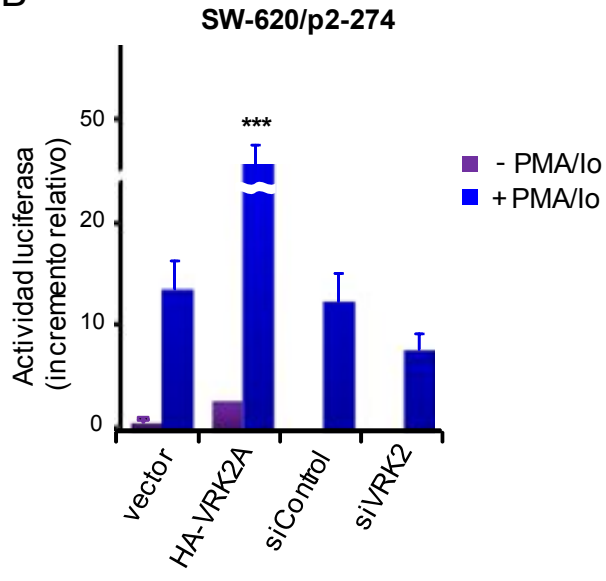

Figura 42. El silenciamiento de VRK2A disminuye la transcripción del gen de ciclooxigenasa-2 en células de cáncer de colon. A) Se transfectaron células SW-620 con ARN de interferencia control (siC) y específico para VRK2 (siVRK2). También se utilizaron células sin transfectar (ST). Se recogieron extractos a las 48 y 90 horas y se llevó a cabo un western blot para detectar los niveles de proteína VRK2. Las bandas se cuantificaron y se representó gráficamente el nivel relativo de proteína. B) Células SW-620 tratadas durante 2 días con ARN de interferencia control o específico para VRK2 se transfectaron con $1 \mu \mathrm{g}$ del reportero de luciferasa p2-274 y del plásmido pCEFL-HAVRK2A en el caso del control de la sobreexpresión de esta quinasa. 24 horas después se estimularon o no con $100 \mathrm{ng} / \mathrm{mL}$ de PMA y $0,5 \mu \mathrm{M}$ de ionomicina (lo) durante 16 horas. Posteriormente, se recogieron los extractos y se midió la actividad luciferasa. Los resultados se expresan en unidades relativas y se analizaron con el test estadístico T de Student. ${ }^{* * *} p<0,0005$.

Decidimos comprobar si la bajada de proteína VRK2 que conseguíamos en estas condiciones experimentales conllevaba una disminución en la transcripción del reportero de luciferasa del promotor de COX-2. Para ello, llevamos a cabo ensayos de luciferasa sobreexpresando la quinasa VRK2A y transfectando las células con ARN de interferencia control y específico para VRK2A. En este último caso, primero transfectamos el ARN de interferencia y, posteriormente, a las 48 horas, transfectamos de nuevo las células con el reportero de luciferasa permitiendo así que en el caso del tratamiento con ARN específico existiesen niveles más bajos de proteína VRK2 en el momento de estimular las células con PMA más Io (fig. 42B). Observamos que, como habíamos determinado anteriormente, la sobreexpresión de VRK2A conllevaba un aumento de la transcripción del reportero de luciferasa. En condiciones opuestas, es decir, cuando disminuimos los niveles de la quinasa VRK2, la transcripción del reportero de luciferasa fue menor. Incluso cuando el silenciamiento de VRK2 sólo 
llega a ser del 50\%, la transcripción del reportero de COX-2 experimenta una bajada de aproximadamente el $45 \%$.

2.3. El silenciamiento de VRK2 conlleva una disminución de los niveles de expresión de COX-2

Puesto que en los ensayos de luciferasa con el silenciamiento de VRK2 observábamos una disminución de la transcripción del promotor de ciclooxigenasa-2, decidimos estudiar qué ocurría tanto a nivel de ARN mensajero como a nivel de proteína de COX-2 y determinar si esa disminución de la transcripción se traduce en una bajada en los niveles de expresión de COX-2 cuando también disminuyen los niveles de expresión de VRK2.

\subsubsection{Niveles de ARNm de COX-2 tras el silenciamiento de VRK2}

En primer lugar estudiamos el efecto en los niveles de ARN mensajero de cicloxigenasa-2. Para ello transfectamos células MDA-MB-435 con ARN de interferencia control o especifico para VRK2 y tres días después las estimulamos con $100 \mathrm{ng} / \mathrm{mL}$ de PMA y $0,5 \mu \mathrm{M}$ de Io durante 6 horas o las dejamos sin estimular como control, para posteriormente extraer el ARN de las células y realizar una RT-PCR cuantitativa con oligonucleótidos diseñados específicamente para los ARN mensajeros de COX-2 y VRK2 y determinar así sus niveles en esas condiciones. Tras cuantificar y

A

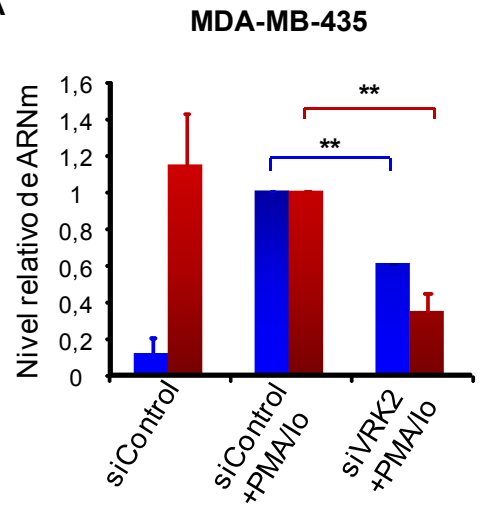

B

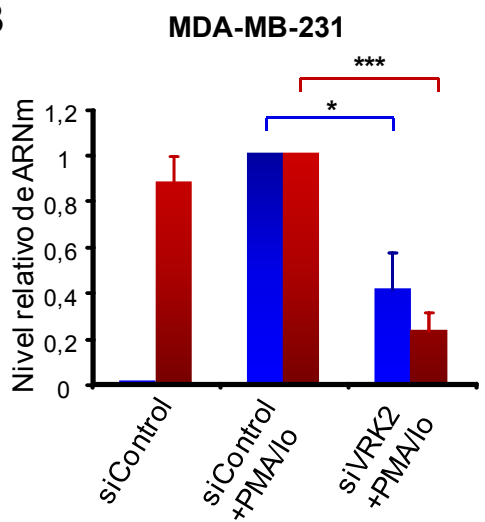

Figura 43. Niveles de ARN mensajero de COX-2 tras el silenciamiento de VRK2. Células MDAMB-435 (A) y MDA-MB-231 (B) se trataron con ARN de interferencia control o específico para VRK2, se estimularon o no con PMA más lo y se extrajo el ARN para llevar a cabo RT-PCR cuantitativa. Los resultados se normalizaron con el control GAPDH y se representaron gráficamente las medias con sus desviaciones típicas. ${ }^{*} p<0,05 ;{ }^{* *} p<0,005 ;{ }^{* *} p<0,0005$. 
normalizar los resultados (fig. 43A), observamos que en el caso del ARN de interferencia control, el tratamiento con PMA más Io induce la expresión del ARNm de COX-2 y que esta expresión disminuía cuando bajaban los niveles de ARNm de VRK2 al tratar las células con ARN de interferencia específico.

Además, quisimos comprobar si esto mismo ocurría en una línea celular de cáncer de mama invasiva, ya que se ha visto que la inducción de COX-2 por NFAT aumenta la invasión de células tumorales de cáncer de mama (Yiu and Toker, 2006). Así, llevamos a cabo el mismo experimento de RT-PCR cuantitativa en la línea celular MDA-MB-231, obteniendo resultados similares (fig. 43B): la expresión de ARNm de COX-2 se induce tras la estimulación con PMA más Io, pero la bajada de los niveles de ARNm de VRK2 en las células tratadas con el ARN de interferencia específico producen una disminución de la expresión de COX-2 a nivel transcripcional.

A la vista de los resultados obtenidos, la regulación que VRK2 lleva a cabo sobre NFAT1 se debe a una modificación postraduccional que implica la fosforilación de este factor, con la consiguiente modulación de la transcripción del gen de COX-2. Por lo tanto, VRK2 no debería afectar a la expresión de NFAT1 a nivel transcripcional. Para comprobar esto, analizamos el ARN mensajero de NFAT1 en ambas líneas celulares mediante RT-PCR cuantitativa con las muestras utilizadas para estudiar el ARN mensajero de COX-2. Como esperábamos, los niveles de transcripción de NFAT1 no variaron en ninguna de las dos líneas celulares al silenciar el gen de VRK2 con ARN de interferencia específico (fig. 44).

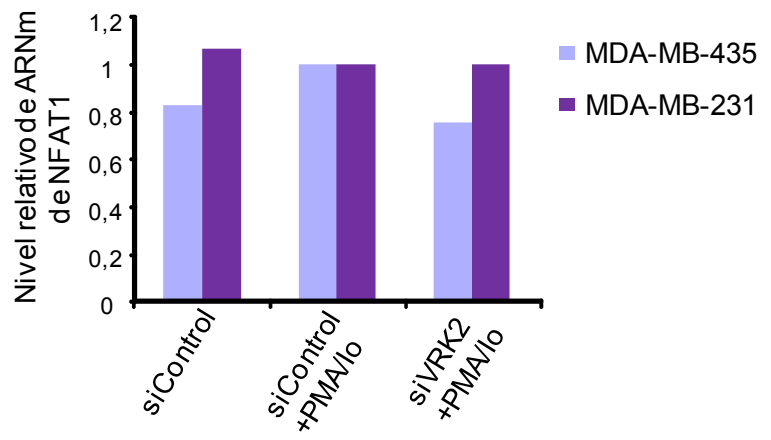

Figura 44. Niveles de ARN mensajero de NFAT tras el silenciamiento de VRK2. Se trataron células MDA-MB435 y MDA-MB-231 con los ARN de interferencia control o específico para VRK2, se estimularon o no con PMA más lo y se extrajo el ARN para llevar a cabo una RT-PCR cuantitativa. Los resultados se normalizaron con el control GAPDH. 
2.3.2. Efecto del silenciamiento de VRK2 sobre los niveles de proteína COX-2

Una vez determinado lo que ocurría a nivel de transcripción del gen de ciclooxigenasa-2, quisimos analizar si la disminución de los niveles de ARNm de COX-2 iban acompañados de una bajada de la expresión de proteína cuando se silenciaba el gen de VRK2 con ARN de interferencia específico. Para ello transfectamos células MDA-MB-231 con los ARN de interferencia control y específico para VRK2 y tres días después (momento en que analizábamos los niveles de ARN mensajero) se estimularon las células con PMA más ionomicina (Io) durante 30 minutos y se incubaron 24 horas más para dar tiempo a la expresión de proteína COX2, la cual se induce tras la estimulación. En la figura 45, observamos que la proteína COX-2 es inducible y se expresa tras la estimulación con PMA más Io. Sin embargo, esta expresión disminuyó cuando transfectamos las células con ARN de interferencia específico para VRK2, resultados acordes con lo observado en los experimentos de RT-PCR a nivel transcripcional. Además, los niveles de proteína NFAT1, al igual que sucedía con el ARN mensajero, tampoco experimentan variación al disminuir los niveles proteicos de VRK2.

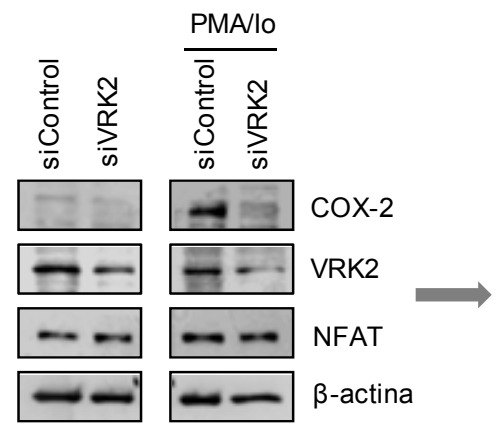

Línea celular MDA-MB-231

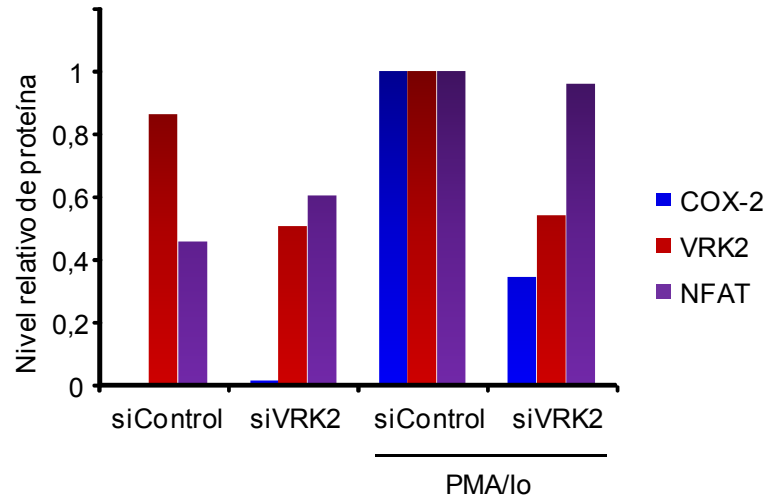

PMA/lo

Figura 45. Expresión de la proteína COX-2 tras el silenciamiento de VRK2. Células MDA-MB-231 se trataron con los ARN de interferencia control o específico para VRK2 y se estimularon o no con $100 \mathrm{ng} / \mathrm{mL}$ de PMA más $0,5 \mu \mathrm{M}$ de lo. A la izquierda se muestra el western blot de los extractos celulares con anticuerpos específicos contra las proteínas endógenas y $\beta$-actina como control de carga. A la derecha se muestra la cuantificación y normalización de la expresión de cada proteína con respecto a la proteína $\beta$ actina. Se observa una disminución de la expresión de COX-2 tras la estimulación con PMA más lo en las células con niveles reducidos de VRK2. 
2.4. El aumento de la expresión del gen de ciclooxigenasa-2 depende de los sitios de unión para NFAT presentes en el promotor de COX-2

Parecía bastante claro que VRK2A participaba en la regulación de la transcripción del gen de COX-2 mediante su efecto sobre NFAT, ya que al tratar las células con ciclosporina A, VRK2A no era capaz de llevar a cabo el aumento de la actividad del promotor de COX-2. Sin embargo, para seguir corroborando esta idea, decidimos utilizar construcciones del reportero de luciferasa del promotor de COX-2 que presentan los sitios de unión para NFAT mutados, bien sólo uno de ellos o ambos (fig. 46A). Si VRK2A participa en la regulación del promotor de COX-2 a través de su efecto sobre NFAT, no deberíamos observar efecto sobre el reportero de luciferasa en el caso en que los sitios de unión para este factor presenten mutaciones. Con esta idea, llevamos a cabo ensayos de luciferasa con dichos plásmidos reporteros tanto en células

A

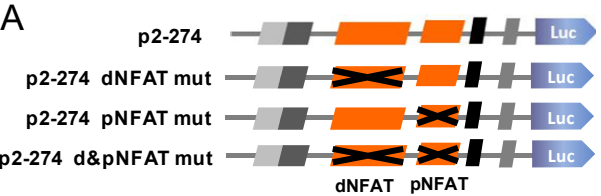

C

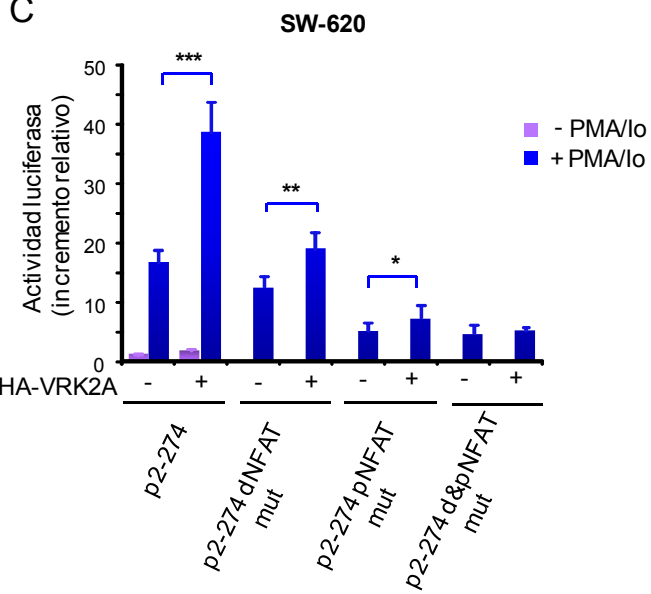

B MDA-MB-435

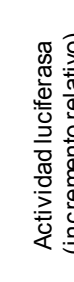

HA-VRK2A
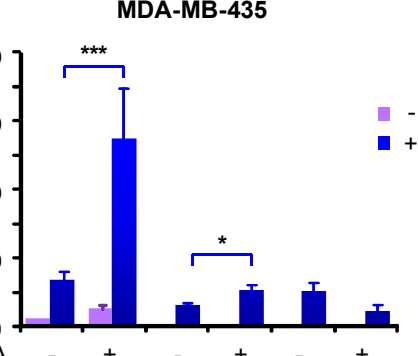

HA-VRK2A

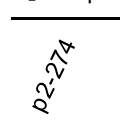

- PMA/lo

+ PMAlo

Figura 46. VRK2A aumenta la transcripción del gen de ciclooxigenasa-2 a través de NFAT. A) Esquema de la estructura de los reporteros de luciferasa con los sitios NFAT mutados. B y C) Ensayo de luciferasa de células MDA-MB-435 o SW-620 transfectadas con $1 \mu \mathrm{g}$ de los reporteros de luciferasa del promotor de COX-2, estimuladas o no con $100 \mathrm{ng} / \mathrm{mL}$ de PMA y 0,5 $\mu \mathrm{M}$ de ionomicina (lo) durante 16 horas. Posteriormente, se recogieron los extractos y se midió la actividad luciferasa. Los resultados se expresan en unidades relativas y son una media de tres experimentos independientes realizados por triplicado y se analizaron con T de Student. ${ }^{*} p<0,05 ;{ }^{* *} p<0,005 ;{ }^{* \star} p<0,0005$. 
MDA-MB-435 (fig. 46B) como en células SW-620 (fig. 46C) en presencia de VRK2A sobreexpresada, tras estimular las células con PMA más Io durante 16 horas. En ambas líneas celulares los resultados fueron similares: VRK2A no aumenta la transcripción del reportero de luciferasa al estimular las células con PMA más Io cuando este presenta los sitios para NFAT mutados. En el caso de estar mutado sólo uno de los sitios de unión de NFAT, el aumento en la transcripción sigue produciéndose aunque en menor medida, debido seguramente a que todavía queda uno de los sitios donde NFAT puede unirse. Por tanto, los resultados demuestran que el efecto de potenciación de la actividad transcripcional que lleva a cabo VRK2A sobre NFAT es el responsable de la regulación de la transcripción del gen de COX-2 que ejerce esta quinasa.

\section{Efecto del silenciamiento de VRK2 en la migración e invasión celular}

Diversos estudios han descrito el papel del factor de transcripción NFAT y ciclooxigenasa-2 en la migración e invasión celular (Yiu and Toker, 2006; Corral et al., 2007; Paquette et al., 2011). Por este motivo, decidimos analizar si el efecto de VRK2 sobre la expresión de COX-2 a través de la regulación de NFAT tenía consecuencias en la migración e invasión de las células.

\subsection{Efecto del silenciamiento de VRK2 en la invasión celular}

Para estudiar la consecuencia de la disminución de los niveles de VRK2 sobre la invasión celular llevamos a cabo ensayos de invasión en Matrigel. Utilizamos para ello la línea de cáncer de mama MDA-MB-231. Esta línea es invasiva y además se ha descrito que presenta niveles elevados de NFAT endógeno (Yiu and Toker, 2006). Transfectamos células MDA-MB-231 con los ARN de interferencia control y específico para VRK2 durante tres días, tras los cuales se estimularon durante media hora con PMA más ionomicina (Io), tratamiento que aumenta la capacidad de invasión de las células. A continuación, llevamos a cabo el ensayo de invasión como se describe en el apartado de materiales y métodos (página 162). Permitimos a las células invadir la capa de Matrigel durante 42 horas y posteriormente fijamos y teñimos las células invasivas. En cada caso realizamos fotos de diferentes campos para luego llevar a cabo el contaje del número total de células invasivas, tanto para las células tratadas con 
ARN de interferencia control como con el ARN de interferencia específico para VRK2 (fig. 47A). Tras representar gráficamente, en valores de tanto por ciento, la media del número de células de varios experimentos independientes (fig. 47B), observamos que el número de células invasivas era mayor cuando se estimulan las células con PMA más Io. Sin embargo, tras disminuir la expresión de VRK2 con ARN de interferencia específico, el número de células que invadieron la matriz de Matrigel fue significativamente menor. En el caso de las células sin estimular, no apreciamos variación en la invasión celular entre las células transfectadas con ARN de

A

Control

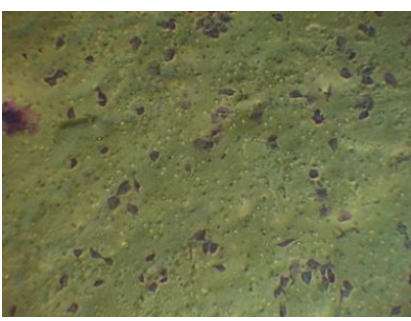

siVRK2

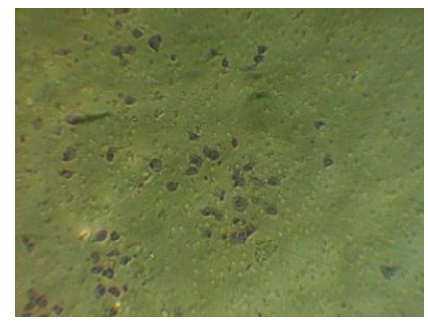

PMA/lo
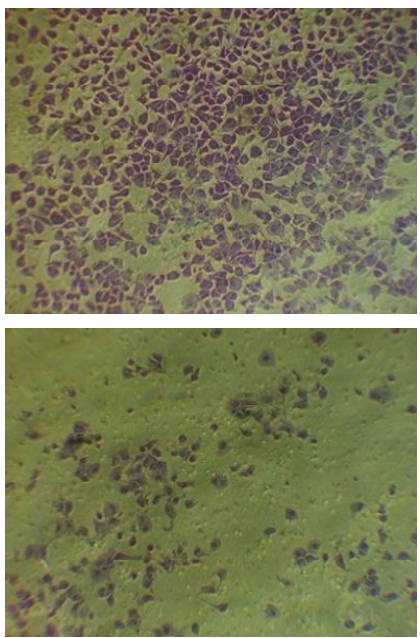

Línea celular MDA-MB-231

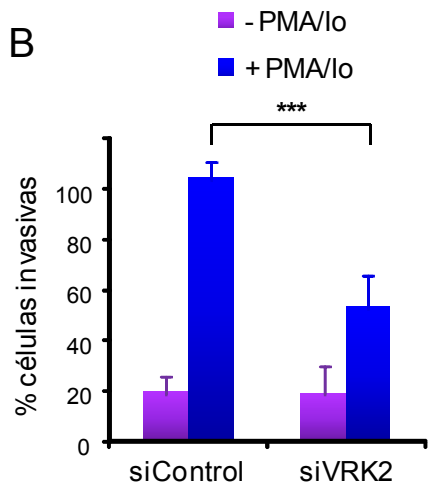

C

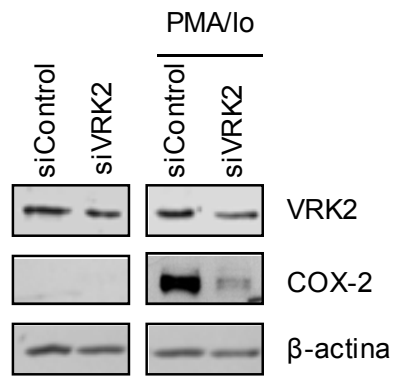

D

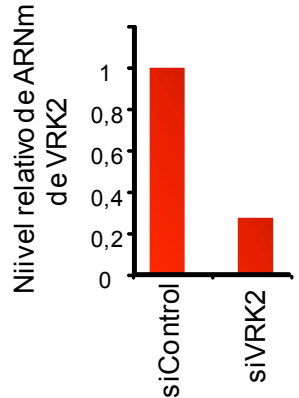

Figura 47. El silenciamiento de VRK2 reduce la invasión de las células de cáncer de mama MDAMB-231. A) Ensayo de invasión en Matrigel de células MDA-MB-231. Células tratadas tres días con ARN de interferencia control o específico para VRK2 se estimularon o no con PMA más lo durante 30 minutos. Posteriormente se llevó a cabo el ensayo de invasión durante 42 horas. B) Cuantificación del número de células invasivas y representación de la media de tres experimentos independientes con sus deviaciones típicas. ${ }^{* * *} p<0,0005$. C) Western blot de los extractos celulares. D) Niveles de ARN mensajero de VRK2. 
interferencia control o específico para VRK2. También observamos que la disminución de la invasión en el caso de las células con menores niveles de expresión de VRK2 se relacionaba con un menor nivel de expresión de la proteína COX-2 (fig. 47C). En la figura 47D se muestra la disminución del ARN mensajero de VRK2 en el momento de comenzar el ensayo de invasión. Observamos que la transcripción de VRK2 es un 80\% menor; aunque a nivel de proteína (fig. 47B) no observamos una bajada correspondiente debido a que es una proteína muy estable.

\subsection{Efecto del silenciamiento de VRK2 en la migración celular}

Para determinar si VRK2 producía algún cambio en la migración celular, llevamos a cabo ensayos de herida en la línea celular de cáncer de mama MDA-MB231 transfectada con ARN de interferencia control y ARN de interferencia específico para VRK2 (fig. 48). Incubamos células sin estimular como control y estimuladas con PMA más ionomicina, puesto que este tratamiento activa el factor de transcripción NFAT, induce la expresión de COX-2 y con ello la migración celular es mayor. Los resultados de este experimento mostraron que en el control las células migraron más rápidamente al estimularlas con PMA más Io. A las 30 horas después de haber producido la herida en la placa de cultivo, tanto en el control sin estimular como en el estimulado, las células habían ocupado todo el espacio. Por el contrario, las células en las que se disminuyeron los niveles de VRK2 con ARN de interferencia específico presentaron una migración más lenta y no llegaron a cerrar la herida a las 30 horas. Observamos además, que el retraso en la migración es mayor en el caso de las células estimuladas con PMA más Io. Cuantificamos el tamaño de la herida medido a diferentes tiempos y representamos las medias con sus desviaciones típicas por separado para el caso de las células sin estimular (fig 48A) y para las células estimuladas (fig. 48B). En las gráficas se observa que en ambos casos hay un retraso significativo en la migración celular cuando las células presentan menores niveles de VRK2, lo que sugiere que VRK2 podría participar también en la migración celular a través de su efecto sobre NFAT y la transcripción de COX-2.

A la vista de los resultados obtenidos, VRK2A es una quinasa con implicaciones en la invasión y migración de las células tumorales de cáncer de mama 
mediante la regulación de la actividad del factor de transcripción NFAT y la expresión de ciclooxigenasa- 2 .

A Línea celular MDA-MB-231

siControl

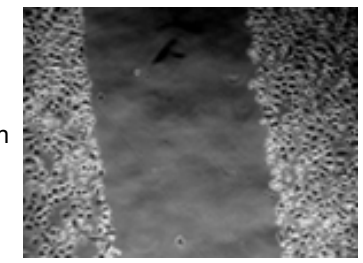

$8 \mathrm{~h}$

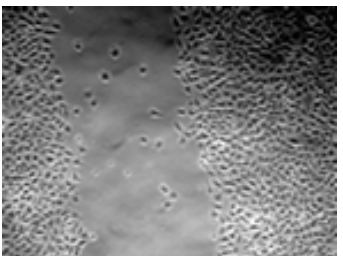

$22 \mathrm{~h}$

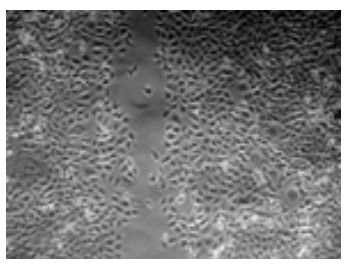

$30 \mathrm{~h}$

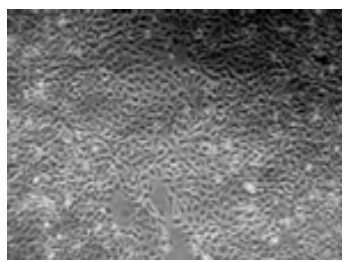

siVRK2
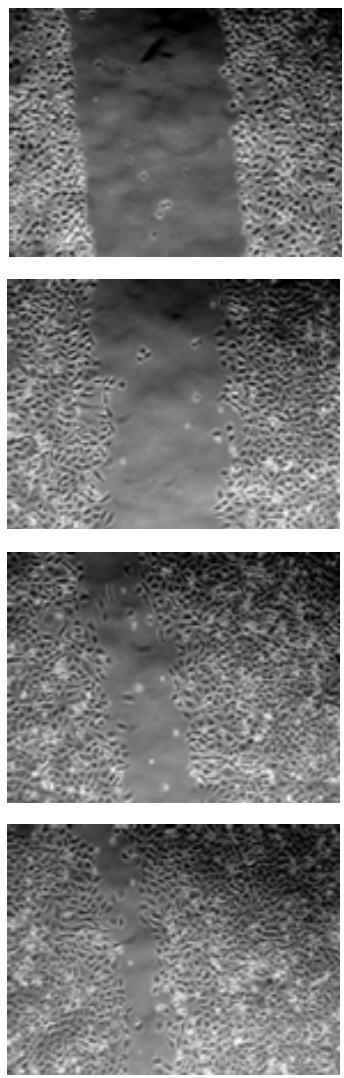

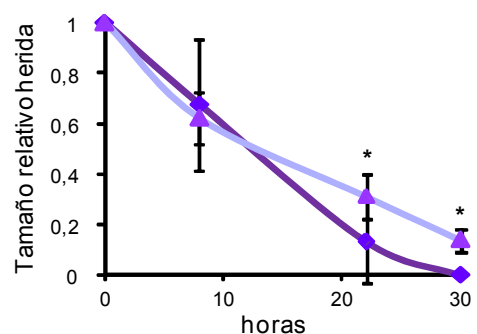

$\longrightarrow \mathrm{siC}$ siVRK2

Figura 48. La bajada de los niveles de VRK2 produce un retraso en la migración celular de la línea de cáncer de mama MDA-MB-231. A) Ensayo de herida en células MDA-MB-231. Tres días después de transfectar los ARN de interferencia se dividieron las células en placas de seis pocillos y se dejaron llegar a la confluencia. Posteriormente se realizó la herida y se tomaron fotos a diferentes tiempos. Se midió el tamaño de la herida y se representaron las medias de los resultados con sus desviaciones típicas. ${ }^{*} \mathrm{p}<0,05$. 
B

Línea celular MDA-MB-231

siControl + PMA/lo

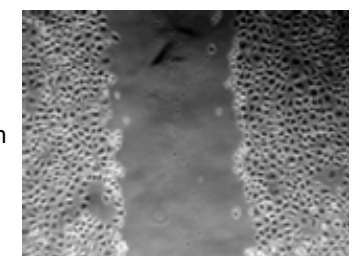

$8 \mathrm{~h}$

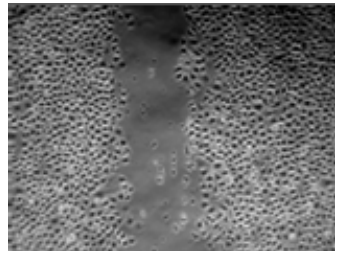

$22 \mathrm{~h}$

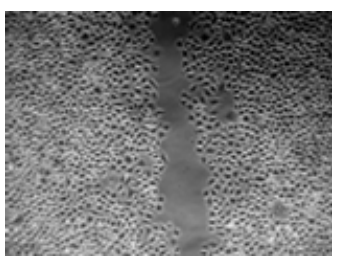

$30 \mathrm{~h}$

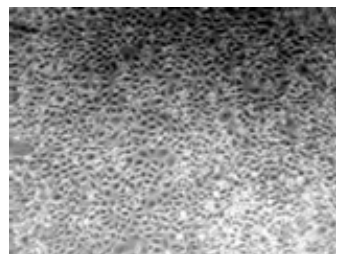

SiVRK2 + PMA/lo
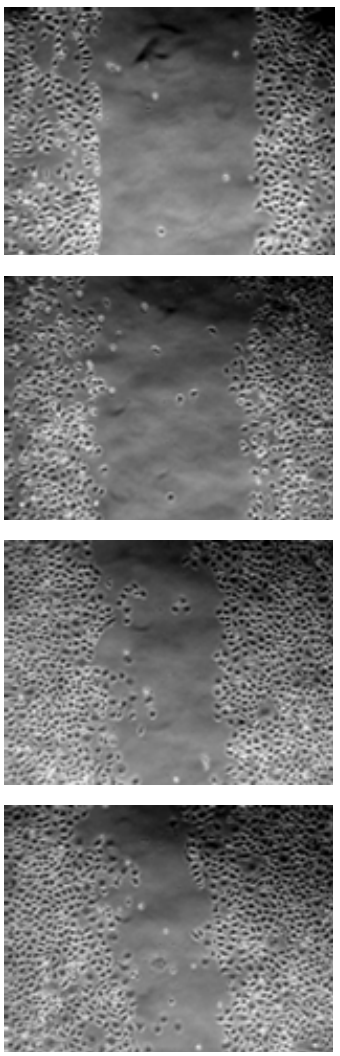

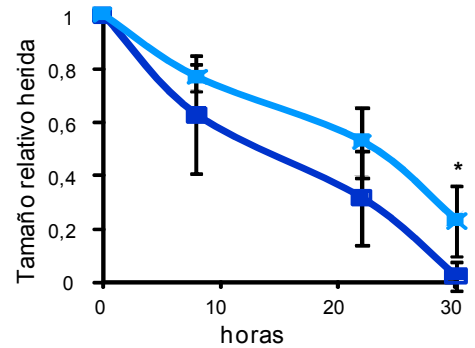

- siC+PMAllo

siVRK2+PMA/lo

Figura 48 (continuación). B) Ensayo de herida en células MDA-MB-231. Tres días después de transfectar los ARN de interferencia se dividieron las células en placas de seis pocillos y se dejaron llegar a la confluencia. Posteriormente se estimularon con PMA más lo durante 45 minutos y a continuación se realizó la herida en la placa. Se representaron gráficamente las medias de los resultados de las mediciones del tamaño de la herida con sus desviaciones típicas. ${ }^{*} p<0,05$. 

Discusión

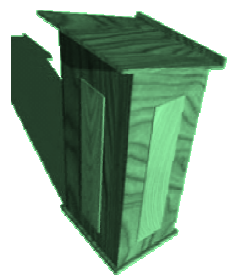





\section{Sensibilidad de VRK1 y VRK2 a inhibidores de la actividad quinasa}

En la actualidad el desarrollo de inhibidores específicos de la actividad de las proteínas quinasa está siendo un campo de estudio importante debido a que las proteínas quinasa son relevantes en todos los procesos celulares y a menudo se observa que su actividad está aumentada en cánceres humanos (Blume-Jensen and Hunter, 2001; Arena et al., 2005). Además, un inhibidor específico de una determinada proteína quinasa permite conocer con más detalle las funciones biológicas de dicha proteína en la célula (Elphick et al., 2007; Anastassiadis et al., 2011). A su vez, la rápida inactivación de la proteína diana por la adición del inhibidor deja a las células con poco tiempo para compensar la pérdida de la actividad de la quinasa, compensación que puede suceder cuando se hace un silenciamiento de la proteína quinasa con ARN de interferencia o con ratones knock-out, que son técnicas utilizadas habitualmente. Además, los inhibidores no suelen alterar el nivel de expresión de la proteína ni romper los complejos proteicos (Gregan et al., 2007).

La familia de quinasas VRK presenta una serie de particularidades en su estructura que las diferencia de la mayoría de proteínas quinasa. Las pequeñas diferencias en la secuencia de aminoácidos entre las quinasas se pueden aprovechar para desarrollar moléculas altamente selectivas (Dar and Shokat, 2011). Por ejemplo, el compuesto STI-571 inhibe a la quinasa Abl mil veces más potentemente que a Src, a pesar de ser casi idénticas en la secuencia aminoacídica (Druker et al., 1996). Por ello, y porque es importante obtener información sobre la susceptibilidad de una quinasa a la inhibición de su actividad antes de iniciar el proceso de desarrollo de un inhibidor específico, nos planteamos comenzar el estudio de la respuesta de inhibición de la actividad quinasa de los miembros catalíticamente activos de la familia VRK frente a una serie de inhibidores ya conocidos.

El desarrollo de inhibidores específicos, además de para conocer más en profundidad las funciones biológicas de las quinasas VRK1 y VRK2, resultaría interesante para su posible utilización en clínica, puesto que se ha encontrado mayor expresión de VRK1 en tejidos tumorales y células en proliferación (Santos et al., 2006), además de observarse un aumento de la actividad de VRK1 en respuesta a diferentes tipos de daño génico. 
Para nuestro estudio seleccionamos una serie de inhibidores que incluyen compuestos específicos frente a quinasas implicadas en diferentes procesos celulares, en muchos de los cuales participan las proteínas VRK. La mayoría de ellos no presentaron efecto sobre las quinasas VRK, algo que podríamos esperar, ya que estudios con inhibidores frente a un gran número de quinasas, no han detectado ningún compuesto que sea eficaz para las VRK (Karaman et al., 2008; Anastassiadis et al., 2011). Además, se describe a las quinasas VRK como proteínas de baja promiscuidad, similar a otras quinasas que presentan estructuras con sitios de unión a ATP atípicos (Fedorov et al., 2007). Por ejemplo, la quinasa Haspin posee un motivo DYT sustituyendo al motivo DFG y además presenta un dominio quinasa altamente divergente con varios insertos únicos, de modo que su inhibidor iodotubercidin es muy selectivo (Eswaran and Knapp, 2009).

Tras la aproximación con el panel de inhibidores a una concentración de 100 $\mu \mathrm{M}$, la primera conclusión es que la familia de quinasas VRK supone un grupo de proteínas que no son sensibles a la mayoría de inhibidores y además, entre VRK1 y VRK2 existe un patrón de respuesta de inhibición diferente. Por ello, continuamos el estudio realizando curvas de dosis de concentración de inhibidor con los que presentaban mayor efecto para alguna de las quinasas VRK. Los inhibidores que a la concentración inicial del panel no mostraron inhibición, o fue muy débil, no se estudiaron más en profundidad, excepto en el caso de los inhibidores de quinasas implicadas en daño al ADN. VRK1 parece ser importante en la señalización frente a daño en el ADN, por ello queríamos comprobar si de algún modo diferentes concentraciones de inhibidores de proteínas importantes en dicha ruta, como son ATM/ATR y DNA-PKs, podrían afectar a la actividad de VRK1.

Los resultados con las curvas de dosis nos sirvieron para calcular los valores de $\mathrm{IC}_{50}$, los cuales indicaron que los pocos inhibidores a los que VRK1 y VRK2 son sensibles resultan ser poco específicos. Esto es debido a que los valores de $\mathrm{IC}_{50}$ se encuentran en la mayoría de los casos en el rango micromolar, lejanos a los descritos para las quinasas específicas. Para que la inhibición de un compuesto competitivo sobre una quinasa pueda considerarse un efecto específico y además se pueda aplicar en estudios in vivo, los valores de inhibición deberían situarse en el rango nanomolar. 
Esto es debido a que in vivo la potencia de los inhibidores competitivos está determinada, además de por la afinidad del inhibidor por la quinasa, por la constante de Michaelis-Menten para la unión de ATP y la concentración de ATP celular (Knight and Shokat, 2005); y la concentración de ATP en la célula es mil veces mayor que la concentración de ATP utilizada en nuestros ensayos. Así, por ejemplo el inhibidor de $\mathrm{Cdk} 1$, que es el que valores más bajos de $\mathrm{IC}_{50}$ presenta en el caso de VRK2 y más cercanos a los valores de $\mathrm{IC}_{50}$ de la quinasa específica, debería utilizarse in vivo a una concentración que resultaría demasiado alta y que probablemente sería tóxica o con muchos efectos no deseables en la célula.

Muchos estudios sobre la especificidad de inhibidores se basan en ensayos de interacción más que de actividad quinasa. Sin embargo, aunque en términos generales interacción e inhibición están correlacionadas, a menudo los experimentos de interacción quinasa-inhibidor muestran falsos positivos y falsos negativos con respecto a su capacidad para predecir compuestos que inhiben la actividad catalítica (Anastassiadis et al., 2011). En nuestro caso, entre los compuestos seleccionados están dos inhibidores para los que se describió interacción con las proteínas VRK: el inhibidor de Cdk1 y oxindole I (Scheeff et al., 2009). Nuestros resultados mostraron que este último compuesto no afecta a la actividad de VRK1 ni de VRK2. Sin embargo, el inhibidor de Cdk1 sí actúa sobre la quinasa VRK2. Esto indica que no siempre la interacción con un compuesto inhibidor supone la inhibición de la actividad quinasa.

La mayoría de las moléculas que se están utilizando como inhibidores de quinasas actúan uniéndose en el sitio de unión del ATP. Los inhibidores competitivos de tipo I, aquellos que se unen a la quinasa en estado activo, suelen establecer puentes de hidrógeno con sus anillos heterocíclicos y los aminoácidos localizados en la región bisagra del dominio quinasa, mimetizando los puentes de hidrógeno de los anillos de la adenina del ATP. La mayor parte de los inhibidores utilizados en este trabajo con la familia de quinasas VRK son moléculas competitivas con el ATP; y la mayoría de los que han mostrado algún efecto en alguna de las quinasas son inhibidores de tipo I. Muchas quinasas se activan por fosforilación del segmento de activación, que típicamente está desordenado en el estado inactivo bloqueando el sitio de unión de 
sustrato, pero que en su estado activo fosforilado alcanza una estructura estable adecuada para la unión del sustrato (Eswaran and Knapp, 2009). En la resolución de las estructuras tridimensionales de VRK1 y VRK2 se observó a la proteína quinasa bien estructurada (Scheeff et al., 2009; Shin et al., 2011), sugiriendo que su segmento de activación se encuentra en conformación activa y que probablemente se trata de quinasas constitutivamente activas, algo que también sugiere la falta de un sitio de fosforilación conservado en el segmento de activación (Scheeff et al., 2009).

Por otro lado, los inhibidores competitivos de tipo II tienen una actividad en las células más potente, probablemente porque reconocen o inducen la conformación inactiva DFG-out, que tiene una afinidad más baja por el ATP que la conformación activa de la quinasa (Liu and Gray, 2006). Sin embargo, como las proteínas VRK se han cristalizado sólo en conformación activa, quizá en ausencia de reguladores no puedan presentarse en conformación inactiva y, en consecuencia, que inhibidores de tipo II no tengan efecto sobre ellas. Podría ocurrir que en los ensayos in vitro la molécula de quinasa, ante la falta de proteínas reguladoras o de algún estímulo que pueda inducir su cambio a un estado inactivo, únicamente esté como activa y por eso sólo inhibidores de tipo I afectarían a estas quinasas in vitro. Sin embargo, los inhibidores pueden presentar la capacidad de inducir cambio conformacional. Por ejemplo, el compuesto PIK-39 inhibe a PI3K $\gamma$ por inducción de un reordenamiento de la cadena lateral del residuo M804 para formar un nuevo bolsillo en la entrada del sitio activo de un modo similar a la conformación DFG-out (Knight et al., 2006). También, los compuestos Imatinib y Sorafenib se unen al estado DFG-out de las quinasas específicas (Liu and Gray, 2006; Zhang et al., 2009). Quizá alguno de los inhibidores utilizados en nuestro trabajo esté actuando sobre las proteínas VRK de este modo, induciendo un cambio al estado inactivo y en consecuencia, inhibiendo su actividad.

Los inhibidores competitivos pueden ser útiles para la determinación de la estructura tridimensional mediante cristalografía ayudando a estabilizar la quinasa (Anastassiadis et al., 2011). Muchas de las conformaciones atípicas identificadas en las quinasas se han descrito gracias al descubrimiento de inhibidores selectivos que estabilizan la conformación de la proteína en cristales (Knight et al., 2006). Por este motivo, tal vez un inhibidor específico podría ayudar a cristalizar VRK1 sin tener que 
mutar residuos en su secuencia, ya que la estructura conseguida se obtuvo con la proteína mutada en determinados residuos (ID: 3OP5, base de datos PDB).

La estaurosporina se describió como un posible inhibidor aunque poco eficiente de las proteínas VRK. Probablemente esta idea se debe a la débil especificidad de este compuesto, ya que se encuentra entre los inhibidores más promiscuos (Fedorov et al., 2007; Karaman et al., 2008; Davis et al., 2011). En nuestro trabajo comprobamos que esta idea es cierta en el caso de VRK1. Sin embargo, VRK2 no presentó inhibición frente a estaurosporina. Este dato resulta curioso debido a que este compuesto inhibe a una gran mayoría de quinasas. Que no afecte a VRK2 y sí a VRK1 tiene que ser debido a las pequeñas diferencias en la secuencia y estructura de ambas proteínas, que quizá hacen a VRK2 inaccesible a estaurosporina o que su unión sea muy débil y nada eficiente y por ello no puede inhibir la actividad quinasa de VRK2. Se ha descrito que la estaurosporina puede unirse a sub-bolsillos presentes en el sitio activo de la quinasa que el ATP no ocupa y de esta forma genera su gran afinidad por el sitio activo de la mayoría de quinasas, en las que se cree que existen estos sitios de unión para inhibidores (Dar and Shokat, 2011). Nuestros resultados sugieren que VRK1, pero no VRK2, podría presentar también lugares de unión de este tipo en el dominio catalítico de la proteína.

Otra idea que explicaría la diferencia de sensibilidad entre VRK1 y VRK2 frente a inhibidores competitivos se podría apoyar en la observación de que los inhibidores que funcionaron para VRK1, estaurosporina y RO 31-8220 (fig. 49A), tienen estructura de mayor tamaño y más compleja, mientras que los de VRK2, roscovitina, inhibidor de Cdk1 y AZD7762 (fig. 49B), son moléculas un poco más pequeñas. Quizá el sitio de unión de ATP en VRK1 esté más accesible porque los dos lóbulos dejan una apertura mayor que permite la interacción de moléculas más grandes que en el caso de VRK2. De hecho se describe que VRK2 presenta en su estructura dos hélices acortadas (Scheeff et al., 2009) y que VRK1 posee un lóbulo carboxilo más extendido comparado con VRK2 (Shin et al., 2011). Entre otras quinasas que también presentan un lóbulo carboxilo extendido está la quinasa Aurora B, en la cual el lóbulo carboxilo interacciona con la proteína INCENP, lo que ocasiona cambios de conformación en el lóbulo amino del dominio quinasa de modo que se impide el 
A

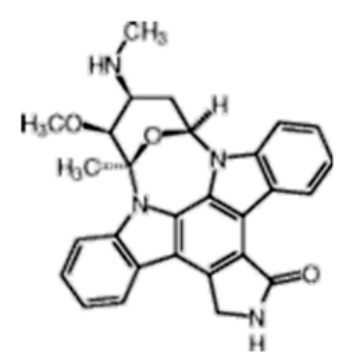

Estaurosporina $\mathrm{C}_{28} \mathrm{H}_{26} \mathrm{~N}_{4} \mathrm{O}_{3}$

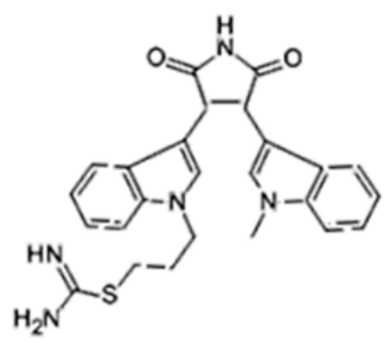

RO 31-8220

$\mathrm{C}_{25} \mathrm{H}_{23} \mathrm{~N}_{5} \mathrm{O}_{2} \mathrm{~S} \cdot \mathrm{CH}_{3} \mathrm{SO}_{3} \mathrm{H}$

B

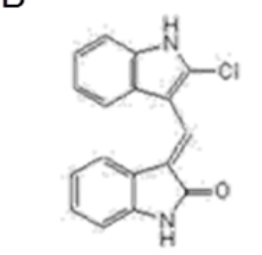

Inhibidor de Cdk1 $\mathrm{C}_{17} \mathrm{H}_{11} \mathrm{CIN}_{2} \mathrm{O}$<smiles>CC[C@H](CO)Nc1nc(NCc2ccccc2)c2ncn(C(C)C)c2n1</smiles>

Roscovitina $\mathrm{C}_{19} \mathrm{H}_{26} \mathrm{~N}_{6} \mathrm{O}$

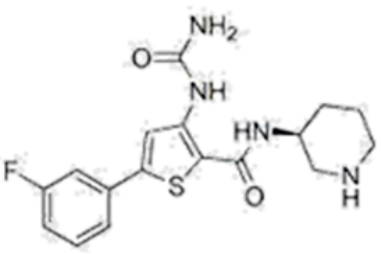

AZD7762

$\mathrm{C}_{17} \mathrm{H}_{19} \mathrm{FN}_{4} \mathrm{O}_{2} \mathrm{~S}$

Figura 49. Estructura y fórmula química de inhibidores de actividad quinasa. $A$ ) Inhibidores frente a los que VRK1 presentó mayor sensibilidad. B) Inhibidores frente a los que VRK2A fue más sensible.

emparejamiento entre residuos lisina y ácido glutámico y así se inactiva la quinasa. También en VRK1 la hélice $\alpha$ I es relativamente recta y larga comparada con VRK2 y otras quinasas, las cuales poseen un bucle en esta hélice que orienta la cola carboxilo hacia el lóbulo amino o la parte trasera de la región bisagra de la proteína (Shin et al., 2011).

Todos los resultados en conjunto indican claramente que VRK1 y VRK2, a pesar de su alto grado de similitud, presentan una sensibilidad diferente a los compuestos inhibidores, lo cual permite utilizarlos para discriminar entre ambas quinasas y sería útil para poder estudiar la función de cada uno de los miembros puesto que se podría inhibir la actividad de una de las quinasas sin afectar a la otra. Existen más ejemplos donde las pequeñas diferencias en identidad de aminoácidos entre proteínas quinasa hacen posible el desarrollo de moléculas altamente selectivas. Por ejemplo, la subfamilia de quinasas CLK (Cdc-like kinase), donde CLK1 presenta 
mayores valores de inhibición que CLK3 para varios compuestos, de forma que se pueden identificar inhibidores relativamente selectivos para CLK1 (Mott et al., 2009). También existen inhibidores selectivos para PIM1 y no para PIM2, a pesar de la similitud entre ambas isoformas (Holder et al., 2007). La selectividad de los inhibidores en estas dos familias de quinasas altamente conservadas sugiere que en el diseño de compuestos inhibidores se deberían considerar parámetros dinámicos como la flexibilidad de los dominios quinasa o la plasticidad de elementos reguladores presentes en la estructura de la quinasa (Fedorov et al., 2007). La aplicación clínica de compuestos con esta especificidad también sería de utilidad para el tratamiento de enfermedades, ya que supondría menos efectos secundarios por inhibición de otras proteínas.

En uno de los casos de nuestro estudio no se observó diferente sensibilidad a inhibidores entre VRK1 y VRK2. Frente al compuesto RO 31-8220 tanto VRK1 como VRK2 presentaron inhibición con unos valores de $\mathrm{IC}_{50}$ similares para la fosforilación del sustrato histona H3; aunque sí se diferenciaron en los valores de inhibición de la actividad de autofosforilación, siendo VRK1 más sensible. Que VRK1 sea más sensible a RO 31-8220 cabría esperarlo ya que se trata de un compuesto derivado de la estaurosporina, la cual inhibe a VRK1 pero no a VRK2. Sin embargo, el hecho de que RO 31-8220 afecte a VRK2, mientras que la estaurosporina no lo hace, sugiere que alguno de los cambios en la estructura química de RO 31-8220 hace que VRK2 se vuelva sensible. Si observamos las estructuras de RO 31-8220 y el inhibidor de Cdk1 (compuesto con el que mejor inhibición se obtuvo para VRK2) (fig. 49) se encuentra cierta similitud. La molécula de RO 31-8220 presenta un núcleo que es similar al del inhibidor de Cdk1, con cadenas laterales diferentes. Esto sugiere que para el desarrollo de inhibidores específicos de VRK2 podría tomarse como punto de partida moléculas con una estructura derivada de la del compuesto inhibidor de Cdk1.

Un método que se está empleando para desarrollar inhibidores selectivos es alterar el llamado residuo gatekeeper de las quinasas. Este residuo es un único aminoácido en el bolsillo de unión del ATP que controla la sensibilidad de las quinasas a inhibidores al situarse cercano al ATP; y se ha observado que frecuentemente forma contactos con inhibidores en estructuras cristalinas (Dar and Shokat, 2011). El residuo 
gatekeeper está conservado como un residuo de tamaño grande, como fenilalanina, metionina o treonina. Mutación de este residuo a alanina o glicina, que son aminoácidos pequeños, crea un nuevo bolsillo en la estructura de la quinasa que únicamente puede ser diana de inhibidores con los sustituyentes adecuados. La mutación aporta sensibilidad pero no interfiere con la función de la quinasa en ausencia del inhibidor. El bolsillo de ATP de las quinasas está tan conservado que el inhibidor sólo puede unirse a la quinasa mutante y no a ninguna quinasa silvestre debido a impedimentos estéricos del sustituyente y el residuo gatekeeper silvestre. Por ello se consigue inactivación específica de la quinasa mutante. El hecho de que sólo la quinasa mutante sensibilizada se inhiba permite un control de los experimentos realizados en células silvestres tratadas con el inhibidor, revelando cualquier posible efecto secundario del inhibidor (Gregan et al., 2007).

El residuo gatekeeper, en ausencia de otros datos cristalográficos que den idea de su posición en la proteína, se puede identificar por alineamiento de secuencias entre quinasas. Así, en el caso de VRK1 y VRK2 podría llevarse a cabo una aproximación de este tipo para tratar de identificar este residuo en su secuencia. El alineamiento con las quinasas C-Abl, PKA y $\mathrm{CK} 1 \delta$, cuyo residuo gatekeeper está descrito (fig. 50), sugiere que en las quinasas VRK1 y VRK2 los residuos gatekeeper podrían ser M131 y M121 respectivamente. Sería interesante estudiar si la mutación en estos residuos sensibiliza a estas quinasas frente a los inhibidores. La limitación de esta estrategia de mutación del residuo gatekeeper es que a veces podría afectar a la actividad de la proteína quinasa, es decir, que la mutación disminuya la actividad catalítica (aunque podría rescatarse introduciendo un segundo sitio mutado que la active) y que sólo es aplicable en organismos que se pueden modificar genéticamente.

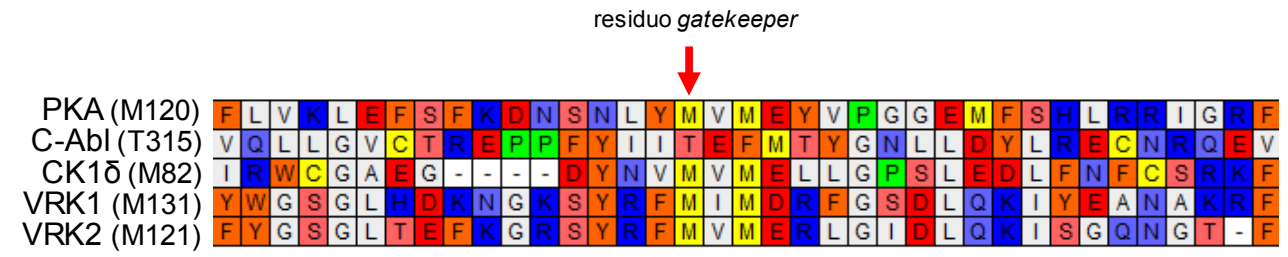

Figura 50. Alineamiento de los residuos gatekeeper de diversas quinasas. Las secuencias completas de las proteínas indicadas se alinearon con el programa DSGene 1.5. Se muestra la zona del alineamiento donde se localizan los residuos gatekeeper (flecha roja) y se indica entre paréntesis la posición del aminoácido descrita para las proteínas PKA, C-Abl y CK1ס y el candidato a residuo gatekeeper en las proteínas VRK. 
Otra estrategia para desarrollar moléculas potentes y selectivas es la utilización de inhibidores organometálicos, ya que los centros de unión para metal de las quinasas ofrecen una gran diversidad química (Eswaran and Knapp, 2009). También, las regiones fuera del dominio catalítico de las proteínas quinasa implicadas en la unión del sustrato y de la regulación de su actividad son útiles para el desarrollo de inhibidores selectivos debido a la divergencia entre las quinasas. Con inhibidores de este tipo la especificidad sería más fácil de alcanzar y su modo de actuación puede diferir respecto a la de los inhibidores competitivos y revelar nuevos aspectos de la quinasa en cuestión y su función biológica (Dar and Shokat, 2011). En este sentido, inhibidores dirigidos a la región carboxilo terminal de VRK1 podrían ser muy específicos ya que esta región de VRK1 posee una secuencia única que no se encuentra en otras quinasas. El problema es el escaso conocimiento de la estructura tridimensional de VRK1 que no permite predecir por modelaje informático moléculas potencialmente inhibidoras de VRK1. Con lo cual, la utilización de moléculas conocidas nos puede orientar sobre la estructura de posibles moléculas inhibidoras de VRK1.

Para este trabajo se seleccionaron tres inhibidores no competitivos. De ellos, sólo TDZD-8 inhibió la actividad de VRK1, efecto que es de todo o nada. TDZD-8 se describe como inhibidor selectivo para GSK3 $\beta$ ya que frente a otras quinasas como PKA, PKC, CKII y Cdk1 presenta valores de $\mathrm{IC}_{50}$ mayores de $100 \mu \mathrm{M}$. En la estructura de GSK3 $\beta$ existe un sitio de unión de oxianión, el cual confiere una carga negativa que debe ser contrarrestada para que la quinasa pueda adquirir la conformación activa. El modelo de unión de TDZD propuesto es que la carga negativa del anillo heterocíclico de la molécula TDZD reconoce el sitio de oxianión en la quinasa y además, podrían existir interacciones entre las cadenas laterales de determinados aminoácidos de la quinasa y grupos carbonil de TDZD (Martinez et al., 2002). El efecto de todo o nada sobre la actividad de VRK1 frente a TDZD-8 puede ser debido a que al alcanzar cierto umbral de concentración del inhibidor, la interacción del compuesto con la quinasa induce un cambio a una conformación inactiva. Por debajo de ese umbral, aunque el inhibidor interaccione con la quinasa, no afecta a su conformación y como tampoco existe competición con el ATP, la quinasa puede llevar a cabo su actividad de 
fosforilación al mismo nivel que sin inhibidor. Puesto que el dominio carboxilo de VRK1 forma interacciones con el dominio catalítico cruciales para la estabilidad estructural y la actividad quinasa (Shin et al., 2011), podría ocurrir que la unión de una molécula en esta región provoque un reordenamiento estructural que cambie las propiedades dinámicas de esos residuos y por ello, la actividad de VRK1. En esta región se encuentra el motivo $\mathrm{BAB}$, que se ha postulado como importante en la regulación de la quinasa. Quizá moléculas que se unan en este motivo podrían resultar selectivas para la inhibición de VRK1.

Por otro lado, las quinasas de organismos patógenos pueden ser una diana útil para el tratamiento de enfermedades infecciosas. Estas quinasas generalmente son muy diversas estructuralmente y pueden tener características únicas en el sitio activo que se pueden aprovechar para desarrollar inhibidores específicos (Manhani et al., 2005; Scherr et al., 2007). En este sentido, el estudio de la sensibilidad a inhibidores de la quinasa viral B1R, homóloga de las proteínas VRK, podría abrir nuevas posibilidades. Ya que encontramos una sensibilidad a inhibidores diferente entre VRK1 y VRK2, decidimos estudiar si la quinasa viral B1R presentaba un patrón de inhibición similar o diferente. Así, estudiamos el panel de inhibidores con B1R y los resultados indicaron que existe cierta similitud en cuanto a inhibición. Sin embargo, inhibidores que no afectaron a ninguna de las proteínas VRK sí lo hicieron sobre B1R. Las diferencias, una vez más, se deben a la secuencia de B1R, distinta de las quinasas VRK. Esto sugiere que también es posible encontrar inhibidores selectivos para la quinasa viral B1R que no afecten a las quinasas humanas VRK. 


\section{Potenciación de la actividad transcripcional de NFAT por parte de VRK2A}

La familia de serina-treonina quinasas VRK apareció de forma tardía en la evolución en la rama de las caseína quinasas, aunque se separaron de estas de forma temprana. Dentro de la familia, sólo los miembros VRK1 y VRK2 son catalíticamente activos. VRK3 evolucionó perdiendo su capacidad de actividad quinasa y sus funciones son como proteína de anclaje (Kang and Kim, 2006), al igual que sucede con otras pseudoquinasas (Boudeau et al., 2006). Las funciones descritas hasta el momento para VRK2A son independientes de su actividad y se deben a interacciones con complejos proteicos de rutas implicadas en proliferación y diferenciación celular (Blanco et al., 2007; Blanco et al., 2008; Fernandez et al., 2010). Sin embargo, el hecho de que VRK2A conserve su actividad quinasa, indica que también debe desempeñar funciones como quinasa activa en la célula, pues de lo contrario debería haber perdido su capacidad catalítica en la evolución, como es el caso de VRK3. Además, la observación de que la isoforma VRK2A se expresa en todas las líneas celulares, pero VRK2B sólo en determinadas líneas (Blanco et al., 2006), sugiere que VRK2A desempeña funciones específicas en todos los tipos celulares. Esto nos llevó a tratar de buscar una función dependiente de la actividad quinasa de VRK2A para ampliar el escaso conocimiento de esta quinasa y sus implicaciones biológicas.

Las modificaciones postraduccionales de las proteínas, como la fosforilación de factores de transcripción, suponen un mecanismo esencial para la integración rápida y reversible de las señales intracelulares. La fosforilación del dominio de transactivación de las proteínas se ha descrito como un mecanismo importante en la modulación de la actividad de los factores de transcripción favoreciendo su asociación con coactivadores (Holmberg et al., 2002), siendo la proteína NFAT un claro ejemplo.

VRK1 es el miembro más conocido de la familia VRK y fosforila a diversos factores de transcripción participando en la regulación de su actividad. Del mismo modo, alguna de las funciones de VRK2A como quinasa activa también podría ser la fosforilación de algún factor de transcripción. Puesto que el gen de VRK2 se regula positivamente en células T estimuladas con PMA más ionomicina (Boldrick et al., 2002; Diehn et al., 2002) y se describió como un gen indicador de células inmunes 
activadas (Rhodes et al., 2009), pensamos en el factor de transcripción NFAT como un posible candidato a estar regulado por VRK2A.

El factor de transcripción NFAT está estrictamente regulado por mecanismos de fosforilación. En estado basal se encuentra inactivo en el citosol en una forma hiperfosforilada y tras su desfosforilación por calcineurina puede translocarse al núcleo, donde lleva a cabo la activación de genes. Mediante técnicas proteómicas de análisis de fosfopéptidos se localizaron diferentes residuos en NFAT1 implicados en la regulación de este factor (Okamura et al., 2000; Villar et al., 2006). No se ha encontrado ninguna fosforilación en el dominio de unión a ADN de NFAT1 que sea causa del aumento de su actividad transcripcional cuando las células se estimulan con PMA más Io; aunque en el caso de NFAT3, sí se ha descrito que la fosforilación del dominio de unión al ADN mediante señalización de Erk/RSK está implicada en la activación de esta isoforma (Yang et al., 2005). Existen quinasas encargadas de fosforilar a NFAT en el dominio de regulación para mantenerlo inactivo en el citosol o para que sea exportado del núcleo y cese su actividad transcripcional (Beals et al., 1997b; Okamura et al., 2004; Gwack et al., 2006). Otras fosforilaciones contribuyen a aumentar la actividad transcripcional de NFAT (Rainio et al., 2002; Ortega-Perez et al., 2005; Gomez-Casero et al., 2007), ya sea de forma independiente de calcineurina, es decir, que en ausencia de estimulación también aumentan la actividad de NFAT, o bien de forma dependiente de la estimulación con PMA más Io. El hecho de que pueda haber potenciación independiente de calcineurina se explica mediante un modelo en el que NFAT presenta dos conformaciones: una activa, con la señal de localización nuclear expuesta, y otra inactiva. En estado basal la mayoría de moléculas de NFAT se encuentran en conformación inactiva, pero también, aunque con baja probabilidad, existen moléculas en conformación activa. La actuación de calcineurina sobre NFAT promueve el cambio a la conformación activa y aumenta la importación de NFAT al núcleo (Okamura et al., 2000). Todo esto indica que las fosforilaciones sobre NFAT según en qué región o residuos ocurran tienen diferentes efectos, ya sea inactivando y reteniendo a NFAT en el citoplasma o potenciando su actividad de transactivación.

Se ha descrito que para la activación total de una forma constitutivamente nuclear de NFAT es necesaria la estimulación con PMA más Io, lo que indica que sólo 
la localización nuclear no es suficiente para que NFAT alcance la máxima actividad transcripcional. Del mismo modo, sólo la desfosforilación de NFAT por calcineurina tampoco es suficiente para conseguir la máxima actividad transcripcional de NFAT (Okamura et al., 2000).

Nuestros resultados muestran que VRK2A y VRK2B, pero no VRK1, aumentan la actividad transcripcional de NFAT. Esto indica que se trata de una función específica de VRK2. Este efecto, además, es dependiente de la estimulación con PMA más Io. Algunas quinasas presentan un efecto diferente sobre NFAT según el tipo celular. Así, JNK promueve la acumulación citoplasmática de NFAT1 en cardiomiocitos, pero no en células HeLa (Gomez del Arco et al., 2000). Incluso la misma quinasa puede fosforilar la misma región con efectos diferentes dependiendo del miembro NFAT. Por ejemplo, JNK modula negativamente a NFAT2, pero positivamente a NFAT1, y no fosforila a NFAT3 (Ortega-Perez et al., 2005). En nuestro caso parece que el efecto de VRK2A sobre NFAT es independiente del tipo celular; o al menos tiene lugar en células $\mathrm{T}$, células de cáncer de mama y de colon. Quizá donde VRK2A tiene efecto sobre NFAT es en el caso de células que expresan la isoforma NFAT1, que ha sido la isoforma sobre la que determinamos fosforilación directa. Habría que comprobar si VRK2A es una quinasa específica de NFAT1 o también afecta a otros miembros de la familia.

Que sólo tenga lugar potenciación de la actividad transcripcional de NFAT tras la estimulación de las células con PMA más Io, y que el uso de ciclosporina A no permita esta potenciación, indica que se trata de un efecto que depende de la actuación de la fosfatasa calcineurina. Esta dependencia por calcineurina podría ser debida a un efecto indirecto de VRK2A sobre NFAT a través de la regulación de la actividad de esta fosfatasa. La actividad de calcineurina puede modularse a través de proteínas reguladoras. La proteína RCAN1 actúa inhibiendo a calcineurina, y por tanto, inhibiendo la señalización de NFAT (Fuentes et al., 2000). Existen proteínas quinasa de la ruta de MAPK que fosforilan a RCAN1, de modo que se disocia su interacción con calcineurina y así esta fosfatasa queda libre para actuar sobre sus sustratos como NFAT, activando la señalización (Abbasi et al., 2006). Pensamos en la posibilidad de que VRK2A fosforilase a RCAN1 y aumentase la actividad de NFAT al impedir la 
inhibición de RCAN1 sobre calcineurina. Los resultados nos llevaron a descartar que el mecanismo de actuación de VRK2A sobre NFAT fuese indirectamente de este modo, dado que VRK2A no pudo revertir el efecto inhibidor de RCAN1 sobre la actividad de NFAT, que sí es capaz una forma constitutivamente activa de Mek5. Además, RCAN1 no es sustrato de fosforilación directo de VRK2A in vitro.

Descartado este efecto indirecto, comprobamos que VRK2A, y la isoforma VRK2B, fosforilan directamente a NFAT1, de forma similar a otras quinasas como JNK, Cot1/Tp12 y PKCל. (Ortega-Perez et al., 2005; Gomez-Casero et al., 2007). Esta fosforilación ocurre en el dominio de transactivación amino terminal de NFAT1, antes del aminoácido 57. Los primeros 57 aminoácidos de NFAT1 contienen cuatro residuos de serina, siendo las serinas 53 y 56 las mejores candidatas como sustrato de fosforilación de serina quinasas. Se podría estudiar si la mutación de esas serinas evita la fosforilación de NFAT1 por parte de VRK2. Sin embargo, no podemos descartar que VRK2 también fosforile residuos localizados en otras regiones. De hecho, los motivos SP1 y SP2 del dominio de regulación de NFAT1, que fosforila JNK, tienen un papel importante en la actividad de transactivación de NFAT1 inducida por PMA más Io. Así, JNK potencia la actividad transcripcional de NFAT1 mediante la fosforilación cooperativa de residuos en esas regiones que contribuyen a la actividad transcripcional del dominio de transactivación (Ortega-Perez et al., 2005).

A menudo, quinasas pertenecientes a la misma familia comparten sustratos de fosforilación in vitro. Por ejemplo, tanto VRK1 como ambas isoformas de VRK2 fosforilan a p53 in vitro. Sin embargo, la diferente localización subcelular y regulación de cada quinasa hace que in vivo sólo VRK1 y la isoforma nuclear VRK2B, pero no VRK2A citosólica, participen en la regulación de p53 (Vega et al., 2004; Blanco et al., 2006). Nuestros resultados indican que VRK1 no fosforila a NFAT1 in vitro, descartando, junto con los ensayos de luciferasa, que VRK1 participe en la regulación de NFAT1 e indicando que la potenciación de la actividad de este factor de transcripción es específica de VRK2. El hecho de que ambas isoformas de VRK2 activen y fosforilen a NFAT1 sugiere que la fosforilación puede tener lugar sobre NFAT1 citoplasmático y sobre NFAT1 translocado al núcleo, donde sólo VRK2B actuaría sobre él en aquellas células que expresen esta isoforma (fig. 51). 


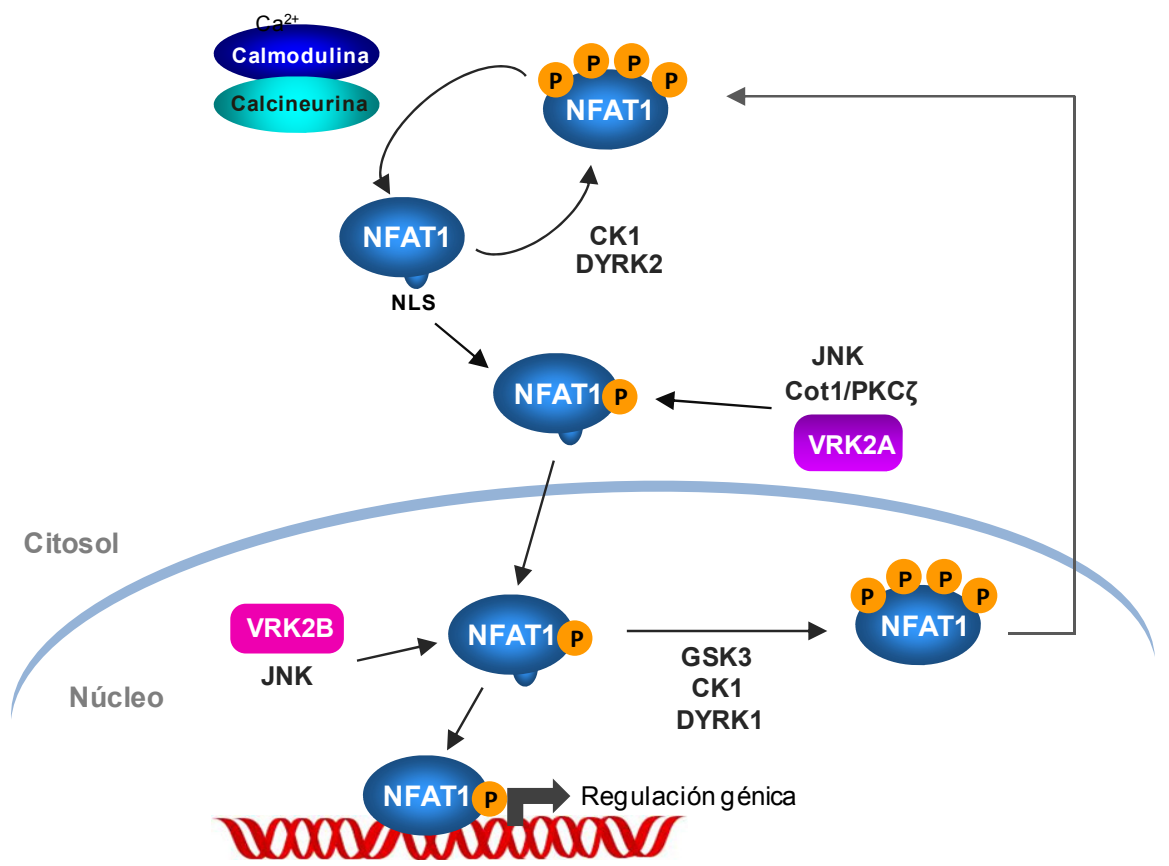

Figura 51. Regulación por fosforilación del factor de transcripción NFAT1. Se incluye el modelo de la situación de VRK2 en la regulación de NFAT1 mediante fosforilación. La desfosforilación de NFAT1 por calcineurina permite que la señal de localización nuclear (NLS) quede expuesta y que NFAT1 se transloque al núcleo. Tanto en el citoplasma como en el núcleo existen quinasas, entre las que se incluirían ambas isoformas de VRK2, que fosforilan a NFAT1 potenciando su actividad transcripcional. Otras quinasas se encargan de refosforilar a NFAT1 para su exportación del núcleo o para mantenerlo hiperfosforilado en el citosol.

La fosforilación de una proteína implica la interacción transitoria entre la quinasa y su sustrato. En consecuencia, determinamos que VRK2A y NFAT1 interaccionan. Esta interacción tiene lugar por el dominio catalítico de VRK2A (entre los aminoácidos 1-320), lo que concuerda con la interacción vista entre NFAT1 y VRK2B, ya que ambas isoformas de VRK2 presentan una secuencia idéntica hasta el aminoácido 394. Además, sería lógico pensar que la interacción ocurra por la región catalítica de VRK2, dado que NFAT1 es un sustrato de fosforilación de esta quinasa. En cuanto a NFAT1, es la región adyacente a los residuos de fosforilación dentro del dominio de transactivación, o quizá el dominio de regulación, la zona de interacción con VRK2. Cabría pensar que la región de interacción en NFAT1 fuese la región de transactivación, ya que es donde VRK2A fosforila a NFAT1. Por eso pensamos que dicha interacción ocurre por la parte final del dominio de transactivación de NFAT1, 
entre los aminoácidos 68 y 100, permitiendo que los residuos de NFAT1 que fosforila VRK2A queden situados en el bolsillo de unión del ATP del dominio catalítico de la quinasa y tenga lugar la transferencia del grupo fosfato. Calcineurina también interacciona con NFAT1 en una región del dominio de regulación cercana a los sitios que desfosforila en NFAT1 (fig. 10, página 47).

El mecanismo a través del cual la fosforilación de NFAT1 por VRK2A aumenta la actividad transcripcional de este factor podría ser debido a que la fosforilación sobre NFAT1 por parte de VRK2A alarga el tiempo de vida de la conformación activa de NFAT1, o a que promueve interacciones con proteínas coactivadoras en el núcleo. Además, ya que existen varias quinasas diferentes participando de esta potenciación de la actividad transcripcional de NFAT1, cada una podría estar encargada del reclutamiento de cofactores específicos en diferentes tipos celulares a las regiones reguladoras de distintos genes diana de NFAT1, y así dar lugar a la transcripción génica específica en cada tipo celular. También podría ser que VRK2 coopere con otras proteínas para potenciar el efecto de activación de NFAT1, como sucede en el caso de Cot1/Tpl2 y PKCל (Gomez-Casero et al., 2007) o de la quinasa PIM1, que participa en la activación de NFAT2 mediante la cooperación con la señalización de Ras (Rainio et al., 2002). 


\section{VRK2A participa en la regulación de la invasión celular a través de la expresión de COX-2}

Dado que VRK2A fosforila al factor de transcripción NFAT1 potenciando su actividad transcripcional, el siguiente paso es estudiar el efecto sobre sus genes diana. La fosforilación de NFAT es importante en la regulación de la expresión de ciclooxigenasa-2 (Robida et al., 2000; Duque et al., 2005), sugiriendo que las proteínas quinasa tienen un papel significativo en las funciones de COX-2. Nuestro trabajo muestra que la potenciación de la actividad de NFAT por parte de VRK2A conlleva a un aumento de la transcripción de COX-2; y el silenciamiento de VRK2A se traduce en una menor expresión de $\mathrm{COX}-2$, tanto a nivel transcripcional como traduccional.

En células T, el sitio pNFAT presente en el promotor de COX-2 es crucial para la regulación de la transcripción de COX-2 (Iniguez et al., 2000). En nuestro trabajo parece que también este sitio es más importante, ya que la mutación sólo del sitio pNFAT reduce en mayor medida el aumento de la expresión de COX-2 producido por VRK2A que cuando sólo está mutado el sitio dNFAT, en células de cáncer de colon.

Se podría analizar el efecto de VRK2A sobre la expresión de COX-2 en células carentes de expresión de NFAT, puesto que los resultados indican que VRK2A aumenta la actividad del promotor de COX-2 de forma dependiente de NFAT. Además, con ello se determinaría si la expresión de COX-2 inducida por VRK2A ocurre también por otras rutas de señalización independientes de NFAT.

La invasión de un tumor se define como la penetración de células tumorales en tejidos adyacentes y es uno de los marcadores de los tumores malignos. Además, los tumores invasivos tienen potencial para causar metástasis. NFAT se ha descrito como un factor necesario y suficiente para promover invasión en células de cáncer de mama y colon (Jauliac et al., 2002). En cáncer de mama la expresión de NFAT1 y su activación están poco caracterizadas pero se sabe que NFAT1 tiene un papel en la diseminación del tumor. Esto se debe a la expresión de diversos genes, siendo COX-2 un gen diana de NFAT importante en la invasión celular (Yiu and Toker, 2006; Yiu et al., 2011) y un gen que se ha asociado a metástasis de cáncer de mama a cerebro o hueso (Singh et al., 2007; Bos et al., 2009). Además, COX-2 puede facilitar la invasión tumoral mediante la respuesta inflamatoria que desencadena en el microambiente del 
tumor (Mancini and Toker, 2009; Werneck et al., 2011). Por ello, COX-2 parece ser un enzima importante como diana terapéutica para prevenir el cáncer (Flockhart et al., 2009; Kang et al., 2011) y así el silenciamiento de su expresión reduce el fenotipo maligno de células de cáncer de mama (Stasinopoulos et al., 2008).

La reducción de los niveles de COX-2 en células de cáncer de mama con niveles disminuidos de VRK2A conlleva a una menor capacidad invasiva de estas células tras la estimulación con PMA más Io. Estos resultados sugieren que VRK2A juega un papel modulando el fenotipo invasivo de células de cáncer de mama. Probablemente, también participe en la modulación de la invasión de otros tipos celulares dado que en células de cáncer de colon, la sobreexpresión de VRK2A aumenta la actividad del promotor del gen de COX-2. Este efecto ocurre a través de la modulación de la actividad de NFAT1 mediante un mecanismo postraduccional de fosforilación que no implica variaciones en los niveles de expresión de NFAT1.

Sería interesante estudiar si alguna de las funciones de COX-2 se ven afectadas por VRK2A, ya que el producto principal de COX-2, la prostaglandina $\mathrm{E}_{2}\left(\mathrm{PGE}_{2}\right)$, aumenta el potencial invasivo y metastásico de las células (Chang et al., 2004) a través de mecanismos que implican la estimulación de la proliferación celular mediante el aumento de la síntesis de estrógenos (Gadducci et al., 2005) o la activación de la señalización de $\beta$-catenina (Castellone et al., 2005). También $\mathrm{PGE}_{2}$ contribuye a la invasión celular a través del aumento de la supervivencia de las células (Kakiuchi et al., 2002), de la elevación de la expresión de la metaloproteasa MPP-2 (Ito et al., 2004), asociada a cánceres de mama invasivos (Sivula et al., 2005), o también favoreciendo angiogénesis (Tsujii et al., 1998). Además, VRK2A, a través de la activación de NFAT, podría estar induciendo la expresión de otros genes que participan en la invasión celular. Por ejemplo, NFAT induce la secreción de autotaxina en células de cáncer de mama y promueve invasión (Chen and O'Connor, 2005).

La quimioterapia es importante en el tratamiento del cáncer, pero a largo plazo puede derivar en resistencia de las células, conduciendo a recurrencia de la enfermedad y metástasis. Hay estudios que sugieren que la resistencia a apoptosis y el aumento de la supervivencia celular dan lugar a la adquisición de propiedades invasivas en las células y originan metástasis. De hecho, células de cáncer altamente metastásicas 
presentan mayor supervivencia y resistencia a apoptosis que las células poco metastásicas (Kang et al., 2011). COX-2 se ha descrito como un regulador de la resistencia a quimioterapia en cáncer (Ferrandina et al., 2002) y su expresión es indicativa de un fenotipo agresivo en cáncer de mama resistente a doxorrubicina (Park et al., 2006). También existe correlación entre expresión de COX-2 y resistencia a quimioterapia en alguna línea de cáncer de mama (Ratnasinghe et al., 2001); e inhibidores de COX-2 muestran eficacia en la quimiosensibilización de las células cancerosas (Kang et al., 2011).

Los tumores de mama ErbB2 positivos son resistentes al tratamiento con quimioterapia; y en ellos suelen detectarse niveles elevados de COX-2 (Subbaramaiah et al., 2002; Glynn et al., 2010). La inhibición de COX-2 reduce los niveles de ErbB2 y aumenta la sensibilidad al tratamiento con trastuzumab, un inhibidor de ErbB2 (Benoit et al., 2004). Por el contrario, los pacientes con cáncer de mama positivo para el receptor de estrógenos, en los cuales VRK2 presenta niveles elevados (Fernandez et al., 2010), responden bien a la terapia con hormonas (Esteva and Hortobagyi, 2004). Sin embargo, en estos tumores podría ocurrir que la llegada de señales estimuladoras a las células tumorales permita un cambio a un fenotipo potencialmente invasivo debido a la acción de VRK2A en la actividad de NFAT1 y la expresión de COX-2, y quizá de este modo estos tumores podrían volverse resistentes al tratamiento.

El silenciamiento de VRK2 conduce a un aumento de la señalización mediada por Erk1/2, implicada en rutas de proliferación celular, sin afectar a las señales de supervivencia mediadas por Akt (Fernandez et al., 2010). También, VRK2A inhibe la señal mitogénica mediada por AP-1 (Blanco et al., 2007). Sin embargo, estos efectos son mediante interacciones con complejos de proteínas independientemente de la actividad quinasa de VRK2A. Podría suceder que VRK2A actúe como proteína moduladora mediante interacciones inhibiendo proliferación, pero en cuanto a proteína quinasa activa, ante la presencia de estímulos en las células, se encargue de promover invasión celular. Esto se explicaría porque, aunque las células no se dividan, la supervivencia celular no se ve afectada, de modo que la célula se mantiene viva y la llegada de estímulos podría hacer que la célula modifique su fenotipo y expresión génica para transformarse en una célula capaz de transvasar al torrente circulatorio y 
producir invasión en otras regiones fuera del tumor. De hecho, otra de las funciones descritas de VRK2A es la interacción con una proteína viral homóloga a Bcl-2 aumentando la supervivencia celular del virus tras la infección a través de la inhibición de la apoptosis de las células infectadas ( $\mathrm{Li}$ et al., 2006). Resultaría interesante estudiar la expresión y correlación de VRK2A y COX-2 en muestras de tumores de mama, ya que COX-2 se ha descrito como marcador de mal pronostico en cáncer de mama (Denkert et al., 2004; Barisik et al., 2011) y su expresión es mayor en tumores metastásicos (Flockhart et al., 2009). Quizá VRK2 podría ayudar a identificar nuevos subgrupos de cáncer de mama en relación a COX-2 y la capacidad invasiva del tumor. Y puede que una terapia combinada de inhibidores de COX-2 y VRK2 sea una estrategia útil en el futuro para reducir la invasividad de las células tumorales en pacientes con cáncer de mama.

En resumen, este trabajo describe la primera función de VRK2A como quinasa activa, fosforilando el dominio de transactivación de NFAT1. La interacción entre NFAT1 y VRK2A es transitoria para fosforilar al factor de transcripción NFAT1 (y no estable para secuestrar complejos proteicos, como sucede en el caso de las funciones ya descritas de VRK2A en las rutas de señalización de Erk y JNK) y potenciar su actividad transcripcional tras la estimulación con PMA más ionomicina. Todo ello sirve para conocer más detalles de la red de señalización en la que está implicada VRK2A y ampliar la caracterización de esta quinasa. Una de las implicaciones biológicas de esta fosforilación de VRK2A sobre NFAT1 es participar en la modulación de la invasión de las células tumorales a través de la expresión de COX-2. Quizá VRK2 podría resultar un marcador del potencial invasivo de las células y que una terapia combinada con inhibidores de la actividad de VRK2 y COX-2 sea un tratamiento útil en algunos tipos de cánceres invasivos. 


\section{CONCLUSIONES}

1. La familia de proteínas quinasa VRK presenta baja sensibilidad a inhibidores de la actividad quinasa.

2. VRK1 y VRK2 presentan una sensibilidad diferente a los inhibidores de la actividad quinasa, lo que permitiría el diseño de moléculas selectivas para cada uno de los miembros de la familia.

3. La proteína quinasa viral B1R posee un patrón de respuesta a inhibidores de la actividad quinasa diferente al de las proteínas humanas VRK1 y VRK2.

4. La fosforilación del factor de transcripción NFAT1 por VRK2A es la primera función como quinasa activa descrita para VRK2A. Esta quinasa, $y$ la isoforma VRK2B, fosforilan y potencian la actividad transcripcional de NFAT1 tras la estimulación con PMA más ionomicina.

5. VRK2A aumenta la transcripción del promotor de ciclooxigenasa-2 tras la estimulación con PMA más ionomicina, a través de la regulación de la actividad de NFAT1.

6. El silenciamiento de VRK2A con ARN de interferencia produce una bajada de la expresión de ciclooxigenasa-2, tanto a nivel de ARN mensajero como de proteína, sin afectar a los niveles de expresión de NFAT1.

7. El silenciamiento de VRK2A con ARN de interferencia conlleva una reducción de la capacidad invasiva de células de cáncer de mama tras la estimulación con PMA más ionomicina y un retraso en la migración celular. 



\section{Materiales y métodos}





\section{TÉCNICAS DE MANIPULACIÓN DE ÁCIDOS NUCLEICOS}

\subsection{Aislamiento de ADN plasmídico de $E$. coli}

La obtención de ADN plasmídico a pequeña escala a partir de E. coli se realizó principalmente por el método de lisis alcalina (Birnboim and Doly, 1979). Para obtener mayor pureza, el ADN se purificó mediante lavados con fenol/cloroformo seguido de cloroformo y precipitación con etanol y sales a baja temperatura. El método empleado para la obtención de ADN plasmídico de alta calidad a pequeña escala fue mediante el sistema comercial High Pure Plasmid Isolation Kit (Roche). La obtención de ADN a gran escala se realizó con el sistema comercial JETSTAR 2.0 Plasmid Purification Kit (GENOMED). En ambos casos, se siguieron las especificaciones del fabricante.

La concentración del ADN purificado se determinó en un espectrofotómetro U2001 UV/Visible (HITACHI) con la medición de la absorbancia a $260 \mathrm{~nm}$ y considerando la relación de absorbancias $260 \mathrm{~nm} / 280 \mathrm{~nm}$, que debe estar comprendida entre 1,8 y 2,0 en el caso de que la preparación de ADN sea homogénea y no esté contaminada con ningún otro cromóforo. Posteriormente se confirmó la cuantificación de ADN mediante electroforesis en geles de agarosa analizando la fluorescencia emitida y comparándola con la de una muestra control de concentración conocida.

\subsection{Electroforesis de fragmentos de $\mathrm{ADN}$}

La separación de fragmentos de ADN en función de su tamaño se llevó a cabo mediante electroforesis en geles de agarosa preparados a la concentración adecuada para el tamaño de los fragmentos a separar (entre 1 y $1,5 \% \mathrm{~m} / \mathrm{v}$ de agarosa) en tampón de carrera TAE (Tris-acetato $40 \mathrm{mM}$, EDTA $1 \mathrm{mM}$ ) y a voltaje constante (entre 50-70 V). Para la visualización de la migración del ADN se utilizaron dos colorantes incluidos en el tampón de carga: el xilenocianol, que en un gel de agarosa al 0,8\% migra con los fragmentos de $5 \mathrm{~Kb}$, y el azul de bromofenol, que migra con los fragmentos de 0,5 Kb. Como marcador de tamaño se utilizó $1 \mathrm{~Kb}$ ladder (Biotools). Para la visualización de las bandas se añadió $0,5 \mu \mathrm{g} / \mathrm{mL}$ de bromuro de etidio al tampón de carrera, agente que se intercala entre las bases nitrogenadas del ADN emitiendo fluorescencia al exponerse a luz ultravioleta. Las imágenes se captaron con una cámara digital acoplada al analizador de imagen Gel Doc ${ }^{T M} 2000$ (BioRad). 


\subsection{Generación de vectores recombinantes de ADN}

Las construcciones de ADN utilizadas en este estudio están detalladas en la tabla I (página 164). Las construcciones diseñadas en el laboratorio se generaron insertando una secuencia de ADN complementario amplificada por PCR (reacción en cadena de la polimerasa) en los correspondientes vectores mediante reacciones de digestión de fragmentos con endonucleasas de restricción (Fermentas) y posterior ligación con la enzima T4 ADN-ligasa (Promega) según el protocolo estándar (Sambrook and Rusell, 2001). Posteriormente, estas construcciones se transformaron en cepas de E. coli competentes DH5 $\alpha$ o BL21DE3 y se seleccionaron las colonias transformadas mediante el cultivo con medio LB con el antibiótico al que confiere resistencia cada vector (ampicilina o kanamicina). Se confirmó la presencia de la construcción correcta mediante análisis de restricción y posterior electroforesis en gel de agarosa y mediante secuenciación, verificando la exactitud de la secuencia mediante su alineamiento con el programa DS Gene 1.5 (Accelrys Inc). Las colonias positivas se guardaron a $-80^{\circ} \mathrm{C}$ en medio de cultivo con antibiótico y glicerol al $30 \%$ (v/v) como crioprotector.

\subsection{Transformación de plásmidos en bacterias $E$. coli}

Las plásmidos de $\mathrm{ADN}$ recombinante utilizados se transformaron en las cepas de bacterias E. coli competentes DH5 $\alpha$ o BL21DE3 mediante la técnica de choque térmico. La cepa DH5a se empleó para la purificación de ADN plasmídico; y la cepa BL21DE3, para la expresión de proteínas recombinantes puesto que carece de dos proteasas, lo que permite obtener mayor cantidad de proteína recombinante intacta. Las células competentes se incubaron con el ADN plasmídico durante $15-30$ minutos a $4^{\circ} \mathrm{C}$ y se sometieron a un choque térmico 30 segundos a $42^{\circ} \mathrm{C}$. Se volvieron a enfriar a $4^{\circ} \mathrm{C}$ y se les añadió $1 \mathrm{~mL}$ de medio de cultivo LB para incubarlas $1-2 \mathrm{~h} \mathrm{a} 37^{\circ} \mathrm{C}$ en agitación, para dar tiempo a la expresión del gen de resistencia al antibiótico. Finalmente se sembraron en placas Petri con LB-agar y el antibiótico de selección correspondiente (generalmente ampicilina $50 \mu \mathrm{g} / \mathrm{mL}$ ). Las placas se incubaron toda la noche a $37^{\circ} \mathrm{C}$ hasta obtener colonias individuales en las cuales se verificó la presencia del plásmido correcto como se describe en el apartado 1.3. 


\section{PRODUCCIÓN DE ANTICUERPOS POLICLONALES FRENTE A VRK2}

El anticuerpo policlonal frente a VRK2 humana se generó inmunizando un conejo con la proteína de fusión GST-VRK2A previamente purificada a partir de cultivos de bacterias E. coli. Para cada inoculación se emplearon $500 \mu \mathrm{g}$ de proteína GST-VRK2A purificada. En la primera inmunización, la proteína se emulsionó con el Adyuvante de Freund's Completo (SIGMA) y la inyección fue subcutánea. Las siguientes dosis, hasta un total de cuatro cada 28 días, se realizaron emulsionando la proteína con el adyuvante de Freund's Incompleto (SIGMA). Antes de la primera inoculación se realizó la extracción del suero pre-inmune. Las demás extracciones se hicieron 14 días después de cada inoculación. Para comprobar el título de anticuerpo se llevaron a cabo western blots de geles preparativos con la proteína de fusión GSTVRK2A utilizando varias diluciones del suero inmune.

Posteriormente, el suero inmune se purificó y concentró mediante columna de afinidad o mediante diálisis. Para la columna de afinidad se prepararon $10 \mathrm{mg}$ de GSTVRK2A purificada por cada $\mathrm{mL}$ de resina NHS-activated sepharose 4B Fast Flow (Amersham Pharmacia Biotech). En primer lugar se concentró la proteína mediante el uso de un centricón Amicon Ultra (Millipore) y se resuspendió en el tampón COUPLING SOLUTION $\left(\mathrm{Na}_{2} \mathrm{PO}_{4} \mathrm{pH} 7,5\right)$ a una concentración de $0,5 \mathrm{M}$. La resina y la disolución con la proteína se incubaron toda la noche a $4^{\circ} \mathrm{C}$ y posteriormente se incubó con 10 volúmenes de etanolamina $100 \mathrm{mM}$ a pH 7,5 durante 4 horas a $4^{\circ} \mathrm{C}$. Para eliminar el antígeno no unido se realizaron una serie de lavados con diferentes tampones: $10 \mathrm{mM}$ de Tris $\mathrm{pH}$ 7,5, $100 \mathrm{mM}$ de Glicina $\mathrm{pH}$ 2,5, $10 \mathrm{mM}$ Tris $\mathrm{pH}$ 8,8 hasta que el $\mathrm{pH}$ de los lavados fue de $8,8,100 \mathrm{mM}$ trietanolamina $\mathrm{pH} 11,5$, y por último, $10 \mathrm{mM}$ Tris $\mathrm{pH}$ 7,5 hasta que el $\mathrm{pH}$ de los lavados fue 7,5. El suero inmune se diluyó 1:10 en $10 \mathrm{mM}$ Tris $\mathrm{pH}$ 7,5 y se pasó por la columna de afinidad con flujo lento. Posteriormente, se lavó la columna con $10 \mathrm{mM}$ Tris pH 7,5 y a continuación con 500 $\mathrm{mM} \mathrm{NaCl}+10 \mathrm{mM}$ Tris pH 7,5. Luego se eluyeron los anticuerpos en dos pasos: los unidos a cargas positivas se eluyeron con $100 \mathrm{mM}$ Glicina $\mathrm{pH} 2,5$, y los unidos a cargas negativas con $100 \mathrm{mM}$ trietanolamina $\mathrm{pH}$ 11,5. Finalmente, los anticuerpos eluidos se concentraron con un centricón Amicon Ultra (Millipore) frente a PBS con 
$0,02 \%$ de azida sódica. Una vez purificados se titularon para su uso en western blot, inmunofluoresncencia e inmunoprecipitación.

Para la purificación del anticuerpo mediante diálisis se preparó una dilución 1:5 del suero inmune en tampón de acetato de sodio $60 \mathrm{mM} \mathrm{pH} 4$ y ajustando el $\mathrm{pH} \mathrm{a}$ 4,5 con $\mathrm{NaOH}$. A continuación, para precipitar las proteínas, se añadió ácido caprílico para obtener una concentración final de $25 \mu \mathrm{L} / \mathrm{mL}$, se incubó en agitación durante 1 hora y se centrifugó a 4000 r.p.m. a $4^{\circ} \mathrm{C}$ durante 30 minutos. Posteriormente, se dializó con Dialysis tubing, high retention seamless cellulose tubing (SIGMA) frente a PBS toda la noche a $4^{\circ} \mathrm{C}$. Luego se transfirió el suero a un tubo, se ajustó el pH a 7,5 y se añadió $0,35 \mathrm{~g}$ de sulfato de amonio por cada $\mathrm{mL}$ de solución para incubar en agitación a $4^{\circ} \mathrm{C}$ durante toda la noche. Se centrifugó a 10000 r.p.m. durante 20 minutos y el precipitado se resuspendió en PBS para realizar una nueva diálisis durante 8 horas a $4^{\circ} \mathrm{C}$. Por último, se incubó el dializado a $55^{\circ} \mathrm{C}$ durante 20 minutos y luego 30 minutos a $4^{\circ} \mathrm{C}$ en agitación, para posteriormente centrifugar a 5000 r.p.m. durante 20 minutos a $4^{\circ} \mathrm{C}$. El sobrenadante conteniendo los anticuerpos se conservó con $0,02 \%$ de azida sódica y $20 \%$ de glicerol.

\section{TÉCNICAS DE MANIPULACIÓN DE PROTEÍNAS}

\subsection{Purificación de proteínas de fusión unidas a GST}

El sistema de fusión de proteínas con GST (Glutatión-S-Transferasa) permite una expresión y purificación rápida y fácil de proteínas sobreexpresadas en $E$. coli. Las proteínas de interés se clonaron previamente en un vector pGEX-GST y se transformaron en la cepa BL21DE3. Este vector presenta un promotor tac que permite inducir su expresión químicamente con lactosa o algún análogo como el isopropil $\beta$-Dtiogalactopiranósido (IPTG). Los clones de bacterias con los plásmidos correspondientes se crecieron toda la noche a $37^{\circ} \mathrm{C}$ en medio $\mathrm{LB}$ con el antibiótico de selección ampicilina $(50 \mu \mathrm{g} / \mathrm{mL})$ y al día siguiente se hizo una dilución 1:10 de ese cultivo en medio selectivo fresco y se incubó a $37^{\circ} \mathrm{C}$ hasta que el cultivo alcanzó una densidad óptica entre 0,6-0,8 a $600 \mathrm{~nm}$. En ese momento, cuando el cultivo está en fase exponencial, se indujo la expresión de la proteína de fusión añadiendo 0,2 $\mathrm{mM}$ de IPTG (Boehringer Mannheim) y se incubó $2-4$ horas a $37^{\circ} \mathrm{C}$. Pasado este tiempo, el 
cultivo se centrifugó a 8000 r.p.m. durante 10 minutos y el precipitado de bacterias se resuspendió en tampón de lisis (PBS frío con 1\% Tritón X-100, 0,2 $\mu \mathrm{g} / \mathrm{mL}$ lisozima, 1 mM PMSF, $10 \mu \mathrm{g} / \mathrm{mL}$ Leupeptina y $10 \mu \mathrm{g} / \mathrm{mL}$ Aprotinina). La suspensión se sonicó a $4^{\circ} \mathrm{C}$ con 5 pulsos de 10 segundos cada uno separados por un intervalo de 10 segundos sin sonicar en un sonicador Misonic XL2010 y tras 30 minutos a $4^{\circ} \mathrm{C}$ se centrifugó a 15000 r.p.m. durante 30 minutos a $4^{\circ} \mathrm{C}$. El sobrenadante resultante contiene las proteínas solubles, entre las que se encuentra mayoritariamente la proteína de fusión expresada. Esta fracción soluble se incubó con la resina Glutathion Sepharose 4B beads (GE Healthcare) durante toda la noche a $4^{\circ} \mathrm{C}$. Esta resina tiene alta afinidad por el GST que se encuentra fusionado a la proteína de interés. Posteriormente, se lavó la resina varias veces con PBS más inhibidores de proteasas centrifugando a 2000 r.p.m. durante 3 minutos a $4^{\circ} \mathrm{C}$. La elución de la proteína de fusión unida a la resina se llevó a cabo con una solución de $10 \mathrm{mM}$ de glutatión reducido en $50 \mathrm{mM}$ Tris- $\mathrm{HCl} \mathrm{pH} 8$ a $4^{\circ} \mathrm{C}$ durante 4-12 horas en agitación orbital. Tras una centrifugación de 3 minutos a 2000 r.p.m. se recogió el sobrenadante con la proteína eluida y se comprobó la purificación de la proteína mediante electroforesis SDS-PAGE seguida de tinción con azul de Coomassie. La concentración proteica se determinó por colorimetría mediante $B I O$ RAD protein assay (Bio-Rad), empleando BSA para la recta patrón.

\subsection{Electroforesis en geles SDS-PAGE}

La separación de proteínas en función de su tamaño se realizó mediante electroforesis vertical en geles SDS-PAGE (Sodium-Dodecylsulfate-Polyacrilamide Gel Electrophoresis). El SDS es un detergente aniónico que desnaturaliza las proteínas y se une a ellas confiriéndoles una distribución negativa uniforme debido a sus grupos sulfato, enmascarando la carga propia de las proteínas. De este modo todas las proteínas presentan una relación carga:masa uniforme y migrarán hacia el polo positivo en función de su masa molecular a través del poro del gel, el cual depende de la concentración de acrilamida utilizada. Los geles se prepararon con un porcentaje de acrilamida adecuada al tamaño de las proteínas a separar (5-15\% acrilamida/0,13-0,4\% bis-acrilamida) en un tampón 0,375 M Tris- $\mathrm{HCl}$ pH 8,8 y 3,5 mM SDS. Encima de este gel separador, se preparó un gel concentrador del 4,8\% acrilamida/0,128\% bis- 
acrilamida en tampón 0,125 M Tris- $\mathrm{HCl}$ pH 6,8 y SDS 3,5 mM. Para la solidificación de los geles se utilizó persulfato de amonio y TEMED (N,N, N', N'tetrametiletilenodiamina) como catalizador de la formación de radicales libres.

Las muestras de proteína se procesaron con tampón de carga $(62,5 \mathrm{mM}$ Tris$\mathrm{HCl} \mathrm{pH}$ 6,8, 10\% glicerol, 2,3\% SDS, 0,1\% azul de bromofenol y 5\% $\beta$ mercaptoetanol) y se hirvieron durante 5 minutos. El gel se corrió en condiciones desnaturalizantes en tampón de carrera (25 mM Tris- $\mathrm{HCl}, 200 \mathrm{mM}$ Glicina y 0,05\% SDS) según (Laemmli, 1970). Como marcadores de masa molecular se utilizaron marcadores preteñidos Precision Plus Protein ${ }^{T M}$ Standards Dual Color (Bio-Rad).

\subsection{Tinción con Azul de Coomassie}

La visualización de las proteínas separadas en geles de poliacrilamida por electroforesis SDS-PAGE se llevó a cabo mediante la fijación y tinción con azul de Coomassie. Para esta tinción se sumergió y se incubó el gel en una disolución compuesta de 0,5\% Coomassie brilliant blue R-250 (Merck), 50\% metanol y 10\% ácido acético glacial durante 5 minutos. A continuación, se hicieron una serie de lavados con solución de destinción (con la misma composición que la de tinción excepto que no lleva el colorante) hasta la correcta visualización de las bandas de las proteínas de interés. Posteriormente, los geles se transfirieron a papel Whatman $3 M$ y se secaron en un secador de geles (Bio-Rad) durante 2 horas a $80^{\circ} \mathrm{C}$.

\subsection{Transferencia húmeda, western blot y tinción rojo Ponceau}

Para la detección de las proteínas separadas por electroforesis con anticuerpos específicos se realizó la transferencia de las proteínas a una membrana de PVDF Immobilon-P (Millipore) mediante transferencia húmeda según (Towbin et al., 1979) en tampón 25 mM Tris-HCl, 192 mM Glicina y 10-20\% metanol (el porcentaje de metanol varió en función de la masa molecular de las proteínas a transferir, siendo mayor cuanto menos masa y viceversa).

Posteriormente a la transferencia, se llevó a cabo la detección con anticuerpos específicos o western blot. Para ello, la membrana se bloqueó durante 1 hora a temperatura ambiente o toda la noche a $4^{\circ} \mathrm{C}$ con $5 \%$ de leche en polvo desnatada 
preparada en el tampón TBS-T (25 mM Tris- $\mathrm{HCl} \mathrm{pH} 8,50 \mathrm{mM} \mathrm{NaCl,} \mathrm{2,5} \mathrm{mM} \mathrm{KCl} \mathrm{y}$ 0,1\% Tween-20). A continuación la membrana se incubó con el anticuerpo primario, específico para la proteína de interés, a la dilución adecuada (tabla II, página 166) durante 1-2 horas a temperatura ambiente o toda la noche a $4^{\circ} \mathrm{C}$, seguido de varios lavados con TBS-T. Luego la membrana se incubó con la dilución adecuada del anticuerpo secundario correspondiente (tabla II) conjugado con peroxidasa (HRP) durante 45 minutos-1 hora a temperatura ambiente. Tras varios lavados de la membrana, se detectó la luminiscencia con el reactivo ECL Western Blotting Detection Reagents (GE Healthcare). La luminiscencia emitida se detectó exponiendo las membranas a películas de rayos $\mathrm{X}$ (Fujifilm).

En algunos casos las proteínas transferidas a la membrana de PVDF se visualizaron con tinción con rojo Ponceau. En este caso, la membrana se incubó con la solución de tinción Ponceau compuesta de 0,2\% Ponceau S (ácido 3-Hidroxi-4[2-sulfo4-(4-sulfo-fenilazo)fenilazo]-2,7-naftalenodisulfónico), 3\% ácido sulfosalicílico, 3\% ácido trifluoroacético y $1 \%$ ácido acético durante 5 minutos, seguido de lavados con agua hasta la visualización de las bandas de interés.

\section{ALINEAMIENTO DE SECUENCIAS DE PROTEÍNAS}

El alineamiento de dos secuencias de proteínas para determinar la identidad y similitud entre ellas se realizó con el algoritmo ClustalW2 desde la web del Instituto Europeo de Bioinformática (EMBL-EBI). La identidad de secuencias se calculó como la suma del número de residuos idénticos (señalados con un asterisco, *) dividido por la longitud media de las secuencias alineadas. La similitud de secuencias se calculó como la suma del número de residuos idénticos más el número de residuos que suponen sustituciones conservadas (es decir, aminoácidos con características físicoquímica similares y que pueden ser sustituidos entre sí, representados con dos puntos, :) dividido por la longitud media de las secuencias alineadas.

El alineamiento de múltiples secuencias se realizó con el algoritmo ClustalW del programa DSGene 1.5 (Accelrys Inc.). 


\section{CULTIVO DE LÍNEAS CELULARES}

Las líneas celulares utilizadas, así como el medio de cultivo correspondiente a cada una, se indican en la tabla III (página 167). Los cultivos se crecieron en Flasks o en placas Petri en un incubador a $37^{\circ} \mathrm{C}$ con una atmósfera de $5 \% \mathrm{CO}_{2}$ y $98 \%$ humedad relativa. Los medios de cultivo fueron suplementados con $10 \%$ de suero bovino fetal (FBS), $2 \mathrm{mM}$ de glutamina y como antibióticos, 50 unidades $/ \mathrm{mL}$ de penicilina y 50 $\mu \mathrm{g} / \mathrm{mL}$ de estreptomicina. Los pases se realizaron levantando las células con TripsinaEDTA. Todos los medios y suplementos se obtuvieron de GIBCO-Life Technologies. Las células en cultivo se observaron con un microscopio invertido Zeiss Axiovert 25.

\section{TRANSFECCIÓN TRANSITORIA DE ADN EN CÉLULAS EUCARIOTAS}

Los experimentos de sobreexpresión de proteínas en células eucariotas se llevaron a cabo con la transfección transitoria de ADN de células en cultivo. En el caso de células de cultivo monocapa, 24 horas antes de la transfección se pasaron a placas Petri de modo que en el momento de la transfección llegasen a una confluencia del 60$80 \%$. El ADN utilizado para las transfecciones se obtuvo con el sistema comercial JETSTAR 2.0 Plasmid Purification Kit (GENOMED) a partir de cultivos de clones bacterianos con el plásmido de interés. Las células se transfectaron con distintos métodos según la eficiencia deseada y tipo celular a transfectar.

\subsection{Electroporación de células en cultivo en suspensión}

El volumen de cultivo conteniendo $10 \times 10^{6}$ células se centrifugó a 1200 r.p.m. durante 5 minutos para a continuación resuspender las células en $200 \mu \mathrm{L}$ de medio de cultivo sin suero. En una cubeta de electroporación Gene Pulser ${ }^{\circledR}$ Cuvette (Bio-Rad) fría se añadieron las cantidades correspondientes de ADN a transfectar y se mezcló con la suspensión de células. Para la incorporación del ADN se sometieron las células a un pulso eléctrico de $250 \mathrm{~V}$ y $950 \mu \mathrm{F}$ con un aparato Gene Pulser ${ }^{\circledR}$ II (Bio-Rad) e inmediatamente se pasaron las células a un Flask con $10 \mathrm{~mL}$ de medio de cultivo con $10 \%$ de suero. 


\subsection{Transfección de células en cultivo monocapa}

Para la sobreexpresión de proteínas en las células de cultivo monocapa se empleó el reactivo comercial JetPEI ${ }^{T M}$ DNA transfection reagent (Polyplus Transfection) siguiendo las indicaciones del fabricante. Se trata de un polímero catiónico que compacta el $\mathrm{ADN}$ en el interior de partículas cargadas positivamente que se adhieren a los proteoglicanos cargados negativamente de la superficie celular y son introducidos en la célula por endocitosis. Se diluyeron por separado el ADN y el reactivo JetPEI en un volumen determinado de $\mathrm{NaCl} 150 \mathrm{mM}$ en una proporción N/P (número de residuos de nitrógeno del reactivo por fosfato del $\mathrm{ADN})$ de $5(2 \mu \mathrm{L}$ de reactivo por $\mu \mathrm{g}$ de $\mathrm{ADN})$. A continuación se añadió la solución de JetPEI sobre la solución de ADN, se mezcló con pipeta y se incubó a temperatura ambiente durante 20-30 minutos. Pasado ese tiempo, la mezcla se añadió a las células y se homogeneizó con el medio de cultivo.

\section{SUPRESIÓN DE LA EXPRESIÓN GÉNICA MEDIANTE ARN DE INTERFERENCIA}

En los experimentos de silenciamiento del gen de VRK2 se utilizó el ARN de interferencia (siRNA) indicado en la tabla IV (pagina 167) como siVRK2-06, que fue diseñado utilizando el algoritmo SMARTselection (Dharmacon RNA Technologies). Además, se utilizó como control negativo un ARN de interferencia funcional sin diana en células humanas, ON-TARGETplus siCONTROL Non-targeting siRNA (Dharmacon). Como control de la eficiencia de la transfección se utilizó el ARN de interferencia siGLO RISC-free siRNA (Dharmacon) que emite señal de fluorescencia en rojo. Para la transfección de estos $\mathrm{ARN}$ de interferencia se empleó el reactivo Lipofectamine $^{T M} 2000$ (Invitrogen) siguiendo las instrucciones del fabricante. Se diluyó el reactivo en un volumen de medio Opti-MEM (GIBCO) sin suero y tras 10 minutos se adicionó a un volumen de Opti-MEM en el que previamente se resuspendieron los oligonucleótidos de ARN de interferencia a una concentración de 100-200 nM. Tras 20 minutos de incubación, la mezcla se añadió a las células, previamente cultivadas en medio sin antibiótico. 


\section{OBTENCIÓN DE EXTRACTOS PROTEICOS DE CÉLULAS EN CULTIVO Y DETECCIÓN DE PROTEINAS ENDÓGENAS O SOBREEXPRESADAS}

La obtención de extractos celulares totales se llevó a cabo lisando las placas de las células en cultivo en monocapa o el precipitado de células en suspensión, previamente lavadas con PBS frío, con tampón de lisis normalmente $50 \mathrm{mM}$ Tris- $\mathrm{HCl}$ pH 8, 200 mM NaCl, 1\% Tritón X-100, 10 mM NaF y 5 mM EDTA más inhibidores de proteasas ( $1 \mathrm{mM}$ PMSF, $10 \mu \mathrm{g} / \mathrm{mL}$ aprotinina, $10 \mu \mathrm{g} / \mathrm{mL}$ leupeptina) y fosfatasas (1 $\mathrm{mM}$ ortovanadato de sodio, $1 \mathrm{mM} \mathrm{NaF}$ ). Tras la incubación en hielo durante 20 minutos, los extractos se centrifugaron 20 minutos a 13200 r.p.m. a $4^{\circ} \mathrm{C}$. La fracción soluble se recuperó a un tubo nuevo y se cuantificó la concentración proteica con el reactivo BIORAD protein assay (Bio-Rad) utilizando una disolución de concentración conocida de BSA (Bio-Rad) para establecer la recta patrón. Para comprobar la expresión de las proteínas de interés, se procesaron 25-40 $\mu \mathrm{g}$ de extracto proteico como se describe en el apartado 3.2 y se resolvieron mediante electroforesis vertical en geles SDS-PAGE.

\section{ENSAYOS DE PULLDOWN}

La técnica de pulldown se utilizó para llevar a cabo la precipitación de proteínas fusionadas a GST y analizar la interacción con otras proteínas con las que estén interaccionando. En todos los casos, se partió de 1-1,5 mg de extracto proteico total recogido en un tampón de lisis $(20 \mathrm{mM}$ Tris- $\mathrm{HCl} \mathrm{pH}$ 7,4, $137 \mathrm{mM} \mathrm{NaCl}, 2 \mathrm{mM}$ EDTA, $25 \mathrm{mM} \beta$-glicerofosfato, $10 \%$ (v/v) glicerol y 1\% Tritón X-100) más inhibidores de proteasas y fosfatasas ( $1 \mathrm{mM}$ PMSF, $10 \mu \mathrm{g} / \mathrm{mL}$ aprotinina, $10 \mu \mathrm{g} / \mathrm{mL}$ leupeptina, $1 \mathrm{mM}$ ortovanadato de sodio). Cuando las proteínas fusionadas a GST se expresaron en células eucariotas, la precipitación de estas proteínas de fusión con GST presentes en el lisado celular se llevó a cabo mediante la incubación de los extractos con $20 \mu \mathrm{L}$ de resina Glutathion Sepharose 4B beads (GE Healthcare) durante toda la noche a $4^{\circ} \mathrm{C}$ en agitación orbital. Tras ese tiempo, se precipitó la resina con las proteínas unidas mediante centrifugación suave y se lavó varias veces con tampón de lisis. Tras el último lavado se resuspendió la resina al $50 \%$ con buffer de lisis y se 
procesaron las muestras con tampón de carga para ser analizadas mediante electroforesis y western blot.

En el caso de los ensayos de pulldown in vitro con proteínas fusionadas a GST purificadas de bacterias, se realizó en primer lugar, y a modo de "preclearing" (para evitar la unión inespecífica de proteínas a la resina), una incubación de los extractos celulares con $10 \mu \mathrm{g}$ de proteína GST sola unida a $20 \mu \mathrm{L}$ de resina Glutathion Sepharose $4 B$ beads (GE Healthcare) durante 2 horas a $4^{\circ} \mathrm{C}$. A continuación, cada extracto se incubó 2 horas a $4^{\circ} \mathrm{C}$ con $5 \mu \mathrm{g}$ de la proteína purificada fusionada a GST correspondiente unida a $20 \mu \mathrm{L}$ de resina Glutathion Sepharose $4 B$ beads (GE Healthcare). Posteriormente, las proteínas se precipitaron mediante centrifugación suave y la resina se lavó varias veces con tampón de lisis. Finalmente, las muestras se procesaron añadiendo tampón de carga y se analizaron mediante electroforesis SDSPAGE y se detectaron las proteínas endógenas que interaccionaron con anticuerpos específicos. La detección de las proteínas purificadas utilizadas en el ensayo se realizó mediante la tinción de la membrana con el colorante rojo Ponceau.

\section{DETERMINACIÓN DE LA ACTIVIDAD TRANSCRIPCIONAL CON GENES REPORTEROS DE LUCIFERASA}

Para determinar la actividad transcripcional de un factor de transcripción se utilizaron diferentes construcciones con elementos de respuesta sintéticos o específicos para genes que son activados por el factor de transcripción a estudiar. En cualquier caso, el promotor utilizado contiene además el gen de la luciferasa, con lo cual la unión del factor de transcripción adecuado a los sitios de unión del promotor que contiene la construcción permitirá la transactivación del gen reportero de luciferasa, con la consiguiente síntesis de la proteína luciferasa. En los experimentos se utilizaron el plásmido reportero NFATLuc, con tres sitios de unión para el factor de transcripción NFAT, y distintos reporteros p2-274 que contienen parte del promotor del gen de la ciclooxigenasa-2 donde se encuentran los sitios de unión para el factor de transcripción NFAT. Las células se recogieron en los tiempos indicados en cada experimento y se lisaron en tampón de lisis pasivo de luciferasa (PROMEGA) para a continuación medir la actividad luciferasa con el sistema Luciferase assay system (PROMEGA). El 
mecanismo de acción se basa en la adición de un reactivo que la luciferasa es capaz de oxidar produciendo señal luminosa, la cual fue cuantificada en un luminómetro Lumat LB 9507 (Berthold Technologies).

Estos experimentos se realizaron al menos 3 veces de forma independiente y cada punto por duplicado en el caso de la línea celular Jurkat y por triplicado en el resto de líneas celulares. Los resultados se analizaron con el test estadístico $\mathrm{T}$ de Student para determinar la significación del aumento o disminución de la actividad luciferasa.

\section{ENSAYOS DE ACTIVIDAD QUINASA IN VITRO}

La actividad serina/treonina quinasa se analizó mediante ensayos de fosforilación utilizando las proteínas quinasa GST-VRK y GST-B1R recombinantes expresadas en E. coli en el tampón específico para caseína quinasas $(20 \mathrm{mM}$ Tris- $\mathrm{HCl}$ pH 7,5, $5 \mathrm{mM} \mathrm{MgCl} 2,0,5 \mathrm{mM}$ DTT y $150 \mathrm{mM} \mathrm{KCl})$ con $5 \mu \mathrm{M}$ de ATP y $5 \mu \mathrm{Ci}(0,1$ $\mu \mathrm{M})$ de $\left[\gamma-{ }^{32} \mathrm{P}\right] \mathrm{ATP}$ (PerkinElmer), en un volumen final de 30-40 $\mu \mathrm{L}$. Como sustratos, por un lado se utilizaron las proteínas recombinantes que corresponden a fragmentos de NFAT1 fusionados a GST o bien la proteína NFAT1 completa, fusionada a HA, sobreexpresada e inmunoprecipitada de células HEK-293T; y por otro lado, en los experimentos con inhibidores de la actividad quinasa, el sustrato utilizado fue la histona H3 recombinante de Xenopus laevis (Upstate) y también la proteína recombinante GST-p53 correspondiente al fragmento de p53 murino que va del aminoácido 1 al 85. En estos últimos ensayos, se realizó una pre-incubación de 10 minutos con el inhibidor, la quinasa recombinante y el sustrato antes de añadir el ATP. Las reacciones de fosforilación se llevaron a cabo a $30^{\circ} \mathrm{C}$ durante 30 minutos en agitación con un Thermomixer Compact (Eppendorf). En el caso de la determinación de la actividad quinasa de la proteína VRK1 endógena se utilizó la quinasa inmunoprecipitada de células HEK-293T en las mismas condiciones que las reacciones para la quinasa recombinante.

Las reacciones de fosforilación se pararon mediante la adición de tampón de carga $(62,5 \mathrm{mM}$ Tris- $\mathrm{HCl} \mathrm{pH}$ 6,8, 10\% glicerol, 2,3\% SDS, 0,1\% azul de bromofenol y $5 \% \beta$-mercaptoetanol) e incubación durante 5 minutos a $100^{\circ}$ C. Las proteínas 
fosforiladas se analizaron por electroforesis SDS-PAGE. Los geles se tiñeron con tinción de Coomassie y se secaron; o se transfirieron a membranas de PVDF Immobilon-P (Millipore). Para la detección de la radiactividad incorporada los geles o las membranas fueron expuestos en películas de rayos $\mathrm{X}$ (Fujifilm). Las señales de fosforilación se interpretaron utilizando como referencia las bandas de proteínas del gel teñido con Coomassie, o de la membrana teñida con rojo Ponceau o incubada con anticuerpos específicos.

En el caso de los experimentos de inhibición de la actividad quinasa, se cuantificó la cantidad de fosfato incorporado y se representó gráficamente con el programa Excel 2007 (Microsoft). La representación de las rectas de regresión se realizó también con Excel 2007 y el cálculo de la recta de regresión lineal se realizó con el programa IBM SPSS Estatistics 19. Se indicó el valor del coeficiente de determinación $\left(\mathrm{R}^{2}\right)$, valor que indica cuánto se ajustan los datos a la recta de regresión. Cuanto más cercano a 1 sea este valor, más fiable es la ecuación de regresión. Con la ecuación de la recta de regresión se calcularon los valores de $\mathrm{IC}_{50}$ (concentración de inhibidor a la cual la actividad quinasa se reduce a la mitad).

\section{RT-PCR CUANTITATIVA EN TIEMPO REAL}

Las células con el tratamiento correspondiente en cada caso se lavaron con PBS frío y se extrajo el ARN total con el sistema RNeasy Mini Kit (Qiagen) siguiendo las instrucciones del fabricante. Este sistema se basa en la extracción y purificación del ARN total celular mediante el uso de columnas con membranas de silica-gel y una serie de tampones de lisis, homogeneización y lavado y centrifugaciones rápidas. Este ARN purificado se cuantificó con el sistema Bioanalyzer 2100 nano-labchip (Agilent Technologies).

Para cada reacción de RT-PCR cuantitativa se emplearon 100 ng de ARN total utilizando el sistema QuantiTect SYBR Green RT-PCR Kit (Qiagen) con los oligonucleótidos específicos para cada caso (Tabla IV, página 167) en un termociclador iCycler (Bio-Rad). Este sistema permite en un solo paso la conversión del ARN total a ADN complementario mediante la acción de la enzima transcriptasa inversa y una posterior reacción de PCR para amplificar la secuencia de interés 
flanqueada por los oligonucleótidos específicos. El termociclador calcula la fluorescencia asociada al ADN amplificado y marcado con el fluorocromo SYBR Green, de modo que cuánto más ARN haya de partida, más temprano es el ciclo en el que empieza a detectarse la señal de fluorescencia de amplificación del ADN complementario. Posteriormente, los resultados de fluorescencia se analizaron con el software del iCycler y se calcularon los niveles relativos de ARN con los datos de ciclo de amplificación y se normalizaron con respecto a los niveles de ARN de la GAPDH, utilizada como control de carga.

\section{DETERMINACIÓN DE MIGRACIÓN E INVASIÓN CELULAR}

\subsection{Ensayo de invasión en Matrigel}

La determinación de la invasión celular se llevó a cabo mediante el análisis de la cantidad de células que fueron capaces de atravesar una fina capa de matriz extracelular. Para estos experimentos las células fueron tratadas durante 3 días con los ARN de interferencia control o específico para VRK2 (tabla IV, página 167), tras los cuales las células fueron estimuladas o no durante 30 minutos con PMA más ionomicina. Posteriormente, $5 \times 10^{4}$ células fueron utilizadas para el ensayo de invasión. El resto de células se volvió a colocar en una placa Petri para realizar un western blot de los extractos celulares al final del experimento de invasión y determinar la expresión de las proteínas endógenas de interés.

Para el ensayo de invasión se preparó una fina capa de matriz extracelular con una disolución en medio de cultivo sin suero de Matrigel $^{T M}$ Basement Membrane Matrix Growth Factor Reduced (BD Biosciences) a una concentración de $1 \mathrm{mg} / \mathrm{mL}$ en la parte superior de una cubeta con un filtro especial para ensayos de invasión (Cell culture Insert $8.0 \mu \mathrm{m}$ pores, Translucent PET Membrane, de BD Biosciencies). Esta cubeta se colocó en placas de 24 pocillos y en la parte inferior se añadió medio de cultivo con $10 \%$ de suero. En la parte superior de la cubeta con la matriz de Matrigel se añadieron las células resuspendidas en $100 \mu \mathrm{L}$ de medio sin suero y se incubaron a $37^{\circ} \mathrm{C}$ durante 42 horas. Posteriormente, se eliminaron las células que no invadieron y la capa de Matrigel con la ayuda de un bastoncillo y las células que quedaron en el filtro (es decir, las células que invadieron) se fijaron con una solución de PBS 4\% 
paraformaldehido durante 15 minutos a temperatura ambiente y se tiñeron con $0,5 \%$ cristal violeta durante 30 minutos. Con una cámara Canon PowerShot A640 acoplada a un microscopio invertido Zeiss Axiovert 25 se tomaron fotos de varios campos para cada punto y se contaron las células con el programa ImageJ (Wayne Rasband, National Institutes of Health, USA) para calcular el número de células que invadieron y cuantificar de forma relativa la invasión en cada caso. Este experimento se realizó al menos tres veces de forma independiente y los resultados se representaron con las medias y sus desviaciones típicas.

\subsection{Ensayo de herida (wound healing)}

La determinación de la migración celular se llevó a cabo mediante ensayos de herida, que consisten en la realización de un surco en una placa de células confluentes y observar cómo van cubriendo de nuevo ese espacio. Para estos experimentos las células fueron tratadas con ARN de interferencia control o específico para VRK2 (tabla IV, página 167) durante 3 días, tras los cuales se levantaron con tripsina y se cuantificaron para poner una misma cantidad de células en cada punto, de modo que al día siguiente alcanzasen la confluencia. Estas células confluentes fueron tratadas o no con PMA más Io según cada caso antes de llevar a cabo la herida. Con una punta de pipeta amarilla se hizo la herida en la placa, se lavaron las células con PBS, se les añadió medio nuevo y se hicieron fotos con una cámara Canon PowerShot A640 acoplada a un microscopio invertido Zeiss Axiovert 25 a lo largo del tiempo hasta que el espacio fue ocupado de nuevo por las células.

\section{REACTIVOS Y ESTIMULACIONES}

Los reactivos utilizados fueron obtenidos de las compañías Sigma, Merck, Selleck Chemicals o TOCRIS Bioscience. Las estimulaciones con el éster de forbol PMA (forbol 12-miristato 13-acetato) y con ionomicina (Io) (SIGMA) se realizaron a la concentración y durante el tiempo indicado en cada experimento mediante su adición al medio de cultivo. El agente inhibidor de la calcineurina ciclosporina A (SIGMA), cuando fue el caso, se añadió previamente durante 1 hora a la estimulación con PMA más Io. 
Tabla I. Construcciones de ADN recombinante

\begin{tabular}{|c|c|c|c|c|c|c|c|c|c|c|c|c|c|}
\hline $\begin{array}{l}\frac{\pi}{0} \\
\frac{0}{0} \\
\frac{0}{0} \\
0 \\
0 \\
0\end{array}$ & 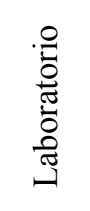 & 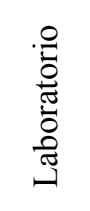 & 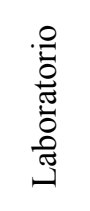 & 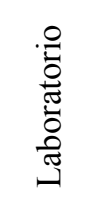 & 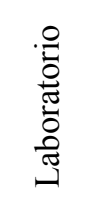 & 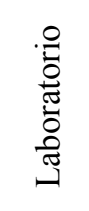 & 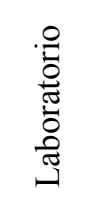 & 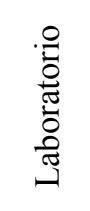 & 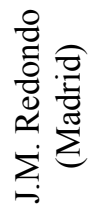 & 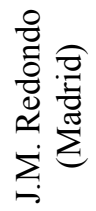 & 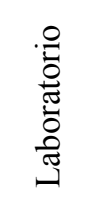 & 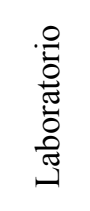 & 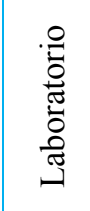 \\
\hline$\stackrel{8}{n}$ & 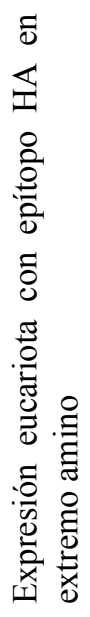 & 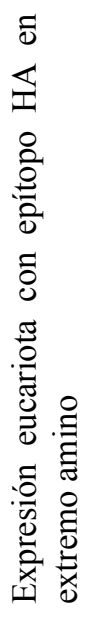 & 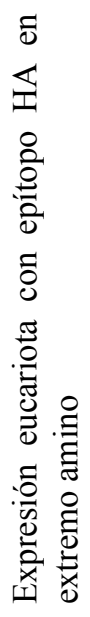 & 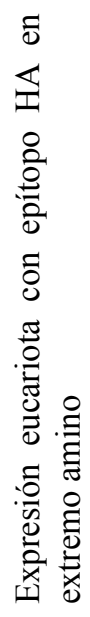 & 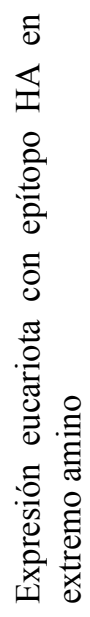 & 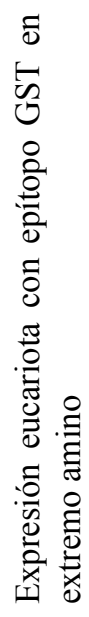 & 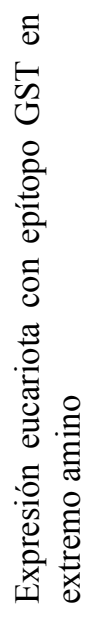 & 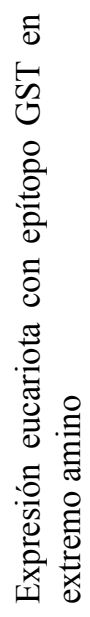 & 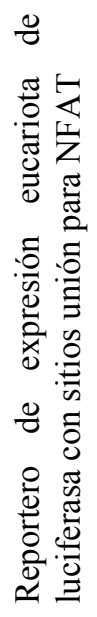 & 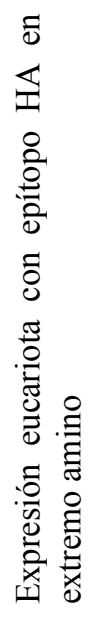 & 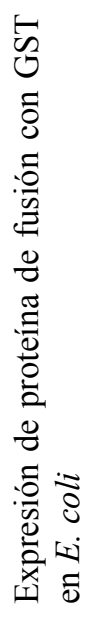 & 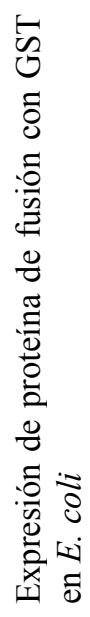 & 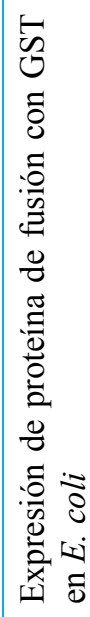 \\
\hline 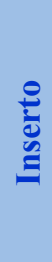 & $\frac{\overleftrightarrow{d}}{\frac{\mathbb{d}}{>}}$ & $\frac{n}{\frac{n}{d}}$ & $\frac{\vec{z}}{\frac{1}{\gamma}}$ & 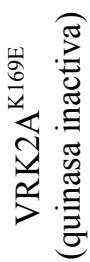 & 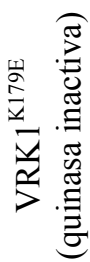 & $\frac{\overleftrightarrow{d}}{\frac{\pi}{>}}$ & $\frac{n}{\frac{n}{d}}$ & $\frac{\vec{z}}{\not{\gamma}}$ & 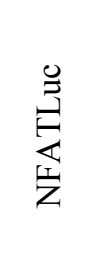 & 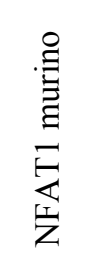 & $\frac{\overleftrightarrow{d}}{\frac{\mathbb{d}}{\not}}$ & 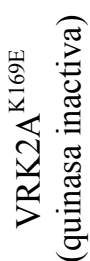 & $\begin{array}{l}\frac{n}{\vec{\nu}} \\
\frac{1}{>}\end{array}$ \\
\hline$\frac{0}{8}$ & 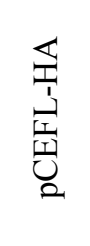 & 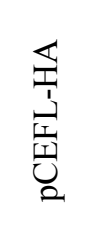 & 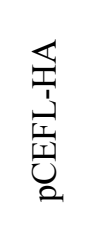 & 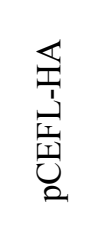 & 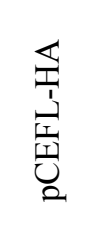 & 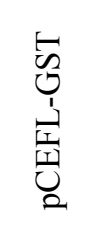 & 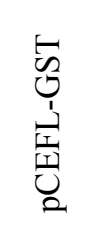 & 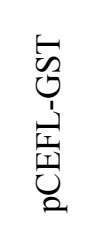 & 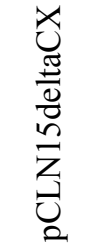 & \begin{tabular}{l}
$\mathscr{n}$ \\
0 \\
0 \\
\multicolumn{1}{|c}{} \\
In
\end{tabular} & 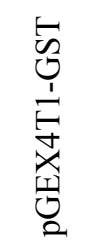 & 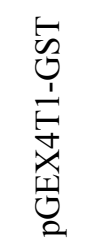 & 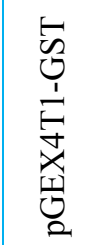 \\
\hline ن & 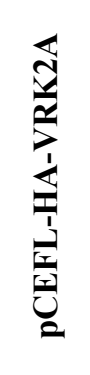 & 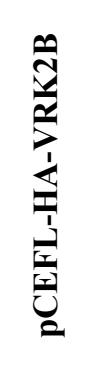 & 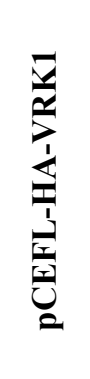 & 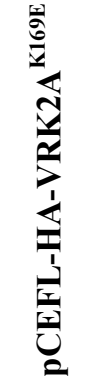 & 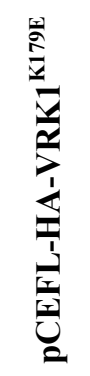 & 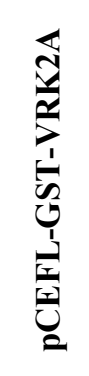 & 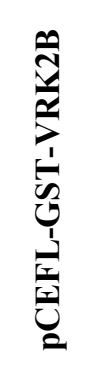 & 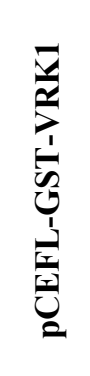 & 总 & 严 & $\begin{array}{l}\frac{\pi}{3} \\
\frac{1}{3} \\
\frac{1}{3} \\
03\end{array}$ & 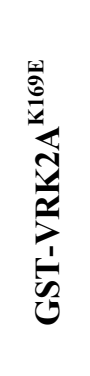 & 苟 \\
\hline
\end{tabular}


Tabla I (Continuación). Construcciones de $\mathrm{ADN}$ recombinante

\begin{tabular}{|c|c|c|c|c|c|c|c|c|c|c|c|c|}
\hline 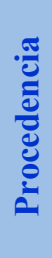 & 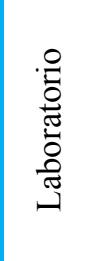 & 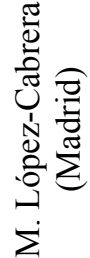 & 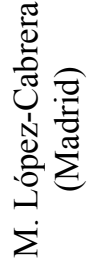 & 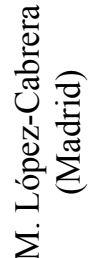 & 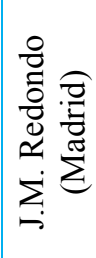 & 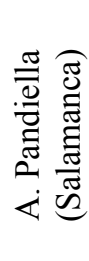 & 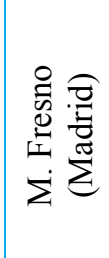 & 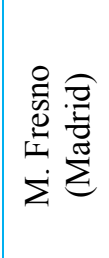 & 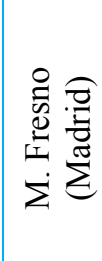 & 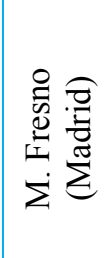 & 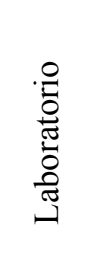 & 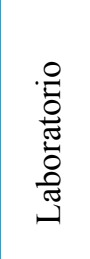 \\
\hline$\stackrel{8}{\circ}$ & 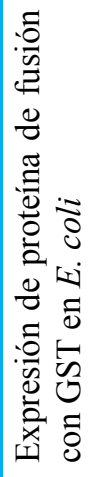 & 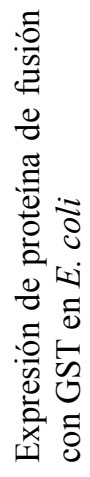 & 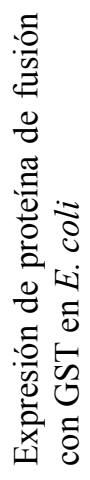 & 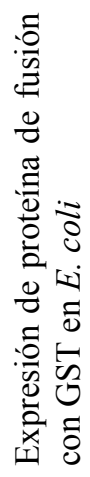 & 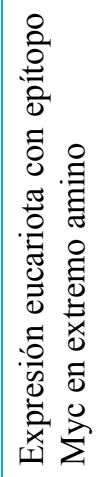 & 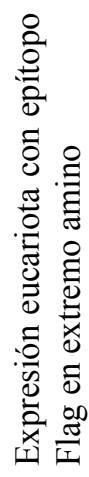 & 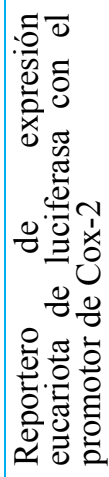 & 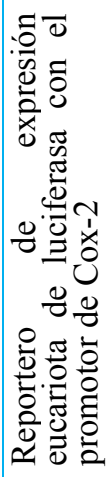 & 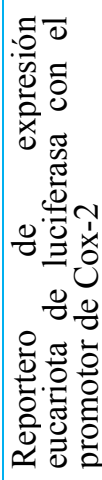 & 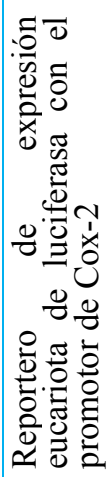 & 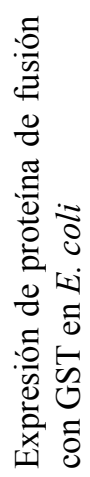 & 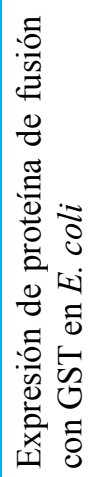 \\
\hline 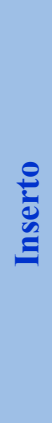 & $\frac{\vec{z}}{\frac{\alpha}{>}}$ & 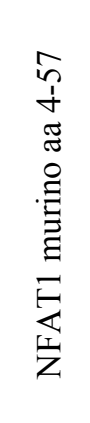 & 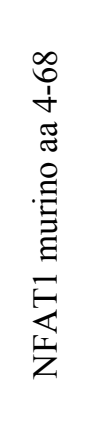 & 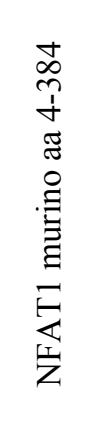 & $\underset{\approx}{Z}$ & 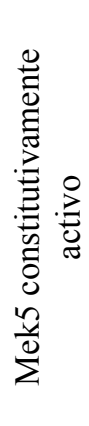 & 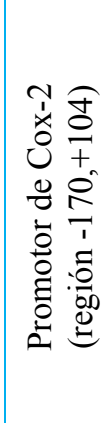 & 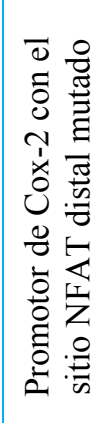 & 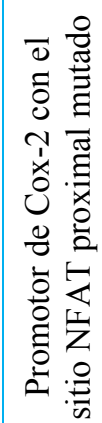 & 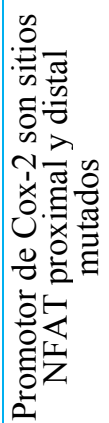 & 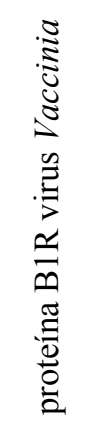 & 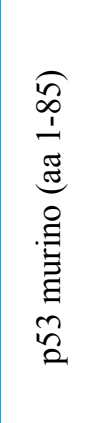 \\
\hline$\frac{0}{8}$ & 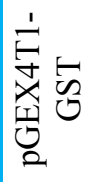 & 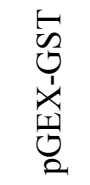 & 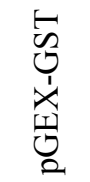 & 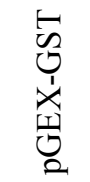 & 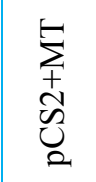 & 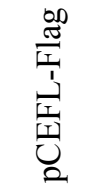 & 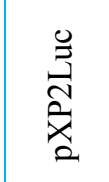 & 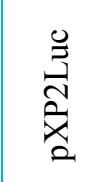 & 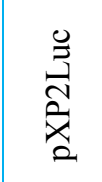 & 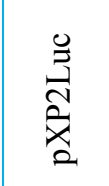 & 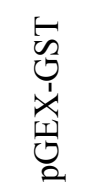 & 夏 \\
\hline 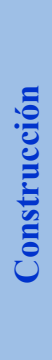 & 光 & 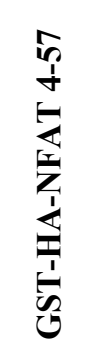 & 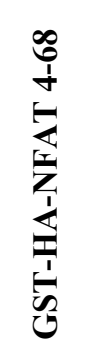 & 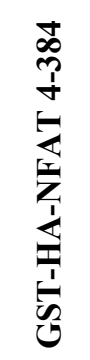 & $\begin{array}{l}\frac{Z}{0} \\
\frac{\pi}{3} \\
\frac{\pi}{3} \\
\sum\end{array}$ & 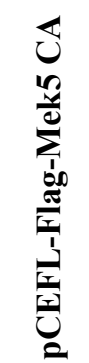 & $\begin{array}{l}\stackrel{\tilde{I}}{\Omega} \\
\text { ปn }\end{array}$ & 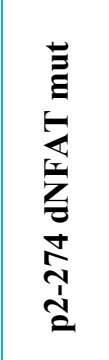 & 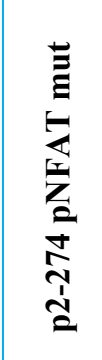 & 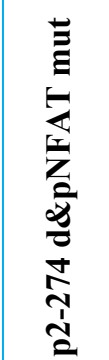 & $\frac{n}{1}$ & $\frac{n}{n}$ \\
\hline
\end{tabular}


Tabla II. Anticuerpos

\begin{tabular}{|c|c|c|c|c|}
\hline Anticuerpo & Antígeno & Especie & $\begin{array}{c}\text { Dilución de } \\
\text { uso }\end{array}$ & Casa comercial \\
\hline HA.11 & Epítopo HA & Monoclonal ratón & $\begin{array}{c}\text { WB } 1: 1000 \\
\text { IP } 1: 150\end{array}$ & Covance \\
\hline $\begin{array}{l}\beta \text {-actina } \\
\text { (AC-15) }\end{array}$ & $\beta$-actina & Monoclonal ratón & WB 1:5000 & Sigma \\
\hline $\begin{array}{c}\text { Anti-myc } \\
\text { (clon 4A6) }\end{array}$ & Epítopo myc & Monoclonal ratón & WB 1:1000 & Upstate \\
\hline Anti-myc & Epítopo myc & Policlonal conejo & IP $1: 150$ & Upstate \\
\hline Anti-Flag & Epítopo Flag & Policlonal conejo & IP $1: 300$ & Sigma \\
\hline $\begin{array}{l}\text { Anti-Flag } \\
\text { (M5) }\end{array}$ & Epítopo Flag & Monoclonal ratón & WB 1:1000 & Sigma \\
\hline Anti-VRK2 & VRK2 humana & Policlonal conejo & WB 1:1000 & Producción propia \\
\hline Anti-COX2 & $\mathrm{COX}-2$ & Monoclonal ratón & WB 1:1000 & R\&D Systems \\
\hline Anti-NFAT1 & NFAT1 & Monoclonal ratón & WB 1:5000 & BD Biosciences \\
\hline GST (B-14) & GST & Monoclonal ratón & WB 1:1000 & $\begin{array}{c}\text { Santa Cruz } \\
\text { Biotechnology }\end{array}$ \\
\hline $1 F 6$ & $\begin{array}{l}\text { VRK1 humana } \\
\text { (aa 333-396) }\end{array}$ & Monoclonal ratón & $\begin{array}{c}\text { WB 1:1000 } \\
\text { IP: } 1: 500\end{array}$ & Producción propia \\
\hline Anti-VRK1 & $\begin{array}{l}\text { VRK1 humana } \\
\text { (aa 5-142) }\end{array}$ & Policlonal conejo & WB 1:1000 & Sigma \\
\hline $\begin{array}{c}\text { Anti-mouse } \\
\text { HRP }\end{array}$ & IgG de ratón & oveja & WB 1:10000 & Amersham \\
\hline $\begin{array}{l}\text { Anti-rabbit } \\
\text { HRP }\end{array}$ & IgG de conejo & cabra & WB 1:10000 & Sigma \\
\hline
\end{tabular}


Tabla III. Líneas celulares

\begin{tabular}{|c|c|c|c|c|}
\hline Línea & Organismo & Procedencia & Características & $\begin{array}{l}\text { Medio de } \\
\text { cultivo }\end{array}$ \\
\hline Jurkat & Humano & $\begin{array}{c}\text { Leucemia } \\
\text { linfoide } \mathrm{T} \text { aguda }\end{array}$ & $\begin{array}{l}\text { Cultivo en } \\
\text { suspensión }\end{array}$ & $\begin{array}{l}\text { R.P.M.I + } \\
10 \% \text { FBS }\end{array}$ \\
\hline MDA-MB-435 & Humano & \multicolumn{2}{|c|}{$\begin{array}{l}\text { Efusión pleural de una paciente con } \\
\text { carcinoma de mama }\end{array}$} & $\begin{array}{l}\text { DMEM + } \\
10 \% \text { FBS }\end{array}$ \\
\hline MDA-MB-231 & Humano & $\begin{array}{l}\text { Carcinoma de } \\
\text { mama }\end{array}$ & Subtipo basal B & $\begin{array}{l}\text { DMEM + } \\
10 \% \text { FBS }\end{array}$ \\
\hline SW-620 & Humano & $\begin{array}{l}\text { Adenocarcinoma } \\
\text { de colon }\end{array}$ & & $\begin{array}{l}\text { R.P.M.I + } \\
10 \% \text { FBS }\end{array}$ \\
\hline HEK-293T & Humano & $\begin{array}{l}\text { Embrionarias de } \\
\text { riñón }\end{array}$ & $\begin{array}{c}\text { Contiene el } \\
\text { antígeno T grande } \\
\text { de SV40 }\end{array}$ & $\begin{array}{l}\text { DMEM + } \\
10 \% \text { FBS }\end{array}$ \\
\hline
\end{tabular}

Tabla IV. Oligonucleótidos

\begin{tabular}{ccc} 
Denominación & Secuencia $\left(\mathbf{5}^{\prime} \rightarrow \mathbf{3}^{\prime}\right)$ & Uso \\
\hline VRK2TA & AGTGAGAGAAGCGCTGAGTCCT & $\begin{array}{c}\text { Amplificación VRK2 } \\
\text { humana RT-PCR }\end{array}$ \\
\hline VRK2TB & CAAAGGTTCTTGAGACTCTTG & $\begin{array}{c}\text { Amplificación VRK2 } \\
\text { humana RT-PCR }\end{array}$ \\
\hline COX-2F & CAAAAGCTGGGAAGCCTTCTCTAA & $\begin{array}{c}\text { Amplificación COX-2 } \\
\text { humana RT-PCR }\end{array}$ \\
\hline COX-2R & GCCCAGCCCGTTGGTGAAAG & $\begin{array}{c}\text { Amplificación COX-2 } \\
\text { humana RT-PCR }\end{array}$ \\
\hline hNFAT1-F & TGCATCTAACCCCATCGAGTG & $\begin{array}{c}\text { Amplificación NFAT1 } \\
\text { humano RT-PCR }\end{array}$ \\
\hline GAPDH5 & TGAGGATCATTTGCTGGCC & $\begin{array}{c}\text { Amplificación NFAT1 } \\
\text { humano RT-PCR }\end{array}$ \\
\hline GAPDH3 & ACCTAACTACATGGTTTACATGTT & $\begin{array}{c}\text { Amplificación GAPDH } \\
\text { humana RT-PCR }\end{array}$ \\
\hline $\begin{array}{c}\text { si-VRK2-06 } \\
\text { (Dharmacon) }\end{array}$ & GCAAGGUUCUGGAUGAUAU & $\begin{array}{c}\text { ARN de interferencia para } \\
\text { VRK2 humana }\end{array}$ \\
\hline
\end{tabular}




\section{ABREVIATURAS}

aa: aminoácido

ADN: ácido desoxirribonucleico

AP1: del inglés "Activator Protein 1"

ARN: ácido ribonucleico

ATF: del inglés "Activating Transcription Factor"

ATM: del inglés "Ataxia-Telangiectasia Mutated"

ATP: adenosín trifosfato

BAF: del inglés "Barrier to Autointegration Factor"

BSA:del inglés "Bovine Serum Albumin"

Cdk: del inglés "Cyclin Dependent Kinase"

CHK1/2: del inglés "Checkpoint kinase 1/2"

CK1: del inglés "Casein Kinase 1"

COX: ciclooxigenasa

CREB: del inglés "c-AMP-Response Element Binding"

DAG: diacilglicerol

DMEM: del inglés “Dulbecco's Modified Eagles's Medium"

DMSO: dimetil sufóxido

DNA-PK: del inglés "DNA-dependent Protein Kinase"

DYRK: del inglés "Dual-specificity Tyrosine(Y)-phosphorylation-Regulated Kinase"

EDTA: del inglés "EthyleneDiamine-Tetraacetic Acid"

EGF: del inglés "Epidermal Growth Factor"

FBS: del inglés "Fetal Bovine Serum"

FGF: del inglés "Fibroblast Growth Factor"

GSK3: del inglés "Glycogen Synthase Kinase 3"

GST: Glutatión-S-Transferasa

HA: hemaglutinina

Io: ionomicina

$\mathrm{IP}_{3}$ : Inositol trifosfato

IPTG: IsoPropil- $\beta$-D-TioGalactopiranósido

JIP1: del inglés "JNK-Interaction Protein 1"

JNK: del inglés "c-Jun N-terminal Kinase"

$\mathrm{Kb}$ : kilobase

KSR1: del inglés "Kinase Supressor of Ras 1"

LB: medio "Luria Bertani"

M: molar

MAPK: del inglés "Mitogen-Activated Protein Kinase"

mL: mililitro

mM: milimolar

$\mathrm{m} / \mathrm{v}$ : relación masa/volumen

NFAT: del inglés "Nuclear Factor of Activated T cells"

NHR: del inglés "NFAT Homology Region"

nM: nanomolar

PBS: del inglés "Phosphate Buffer Salinum"

PCR: del inglés "Polymerase Chain reaction" 
$\mathrm{PGE}_{2}$ : prostaglandina $\mathrm{E}_{2}$

$\mathrm{PGH}_{2}$ : prostaglandina $\mathrm{H}_{2}$

PI3K: del inglés "Phosphatidyl Inositol 3-Kinase"

PKA: del inglés "Protein kinase A"

PKC: del inglés "Protein kinase C"

PLC: del inglés "Phospholipase C"

PLK3: del inglés "Polo-Like Kinase 3"

PMA: del inglés "Phorbol 12-Myristate 13-Acetate"

PMSF: del inglés "Phenyl Methyl Sulfonyl Fluoride"

PVDF: del inglés "PolyVinyliDene Fluoride"

RT-PCR: del inglés "Reverse Transcriptase PCR"

RAN: del inglés "Ras-related Nuclear"

RCAN: del inglés "Regulator of Calcineurin"

r.p.m.: revoluciones por minuto

RPMI: medio de cultivo, del inglés "Roswell Park Memorial Institute"

RSD: del inglés "Rel-Similarity Domain"

SDS: del inglés "Sodium Dodecyl Sulfate"

SDS-PAGE: del inglés "SDS-PolyAcrilamide Gel Electrophoresis"

SP: motivo Serina-Prolina

SRR: del inglés "Serine-Rich Region"

TAD: del inglés "Transactivation Domain"

TAE: Tris-Acetato-EDTA

TAK1: del inglés "Transforming growth factor $\beta$-Activated Kinase 1"

TBS-T: Tris Buffer Salino con Tween-20

TDZD: del inglés "Thiadiazolidinones"

$\mathrm{UV}$ : radiación ultravioleta

$\mathrm{V}$ : voltio

VEGF: del inglés "Vascular Endothelial Growth Factor"

VRK: del inglés "Vaccinia-Related Kinase"

$\mathrm{v} / \mathrm{v}$ : relación volumen/volumen

$\mu \mathrm{Ci}$ : microcurio

$\mu \mathrm{F}$ : microFaradio

$\mu \mathrm{g}$ : microgramo

$\mu \mathrm{L}:$ microlitro

$\mu \mathrm{M}$ : micromolar

$\mu \mathrm{m}$ : micrometro

${ }^{\circ} \mathrm{C}$ : grado centígrado

Bases Nitrogenadas

$\begin{array}{llll}\text { A } & \text { adenina } & \text { C } & \text { citosina } \\ \text { T } & \text { timidina } & \text { G } & \text { guanina } \\ \text { U } & \text { uracilo } & & \end{array}$




\section{Aminoácidos}

$\begin{array}{llllll}\text { A } & \text { Ala } & \text { alanina } & \text { C } & \text { Cys } & \text { cisteína } \\ \text { D } & \text { Asp } & \text { ácido aspártico } & \text { E } & \text { Glu } & \text { ácido glutámico } \\ \text { F } & \text { Phe } & \text { fenilalanina } & \text { G } & \text { Gly } & \text { glicina } \\ \text { H } & \text { His } & \text { histidina } & \text { I } & \text { Ile } & \text { isoleucina } \\ \text { K } & \text { Lys } & \text { lisina } & \text { L } & \text { Leu } & \text { leucina } \\ \text { M } & \text { Met } & \text { metionina } & \text { N } & \text { Asn } & \text { asparagina } \\ \text { P } & \text { Pro } & \text { prolina } & \text { Q } & \text { Gln } & \text { glutamina } \\ \text { R } & \text { Arg } & \text { arginina } & \text { S } & \text { Ser } & \text { serina } \\ \text { T } & \text { Thr } & \text { treonina } & \text { V } & \text { Val } & \text { valina } \\ \text { W } & \text { Trp } & \text { triptófano } & \text { Y } & \text { Tyr } & \text { tirosina }\end{array}$




\section{Bibliografía}

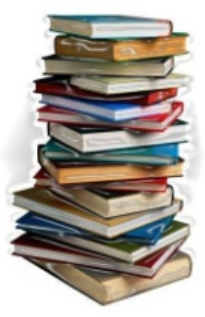



Abbasi, S., J. D. Lee, et al. (2006). "Protein kinase-mediated regulation of calcineurin through the phosphorylation of modulatory calcineurin-interacting protein 1." J Biol Chem 281: 7717-26.

Abbasi, S., B. Su, et al. (2005). "The essential role of MEKK3 signaling in angiotensin II-

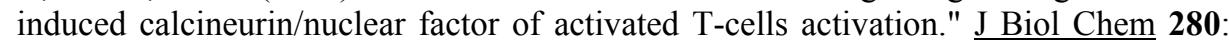
36737-46.

Aguilar-Morante, D., J. A. Morales-Garcia, et al. (2010). "Inhibition of glioblastoma growth by the thiadiazolidinone compound TDZD-8." PLoS One 5: e13879.

Aihara, H., T. Nakagawa, et al. (2004). "Nucleosomal histone kinase-1 phosphorylates H2A Thr 119 during mitosis in the early Drosophila embryo." Genes Dev 18: 877-88.

Al-Daraji, W. I., K. R. Grant, et al. (2002). "Localization of calcineurin/NFAT in human skin and psoriasis and inhibition of calcineurin/NFAT activation in human keratinocytes by cyclosporin A." J Invest Dermatol 118: 779-88.

Alessi, D. R., A. Cuenda, et al. (1995). "PD 098059 is a specific inhibitor of the activation of mitogen-activated protein kinase kinase in vitro and in vivo." J Biol Chem 270: 2748994.

Allavena, P., G. Germano, et al. (2011). "Chemokines in cancer related inflammation." Exp Cell Res 317: 664-73.

Allen, C., J. Halbrook, et al. (2003). "Interactive competition between homologous recombination and non-homologous end joining." Mol Cancer Res 1: 913-20.

Amrein, L., M. Loignon, et al. (2007). "Chlorambucil cytotoxicity in malignant B lymphocytes is synergistically increased by 2-(morpholin-4-yl)-benzo[h]chomen-4-one (NU7026)mediated inhibition of DNA double-strand break repair via inhibition of DNAdependent protein kinase." J Pharmacol Exp Ther 321: 848-55.

Anastassiadis, T., S. W. Deacon, et al. (2011). "Comprehensive assay of kinase catalytic activity reveals features of kinase inhibitor selectivity." Nat Biotechnol 29: 1039-45.

Andersen, J. S., Y. W. Lam, et al. (2005). "Nucleolar proteome dynamics." Nature 433: 77-83.

Andreani, A., A. Cavalli, et al. (2000). "Imidazo[2,1 -b]thiazolylmethylene- and indolylmethylene-2-indolinones: a new class of cyclin-dependent kinase inhibitors. Design, synthesis, and CDK1/cyclin B inhibition." Anticancer Drug Des 15: 447-52.

Aramburu, J., M. B. Yaffe, et al. (1999). "Affinity-driven peptide selection of an NFAT inhibitor more selective than cyclosporin A." Science 285: 2129-33.

Arena, S., S. Benvenuti, et al. (2005). "Genetic analysis of the kinome and phosphatome in cancer." Cell Mol Life Sci 62: 2092-9.

Ariga, R., A. Zarif, et al. (2005). "Correlation of her-2/neu gene amplification with other prognostic and predictive factors in female breast carcinoma." Breast J 11: 278-80.

Arron, J. R., M. M. Winslow, et al. (2006). "NFAT dysregulation by increased dosage of DSCR1 and DYRK1A on chromosome 21." Nature 441: 595-600.

Ashwell, S., J. W. Janetka, et al. (2008). "Keeping checkpoint kinases in line: new selective inhibitors in clinical trials." Expert Opin Investig Drugs 17: 1331-40.

Aubareda, A., M. C. Mulero, et al. (2006). "Functional characterization of the calcipressin 1 motif that suppresses calcineurin-mediated NFAT-dependent cytokine gene expression in human T cells." Cell Signal 18: 1430-8.

Baek, K. H., A. Zaslavsky, et al. (2009). "Down's syndrome suppression of tumour growth and the role of the calcineurin inhibitor DSCR1." Nature 459: 1126-30.

Baek, S. H. (2011). "When signaling kinases meet histones and histone modifiers in the nucleus." Mol Cell 42: 274-84.

Bain, J., L. Plater, et al. (2007). "The selectivity of protein kinase inhibitors: a further update." Biochem J 408: 297-315.

Barcia, R., S. Lopez-Borges, et al. (2002). "Kinetic properties of p53 phosphorylation by the human vaccinia-related kinase 1." Arch Biochem Biophys 399: 1-5. 
Barisik, N. O., S. H. Keser, et al. (2011). "The value of COX-2 expression in the prognostic parameters of invasive ductal carcinoma of the breast." Med Oncol 28: 703-8.

Basehoar, A. D., S. J. Zanton, et al. (2004). "Identification and distinct regulation of yeast TATA box-containing genes." Cell 116: 699-709.

Baselga, J. (2011). "Targeting the phosphoinositide-3 (PI3) kinase pathway in breast cancer." Oncologist 16 Suppl 1: 12-9.

Beals, C. R., N. A. Clipstone, et al. (1997a). "Nuclear localization of NF-ATc by a calcineurindependent, cyclosporin-sensitive intramolecular interaction." Genes Dev 11: 824-34.

Beals, C. R., C. M. Sheridan, et al. (1997b). "Nuclear export of NF-ATc enhanced by glycogen synthase kinase-3." Science 275: 1930-4.

Benoit, V., B. Relic, et al. (2004). "Regulation of HER-2 oncogene expression by cyclooxygenase-2 and prostaglandin E2." Oncogene 23: 1631-5.

Benson, C., J. White, et al. (2007). "A phase I trial of the selective oral cyclin-dependent kinase inhibitor seliciclib (CYC202; R-Roscovitine), administered twice daily for 7 days every 21 days." Br J Cancer 96: 29-37.

Benvenuti, S., S. Arena, et al. (2005). "Identification of cancer genes by mutational profiling of tumor genomes." FEBS Lett 579: 1884-90.

Bhoumik, A., P. Lopez-Bergami, et al. (2007). "ATF2 on the double - activating transcription factor and DNA damage response protein." Pigment Cell Res 20: 498-506.

Birnboim, H. C. and J. Doly (1979). "A rapid alkaline extraction procedure for screening recombinant plasmid DNA." Nucleic Acids Res 7: 1513-23.

Blanco, S., L. Klimcakova, et al. (2006). "The subcellular localization of vaccinia-related kinase-2 (VRK2) isoforms determines their different effect on p53 stability in tumour cell lines." Febs J 273: 2487-504.

Blanco, S., C. Santos, et al. (2007). "Vaccinia-related kinase 2 modulates the stress response to hypoxia mediated by TAK1." Mol Cell Biol 27: 7273-83.

Blanco, S., M. Sanz-Garcia, et al. (2008). "Modulation of Interleukin-1 Transcriptional Response by the Interaction between VRK2 and the JIP1 Scaffold Protein." PLoS ONE 3: e1660.

Blume-Jensen, P. and T. Hunter (2001). "Oncogenic kinase signalling." Nature 411: 355-65.

Boldrick, J. C., A. A. Alizadeh, et al. (2002). "Stereotyped and specific gene expression programs in human innate immune responses to bacteria." Proc Natl Acad Sci U S A 99: $972-7$.

Bos, P. D., X. H. Zhang, et al. (2009). "Genes that mediate breast cancer metastasis to the brain." Nature 459: 1005-9.

Bossemeyer, D. (1995). "Protein kinases--structure and function." FEBS Lett 369: 57-61.

Boudeau, J., D. Miranda-Saavedra, et al. (2006). "Emerging roles of pseudokinases." Trends Cell Biol 16: 443-52.

Boyle, K. A. and P. Traktman (2004). "Members of a novel family of mammalian protein kinases complement the DNA-negative phenotype of a vaccinia virus ts mutant defective in the B1 kinase." J Virol 78: 1992-2005.

Calkhoven, C. F. and G. Ab (1996). "Multiple steps in the regulation of transcription-factor level and activity." Biochem J 317 ( Pt 2): 329-42.

Capra, M., P. G. Nuciforo, et al. (2006). "Frequent alterations in the expression of serine/threonine kinases in human cancers." Cancer Res 66: 8147-54.

Castellone, M. D., H. Teramoto, et al. (2005). "Prostaglandin E2 promotes colon cancer cell growth through a Gs-axin-beta-catenin signaling axis." Science 310: 1504-10.

Clipstone, N. A. and G. R. Crabtree (1992). "Identification of calcineurin as a key signalling enzyme in T-lymphocyte activation." Nature 357: 695-7. 
Cockerill, G. W., A. G. Bert, et al. (1995). "Regulation of granulocyte-macrophage colonystimulating factor and E-selectin expression in endothelial cells by cyclosporin A and the T-cell transcription factor NFAT." Blood 86: 2689-98.

Cohen, P. (2001). "The role of protein phosphorylation in human health and disease. The Sir Hans Krebs Medal Lecture." Eur J Biochem 268: 5001-10.

Connolly, E. M., J. H. Harmey, et al. (2002). "Cyclo-oxygenase inhibition reduces tumour growth and metastasis in an orthotopic model of breast cancer." Br J Cancer 87: 231-7.

Cook-Johnson, R. J., M. Demasi, et al. (2006). "Endothelial cell COX-2 expression and activity in hypoxia." Biochim Biophys Acta 1761: 1443-9.

Corral, R. S., M. A. Iniguez, et al. (2007). "Bombesin induces cyclooxygenase-2 expression through the activation of the nuclear factor of activated $\mathrm{T}$ cells and enhances cell migration in Caco-2 colon carcinoma cells." Oncogene 26: 958-69.

Crabtree, G. R. and E. N. Olson (2002). "NFAT signaling: choreographing the social lives of cells." Cell 109 Suppl: S67-79.

Crosio, C., G. M. Fimia, et al. (2002). "Mitotic phosphorylation of histone H3: spatio-temporal regulation by mammalian Aurora kinases." Mol Cell Biol 22: 874-85.

Cuzzocrea, S., S. Bruscoli, et al. (2008). "Peroxisome proliferator-activated receptor-alpha contributes to the anti-inflammatory activity of glucocorticoids." Mol Pharmacol 73: 323-37.

Chabchoub, E., J. R. Vermeesch, et al. (2008). "The facial dysmorphy in the newly recognised microdeletion 2p15-p16.1 refined to a $570 \mathrm{~kb}$ region in 2p15." J Med Genet 45: 18992.

Chandler, K. E., A. Del Rio, et al. (2006). "Leucodysplasia, microcephaly, cerebral malformation (LMC): a novel recessive disorder linked to 2p16." Brain 129: 272-7.

Chang, S. H., C. H. Liu, et al. (2004). "Role of prostaglandin E2-dependent angiogenic switch in cyclooxygenase 2-induced breast cancer progression." Proc Natl Acad Sci U S A 101: 591-6.

Chen, L., J. N. Glover, et al. (1998). "Structure of the DNA-binding domains from NFAT, Fos and Jun bound specifically to DNA." Nature 392: 42-8.

Chen, M. and K. L. O'Connor (2005). "Integrin alpha6beta4 promotes expression of autotaxin/ENPP2 autocrine motility factor in breast carcinoma cells." Oncogene 24: 5125-30.

Cheng, H., E. Merika, et al. (2011). "Novel agents for the treatment of pancreatic adenocarcinoma. Highlights from the "2011 ASCO Annual Meeting". Chicago, IL, USA; June 3-7, 2011." Jop 12: 334-8.

Chin, Y. R. and A. Toker (2009). "Function of Akt/PKB signaling to cell motility, invasion and the tumor stroma in cancer." Cell Signal 21: 470-6.

Cho, I. J. and S. G. Kim (2009). "A novel mitogen-activated protein kinase phosphatase-1 and glucocorticoid receptor (GR) interacting protein-1-dependent combinatorial mechanism of gene transrepression by GR." Mol Endocrinol 23: 86-99.

Choi, Y. H., C. H. Park, et al. (2010). "Vaccinia-related kinase 1 is required for the maintenance of undifferentiated spermatogonia in mouse male germ cells." PLoS One 5: e15254.

Chuvpilo, S., A. Avots, et al. (1999). "Multiple NF-ATc isoforms with individual transcriptional properties are synthesized in T lymphocytes." J Immunol 162: 7294301.

Dai, J., S. Sultan, et al. (2005). "The kinase haspin is required for mitotic histone H3 Thr 3 phosphorylation and normal metaphase chromosome alignment." Genes Dev 19: 47288.

Dar, A. C. and K. M. Shokat (2011). "The evolution of protein kinase inhibitors from antagonists to agonists of cellular signaling." Annu Rev Biochem 80: 769-95. 
Davidson, D., Y. Coulombe, et al. (2011). "Irinotecan and DNA-PKcs inhibitors synergize in killing of colon cancer cells." Invest New Drugs.

Davies, S. P., H. Reddy, et al. (2000). "Specificity and mechanism of action of some commonly used protein kinase inhibitors." Biochem J 351: 95-105.

Davis, M. I., J. P. Hunt, et al. (2011). "Comprehensive analysis of kinase inhibitor selectivity." Nat Biotechnol 29: 1046-51.

Davis, P. D., C. H. Hill, et al. (1989). "Potent selective inhibitors of protein kinase C." $\underline{\text { FEBS }}$ Lett 259: 61-3.

De Azevedo, W. F., S. Leclerc, et al. (1997). "Inhibition of cyclin-dependent kinases by purine analogues: crystal structure of human cdk2 complexed with roscovitine." Eur J Biochem 243: 518-26.

de Gregorio, R., M. A. Iniguez, et al. (2001). "Cot kinase induces cyclooxygenase-2 expression in $\mathrm{T}$ cells through activation of the nuclear factor of activated $\mathrm{T}$ cells." J Biol Chem 276: 27003-9.

Dempke, W., C. Rie, et al. (2001). "Cyclooxygenase-2: a novel target for cancer chemotherapy?" J Cancer Res Clin Oncol 127: 411-7.

Denkert, C., K. J. Winzer, et al. (2004). "Prognostic impact of cyclooxygenase-2 in breast cancer." Clin Breast Cancer 4: 428-33.

Deryugina, E. I. and J. P. Quigley (2006). "Matrix metalloproteinases and tumor metastasis." Cancer Metastasis Rev 25: 9-34.

Di Paola, R., M. Galuppo, et al. (2010). "PD98059, a specific MAP kinase inhibitor, attenuates multiple organ dysfunction syndrome/failure (MODS) induced by zymosan in mice." Pharmacol Res 61: 175-87.

Diehn, M., A. A. Alizadeh, et al. (2002). "Genomic expression programs and the integration of the CD28 costimulatory signal in T cell activation." Proc Natl Acad Sci U S A 99: 11796-801.

Dieter, P. and E. Fitzke (1991). "RO 31-8220 and RO 31-7549 show improved selectivity for protein kinase $\mathrm{C}$ over staurosporine in macrophages." Biochem Biophys Res Commun 181: 396-401.

Druker, B. J., S. Tamura, et al. (1996). "Effects of a selective inhibitor of the Abl tyrosine kinase on the growth of Bcr-Abl positive cells." Nat Med 2: 561-6.

Duque, J., M. Fresno, et al. (2005). "Expression and function of the nuclear factor of activated T cells in colon carcinoma cells: involvement in the regulation of cyclooxygenase-2." $\mathbf{J}$ Biol Chem 280: 8686-93.

Eglen, R. M. and T. Reisine (2009). "The current status of drug discovery against the human kinome." Assay Drug Dev Technol 7: 22-43.

Elphick, L. M., S. E. Lee, et al. (2007). "Using chemical genetics and ATP analogues to dissect protein kinase function." ACS Chem Biol 2: 299-314.

Esteva, F. J. and G. N. Hortobagyi (2004). "Prognostic molecular markers in early breast cancer." Breast Cancer Res 6: 109-18.

Eswaran, J. and S. Knapp (2009). "Insights into protein kinase regulation and inhibition by large scale structural comparison." Biochim Biophys Acta 1804: 429-32.

Falvo, J. V., C. H. Lin, et al. (2008). "A dimer-specific function of the transcription factor NFATp." Proc Natl Acad Sci U S A 105: 19637-42.

Fedorov, O., B. Marsden, et al. (2007). "A systematic interaction map of validated kinase inhibitors with Ser/Thr kinases." Proc Natl Acad Sci U S A 104: 20523-8.

Felix, T. M., A. L. Petrin, et al. (2010). "Further characterization of microdeletion syndrome involving 2p15-p16.1." Am J Med Genet A 152A: 2604-8.

Fernandez, I. F., S. Blanco, et al. (2010). "VRK2 inhibits mitogen-activated protein kinase signaling and inversely correlates with ErbB2 in human breast cancer." $\underline{\text { Mol Cell Biol }}$ 30: 4687-97. 
Ferrandina, G., L. Lauriola, et al. (2002). "Increased cyclooxygenase-2 expression is associated with chemotherapy resistance and poor survival in cervical cancer patients." J Clin Oncol 20: 973-81.

Ferreon, J. C., C. W. Lee, et al. (2009). "Cooperative regulation of $\mathrm{p} 53$ by modulation of ternary complex formation with CBP/p300 and HDM2." Proc Natl Acad Sci U S A 106: 65916.

Feske, S., H. Okamura, et al. (2003). "Ca2+/calcineurin signalling in cells of the immune system." Biochem Biophys Res Commun 311: 1117-32.

Finetti, P., N. Cervera, et al. (2008). "Sixteen-kinase gene expression identifies luminal breast cancers with poor prognosis." Cancer Res 68: 767-76.

Fischer, P. M. and A. Gianella-Borradori (2005). "Recent progress in the discovery and development of cyclin-dependent kinase inhibitors." Expert Opin Investig Drugs 14: 457-77.

Flanagan, W. M., B. Corthesy, et al. (1991). "Nuclear association of a T-cell transcription factor blocked by FK-506 and cyclosporin A." Nature 352: 803-7.

Flockhart, R. J., J. L. Armstrong, et al. (2009). "NFAT signalling is a novel target of oncogenic BRAF in metastatic melanoma." Br J Cancer 101: 1448-55.

Flotow, H., P. R. Graves, et al. (1990). "Phosphate groups as substrate determinants for casein kinase I action." J Biol Chem 265: 14264-9.

Fosslien, E. (2000). "Molecular pathology of cyclooxygenase-2 in neoplasia." Ann Clin Lab Sci 30: 3-21.

Fournier, M. V., K. J. Martin, et al. (2006). "Gene expression signature in organized and growth-arrested mammary acini predicts good outcome in breast cancer." Cancer Res 66: 7095-102.

Fuentes, J. J., L. Genesca, et al. (2000). "DSCR1, overexpressed in Down syndrome, is an inhibitor of calcineurin-mediated signaling pathways." Hum Mol Genet 9: 1681-90.

Fuentes, J. J., M. A. Pritchard, et al. (1997). "Genomic organization, alternative splicing, and expression patterns of the DSCR1 (Down syndrome candidate region 1) gene." Genomics 44: 358-61.

Futreal, P. A., L. Coin, et al. (2004). "A census of human cancer genes." Nat Rev Cancer 4: 177-83.

Gadducci, A., N. Biglia, et al. (2005). "Breast cancer and sex steroids: critical review of epidemiological, experimental and clinical investigations on etiopathogenesis, chemoprevention and endocrine treatment of breast cancer." Gynecol Endocrinol 20: 343-60.

Galuppo, M., E. Esposito, et al. (2011). "MEK inhibition suppresses the development of lung fibrosis in the bleomycin model." Naunyn Schmiedebergs Arch Pharmacol 384: 21-37.

Garcia-Cozar, F. J., H. Okamura, et al. (1998). "Two-site interaction of nuclear factor of activated T cells with activated calcineurin." J Biol Chem 273: 23877-83.

Gautschi, O., J. Heighway, et al. (2008). "Aurora kinases as anticancer drug targets." Clin Cancer Res 14: 1639-48.

Giamas, G., J. Stebbing, et al. (2007). "Protein kinases as targets for cancer treatment." Pharmacogenomics 8: 1005-16.

Glynn, S. A., R. L. Prueitt, et al. (2010). "COX-2 activation is associated with Akt phosphorylation and poor survival in ER-negative, HER2-positive breast cancer." BMC Cancer 10: 626.

Gomez-Casero, E., B. San-Antonio, et al. (2007). "Cot/Tpl2 and PKCzeta cooperate in the regulation of the transcriptional activity of NFATc2 through the phosphorylation of its amino-terminal domain." Cell Signal 19: 1652-61.

Gomez del Arco, P., S. Martinez-Martinez, et al. (2000). "A role for the p38 MAP kinase pathway in the nuclear shuttling of NFATp." J Biol Chem 275: 13872-8. 
Gorjanacz, M., E. P. Klerkx, et al. (2007). "Caenorhabditis elegans BAF-1 and its kinase VRK1 participate directly in post-mitotic nuclear envelope assembly." Embo J 26: 132-43.

Graef, I. A., F. Chen, et al. (2001a). "NFAT signaling in vertebrate development." Curr Opin Genet Dev 11: 505-12.

Graef, I. A., F. Chen, et al. (2001b). "Signals transduced by $\mathrm{Ca}(2+) /$ calcineurin and NFATc3/c4 pattern the developing vasculature." Cell 105: 863-75.

Greenhough, A., H. J. Smartt, et al. (2009). "The COX-2/PGE2 pathway: key roles in the hallmarks of cancer and adaptation to the tumour microenvironment." $\underline{\text { Carcinogenesis }}$ 30: $377-86$.

Gregan, J., C. Zhang, et al. (2007). "Construction of conditional analog-sensitive kinase alleles in the fission yeast Schizosaccharomyces pombe." Nat Protoc 2: 2996-3000.

Grishin, A. V., J. Wang, et al. (2006). "Lipopolysaccharide induces cyclooxygenase-2 in intestinal epithelium via a noncanonical p38 MAPK pathway." J Immunol 176: 580-8.

Grosser, T., S. Fries, et al. (2006). "Biological basis for the cardiovascular consequences of COX-2 inhibition: therapeutic challenges and opportunities." J Clin Invest 116: 4-15.

Guermah, M., V. B. Palhan, et al. (2006). "Synergistic functions of SII and p300 in productive activator-dependent transcription of chromatin templates." Cell 125: 275-86.

Guzi, T. (2004). "CYC-202 Cyclacel." Curr Opin Investig Drugs 5: 1311-8.

Gwack, Y., S. Sharma, et al. (2006). "A genome-wide Drosophila RNAi screen identifies DYRK-family kinases as regulators of NFAT." Nature 441: 646-50.

Han, Z., P. Pantazis, et al. (2000). "The staurosporine analog, Ro-31-8220, induces apoptosis independently of its ability to inhibit protein kinase C." Cell Death Differ 7: 521-30.

Hanks, S. K. and T. Hunter (1995). "Protein kinases 6. The eukaryotic protein kinase superfamily: kinase (catalytic) domain structure and classification." Faseb J 9: 576-96.

Hanks, S. K. and A. M. Quinn (1991). "Protein kinase catalytic domain sequence database: identification of conserved features of primary structure and classification of family members." Methods Enzymol 200: 38-62.

Haraguchi, T., T. Koujin, et al. (2001). "BAF is required for emerin assembly into the reforming nuclear envelope." J Cell Sci 114: 4575-85.

Harris, R. E., G. A. Alshafie, et al. (2000). "Chemoprevention of breast cancer in rats by celecoxib, a cyclooxygenase 2 inhibitor." Cancer Res 60: 2101-3.

Hartel, S., M. Zorn-Kruppa, et al. (2003). "Staurosporine-induced apoptosis in human cornea epithelial cells in vitro." Cytometry A 55: 15-23.

Hassan, M., H. Sallam, et al. (2011). "The Role of Pharmacokinetics and Pharmacodynamics in Early Drug Development with reference to the Cyclin-dependent Kinase (Cdk) Inhibitor - Roscovitine." Sultan Qaboos Univ Med J 11: 165-78.

Hickson, I., Y. Zhao, et al. (2004). "Identification and characterization of a novel and specific inhibitor of the ataxia-telangiectasia mutated kinase ATM." Cancer Res 64: 9152-9.

Hill-Eubanks, D. C., M. F. Gomez, et al. (2003). "NFAT regulation in smooth muscle." Trends Cardiovasc Med 13: 56-62.

Hill, C. S. and R. Treisman (1995). "Transcriptional regulation by extracellular signals: mechanisms and specificity." Cell 80: 199-211.

Ho, I. C., M. R. Hodge, et al. (1996). "The proto-oncogene c-maf is responsible for tissuespecific expression of interleukin-4." Cell 85: 973-83.

Hock, M. B. and M. A. Brown (2003). "Nuclear factor of activated T cells 2 transactivation in mast cells: a novel isoform-specific transactivation domain confers unique FcepsilonRI responsiveness." J Biol Chem 278: 26695-703.

Hoeflich, K. P., S. Herter, et al. (2009a). "Antitumor efficacy of the novel RAF inhibitor GDC0879 is predicted by BRAFV600E mutational status and sustained extracellular signalregulated kinase/mitogen-activated protein kinase pathway suppression." $\underline{\text { Cancer Res }}$ 69: 3042-51. 
Hoeflich, K. P., C. O'Brien, et al. (2009b). "In vivo antitumor activity of MEK and phosphatidylinositol 3-kinase inhibitors in basal-like breast cancer models." Clin Cancer Res 15: 4649-64.

Hoey, T., Y. L. Sun, et al. (1995). "Isolation of two new members of the NF-AT gene family and functional characterization of the NF-AT proteins." Immunity 2: 461-72.

Holder, S., M. Zemskova, et al. (2007). "Characterization of a potent and selective smallmolecule inhibitor of the PIM1 kinase." Mol Cancer Ther 6: 163-72.

Holmberg, C. I., S. E. Tran, et al. (2002). "Multisite phosphorylation provides sophisticated regulation of transcription factors." Trends Biochem Sci 27: 619-27.

Hollick, J. J., L. J. Rigoreau, et al. (2007). "Pyranone, thiopyranone, and pyridone inhibitors of phosphatidylinositol 3-kinase related kinases. Structure-activity relationships for DNA-dependent protein kinase inhibition, and identification of the first potent and selective inhibitor of the ataxia telangiectasia mutated kinase." J Med Chem 50: 195872.

Horsley, V. and G. K. Pavlath (2002). "NFAT: ubiquitous regulator of cell differentiation and adaptation." J Cell Biol 156: 771-4.

Howe, L. R., S. H. Chang, et al. (2005). "HER2/neu-induced mammary tumorigenesis and angiogenesis are reduced in cyclooxygenase-2 knockout mice." Cancer Res 65: 101139.

Huang, G. N., D. L. Huso, et al. (2008). "NFAT binding and regulation of T cell activation by the cytoplasmic scaffolding Homer proteins." Science 319: 476-81.

Hunter, T. (1987). "A thousand and one protein kinases." Cell 50: 823-9.

Hunter, T. (1995). "Protein kinases and phosphatases: the yin and yang of protein phosphorylation and signaling." Cell 80: 225-36.

Hunter, T. and M. Karin (1992). "The regulation of transcription by phosphorylation." Cell 70: 375-87.

Hwang, S. Y., S. H. Cho, et al. (2011). "Cellular imaging assay for early evaluation of an apoptosis inducer." Apoptosis 16: 1068-75.

Imamura, R., E. S. Masuda, et al. (1998). "Carboxyl-terminal 15-amino acid sequence of NFATx 1 is possibly created by tissue-specific splicing and is essential for transactivation activity in T cells." J Immunol 161: 3455-63.

Iniguez, M. A., S. Martinez-Martinez, et al. (2000). "An essential role of the nuclear factor of activated $\mathrm{T}$ cells in the regulation of the expression of the cyclooxygenase- 2 gene in human T lymphocytes." J Biol Chem 275: 23627-35.

Iniguez, M. A., C. Punzon, et al. (1999). "Induction of cyclooxygenase-2 on activated T lymphocytes: regulation of $\mathrm{T}$ cell activation by cyclooxygenase-2 inhibitors." $\underline{\mathrm{J}}$ Immunol 163: 111-9.

Ito, H., M. Duxbury, et al. (2004). "Prostaglandin E2 enhances pancreatic cancer invasiveness through an Ets-1-dependent induction of matrix metalloproteinase-2." Cancer Res 64: 7439-46.

Jain, J., E. Burgeon, et al. (1995). "A similar DNA-binding motif in NFAT family proteins and the Rel homology region." J Biol Chem 270: 4138-45.

Jain, J., P. G. McCaffrey, et al. (1992). "Nuclear factor of activated T cells contains Fos and Jun." Nature 356: 801-4.

Jauliac, S., C. Lopez-Rodriguez, et al. (2002). "The role of NFAT transcription factors in integrin-mediated carcinoma invasion." Nat Cell Biol 4: 540-4.

Johannessen, M., M. P. Delghandi, et al. (2004). "What turns CREB on?" Cell Signal 16: 121127.

Johnson, S. A. and T. Hunter (2005). "Kinomics: methods for deciphering the kinome." Nat Methods 2: 17-25. 
Kaidanovich-Beilin, O. and H. Eldar-Finkelman (2006). "Peptides targeting protein kinases: strategies and implications." Physiology (Bethesda) 21: 411-8.

Kaidi, A., D. Qualtrough, et al. (2006). "Direct transcriptional up-regulation of cyclooxygenase2 by hypoxia-inducible factor (HIF)-1 promotes colorectal tumor cell survival and enhances HIF-1 transcriptional activity during hypoxia." Cancer Res 66: 6683-91.

Kakiuchi, Y., S. Tsuji, et al. (2002). "Cyclooxygenase-2 activity altered the cell-surface carbohydrate antigens on colon cancer cells and enhanced liver metastasis." Cancer Res 62: 1567-72.

Kamath, R. S., A. G. Fraser, et al. (2003). "Systematic functional analysis of the Caenorhabditis elegans genome using RNAi." Nature 421: 231-7.

Kang, J. H., K. H. Song, et al. (2011). "Involvement of Cox-2 in the metastatic potential of chemotherapy-resistant breast cancer cells." BMC Cancer 11: 334.

Kang, T. H. and K. T. Kim (2006). "Negative regulation of ERK activity by VRK3-mediated activation of VHR phosphatase." Nat Cell Biol 8: 863-9.

Kang, T. H., D. Y. Park, et al. (2007). "Mitotic histone H3 phosphorylation by vaccinia-related kinase 1 in mammalian cells." Mol Cell Biol 27: 8533-46.

Kang, T. H., D. Y. Park, et al. (2008). "VRK1 phosphorylates CREB and mediates CCND1 expression." J Cell Sci 121: 3035-41.

Kao, A. P., K. H. Wang, et al. (2011). "Interleukin-1beta induces cyclooxygenase-2 expression and promotes the invasive ability of human mesenchymal stem cells derived from ovarian endometrioma." Fertil Steril 96: 678-684 e1.

Karaman, M. W., S. Herrgard, et al. (2008). "A quantitative analysis of kinase inhibitor selectivity." Nat Biotechnol 26: 127-32.

Karin, M. and T. Hunter (1995). "Transcriptional control by protein phosphorylation: signal transmission from the cell surface to the nucleus." Curr Biol 5: 747-57.

Kashishian, A., H. Douangpanya, et al. (2003). "DNA-dependent protein kinase inhibitors as drug candidates for the treatment of cancer." Mol Cancer Ther 2: 1257-64.

Kashishian, A., M. Howard, et al. (1998). "AKAP79 inhibits calcineurin through a site distinct from the immunophilin-binding region." J Biol Chem 273: 27412-9.

Kent, L. L., N. E. Hull-Campbell, et al. (1999). "Characterization of novel inhibitors of cyclindependent kinases." Biochem Biophys Res Commun 260: 768-74.

Kim, W., G. Chakraborty, et al. (2011). "Macro Histone H2A1.2 (MacroH2A1) Protein Suppresses Mitotic Kinase VRK1 during Interphase." J Biol Chem 287: 5278-89.

Kingsbury, T. J. and K. W. Cunningham (2000). "A conserved family of calcineurin regulators." Genes Dev 14: 1595-604.

Kirkland, L. O. and C. McInnes (2009). "Non-ATP competitive protein kinase inhibitors as anti-tumor therapeutics." Biochem Pharmacol 77: 1561-71.

Klerkx, E. P., P. Alarcon, et al. (2009a). "Protein kinase VRK-1 regulates cell invasion and EGL-17/FGF signaling in Caenorhabditis elegans." Dev Biol 335: 12-21.

Klerkx, E. P., P. A. Lazo, et al. (2009b). "Emerging biological functions of the vaccinia-related kinase (VRK) family." Histol Histopathol 24: 749-59.

Knight, Z. A., B. Gonzalez, et al. (2006). "A pharmacological map of the PI3-K family defines a role for p110alpha in insulin signaling." Cell 125: 733-47.

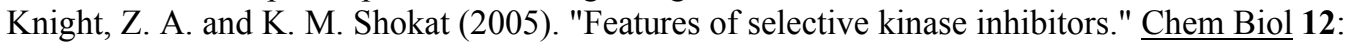
621-37.

Konig, A., M. E. Fernandez-Zapico, et al. (2010). "Primers on molecular pathways--the NFAT transcription pathway in pancreatic cancer." Pancreatology 10: 416-22.

Kostich, M., J. English, et al. (2002). "Human members of the eukaryotic protein kinase family." Genome Biol 3: RESEARCH0043.

Laemmli, U. K. (1970). "Cleavage of structural proteins during the assembly of the head of bacteriophage T4." Nature 227: 680-5. 
Lai, M. M., P. E. Burnett, et al. (1998). "Cain, a novel physiologic protein inhibitor of calcineurin." J Biol Chem 273: 18325-31.

Lancaster, O. M., C. F. Cullen, et al. (2007). "NHK-1 phosphorylates BAF to allow karyosome formation in the Drosophila oocyte nucleus." J Cell Biol 179: 817-24.

Langenbach, R., C. D. Loftin, et al. (1999). "Cyclooxygenase-deficient mice. A summary of their characteristics and susceptibilities to inflammation and carcinogenesis." Ann N Y Acad Sci 889: 52-61.

Lassota, P., G. Singh, et al. (1996). "Mechanism of topoisomerase II inhibition by staurosporine and other protein kinase inhibitors." J Biol Chem 271: 26418-23.

Lauber, S. N. and N. J. Gooderham (2011). "The cooked meat-derived mammary carcinogen 2amino-1-methyl-6-phenylimidazo[4,5-b]pyridine promotes invasive behaviour of breast cancer cells." Toxicology 279: 139-45.

Le Tourneau, C., S. Faivre, et al. (2010). "Phase I evaluation of seliciclib (R-roscovitine), a novel oral cyclin-dependent kinase inhibitor, in patients with advanced malignancies." Eur J Cancer 46: 3243-50.

Li, C. J., J. K. Chang, et al. (2011). "Constitutively expressed COX-2 in osteoblasts positively regulates Akt signal transduction via suppression of PTEN activity." Bone 48: 286-97.

Li, H., A. Rao, et al. (2004). "Structural delineation of the calcineurin-NFAT interaction and its parallels to PP1 targeting interactions." J Mol Biol 342: 1659-74.

Li, J., M. Xu, et al. (2010). "Simultaneous inhibition of MEK and CDK4 leads to potent apoptosis in human melanoma cells." Cancer Invest 28: 350-6.

Li, L. Y., M. Y. Liu, et al. (2006). "Human cellular protein VRK2 interacts specifically with Epstein-Barr virus BHRF1, a homologue of Bcl-2, and enhances cell survival." Virol 87: 2869-78.

Li, Y. and D. Q. Yang (2010). "The ATM inhibitor KU-55933 suppresses cell proliferation and induces apoptosis by blocking Akt in cancer cells with overactivated Akt." Mol Cancer Ther 9: 113-25.

Lin, S., W. Chen, et al. (1992). "The vaccinia virus B1R gene product is a serine/threonine protein kinase." J Virol 66: 2717-23.

Lin, X., R. A. Sikkink, et al. (1999). "Inhibition of calcineurin phosphatase activity by a calcineurin B homologous protein." J Biol Chem 274: 36125-31.

Lipsky, P. E., P. Brooks, et al. (2000). "Unresolved issues in the role of cyclooxygenase-2 in normal physiologic processes and disease." Arch Intern Med 160: 913-20.

Liu, C. H., S. H. Chang, et al. (2001). "Overexpression of cyclooxygenase-2 is sufficient to induce tumorigenesis in transgenic mice." J Biol Chem 276: 18563-9.

Liu, Q., J. C. Busby, et al. (2009). "Interaction between TAK1-TAB1-TAB2 and RCAN1calcineurin defines a signalling nodal control point." Nat Cell Biol 11: 154-61.

Liu, Y. and N. S. Gray (2006). "Rational design of inhibitors that bind to inactive kinase conformations." Nat Chem Biol 2: 358-64.

Loftin, C. D., D. B. Trivedi, et al. (2001). "Failure of ductus arteriosus closure and remodeling in neonatal mice deficient in cyclooxygenase-1 and cyclooxygenase-2." Proc Natl Acad Sci U S A 98: 1059-64.

Lopez-Borges, S. and P. A. Lazo (2000). "The human vaccinia-related kinase 1 (VRK1) phosphorylates threonine-18 within the mdm-2 binding site of the p53 tumour suppressor protein." Oncogene 19: 3656-64.

Lopez-Sanchez, I., M. Sanz-Garcia, et al. (2009). "Plk3 interacts with and specifically phosphorylates VRK1 in Ser342, a downstream target in a pathway that induces Golgi fragmentation." Mol Cell Biol 29: 1189-201.

Lu, B. and C. E. Bishop (2003). "Late onset of spermatogenesis and gain of fertility in POGdeficient mice indicate that POG is not necessary for the proliferation of spermatogonia." Biol Reprod 69: 161-8. 
Luo, C., E. Burgeon, et al. (1996a). "Recombinant NFAT1 (NFATp) is regulated by calcineurin in $\mathrm{T}$ cells and mediates transcription of several cytokine genes." Mol Cell Biol 16: 3955-66.

Luo, C., E. Burgeon, et al. (1996b). "Mechanisms of transactivation by nuclear factor of activated T cells-1." J Exp Med 184: 141-7.

Macian, F., C. Lopez-Rodriguez, et al. (2001). "Partners in transcription: NFAT and AP-1." Oncogene 20: 2476-89.

Mancini, M. and A. Toker (2009). "NFAT proteins: emerging roles in cancer progression." Nat Rev Cancer 9: 810-20.

Manhani, K. K., H. A. Arcuri, et al. (2005). "Molecular models of protein kinase 6 from Plasmodium falciparum." J Mol Model 12: 42-8.

Manning, G., G. D. Plowman, et al. (2002a). "Evolution of protein kinase signaling from yeast to man." Trends Biochem Sci 27: 514-20.

Manning, G., D. B. Whyte, et al. (2002b). "The protein kinase complement of the human genome." Science 298: 1912-34.

Manukyan, I., J. Galatioto, et al. (2010). "Cross-talk between calcineurin/NFAT and Jak/STAT signalling induces cardioprotective alphaB-crystallin gene expression in response to hypertrophic stimuli." J Cell Mol Med 14: 1707-16.

Margalit, A., A. Brachner, et al. (2007). "Barrier-to-autointegration factor--a BAFfling little protein." Trends Cell Biol 17: 202-8.

Martin, K. J., D. R. Patrick, et al. (2008). "Prognostic breast cancer signature identified from 3D culture model accurately predicts clinical outcome across independent datasets." PLoS One 3: e2994.

Martinez-Martinez, S., L. Genesca, et al. (2009). "The RCAN carboxyl end mediates calcineurin docking-dependent inhibition via a site that dictates binding to substrates and regulators." Proc Natl Acad Sci U S A 106: 6117-22.

Martinez, A., M. Alonso, et al. (2002). "First non-ATP competitive glycogen synthase kinase 3 beta (GSK-3beta) inhibitors: thiadiazolidinones (TDZD) as potential drugs for the treatment of Alzheimer's disease." J Med Chem 45: 1292-9.

Masuda, E. S., R. Imamura, et al. (1998). "Signalling into the T-cell nucleus: NFAT regulation." Cell Signal 10: 599-611.

Masuda, E. S., J. Liu, et al. (1997). "Control of NFATx1 nuclear translocation by a calcineurinregulated inhibitory domain." Mol Cell Biol 17: 2066-75.

Masuda, E. S., Y. Naito, et al. (1995). "NFATx, a novel member of the nuclear factor of activated T cells family that is expressed predominantly in the thymus." Mol Cell Biol 15: 2697-706.

Matsumura, T., T. Suzuki, et al. (2009). "Regulation of transforming growth factor-betadependent cyclooxygenase-2 expression in fibroblasts." J Biol Chem 284: 35861-71.

McCaffrey, P. G., C. Luo, et al. (1993). "Isolation of the cyclosporin-sensitive T cell transcription factor NFATp." Science 262: 750-4.

Meijer, L., A. Borgne, et al. (1997). "Biochemical and cellular effects of roscovitine, a potent and selective inhibitor of the cyclin-dependent kinases cdc2, cdk2 and cdk5." Eur J Biochem 243: 527-36.

Meijer, L. and E. Raymond (2003). "Roscovitine and other purines as kinase inhibitors. From starfish oocytes to clinical trials." Acc Chem Res 36: 417-25.

Mestre, J. R., D. E. Rivadeneira, et al. (2001). "Overlapping CRE and E-box promoter elements can independently regulate COX-2 gene transcription in macrophages." FEBS Lett 496: $147-51$.

Miglietta, A., M. Toselli, et al. (2010). "COX-2 expression in human breast carcinomas: correlation with clinicopathological features and prognostic molecular markers." Expert Opin Ther Targets 14: 655-64. 
Minami, T., K. Horiuchi, et al. (2004). "Vascular endothelial growth factor- and thrombininduced termination factor, Down syndrome critical region-1, attenuates endothelial cell proliferation and angiogenesis." J Biol Chem 279: 50537-54.

Mitchell, J. B., R. Choudhuri, et al. (2010). "In vitro and in vivo radiation sensitization of human tumor cells by a novel checkpoint kinase inhibitor, AZD7762." Clin Cancer Res 16: 2076-84.

Molkentin, J. D. (2004). "Calcineurin-NFAT signaling regulates the cardiac hypertrophic response in coordination with the MAPKs." Cardiovasc Res 63: 467-75.

Montes de Oca, R., C. J. Shoemaker, et al. (2009). "Barrier-to-autointegration factor proteome reveals chromatin-regulatory partners." PLoS One 4: e7050.

Monticelli, S., D. C. Solymar, et al. (2004). "Role of NFAT proteins in IL13 gene transcription in mast cells." J Biol Chem 279: 36210-8.

Morgan, M. A., L. A. Parsels, et al. (2010). "Mechanism of radiosensitization by the Chk1/2 inhibitor AZD7762 involves abrogation of the G2 checkpoint and inhibition of homologous recombinational DNA repair." Cancer Res 70: 4972-81.

Mott, B. T., C. Tanega, et al. (2009). "Evaluation of substituted 6-arylquinazolin-4-amines as potent and selective inhibitors of cdc2-like kinases (Clk)." Bioorg Med Chem Lett 19: 6700-5.

Muller, M. R. and A. Rao (2010). "NFAT, immunity and cancer: a transcription factor comes of age." Nat Rev Immunol 10: 645-56.

Nezu, J., A. Oku, et al. (1997). "Identification of two novel human putative serine/threonine kinases, VRK1 and VRK2, with structural similarity to vaccinia virus B1R kinase." Genomics 45: 327-31.

Nguyen, T. and S. Di Giovanni (2008). "NFAT signaling in neural development and axon growth." Int J Dev Neurosci 26: 141-5.

Nichols, R. J. and P. Traktman (2004). "Characterization of three paralogous members of the Mammalian vaccinia related kinase family." J Biol Chem 279: 7934-46.

Nichols, R. J., M. S. Wiebe, et al. (2006). "The vaccinia-related kinases phosphorylate the N' terminus of BAF, regulating its interaction with DNA and its retention in the nucleus." Mol Biol Cell 17: 2451-64.

Nilsson, L. M., J. Nilsson-Ohman, et al. (2008). "Nuclear factor of activated T-cells transcription factors in the vasculature: the good guys or the bad guys?" Curr Opin Lipidol 19: 483-90.

Nishijo, K., Q. R. Chen, et al. (2009). "Credentialing a preclinical mouse model of alveolar rhabdomyosarcoma." Cancer Res 69: 2902-11.

Noble, M. E., J. A. Endicott, et al. (2004). "Protein kinase inhibitors: insights into drug design from structure." Science 303: 1800-5.

Nolan, G. P. (1994). "NF-AT-AP-1 and Rel-bZIP: hybrid vigor and binding under the influence." Cell 77: 795-8.

Nolen, B., S. Taylor, et al. (2004). "Regulation of protein kinases; controlling activity through activation segment conformation." Mol Cell 15: 661-75.

Northrop, J. P., S. N. Ho, et al. (1994). "NF-AT components define a family of transcription factors targeted in T-cell activation." Nature 369: 497-502.

Norwood, V. F., S. G. Morham, et al. (2000). "Postnatal development and progression of renal dysplasia in cyclooxygenase-2 null mice." Kidney Int 58: 2291-300.

Nucera, C., M. A. Nehs, et al. (2011). "Targeting BRAFV600E with PLX4720 displays potent antimigratory and anti-invasive activity in preclinical models of human thyroid cancer." Oncologist 16: 296-309.

Okamura, H., J. Aramburu, et al. (2000). "Concerted dephosphorylation of the transcription factor NFAT1 induces a conformational switch that regulates transcriptional activity." Mol Cell 6: 539-50. 
Okamura, H., C. Garcia-Rodriguez, et al. (2004). "A conserved docking motif for CK1 binding controls the nuclear localization of NFAT1." Mol Cell Biol 24: 4184-95.

Ortega-Perez, I., E. Cano, et al. (2005). "c-Jun N-terminal kinase (JNK) positively regulates NFATc2 transactivation through phosphorylation within the N-terminal regulatory domain." J Biol Chem 280: 20867-78.

Paquette, B., H. Therriault, et al. (2011). "Radiation-enhancement of MDA-MB-231 breast cancer cell invasion prevented by a cyclooxygenase-2 inhibitor." $\mathrm{Br} \mathrm{J}$ Cancer $\mathbf{1 0 5}$ : 534-41.

Park, C. H., B. H. Choi, et al. (2011). "Protein kinase C $\{$ delta $\}$ regulates vaccinia-related kinase 1 in DNA damage-induced apoptosis." Mol Biol Cell 22: 1398-408.

Park, J., Y. Oh, et al. (2009). "Two key genes closely implicated with the neuropathological characteristics in Down syndrome: DYRK1A and RCAN1." BMB Rep 42: 6-15.

Park, K., S. Han, et al. (2006). "Cox-2 expression on tissue microarray of breast cancer." Eur J Surg Oncol 32: 1093-6.

Park, S., M. Uesugi, et al. (2000). "A second calcineurin binding site on the NFAT regulatory domain." Proc Natl Acad Sci U S A 97: 7130-5.

Peddi, P., C. W. Loftin, et al. (2010). "DNA-PKcs deficiency leads to persistence of oxidatively induced clustered DNA lesions in human tumor cells." Free Radic Biol Med 48: 143543.

Perez-Cadahia, B., B. Drobic, et al. (2009). "H3 phosphorylation: dual role in mitosis and interphase." Biochem Cell Biol 87: 695-709.

Perrone, G., D. Santini, et al. (2005). "COX-2 expression in DCIS: correlation with VEGF, HER-2/neu, prognostic molecular markers and clinicopathological features." Histopathology 46: 561-8.

Piersma, S. R., M. Labots, et al. (2010). "Strategies for kinome profiling in cancer and potential clinical applications: chemical proteomics and array-based methods." Anal Bioanal Chem 397: 3163-71.

Plyte, S., M. Boncristiano, et al. (2001). "Identification and characterization of a novel nuclear factor of activated T-cells-1 isoform expressed in mouse brain." J Biol Chem 276: 14350-8.

Porter, C. M., M. A. Havens, et al. (2000). "Identification of amino acid residues and protein kinases involved in the regulation of NFATc subcellular localization." $\underline{\mathrm{J} \text { Biol Chem }}$ 275: 3543-51.

Prigent, C. and S. Dimitrov (2003). "Phosphorylation of serine 10 in histone H3, what for?" $\underline{\mathrm{J}}$ Cell Sci 116: 3677-85.

Rainio, E. M., J. Sandholm, et al. (2002). "Cutting edge: Transcriptional activity of NFATc1 is enhanced by the Pim-1 kinase." J Immunol 168: 1524-7.

Rajakulendran, T. and F. Sicheri (2010). "Allosteric protein kinase regulation by pseudokinases: insights from STRAD." Sci Signal 3: pe8.

Rao, A., C. Luo, et al. (1997). "Transcription factors of the NFAT family: regulation and function." Annu Rev Immunol 15: 707-47.

Ratnasinghe, D., P. J. Daschner, et al. (2001). "Cyclooxygenase-2, P-glycoprotein-170 and drug resistance; is chemoprevention against multidrug resistance possible?" Anticancer Res 21: 2141-7.

Rempel, R. E. and P. Traktman (1992). "Vaccinia virus B1 kinase: phenotypic analysis of temperature-sensitive mutants and enzymatic characterization of recombinant proteins." J Virol 66: 4413-26.

Renbaum, P., E. Kellerman, et al. (2009). "Spinal muscular atrophy with pontocerebellar hypoplasia is caused by a mutation in the VRK1 gene." Am J Hum Genet 85: 281-9.

Rhodes, L. D., S. Wallis, et al. (2009). "Genes associated with an effective host response by Chinook salmon to Renibacterium salmoninarum." Dev Comp Immunol 33: 176-86. 
Robida, A. M., K. Xu, et al. (2000). "Cyclosporin A selectively inhibits mitogen-induced cyclooxygenase-2 gene transcription in vascular smooth muscle cells." Mol Pharmacol 58: $701-8$.

Rodriguez, A., J. Roy, et al. (2009). "A conserved docking surface on calcineurin mediates interaction with substrates and immunosuppressants." Mol Cell 33: 616-26.

Rothermel, B., R. B. Vega, et al. (2000). "A protein encoded within the Down syndrome critical region is enriched in striated muscles and inhibits calcineurin signaling." J Biol Chem 275: $8719-25$.

Rothermel, B. A., R. B. Vega, et al. (2003). "The role of modulatory calcineurin-interacting proteins in calcineurin signaling." Trends Cardiovasc Med 13: 15-21.

Rouzer, C. A. and L. J. Marnett (2009). "Cyclooxygenases: structural and functional insights." J Lipid Res 50 Suppl: S29-34.

Sambrook, J. and D. W. Rusell (2001). Molecular Cloning. A laboratory manual. New York, Cold Spring Harbor Laboratory Press.

San-Antonio, B., M. A. Iniguez, et al. (2002). "Protein kinase Czeta phosphorylates nuclear factor of activated T cells and regulates its transactivating activity." J Biol Chem 277: 27073-80.

Santos, C. R., M. Rodriguez-Pinilla, et al. (2006). "VRK1 signaling pathway in the context of the proliferation phenotype in head and neck squamous cell carcinoma." Mol Cancer Res 4: 177-85.

Santos, C. R., F. M. Vega, et al. (2004). "The vaccinia virus B1R kinase induces p53 downregulation by an Mdm2-dependent mechanism." Virology 328: 254-65.

Sanz-Garcia, M., I. Lopez-Sanchez, et al. (2008). "Proteomics identification of nuclear Ran GTPase as an inhibitor of human VRK1 and VRK2 (vaccinia-related kinase) activities." Mol Cell Proteomics 7: 2199-214.

Sanz-Garcia, M., M. Vazquez-Cedeira, et al. (2011). "Substrate profiling of human vacciniarelated kinases identifies coilin, a Cajal body nuclear protein, as a phosphorylation target with neurological implications." J Proteomics 75: 548-60.

Sauve, D. M., H. J. Anderson, et al. (1999). "Phosphorylation-induced rearrangement of the histone H3 NH2-terminal domain during mitotic chromosome condensation." J Cell Biol 145: 225-35.

Scheeff, E. D., J. Eswaran, et al. (2009). "Structure of the pseudokinase VRK3 reveals a degraded catalytic site, a highly conserved kinase fold, and a putative regulatory binding site." Structure 17: 128-38.

Scherr, N., S. Honnappa, et al. (2007). "Structural basis for the specific inhibition of protein kinase G, a virulence factor of Mycobacterium tuberculosis." Proc Natl Acad Sci U S A 104: 12151-6.

Schober, C. S., F. Aydiner, et al. (2011). "The kinase VRK1 is required for normal meiotic progression in mammalian oogenesis." Mech Dev 128: 178-90.

Schon, O., A. Friedler, et al. (2002). "Molecular mechanism of the interaction between MDM2 and p53." J Mol Biol 323: 491-501.

Segura-Totten, M. and K. L. Wilson (2004). "BAF: roles in chromatin, nuclear structure and retrovirus integration." Trends Cell Biol 14: 261-6.

Sevilla, A., C. R. Santos, et al. (2004a). "c-Jun phosphorylation by the human vaccinia-related kinase 1 (VRK1) and its cooperation with the N-terminal kinase of c-Jun (JNK)." Oncogene 23: 8950-8.

Sevilla, A., C. R. Santos, et al. (2004b). "Human vaccinia-related kinase 1 (VRK1) activates the ATF2 transcriptional activity by novel phosphorylation on Thr-73 and Ser-62 and cooperates with JNK." J Biol Chem 279: 27458-65. 
Shang, Z. F., B. Huang, et al. (2010). "Inactivation of DNA-dependent protein kinase leads to spindle disruption and mitotic catastrophe with attenuated checkpoint protein 2 Phosphorylation in response to DNA damage." Cancer Res 70: 3657-66.

Sharma, R. A., A. Gescher, et al. (2001). "Cyclooxygenase-2, malondialdehyde and pyrimidopurinone adducts of deoxyguanosine in human colon cells." Carcinogenesis 22: $1557-60$.

Sharma, S., G. M. Findlay, et al. (2011). "Dephosphorylation of the nuclear factor of activated T cells (NFAT) transcription factor is regulated by an RNA-protein scaffold complex." Proc Natl Acad Sci U S A 108: 11381-6.

Shaul, Y. D., G. Gibor, et al. (2009). "Specific phosphorylation and activation of ERK1c by MEK1b: a unique route in the ERK cascade." Genes Dev 23: 1779-90.

Shaul, Y. D. and R. Seger (2006). "ERK1c regulates Golgi fragmentation during mitosis." J Cell Biol 172: 885-97.

Shaulian, E. (2010). "AP-1--The Jun proteins: Oncogenes or tumor suppressors in disguise?" Cell Signal 22: 894-9.

Shaw, J. P., P. J. Utz, et al. (1988). "Identification of a putative regulator of early T cell activation genes." Science 241: 202-5.

Sherman, M. A., D. R. Powell, et al. (1999). "NF-ATc isoforms are differentially expressed and regulated in murine $\mathrm{T}$ and mast cells." J Immunol 162: 2820-8.

Shi, Y., T. Reiman, et al. (2007). "Targeting aurora kinases as therapy in multiple myeloma." Blood 109: 3915-21.

Shiio, Y., R. N. Eisenman, et al. (2003). "Quantitative proteomic analysis of chromatinassociated factors." J Am Soc Mass Spectrom 14: 696-703.

Shimizu, D., D. Vallbohmer, et al. (2006). "Increasing cyclooxygenase-2 (cox-2) gene expression in the progression of Barrett's esophagus to adenocarcinoma correlates with that of Bcl-2." Int J Cancer 119: 765-70.

Shin, J., G. Chakraborty, et al. (2011). "NMR solution structure of human vaccinia-related kinase 1 (VRK1) reveals the C-terminal tail essential for its structural stability and autocatalytic activity." J Biol Chem 286: 22131-8.

Shumaker, D. K., K. K. Lee, et al. (2001). "LAP2 binds to BAF.DNA complexes: requirement for the LEM domain and modulation by variable regions." Embo J 20: 1754-64.

Simeone, A. M., R. Nieves-Alicea, et al. (2007). "Cyclooxygenase-2 uses the protein kinase C/ interleukin-8/urokinase-type plasminogen activator pathway to increase the invasiveness of breast cancer cells." Int J Oncol 30: 785-92.

Singh, B., J. A. Berry, et al. (2007). "COX-2 involvement in breast cancer metastasis to bone." Oncogene 26: 3789-96.

Singh, B., J. A. Berry, et al. (2005). "COX-2 overexpression increases motility and invasion of breast cancer cells." Int J Oncol 26: 1393-9.

Sivula, A., A. Talvensaari-Mattila, et al. (2005). "Association of cyclooxygenase-2 and matrix metalloproteinase-2 expression in human breast cancer." Breast Cancer Res Treat 89: 215-20.

Smyth, L. A., T. P. Matthews, et al. (2011). "Design and evaluation of 3aminopyrazolopyridinone kinase inhibitors inspired by the natural product indirubin." Bioorg Med Chem 19: 3569-78.

Soumaoro, L. T., H. Uetake, et al. (2004). "Cyclooxygenase-2 expression: a significant prognostic indicator for patients with colorectal cancer." Clin Cancer Res 10: 8465-71.

Stasinopoulos, I., N. Mori, et al. (2008). "The malignant phenotype of breast cancer cells is reduced by COX-2 silencing." Neoplasia 10: 1163-9.

Steinberg, S., S. de Jong, et al. (2011). "Common variants at VRK2 and TCF4 conferring risk of schizophrenia." Hum Mol Genet 20: 4076-81. 
Stokes, M. P., J. Rush, et al. (2007). "Profiling of UV-induced ATM/ATR signaling pathways." Proc Natl Acad Sci U S A 104: 19855-60.

Subbaramaiah, K., D. T. Lin, et al. (2001). "Peroxisome proliferator-activated receptor gamma ligands suppress the transcriptional activation of cyclooxygenase-2. Evidence for involvement of activator protein-1 and CREB-binding protein/p300." $\mathrm{J}$ Biol Chem 276: $12440-8$.

Subbaramaiah, K., L. Norton, et al. (2002). "Cyclooxygenase-2 is overexpressed in HER-2/neupositive breast cancer: evidence for involvement of AP-1 and PEA3." J Biol Chem 277: 18649-57.

Subbaramaiah, K., N. Telang, et al. (1996). "Transcription of cyclooxygenase-2 is enhanced in transformed mammary epithelial cells." Cancer Res 56: 4424-9.

Sun, H., B. Xu, et al. (2008). "P38 MAPK mediates COX-2 gene expression by corticosterone in cardiomyocytes." Cell Signal 20: 1952-9.

Sun, L., N. Tran, et al. (1998a). "Synthesis and biological evaluations of 3-substituted indolin2-ones: a novel class of tyrosine kinase inhibitors that exhibit selectivity toward particular receptor tyrosine kinases." J Med Chem 41: 2588-603.

Sun, L., H. D. Youn, et al. (1998b). "Cabin 1, a negative regulator for calcineurin signaling in T lymphocytes." Immunity 8: 703-11.

Suzuki, Y., K. Ogawa, et al. (2010). "Functional disruption of the moloney murine leukemia virus preintegration complex by vaccinia-related kinases." J Biol Chem 285: 24032-43.

Takahashi, T. and M. Shibuya (1997). "The $230 \mathrm{kDa}$ mature form of KDR/Flk-1 (VEGF receptor-2) activates the PLC-gamma pathway and partially induces mitotic signals in NIH3T3 fibroblasts." Oncogene 14: 2079-89.

Takeuchi, K., M. H. Roehrl, et al. (2007). "Structure of the calcineurin-NFAT complex: defining a T cell activation switch using solution NMR and crystal coordinates." Structure 15: 587-97.

Tamaoki, T. and H. Nakano (1990). "Potent and specific inhibitors of protein kinase C of microbial origin." Biotechnology (N Y) 8: 732-5.

Tamaoki, T., H. Nomoto, et al. (1986). "Staurosporine, a potent inhibitor of phospholipid/Ca++dependent protein kinase." Biochem Biophys Res Commun 135: 397-402.

Tanabe, T. and N. Tohnai (2002). "Cyclooxygenase isozymes and their gene structures and expression." Prostaglandins Other Lipid Mediat 68-69: 95-114.

Taylor, S. S., D. R. Knighton, et al. (1993). "A template for the protein kinase family." Trends Biochem Sci 18: 84-9.

Terui, Y., N. Saad, et al. (2004). "Dual role of sumoylation in the nuclear localization and transcriptional activation of NFAT1." J Biol Chem 279: 28257-65.

Timoshenko, A. V., G. Xu, et al. (2003). "Role of prostaglandin E2 receptors in migration of murine and human breast cancer cells." Exp Cell Res 289: 265-74.

Tokumitsu, H., E. S. Masuda, et al. (1993). "Purification of the $120 \mathrm{kDa}$ component of the human nuclear factor of activated T cells (NF-AT): reconstitution of binding activity to the cis-acting element of the GM-CSF and IL-2 promoter with AP-1." Biochem Biophys Res Commun 196: 737-44.

Toledo, F. and G. M. Wahl (2006). "Regulating the p53 pathway: in vitro hypotheses, in vivo veritas." Nat Rev Cancer 6: 909-23.

Towbin, H., T. Staehelin, et al. (1979). "Electrophoretic transfer of proteins from polyacrylamide gels to nitrocellulose sheets: procedure and some applications." Proc Natl Acad Sci U S A 76: 4350-4.

Tsai, J., J. T. Lee, et al. (2008). "Discovery of a selective inhibitor of oncogenic B-Raf kinase with potent antimelanoma activity." Proc Natl Acad Sci U S A 105: 3041-6. 
Tsujii, M., S. Kawano, et al. (1998). "Cyclooxygenase regulates angiogenesis induced by colon cancer cells." Cell 93: 705-16.

Tunstall, R. G., R. A. Sharma, et al. (2006). "Cyclooxygenase-2 expression and oxidative DNA adducts in murine intestinal adenomas: modification by dietary curcumin and implications for clinical trials." Eur J Cancer 42: 415-21.

Valbuena, A., S. Blanco, et al. (2008a). "The C/H3 domain of p300 is required to protect VRK1 and VRK2 from their downregulation induced by p53." PLoS ONE 3: e2649.

Valbuena, A., S. Castro-Obregon, et al. (2011a). "Downregulation of VRK1 by p53 in response to DNA damage is mediated by the autophagic pathway." PLoS One 6: e17320.

Valbuena, A., I. Lopez-Sanchez, et al. (2008b). "Human VRK1 Is an Early Response Gene and Its Loss Causes a Block in Cell Cycle Progression." PLoS ONE 3: e1642.

Valbuena, A., I. Lopez-Sanchez, et al. (2007a). "Identification of a dominant epitope in human vaccinia-related kinase 1 (VRK1) and detection of different intracellular subpopulations." Arch Biochem Biophys 465: 219-26.

Valbuena, A., M. Sanz-Garcia, et al. (2011b). "Roles of VRK1 as a new player in the control of biological processes required for cell division." Cell Signal 23: 1267-72.

Valbuena, A., A. Suarez-Gauthier, et al. (2007b). "Alteration of the VRK1-p53 autoregulatory loop in human lung carcinomas." Lung Cancer 58: 303-9.

Valbuena, A., F. M. Vega, et al. (2006). "p53 downregulates its activating vaccinia-related kinase 1, forming a new autoregulatory loop." Mol Cell Biol 26: 4782-93.

van Dam, H. and M. Castellazzi (2001). "Distinct roles of Jun : Fos and Jun : ATF dimers in oncogenesis." Oncogene 20: 2453-64.

Vega, F. M., P. Gonzalo, et al. (2003). "Expression of the VRK (vaccinia-related kinase) gene family of p53 regulators in murine hematopoietic development." FEBS Lett 544: 17680.

Vega, F. M., A. Sevilla, et al. (2004). "p53 Stabilization and accumulation induced by human vaccinia-related kinase 1." Mol Cell Biol 24: 10366-80.

Vega, R. B., J. Yang, et al. (2002). "Multiple domains of MCIP1 contribute to inhibition of calcineurin activity." J Biol Chem 277: 30401-7.

Vesely, P. W., P. B. Staber, et al. (2009). "Translational regulation mechanisms of AP-1 proteins." Mutat Res 682: 7-12.

Veuger, S. J. and B. W. Durkacz (2011). "Persistence of unrepaired DNA double strand breaks caused by inhibition of ATM does not lead to radio-sensitisation in the absence of NFkappaB activation." DNA Repair (Amst) 10: 235-44.

Vihma, H., P. Pruunsild, et al. (2008). "Alternative splicing and expression of human and mouse NFAT genes." Genomics 92: 279-91.

Villar, M., I. Ortega-Perez, et al. (2006). "Systematic characterization of phosphorylation sites in NFATc2 by linear ion trap mass spectrometry." Proteomics 6 Suppl 1: S16-27.

Viola, J. P., L. D. Carvalho, et al. (2005). "NFAT transcription factors: from cell cycle to tumor development." Braz J Med Biol Res 38: 335-44.

Vlahopoulos, S. A., S. Logotheti, et al. (2008). "The role of ATF-2 in oncogenesis." Bioessays 30: $314-27$.

Vogel, C. (2000). "Prostaglandin H synthases and their importance in chemical toxicity." Curr Drug Metab 1: 391-404.

Vogelstein, B. and K. W. Kinzler (2004). "Cancer genes and the pathways they control." Nat Med 10: 789-99.

Wang, D. Z., P. G. McCaffrey, et al. (1995). "The cyclosporin-sensitive transcription factor NFATp is expressed in several classes of cells in the immune system." Ann N Y Acad Sci 766: 182-94.

Wang, F., J. Dai, et al. (2010). "Histone H3 Thr-3 phosphorylation by Haspin positions Aurora $\mathrm{B}$ at centromeres in mitosis." Science 330: 231-5. 
Wang, J. Y., B. K. Chen, et al. (2012). "Involvement of store-operated calcium signaling in EGF-mediated COX-2 gene activation in cancer cells." Cell Signal 24: 162-169.

Waters, K., A. Z. Yang, et al. (2010). "Genome-wide analysis of germ cell proliferation in C.elegans identifies VRK-1 as a key regulator of CEP-1/p53." Dev Biol 344: 1011-25.

Wee, C. D., L. Kong, et al. (2010). "The genetics of spinal muscular atrophies." $\underline{\text { Curr Opin }}$ Neurol 23: 450-8.

Weitzman, S. A. and L. I. Gordon (1990). "Inflammation and cancer: role of phagocytegenerated oxidants in carcinogenesis." Blood 76: 655-63.

Werneck, M. B., A. Vieira-de-Abreu, et al. (2011). "NFAT1 transcription factor is central in the regulation of tissue microenvironment for tumor metastasis." Cancer Immunol Immunother 60: 537-46.

Wesselborg, S., D. A. Fruman, et al. (1996). "Identification of a physical interaction between calcineurin and nuclear factor of activated T cells (NFATp)." J Biol Chem 271: 12747.

Whitmarsh, A. J. and R. J. Davis (2000). "Regulation of transcription factor function by phosphorylation." Cell Mol Life Sci 57: 1172-83.

Whitmarsh, A. J., C. Y. Kuan, et al. (2001). "Requirement of the JIP1 scaffold protein for stress-induced JNK activation." Genes Dev 15: 2421-32.

Wiebe, M. S., R. J. Nichols, et al. (2010). "Mice deficient in the serine/threonine protein kinase VRK1 are infertile due to a progressive loss of spermatogonia." Biol Reprod 82: 18293.

Willmore, E., S. de Caux, et al. (2004). "A novel DNA-dependent protein kinase inhibitor, NU7026, potentiates the cytotoxicity of topoisomerase II poisons used in the treatment of leukemia." Blood 103: 4659-65.

Wolfe, S. A., P. Zhou, et al. (1997). "Unusual Rel-like architecture in the DNA-binding domain of the transcription factor NFATc." Nature 385: 172-6.

Wong, H., M. Belvin, et al. (2009). "Pharmacodynamics of 2-[4-[(1E)-1-(hydroxyimino)-2,3dihydro-1H-inden-5-yl]-3-(pyridine-4-yl)-1 H-pyrazol-1-yl]ethan-1-ol (GDC-0879), a potent and selective B-Raf kinase inhibitor: understanding relationships between systemic concentrations, phosphorylated mitogen-activated protein kinase kinase 1 inhibition, and efficacy." J Pharmacol Exp Ther 329: 360-7.

Wu, C. C., S. C. Hsu, et al. (2003). "Nuclear factor of activated T cells c is a target of p38 mitogen-activated protein kinase in T cells." Mol Cell Biol 23: 6442-54.

$\mathrm{Wu}$, J., Y. Zhang, et al. (2011). "Prostaglandin E2 regulates renal cell carcinoma invasion through the EP4 receptor-Rap GTPase signal transduction pathway." J Biol Chem 286: 33954-62.

Wu, W., R. S. Misra, et al. (2006). "Proteolytic regulation of nuclear factor of activated T (NFAT) c2 cells and NFAT activity by caspase-3." J Biol Chem 281: 10682-90.

Wyckoff, J., W. Wang, et al. (2004). "A paracrine loop between tumor cells and macrophages is required for tumor cell migration in mammary tumors." Cancer Res 64: 7022-9.

Xie, S., Q. Wang, et al. (2004). "MEK1-induced Golgi dynamics during cell cycle progression is partly mediated by Polo-like kinase-3." Oncogene 23: 3822-9.

Yang, J., B. Rothermel, et al. (2000). "Independent signals control expression of the calcineurin inhibitory proteins MCIP1 and MCIP2 in striated muscles." Circ Res 87: E61-8.

Yang, T. T., Q. Xiong, et al. (2005). "Recruitment of the extracellular signal-regulated kinase/ribosomal S6 kinase signaling pathway to the NFATc4 transcription activation complex." Mol Cell Biol 25: 907-20.

Yao, Y. G. and E. J. Duh (2004). "VEGF selectively induces Down syndrome critical region 1 gene expression in endothelial cells: a mechanism for feedback regulation of angiogenesis?" Biochem Biophys Res Commun 321: 648-56. 
Yiu, G. K., A. Kaunisto, et al. (2011). "NFAT promotes carcinoma invasive migration through glypican-6." Biochem J 440: 157-66.

Yiu, G. K. and A. Toker (2006). "NFAT induces breast cancer cell invasion by promoting the induction of cyclooxygenase-2." J Biol Chem 281: 12210-7.

Yoeli-Lerner, M., Y. R. Chin, et al. (2009). "Akt/protein kinase b and glycogen synthase kinase-3beta signaling pathway regulates cell migration through the NFAT1 transcription factor." Mol Cancer Res 7: 425-32.

Yoeli-Lerner, M., G. K. Yiu, et al. (2005). "Akt blocks breast cancer cell motility and invasion through the transcription factor NFAT." Mol Cell 20: 539-50.

Zelko, I., R. Kobayashi, et al. (1998). "Molecular cloning and characterization of a novel nuclear protein kinase in mice." Arch Biochem Biophys 352: 31-6.

Zhang, H. and X. F. Sun (2002). "Overexpression of cyclooxygenase-2 correlates with advanced stages of colorectal cancer." Am J Gastroenterol 97: 1037-41.

Zhang, J., P. L. Yang, et al. (2009). "Targeting cancer with small molecule kinase inhibitors." Nat Rev Cancer 9: 28-39.

Zhang, J. Y., H. Jiang, et al. (2008). "The JNK/AP1/ATF2 pathway is involved in H2O2induced acetylcholinesterase expression during apoptosis." Cell Mol Life Sci 65: 143545.

Zhou, Y., S. Uddin, et al. (2008). "Growth control of multiple myeloma cells through inhibition of glycogen synthase kinase-3." Leuk Lymphoma 49: 1945-53.

Zhu, J. and F. McKeon (1999). "NF-AT activation requires suppression of Crm1-dependent export by calcineurin." Nature 398: 256-60.

Zhu, Q., J. Yang, et al. (2011). "Suppression of glycogen synthase kinase 3 activity reduces tumor growth of prostate cancer in vivo." Prostate 71: 835-45.

Zou, Y., W. Huang, et al. (2011). "Predominant gain of promoter TATA box after gene duplication associated with stress responses." Mol Biol Evol 28: 2893-904. 
Parte del trabajo mostrado en esta Tesis Doctoral ha sido publicado en el siguiente artículo científico, del cual el doctorando es el principal autor:

Vázquez-Cedeira, M., Barcia-Sanjurjo, I., Sanz-García, M., Barcia, R., Lazo, P.A. (2011) "Differential inhibitor sensitivity between human kinases VRK1 and VRK2”. PLoS One, e:23235.

Además, también como resultado de este trabajo, se ha enviado recientemente a publicación el siguiente artículo:

Vázquez-Cedeira, M. and Lazo, P.A. (2012) "VRK2A modulates cell invasion in tumor cells by hyperactivation of NFAT1 and expression of cyclooxygenase-2”. 

En primer lugar, agradecer a mi director la oportunidad de realizar la tesis en su laboratorio, disfrutando de las buenas condiciones que ofrece un centro de estas características, y por el estímulo constante para el desarrollo de mi trabajo. Aunque no hubiera seguido este camino sin la aparición de personas que despertaron mi interés por el mundo de la biología molecular y la investigación. Gracias al causante del giro en esta dirección, mi profesor de biología en el Hogar, que me metió el gusanillo de la genética primero y bioquímica y biología molecular después. Ya en la facultad, gracias al que fue mi profesor de Bioquímica por mostrar interés en mí primero, y luego, creyendo en mi capacidad, darme la oportunidad de dar mis primeros pasos como "científica" antes de terminar la carrera. Y gracias al otro biólogo de la familia por sus opiniones, consejos y ayuda desde su experiencia personal.

En segundo lugar, agradecer a todos los compañeros que he tenido en el laboratorio 4 por su ayuda en los comienzos, por hacer las horas más amenas y por estar siempre dispuestos a echar una mano o simplemente a escuchar. También a todas aquellas personas del CIC que me han alegrado los días o que me han ayudado con algunos experimentos. Gracias por tantos momentos dentro y fuera del labo que quedarán como buenos recuerdos y han hecho más llevadero todo el camino.

Muy feliz de haber tenido la suerte de parar en una ciudad como Salamanca, no sólo por su belleza monumental y por el ambiente, sino por algunas personas que he tenido la fortuna de conocer. Siempre agradecida a "mis tres reyes magos"; a la otra "mamá" del labo; a esa chica tocaya mía, "culpable" de convertirme en Martiña; a la "pequecha"; y a esos dos grandes chicos (no sólo físicamente) que de casualidad conocí en el gimnasio. Mil gracias por todo lo vivido y compartido con vosotros y porque vuestra ayuda ha sido muy importante para poder seguir adelante en los tropiezos. Tampoco olvidar a la "española por el mundo", que a pesar de la distancia y su vida estresante, siempre he podido contar con ella. $Y$ por supuesto, gracias a otras personas que tanto desde Salamanca como desde Galicia, aunque generalmente de forma diferente y quizá sin querer, han contribuido a mantener mi ánimo.

$\Upsilon$ por último, aunque no por ello menos importante (sino todo to contrario), no tendría suficientes palabras para agradecer a mi familia todos los ánimos, confianza y cariño brindados. Especialmente agradecida a mis padres, verdaderos responsables de que todo haya sido posible, por su apoyo incondicional siempre, dejándome seguir la dirección que yo quise con mis propias decisiones, sin tratar de cambiar mi rumbo; aunque siempre atentos a prestarme su ayuda en los momentos en que no veía claro el camino o en los que mis pasos no parecían suficientemente fuertes y decididos. 

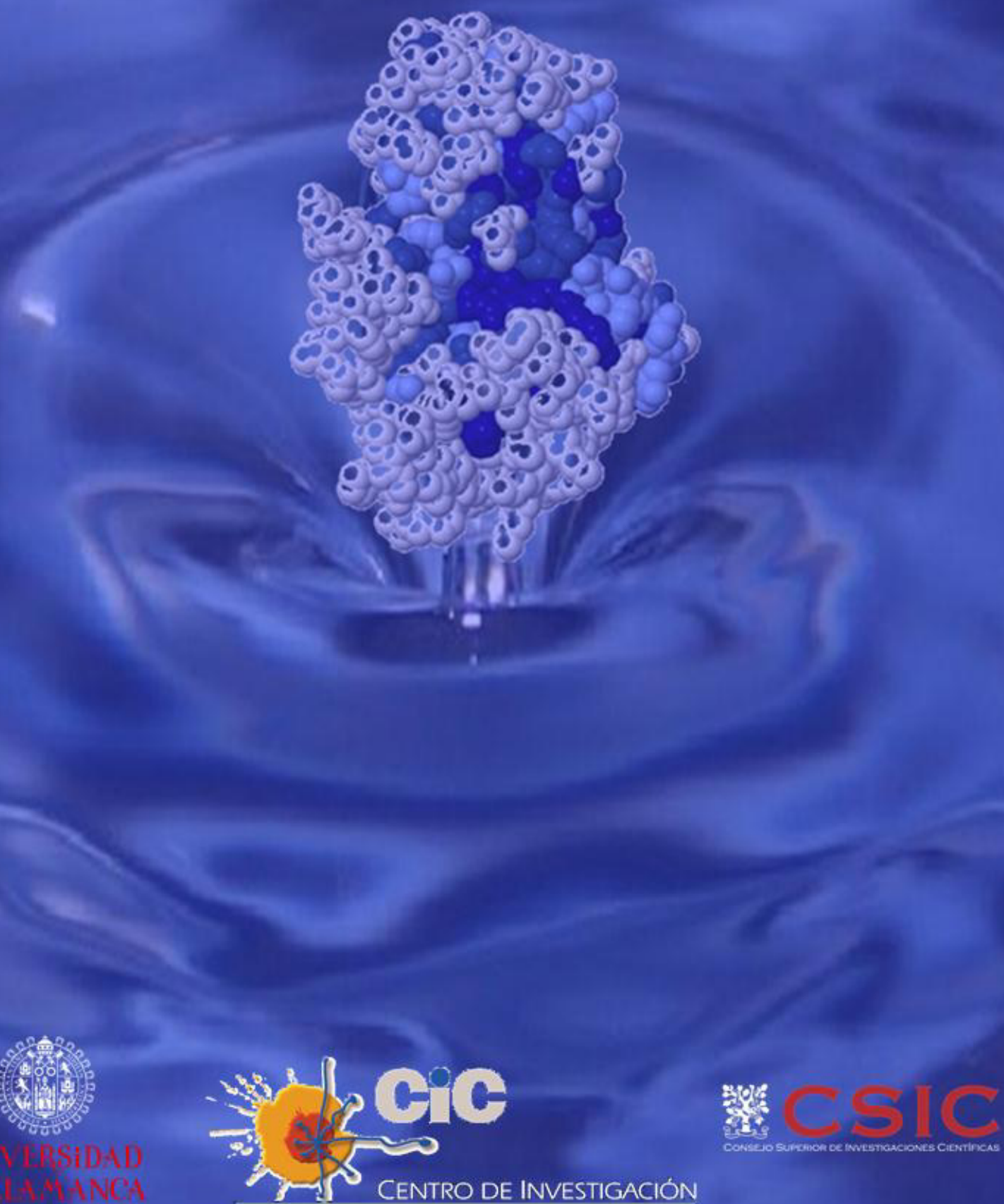

CAMPUS DE EXCELENCIA INTERNACIONAL DEL CÁNCER 